\title{
The Influence of EU Agencies
}

Citation for published version (APA):

Kim, J. (2018). The Influence of EU Agencies: Real but guided influence in the policy-making process. [Doctoral Thesis, Maastricht University]. Datawyse / Universitaire Pers Maastricht. https://doi.org/10.26481/dis.20181211jk

Document status and date:

Published: 01/01/2018

DOI:

10.26481/dis.20181211jk

Document Version:

Publisher's PDF, also known as Version of record

\section{Please check the document version of this publication:}

- A submitted manuscript is the version of the article upon submission and before peer-review. There can be important differences between the submitted version and the official published version of record.

People interested in the research are advised to contact the author for the final version of the publication, or visit the DOI to the publisher's website.

- The final author version and the galley proof are versions of the publication after peer review.

- The final published version features the final layout of the paper including the volume, issue and page numbers.

Link to publication

\footnotetext{
General rights rights.

- You may freely distribute the URL identifying the publication in the public portal. please follow below link for the End User Agreement:

www.umlib.nl/taverne-license

Take down policy

If you believe that this document breaches copyright please contact us at:

repository@maastrichtuniversity.nl

providing details and we will investigate your claim.
}

Copyright and moral rights for the publications made accessible in the public portal are retained by the authors and/or other copyright owners and it is a condition of accessing publications that users recognise and abide by the legal requirements associated with these

- Users may download and print one copy of any publication from the public portal for the purpose of private study or research.

- You may not further distribute the material or use it for any profit-making activity or commercial gain

If the publication is distributed under the terms of Article $25 \mathrm{fa}$ of the Dutch Copyright Act, indicated by the "Taverne" license above, 
The Influence of EU Agencies

Real but guided influence in the policy-making process 
(C) copyright Jinhee Kim, Maastricht 2018

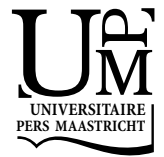

ISBN 978-94-6380-128-7

All rights reserved. No part of this publication may be reproduced, stored in a retrieval system or transmitted, in any form or by any means, electronic, mechanical, photocopying, recording or otherwise, without prior permission of the author or the copyright-owning journals for previous published chapters. 


\title{
The Influence of EU Agencies
}

\section{Real but guided influence in the policy-making process}

\author{
DISSERTATION \\ to obtain the degree of Doctor at Maastricht University, \\ on the authority of the Rector Magnificus, \\ Prof. dr. Rianne M. Letschert \\ in accordance with the decision of the Board of Deans, \\ to be defended in public \\ on Tuesday, 11 December 2018 at 14.00 hours \\ by \\ JINHEE KIM
}




\section{SUPERVISORS:}

Prof. dr. Tannelie Blom

Prof. dr. Esther Versluis

\section{ASSESSMENT COMMITTEE:}

Prof. dr. Christine Neuhold (chair)

Prof. dr. Thomas Conzelmann

Prof. dr. Morten Egeberg (University of Oslo, Norway)

Prof. dr. Martijn Groenleer (Tilburg University, The Netherlands)

Dr. Elissaveta Radulova - Ivanova 


\section{Table of Contents}

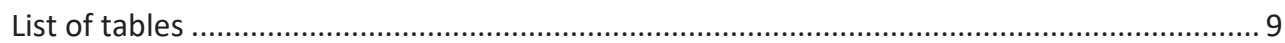

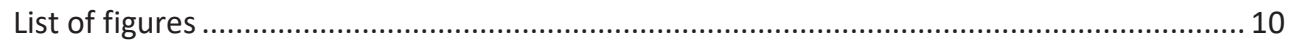

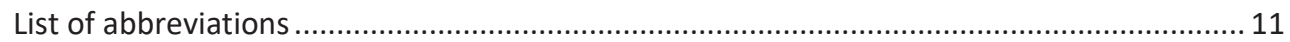

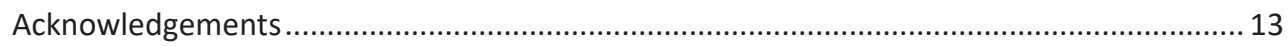

Chapter 1 Introduction: EU Agencies in the Policy-Making Process..................................... 15

1.1 Empirical puzzles and research question.......................................................... 16

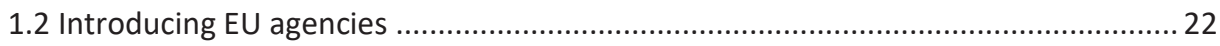

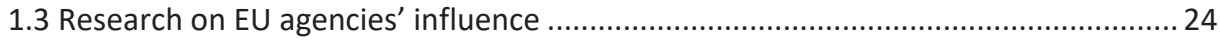

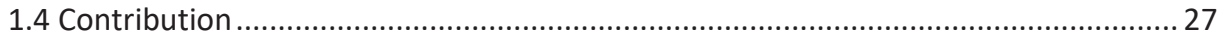

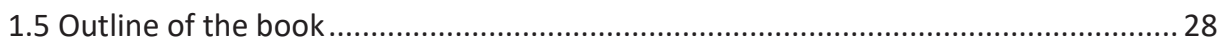

Chapter 2 Conceptualisation: Influence and Power in EU Policy-Making .............................. 29

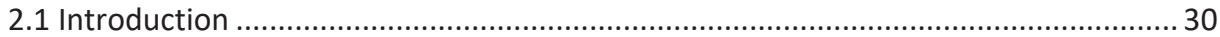

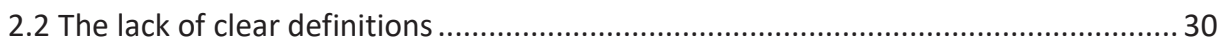

2.3 Concepts of, and relations between, influence and power...................................... 32

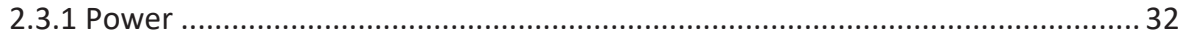

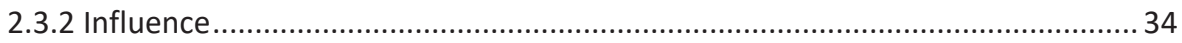

2.4 Positioning EU agencies' influence and power in policy-making .............................. 40

2.4.1 Definitions of, and actors with, influence and power in this research ............... 40

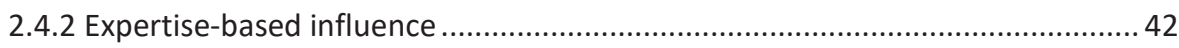

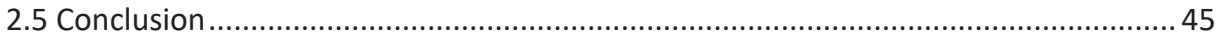

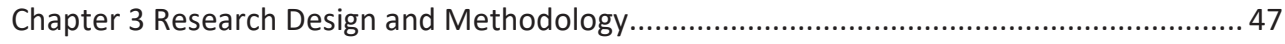

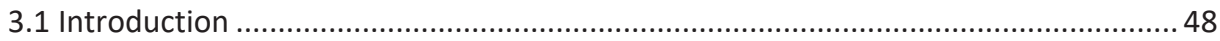

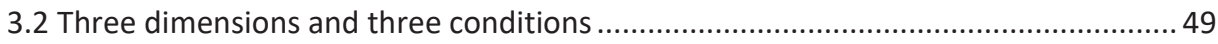

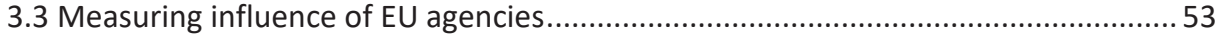

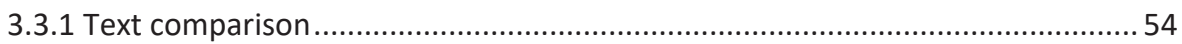

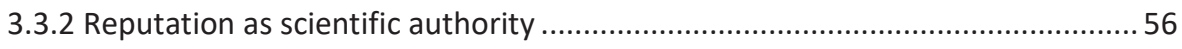

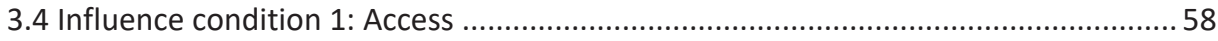

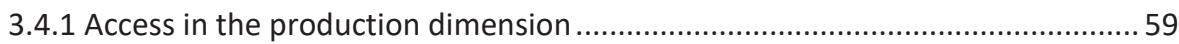

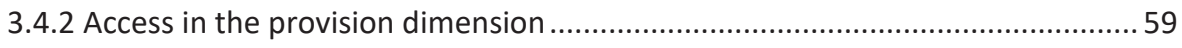

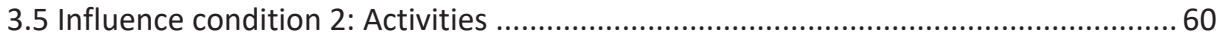




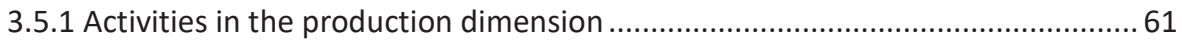

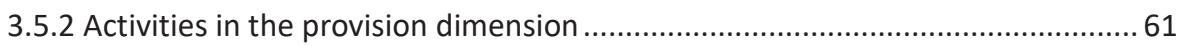

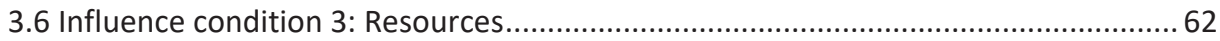

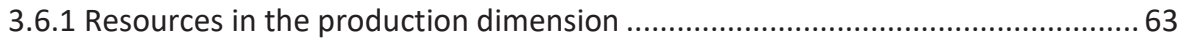

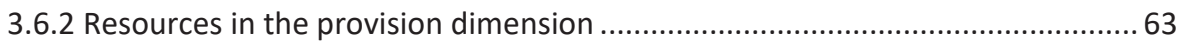

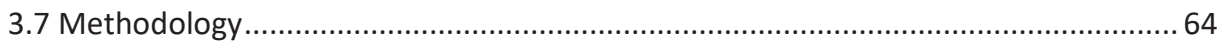

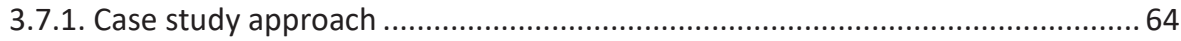

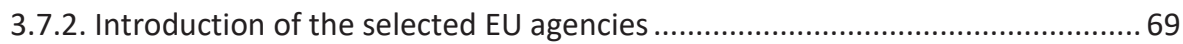

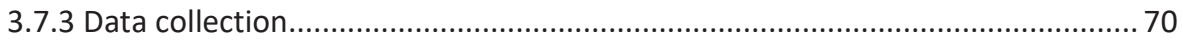

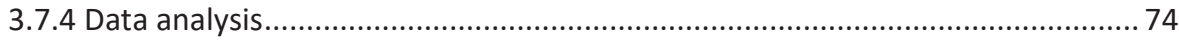

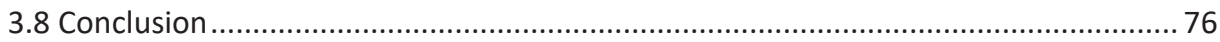

Chapter 4 European Centre for Disease Prevention and Control ......................................... 77

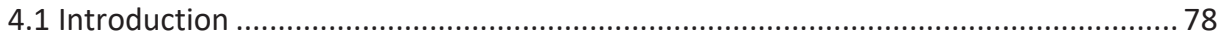

4.2 Case 1: Commission Communication on Pandemic (H1N1) 2009 ............................ 81

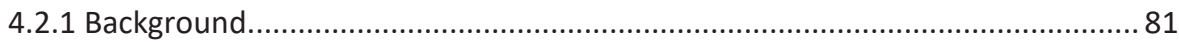

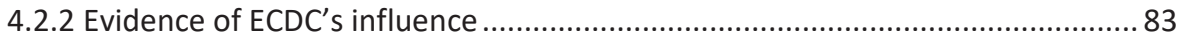

4.2.3 Conditions for influence: Production of expert advice in ECDC ........................ 89

4.2.4 Conditions for influence: Provision of expert advice from ECDC to the European Commission

4.3 Case 2: Commission Proposal for a Decision on Serious Cross-Border Threats to Health 100

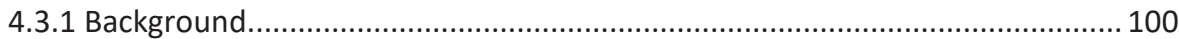

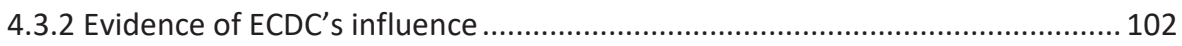

4.3.3 Conditions for influence: Production of expert advice in ECDC ...................... 106

4.3.4 Conditions for influence: Provision of expert advice from ECDC to the European Commission ............................................................................. 110

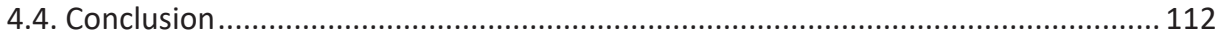

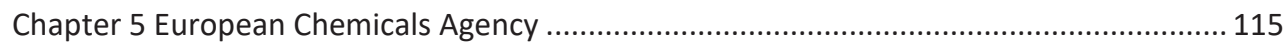

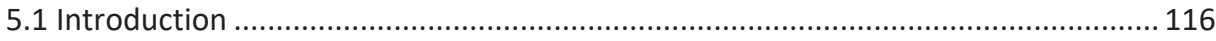

5.2 Case 1: Commission Proposal for a Regulation of Biocidal Products ....................... 118

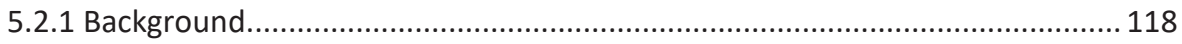

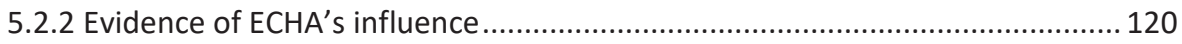

5.2.3 Conditions for influence: Production of expert advice in ECHA ...................... 125 
5.2.4 Conditions for influence: Provision of expert advice from ECHA to the European Commission

5.3 Case 2: Union Authorisation of Biocidal Products ................................................. 131

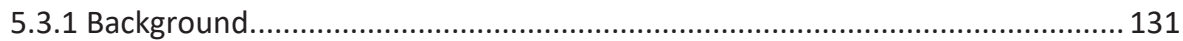

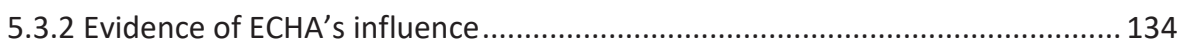

5.3.3 Conditions for influence: Production of expert advice in ECHA ...................... 142

5.3.4 Conditions for influence: Provision of expert advice from ECHA to the European Commission ............................................................................ 148

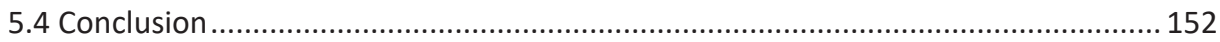

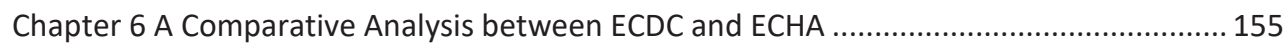

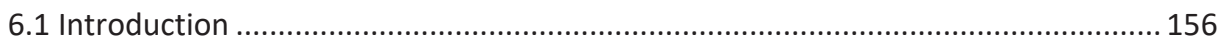

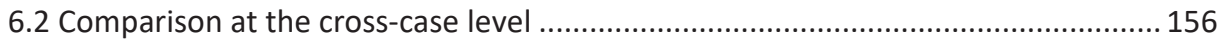

6.2.1 Comparison between the two general legislative proposals.......................... 156

6.2.2 Comparison between the two technical proposals ...................................... 160

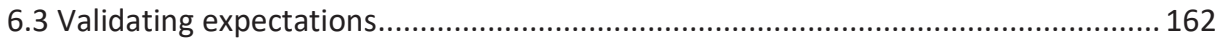

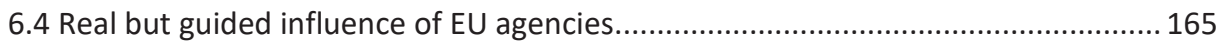

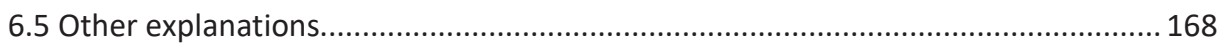

6.5.1 Other potential conditions for influence ...................................................... 168

6.5.2 Observations on reputation as an indicator of influence ............................... 171

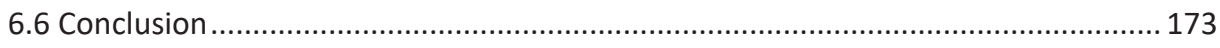

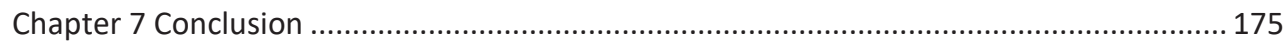

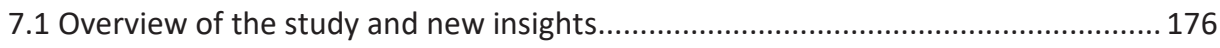

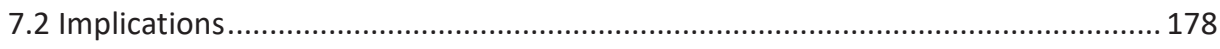

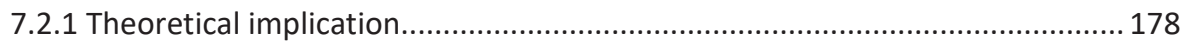

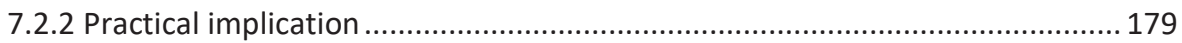

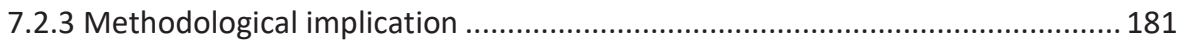

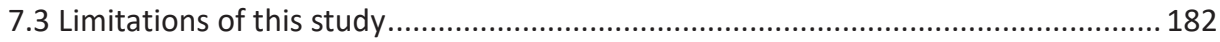

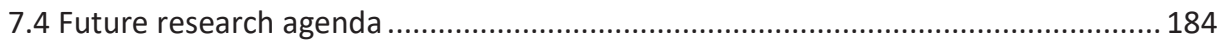

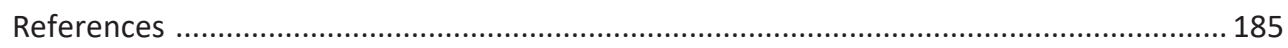

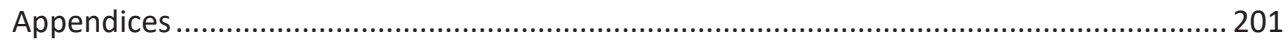

Appendix 1: List of ECDC documents analysed for text comparison of case 1 ............... 202

Appendix 2: List of ECDC documents analysed for text comparison of case 2 .............. 203 
Appendix 3: List of ECHA documents analysed for text comparison of case 1 ..............204

Appendix 4: List of ECHA documents analysed for text comparison of case 2 .............. 205

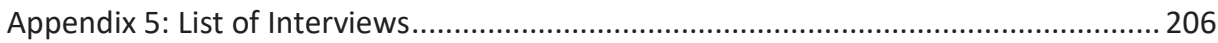

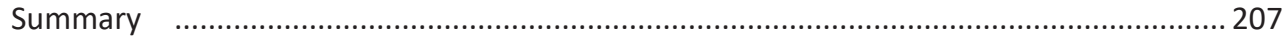

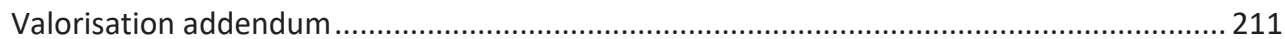

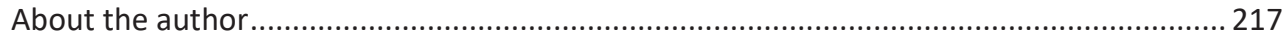




\section{List of tables}

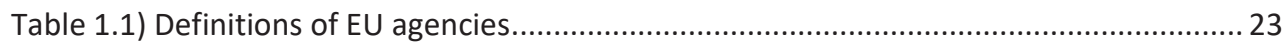

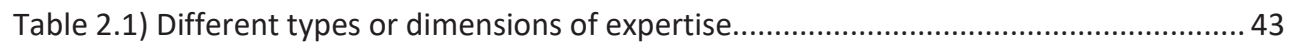

Table 3.1) Framework for analysing EU agencies' influence in the policy formulation stage. 52

Table 3.2) A cross-case analysis: Selection of EU agencies.................................................. 66

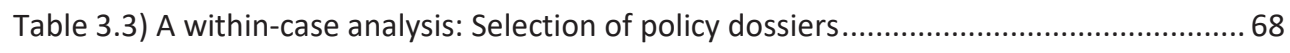

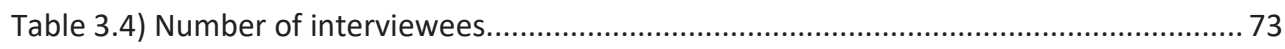

Table 4.1) Examples of similar phrases between the Commission Communication

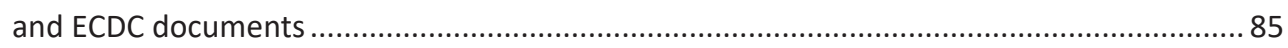

Table 4.2) Key measures agreed at the European level before September 2009 .................. 87

Table 4.3) A comparative look at ECDC influence and influence conditions in two cases .... 113

Table 5.1) List of the active substances selected for text comparison .................................. 136

Table 5.2) Examples of conditions amended by the Commission: Active substances

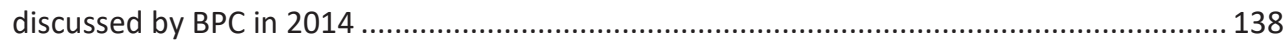

Table 5.3) Examples of conditions amended by the Commission: Active substances

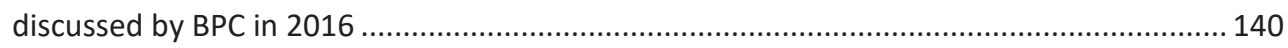

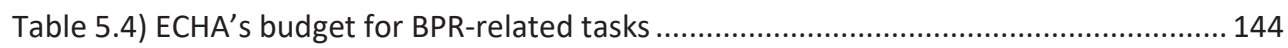

Table 5.5) A comparative look at ECHA influence and influence conditions in two cases .... 152

Table 6.1) Comparison between the two agencies' influence and conditions regarding general legislative proposals (least-likely cases).

Table 6.2) Comparison between the two agencies' influence and conditions regarding

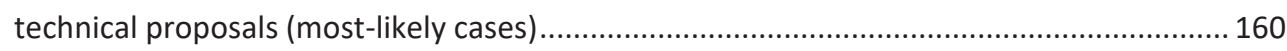

Table 6.3) Expectations about the conditions for influence ............................................... 162 


\section{List of figures}

Figure 1.1) Empirical puzzles and research question ........................................................ 17

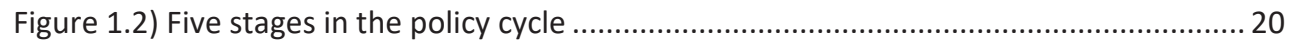

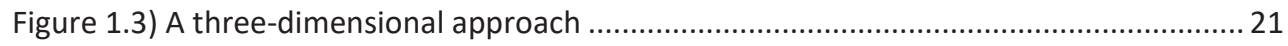

Figure 2.1) Three relations between influence and power ........................................................ 36

Figure 3.1) Three dimensions and three conditions for the analysis...................................... 49

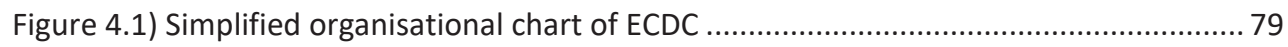

Figure 5.1) Flowchart of the process for active substance approval and Union

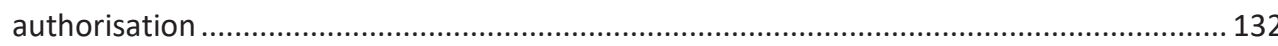

Figure 7.1) Three dimensions and three conditions for the analysis.................................. 177 


\section{List of abbreviations}

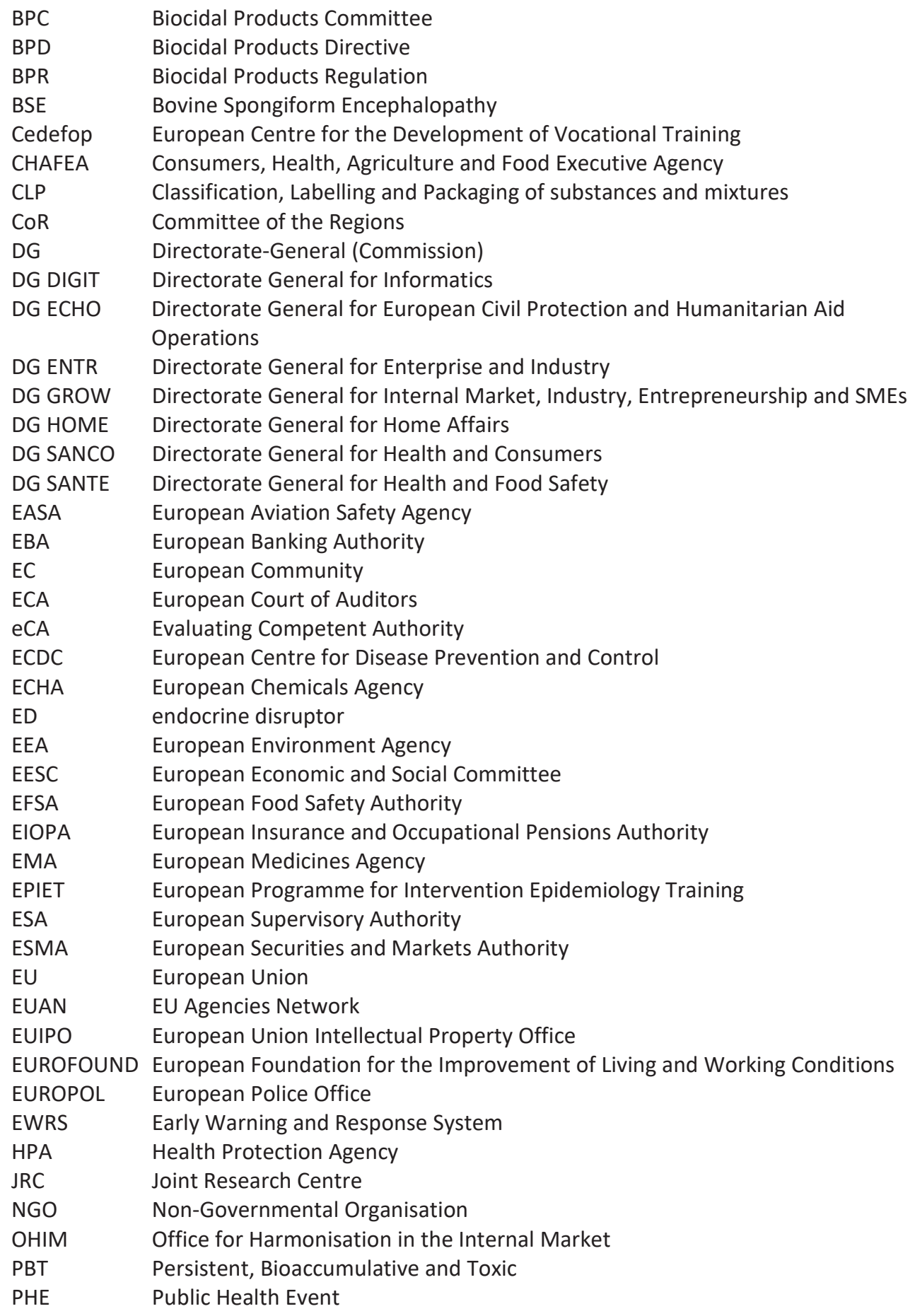

PHE Public Health Event 
PIC

PREP-BPR

PT

REACH

US CDC

WHO
Prior Informed Consent

Preparation for the entry into force of the Biocidal Products Regulation Product Type

Registration, Evaluation, Authorisation and Restriction of Chemicals

Centers for Disease Control and Prevention in the United States

World Health Organization 


\section{Acknowledgements}

Doing a PhD is often described as a long, lonely, and hard journey. It has certainly been a long process. In my case, it has taken longer than the usual four-year PhD period because I became mom two times to my beautiful babies, Mason and Elena. This meant that there were two maternity leaves and two parental leaves along the way, and I was also on long-term sick leave once. Likewise, I would not deny the hard part of a PhD life, involving deadlines, competition, intellectual challenges, stress, and endless writing and rewriting. However, what I can confidently say at the end of my PhD journey is that it has never been a lonely one, thanks to a number of wonderful people who have been there for me in Maastricht, in Eindhoven, and in other parts of the world.

First and foremost, I would like to express my sincere gratitude to my two supervisors, Prof. Tannelie Blom and Prof. Esther Versluis. Their course on EU agencies was my favourite in Research Master European Studies and sparked my interest to the extent that I eventually conducted my PhD research on these remarkable entities. Tannelie, thank you for your continuous support for my PhD research, for your useful academic comments and questions, and for your patience. I truly respect the depth of your philosophical thinking and have always enjoyed our discussions during the supervision meetings. Esther, without you I probably would not have been able to finish my dissertation. When I was going through a hard time, you showed me that you believed in my ability and kept encouraging me. Now I know clearly how powerful some words of comfort such as "all will be fine" and "everything will work out in the end" can be. Your guidance, encouragement, and willingness to make time (to discuss research and also for coffee to catch up) meant a lot to me. I consider myself privileged to have both of you as my supervisors.

I am grateful to the members of the assessment committee, namely Prof. Christine Neuhold (chair), Prof. Thomas Conzelmann, Prof. Morten Egeberg, Prof. Martijn Groenleer, and Dr. Elissaveta Radulova, for their willingness to assess this dissertation as well as for their constructive feedback.

I would also like to thank all my interviewees from the European Commission, ECDC, ECHA, WHO, and stakeholder organisations. Without their interest in my research and willingness to provide information and answer my questions, this research would not have been possible at all. Assistance provided by Carolin Hehr and Ronja Vonderbank, student assistants, was greatly appreciated. My gratitude extends to the coordinators, lecturers, and participants in the 
Netherlands Institute of Government (NIG). Especially in the first two years of my PhD, I gained invaluable knowledge as well as networks with $\mathrm{PhD}$ candidates from other universities.

My time at Maastricht University has been enjoyable in large part because of kind and warm colleagues from the Graduate School, the Department of Political Science, and the PCE research group. A very special appreciation goes to the previous and the current Heads of the department, Prof. Sophie Vanhoonacker and Prof. Christine Neuhold. You provided enormous organisational and moral support when I needed to arrange leaves to welcome my babies and to take care of my health. I admire your excellent skills in managing a good balance between your roles as leading scholar and as mother. I would also like to thank Dr. Aneta Spendzharova for teaching me how to teach and for providing valuable advice to further improve my teaching skills. I am indebted to Anna-Lena, Claudia, Valentina, Hortense, Martina, Christoph, and indeed many of my colleagues. Thank you for your companionship, friendship, advice, and all the pleasant moments with lunches, coffee breaks, and occasional dinners and gettogethers.

At a personal level, a very special gratitude goes to my long-time friend Diana. I am always amazed how much we can talk whenever we meet and how similarly we think and do certain things. Thank you for being genuinely interested in what I am doing and for not being bored with my talk about my research. I am very grateful that we remain close although we live so far apart (so, when are you moving to Europe?).

Last but by no means least, I would like to thank my family for their endless love and support. Mom and dad, thank you for all the love you have given me and for believing in me whenever I planned new adventures in my life. Especially, words cannot express how truly grateful I am to my mom. Although you have your business, hobbies, friends and family in Korea, you have always made time to cross the ocean to visit me and provide tremendous emotional and practical support. Thank you for being my mom. My sincere thanks also go to the Dutch family - Els, Jan, and Dorett. Thank you for always being there for me, for the countless days of babysitting, and for making sure that I do not forget my anniversaries. And Michiel, you told me before that although I am the one doing a PhD, we are in this together. You can never imagine how thankful I am to you for going through all the ups and downs of the PhD process with me, for putting up with all my angst, for making sure that there is always wine at home, and most importantly for taking the kids to the zoo if I need a space to work on the weekend. My love and my everything, Mason and Elena, thank you for being the happiness of my life. 
Chapter 1

Introduction: EU Agencies in the Policy-Making Process 


\subsection{Empirical puzzles and research question}

European Union (EU) agencies are indispensable actors for policy-making and governance in the EU. The work of EU agencies directly impacts the lives of more than 500 million EU citizens, ${ }^{1}$ and the EU now simply could not function without these bodies (e.g., Busuioc, Groenleer, \& Trondal, 2012; Everson, Monda, \& Vos, 2014). In the last three decades, EU agencies have proliferated, ${ }^{2}$ and the "agencification" process at the European level has been "one of the most outstanding transformations of EU executive politics" (Font, 2015, p. 774). At the moment, there are more than 40 EU agencies, ${ }^{3}$ which are decentralised and independent legal entities operating outside Brussels. They perform various tasks in a wide range of policy areas from environment and energy to chemicals, finance, fundamental rights, and so on. In the policy process, EU agencies carry out technical, scientific, or operational tasks by providing expertise as policy input while the Commission is in charge of developing policy proposals and implementing European policies.

The establishment of EU agencies has indeed facilitated the development of EU policies, from agenda-setting to evaluation. In particular, "[p]olicy formulation and decision making in 'risk' sectors such as medicines, food safety, disease prevention, and so on, are more and more influenced by the role of agencies" (Versluis, van Keulen, \& Stephenson, 2011, p. 45; see also Eberlein \& Grande 2005; Kim, Klika, \& Versluis, 2013). In these regulatory policy areas, policymaking demands not only political judgement and societal values but also scientific and technical expertise. Technical knowledge and scientific advice can support policy-makers to make informed decisions on complex policy issues. The essential role of EU agencies lies here:

The independence of their technical and/or scientific assessments is, in fact, their real raison d'être. The main advantage of using the agencies is that their decisions are based on purely technical evaluations of very high quality and are not influenced by political or contingent considerations. (European Commission, 2002a, p 5)

Specifically for the European Commission, which has the right of initiative to propose new legislative proposals in the EU, there are several apparent reasons why it seeks information from external sources such as EU agencies, expert committees, and interest groups. As De Bruycker (2016, p. 600) illustrates, "usually [policy-makers] lack detailed information on each policy issue that they care about and time pressure prevents them from collecting all the relevant information themselves." In addition, since the Commission is highly understaffed and deals with multiple issues at the same time (Klüver, 2013), external actors and their expertise are called upon, and EU agencies may supply the Commission with relevant

\footnotetext{
${ }^{1}$ See the website of the EU Agencies Network (EUAN): https://euagencies.eu/.

${ }^{2}$ In fact, EU agencies are the most proliferating institutional entities at the European level (Busuioc, 2013).

${ }^{3}$ The total number of EU agencies differs depending on sources. The official website of EU agencies lists 33

"decentralised agencies" while EUAN counts 44 EU agencies including both 37 decentralised agencies and 7 Joint Undertakings which are public-private partnerships set up for the "efficient execution of Union research, technological development and demonstration programmes" under the Treaty on the Functioning of the European Union.
} 
administrative and executive capacity (Trondal \& Peters, 2013). The Commission (2008, p. 4) acknowledges the value of EU agencies:

Regulatory agencies have made a significant and useful contribution to the effective operation of the EU. In many cases they have built up a highly-respected scientific or technical know-how and have thereby helped the [EU] institutions to take effective decisions.

In this policy-making context, two closely intertwined puzzles arise which lead to a main research question (see Figure 1.1). The first puzzle stems from the view shared by practitioners and scholars alike that EU agencies as "integral components" (Egeberg, Trondal, \& Vestlund, 2015, p. 609) in policy-making "may eventually influence the actual formulation of the content of the European public policy" (Barbieri \& Ongaro, 2008, p. 397). However, how do EU agencies contribute and how can their influence be traced? How much impact do EU agencies actually have on European policies?

Figure 1.1) Empirical puzzles and research question

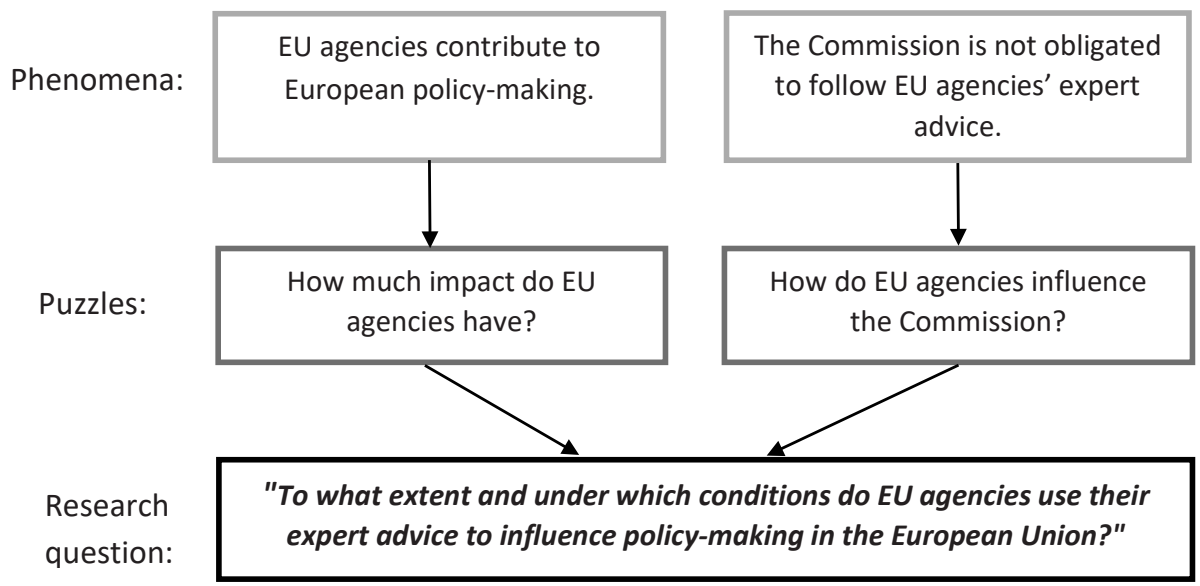

(Source: Author's own compilation)

A comprehensive evaluation on $26 \mathrm{EU}$ agencies in 2009 concludes that activities carried out by them are relevant to the Commission's as well as the Union's work, and that EU agencies provide useful, and sometimes indispensable, input to the Commission and other EU institutions for their policy-making work (Ramboll, Euréval, \& Matrix, 2009a). For example, the evaluation report elaborates:

[The European Centre for Disease Prevention and Control (ECDC)] is responsible for risk assessment within its area, while the Commission is responsible for risk management. 
The European Commission does not have the capacities to carry out the background scientific work for its regulation or action proposals and relies on ECDC's inputs in that regard. (Ramboll et al., 2009b, p. 32, emphasis added)

Likewise, in a more recent evaluation of $41 \mathrm{EU}$ agencies, EU agencies are described as having "significant influence on policy and decision making and programme implementation in areas of vital importance to European citizens' daily life, e.g. health, safety, security, freedom and justice" (ECA, 2017, p. 8, emphasis added). Whereas these evaluations indicate positive influence of EU agencies particularly on the formulation of policy proposals in the Commission, the extent to which EU agencies succeed in making an impact and actual evidence of such influence are still questions for empirical research.

The second puzzle concerns the indication of EU agencies' possible influence in the European Commission. Even though EU agencies provide relevant and useful information and advice to the Commission based on their specialised expertise and may be seen as technically authoritative, the Commission is not obligated to follow what EU agencies advise. ${ }^{4}$ Ossege (2016, p. 50) correctly points out that

[a]s formal decision-maker, the Commission can, for a variety of reasons, take regulatory decisions that deviate from the scientific recommendations that [EU agencies] provide: the Commission might disagree with the scientific opinion or consider it 'too scientific' to be implemented; [and] it could also consider political or economic considerations more relevant.

In addition, there are numerous sources of information that can provide expert advice to the Commission, such as expert groups of the Commission and interest groups, implying that the Commission does not have to rely on EU agencies.

Nevertheless, empirical studies have demonstrated that some EU agencies have a more substantial impact on policy-making than others. For example, the European Medicines Agency (EMA), while having no formal decision-making power, exerts its influence over the adoption of final decisions by the Commission on issues of authorising pharmaceuticals (Gehring \& Krapohl, 2007). As Geradin and Petit (2004, pp. 48-49) assert:

Indeed, the existence of a mere advisory power does not prevent [EU agencies] from enjoying a certain level of authority. The adoption of a non-binding decision (e.g. a recommendation) may well have a considerable impact and, in some circumstances, a similar effect as would a binding-one. This will be the case if the agency

\footnotetext{
${ }^{4}$ What EU agencies provide to the Commission (as well as to other policy-makers at the European and national level) in a policy context is expert advice based on information, specialised knowledge, and expertise. "Expert advice" of EU agencies is also called "expert knowledge," "scientific expertise," "technical information" and so on. Strictly speaking, the definitions of these similar terms differ. For the detailed definitions, see, for example, Blom \& Vanhoonacker (2014), Boswell (2009), Sabatier (1978), and Schrefler (2013). In this book, while the term "expert advice" is preferred primarily, the similar terms stated above are used synonymously. The concept of expert advice covers all the processes and structures aimed at providing scientific knowledge and information for the attention of policy- and decision- makers (Reillon, 2015).
} 
recommendation is respected and followed by stakeholders, or is taken as a binding basis for the adoption of a decision by the Commission.

What then makes the Commission listen to EU agencies' expert advice? Why are some EU agencies more influential than others? How do EU agencies convince the Commission to follow their expert advice when developing policies? In other words, under which conditions do EU agencies exert influence?

Reflecting on these two puzzles, the main question that will direct this research is: To what extent and under which conditions do EU agencies use their expert advice to influence policymaking in the European Union? In order to better grasp the research question, it is necessary to elaborate on two points. Firstly, assessing influence of EU agencies is not aimed at producing a ranking tool to compare how much influence each EU agency exerts. Rather, by comparing the level of influence, the aim is to find different (combinations of) factors that come into play when EU agencies produce their expert advice and disseminate it to policymakers in the policy-making process. By doing so, this research seeks to increase conceptual and empirical understandings about the meanings, pathway, and the degree of EU agencies' influence on policy-making.

With regard to the policy-making process, secondly, this research concentrates only on the policy formulation stage out of five different stages - agenda-setting, formulation (policyshaping), decision-making, implementation, and evaluation - in the policy cycle (see Figure 1.2). Since policy-making is not a linear process, it is not useful and feasible to distinguish exactly when agenda-setting finishes and policy-shaping begins (Versluis et al., 2011). To increase clarity, however, the policy formulation stage at the European level is understood as a phase in which the European Commission, as the main bureaucratic entity with the right of initiative, undertakes planning, drafting, and introducing legislative proposals. Thus, EU agencies' influence on the identification and definition of policy isseus or success with keeping these issues on or off the agenda is not part of this research. 
Figure 1.2) Five stages in the policy cycle

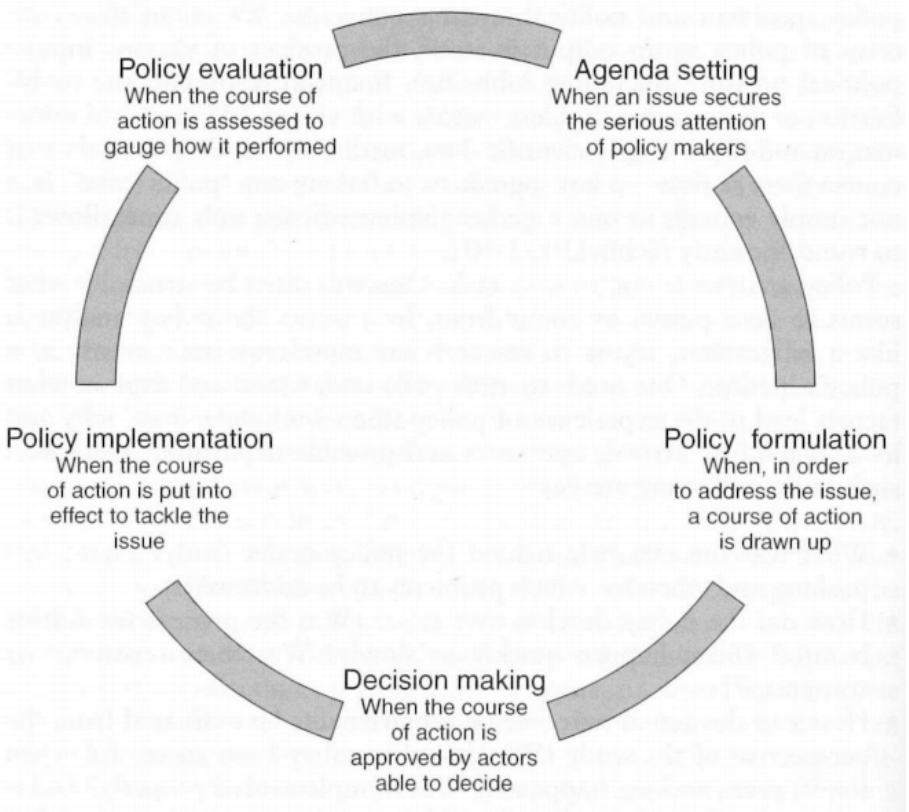

(Source: Versluis et al., 2011, p. 20)

Once these proposals are officially introduced by the Commission, the Council of the European Union alone or together with the European Parliament, depending on the type of proposal, takes a decision on them. Although the Council and the Parliament - not the Commission have the legislative power to amend and adopt new European policies, studying the development of policy proposals in the Commission is essential for actors outside the Commission, such as EU agencies, as well as to understand how European policies are formed. This is because the Commission designs the content of policy proposals on which basis the two legislative institutions debate and bargain about the final legislative acts (Klüver, 2013), and in recent years, choices made at the policy formulation stage have become important determinants of eventual outputs of European policies (Peterson, 1995). The implication is that inaccurate policy design affects the implementation and outcome of policies negatively and may even worsen the policy problems that policy-makers aim to solve. Therefore, it is essential to investigate how policy proposals are developed as well as who determines, and to what extent, the content of policy proposals.

From a political science perspective, moreover, Arts and Verschuren (1999, p. 412) underline four reasons why assessing political influence of actors is important: first, knowing who influences policy-making tests "the premise of democracy: whether the making of decisions [...] is truly democratic in nature or is dominated by one or a few elites"; second, it provides 
an efficient feedback mechanism and an intervention methodology for those who seek to influence; third, it enables an informed prediction about influence of different actors in future decision-making; and lastly, it contributes to theory building regarding "why certain persons are influential and others are not, under what conditions, and in what domains, and the like."

The research question will be analysed in two EU agencies which are selected based on carefully planned criteria (see Chapter 3 ). The two agencies are the European Centre for Disease Prevention and Control (ECDC) and the European Chemicals Agency (ECHA). For the empirical analyses of ECDC and ECHA, influence of these agencies is investigated with two policy dossiers in each agency: one general legislative proposal which requires both scientific expertise and political consideration, and one policy proposal which is predominantly technical in nature and requires scientific expertise as a crucial element to solve policy issues. Each case is analysed based on a three-dimensional approach (see Figure 1.3). The first dimension focuses on the "production" of expert advice within the agencies, and the second dimension inspects the "provision" aspect of expert advice (which is produced in the preceding dimension) given to the Commission as policy input. Access, activities, and resources are selected as the conditions that could potentially affect the level of EU agencies' influence and are analysed in these two dimensions. The "influence" dimension measures the actual level of influence of EU agencies. Two indicators are used here in a complementary manner: text comparison between agencies' expert advice and the Commission's policy proposals, as well as reputation of EU agencies as scientific authority.

Figure 1.3) A three-dimensional approach

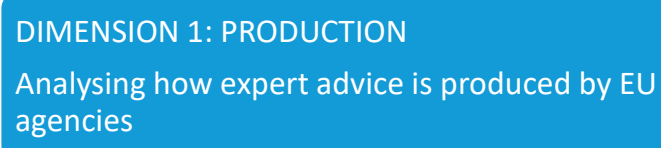

(Source: Author's own compilation) 
In three out of four case studies, ECDC and ECHA did exert moderate or high influence on the formulation of policy proposals in the Commission. Access to the Commission affects their influence and in particular, secured access to the Commission as a necessary prerequisite for developing policy proposals is a crucial condition for a "high" influence. This is because if an agency satisfies this condition, the procedural involvement of the agency gives the Commission a strong incentive to guide the agency through how to format and write expert advice. Expert advice which is produced under the Commission's guidance and feedback reflects better the needs of Commission officials when developing policy proposals and consequently, this increases the agency's influence. Therefore, this study concludes that EU agencies do exert influence in the policy formulation stage, however their influence is "guided" influence because they may exert influence only under the steering and guidance by the Commission.

\subsection{Introducing EU agencies}

EU agencies cannot be explained without addressing their variety. They come in various names, shapes, sizes, functions, and rule-making competences, and were established at different points in time. Such variation is due to the fact that their establishment was pursued to meet specific needs identified on a case-by-case basis, such as the BSE crisis ${ }^{5}$ and most recently the European financial crisis. Thus, the creation of EU agencies is often seen as a "fairly haphazard development" (Dehousse, 2008, p. 790). In 1975, first two EU agencies were set up: the European Centre for the Development of Vocational Training (Cedefop) and the European Foundation for the Improvement of Living and Working Conditions (EUROFOUND). Most scholars see this as the first wave of EU agencies. The second wave came in the 1990s with the creation of $11 \mathrm{EU}$ agencies, whose objective was to facilitate the functioning of the single market in the EU (Musa, 2014). ${ }^{6}$

The period between 2000 and 2009 was the third and most intense wave, witnessing the creation of 24 new EU agencies. The third wave was partly a response to the criticism about a transparency deficit in the comitology procedure, ${ }^{7}$ and the EU aimed at enhancing transparency as well as bringing the Union closer to its citizens by situating EU agencies all over the Union and by inviting various interest groups to participate in agencies' decision-making (Scholten, 2014). Since 2010, agencification has entered the fourth wave with seven new EU agencies. The focus has been on rebuilding stability in the areas of banking and financial

\footnotetext{
${ }^{5}$ Bovine spongiform encephalopathy (BSE), commonly known as mad cow disease, spurred the establishment of the European Food Safety Authority in 2002.

${ }^{6}$ See Musa (2014) for the list of all 44 EU agencies established between the first and fourth wave.

${ }^{7}$ The comitology procedure refers to a system of committees, composed of representatives of the Member States, which must be consulted when adopting the Commission's implementing acts. National representatives in comitology committees may block initiatives from the Commission. But, the operation of and discussions in these committees have been characterised as negotiations behind a closed door and have been criticised for a lack of transparency (see Brandsma, 2013).
} 
regulations and managing public service (for example, energy) as well as transnational cooperation and security (for example, border protection) (Musa, 2014).

EU agencies are sometimes called "decentralised agencies" or "traditional agencies" (European Commission, 2008), and the official name of individual agencies also varies. Some are called "Agency" while others are called "Centre," "Office," "Foundation," "Institute," or "Authority." What they have in common is that "they were created by regulation in order to perform tasks clearly specified in their constituent Acts, all have legal personality and all have a certain degree of organisational and financial autonomy" (European Commission, 2002a, p. 3).

It has long been recognised by scholars that it is difficult to find a clear definition of the term "agency" as well as a clear distinction of the types of agencies (see Schout \& Pereyra, 2011). This is because "[n]either the EC [European Community] Treaty nor the legislative acts creating these bodies provide a definition of 'agency'” (Vos, 2003, p. 118). Table 1.1 shows several not exhaustive - definitions of EU agencies proposed by the Commission and some scholars. Among these definitions, Chamon's seems to be the most comprehensive, and at the same time satisfies the norms of precision and simplicity.

Table 1.1) Definitions of EU agencies

\begin{tabular}{|c|c|}
\hline Source & Definition \\
\hline $\begin{array}{l}\text { Official website } \\
\text { of EU agencies }\end{array}$ & $\begin{array}{l}\text { "[EU] agencies have been set up by the EU to perform technical and } \\
\text { scientific tasks that help the EU institutions implement policies and take } \\
\text { decisions. They are spread across the EU." }\end{array}$ \\
\hline $\begin{array}{l}\text { European } \\
\text { Commission } \\
(2002 a, \text { p. 3) }\end{array}$ & $\begin{array}{l}\text { "[EU agencies] were created by regulation in order to perform tasks } \\
\text { clearly specified in their constituent Acts, all have legal personality and all } \\
\text { have a certain degree of organisational and financial autonomy." }\end{array}$ \\
\hline $\begin{array}{l}\text { Kelemen (2005, } \\
\text { p. 175) }\end{array}$ & $\begin{array}{l}\text { "[EU agencies are] EU level public authorities with a legal personality and } \\
\text { a certain degree of organizational and financial autonomy that are } \\
\text { created by acts of secondary legislation in order to perform clearly } \\
\text { specified tasks." }\end{array}$ \\
\hline $\begin{array}{l}\text { Chiti } \\
(2013, \text { p. 94) }\end{array}$ & $\begin{array}{l}\text { "[EU agencies] are here meant as bodies (1) aimed at establishing and } \\
\text { managing a plurality of cooperative relationships involving both the } \\
\text { Commission and the Member States' administrations; and (2) enjoying a } \\
\text { certain degree of autonomy from the Commission but not fully insulated } \\
\text { from the Commission's influence." }\end{array}$ \\
\hline $\begin{array}{l}\text { Chamon } \\
(2016, \text { p. 10) }\end{array}$ & $\begin{array}{l}\text { "EU agencies may be defined as (i) permanent bodies, (ii) under EU public } \\
\text { law, (iii) established by the institutions through secondary legislation, and } \\
\text { (iv) endowed with their own legal personality." }\end{array}$ \\
\hline
\end{tabular}

(Source: Author's own compilation) 
Just as there are various definitions for EU agencies, there are various ways to classify them. ${ }^{8}$ The simplest classification is proposed by the Commission, which makes a distinction between executive and regulatory agencies. Executive agencies perform "the management of Community programmes, they are set up for a limited period, and they are always located close to Commission headquarters" (European Commission, 2008, p. 3). ${ }^{9}$ This description does not match the definition of EU agencies stated above. In fact, only a few bodies belong to the Commission's typology of executive agencies, and most EU agencies are classified as regulatory agencies. Pointing to the Commission's misunderstanding of the concept of regulation, this classification is criticised as "simply absurd" (Geradin \& Petit, 2004, p. 47; Chamon, 2016)

Amongst various ways to classify EU agencies, the functional classification into three types information, management, and regulatory agencies - fits best with this research due to the small number of cases and resulting necessity for simplification. More specifically, information and regulatory agencies are relevant in this research as they are the ones involved in the policy process. ${ }^{10}$ Management agencies are the executive agencies which are set up to primarily carry out diverse EU programmes, and are thus not considered in this research. Information agencies collect, analyse, produce and disseminate information, coordinate networks in their policy field, and provide expert advice to policy-makers in the EU institutions and the Member States. These agencies aim at supporting evidence-based policy-making with their high-quality expertise. Regulatory agencies, on top of the same functions of information agencies, mainly conduct supervision, inspection, investigation, or enforcement, or assess individual applications for the authorisation of certain products in the internal market. Both information and regulatory agencies assist policy-making by providing expert advice as a primary or a secondary function. However, as mentioned earlier, the non-binding nature of their expert advice means that they are not an equal partner to the Commission in the development of policy proposals. In order to exert influence, they have to effectively argue and convince the Commission, which has the formal power to determine the content of policy proposals (see Chapter 2).

\subsection{Research on EU agencies' influence}

The literature on EU agencies started emerging in the 1990s in accordance with the second wave of proliferation of these agencies. Scholars succeeding Giandomenico Majone, who "pioneered scholarly attention to EU agencies" (Christensen \& Nielsen, 2010, p. 178), have covered quite extensive topics in many disciplines, most notably in political science, public

\footnotetext{
${ }^{8}$ See Chamon (2016) for a comprehensive overview and explanations of how the Commission and other scholars have classified EU agencies.

${ }^{9}$ An example of an executive agency is the European Agency for Reconstruction of Kosovo which was set up in 2000 and officially closed in 2008.

${ }^{10}$ Some scholars refer to these two types of agencies as regulatory and non-regulatory agencies (e.g., Font \& Pérez-Durán, 2016).
} 
administration, and law. In consequence, studies on EU agencies have by now accumulated a vast amount of literature, and scholars have even started publishing "reviews" of the existing literature (e.g., Egeberg \& Trondal, 2017). The usual forms of research outputs in the early period were either book chapters or individual journal articles (e.g., Everson, 1995; Majone, 1997). But in recent years, on top of a continuously growing number of journal articles - for example, the special issue of Journal of European Public Policy in 2011 (volume 4, issue 6) single-authored or edited books solely on the topic of EU agencies are also booming (e.g., Busuioc et al., 2012; Chamon, 2016; Coman-Kund, 2018; Everson et al., 2014; Groenleer, 2009; Ossege, 2016).

A large body of literature on EU agencies has focused on the creation of and delegation to EU agencies (Chiti, 2009; Dehousse, 1997; Kelemen, 2002; Krapohl, 2004; Thatcher, 2011; Vos, 2003). This literature explains institutional designs, functional and political reasons for establishing EU agencies, and their relationship with political principals most commonly through a principal-agent model. These themes are related to research on formal and informal independence and autonomy of EU agencies (Groenleer, 2009; Martens, 2010; Wonka \& Rittberger, 2010). Moreover, the principal-agent logic has prompted scholarly attention to an understanding of how accountable they are to the EU institutions and other stakeholders (Buess, 2015a; Busuioc, 2009, 2013; Busuioc, Curtin, \& Groenleer, 2011). These scholars have demonstrated different accountability mechanisms that are established to control EU agencies, how they are applied in practice, and how effective they are to hold EU agencies accountable.

Another strand of literature investigates EU agencies' relationships with the Commission, the European Parliament, the Member States, and stakeholders. Research on these topics has revolved around questions concerning EU agencies' networks, coordination, and legitimacy (Arras \& Braun, 2018; Buess, 2014, 2015b; Heims, 2016; Lord, 2011) as well as theoretical and conceptual explanations about inter-institutional relationships, following intergovernmental, supranational, and epistemic images (Egeberg et al., 2015; Trondal \& Jappesen, 2008). From a policy-making perspective, furthermore, the role and use of EU agencies' expertise for the development of European policies have attracted scholars' attention (Ossege, 2016; Rimkute, 2015). In the same vein, research on the tasks and effect of EU agencies in improving compliance and implementation of policies has been popular (Groenleer, Kaeding, \& Versluis, 2010; Klika, 2015; Versluis, 2007; Versluis \& Tarr, 2013). What is noticed in the recent literature is a shift of the focus from EU agencies in the broad institutional setting to their internal decision-making, personnel, organisation, and operation (Busuioc, 2012; Chiti, 2013; Egeberg, Gornitzka, \& Trondal, 2017; Font, 2015; Schout \& Pereyra, 2011; Suvarierol, Busuioc, \& Groenleer, 2013; Wonka \& Rittberger, 2011; Wood, 2018).

In the literature on EU agencies no systematic empirical evidence has been gathered so far on their de facto influence on policy-making, particularly on the formulation of policy proposals. It seems, as Klüver (2013, p. 9) argues, that "researchers have usually avoided the question of influence." This is largely due to methodological difficulties in operationalising influence. 
However, even in a rich literature examining political or policy influence - and its similar categories, such as power, success, impact, and effectiveness ${ }^{11}$ - of actors, the same remark about the lack of research on EU agencies' influence can be made.

In the field of influence studies, the political entities that have been analysed the most are interest groups, and "studies on lobbying will never be disconnected from the question of influence" (Woll, 2007, p. 74). Influence scholars in the EU have concentrated on enhancing empirical understandings of whether interest groups exert influence in certain policy areas (Dür \& De Bièvre, 2007), determinants of influence (Bunea, 2013; Dür, Bernhagen, \& Marshall, 2015; Michalowitz, 2007), lobbying strategies (Chalmers, 2013; Eising, 2007), and the unique institutional context of lobbying in the EU (Bouwen, 2002; Chalmers, 2011, 2014; Rasmussen, 2015). What is more, studies that review or propose novel methodological approaches to measure influence of interest groups have increased consistently (Arts \& Verschuren, 1999; Dür, 2008a; Fantini \& Staal, 2018; Klüver, 2009, 2013). Besides interest groups, there are many other political or policy actors who seek to exert influence in the EU. Just to name a few, scholars have analysed influence of expert committees in the Commission (Van Schendelen, 2006), small states or late joiners of the EU (Arter, 2000; Copsey \& Pomorska, 2010; Jakobsen, 2009; Luitwieler, 2009), the European Parliament and its parties (Burns, 2005; Johansson, 2016), and the Council of the European Union (Beach, 2004).

What is noteworthy to mention at this point is studies on two consultative committees in the $\mathrm{EU}$ - the European Economic and Social Committee (EESC) and the Committee of the Regions (CoR) - in the legislative decision-making process (see e.g., Hönnig \& Panke, 2012; McCarthy, 1997; Panke, Hönnig, \& Gollub, 2015). These committees share some common characteristics with EU agencies in a broad sense because they, as advisors, may be involved in the policymaking process and requested to provide opinions based on their expertise. However, their opinions are non-binding to policy-makers. Panke et al. (2015, pp. 44-47) provide an overview of studies on other bodies in the EU which have similar role and competence to the two consultative committees (and thus to EU agencies), such as parliamentary committees, comitology committees, scientific committees in the European Commission, and, of course, interest groups. Although research on influence of these bodies has been increasing, scholars have paid scant attention to assessing influence of EU agencies on the formulation of policy proposals.

The lack of research on this topic is surprising for three reasons. Firstly, such research has long been missing despite the acknowledged importance of EU agencies and the increasing number of studies on them. For instance, it has been almost 20 years since Vos (2000, p. 1130), who contributed to early (as well as current) studies on EU agencies, put forward by supporting Majone (1997) that

\footnotetext{
${ }^{11}$ Some scholars have incorrectly used the term "influence" to describe what is not an influence phenomenon or have used various terms as synonyms for influence without properly defining or understanding what is meant by influence (see Chapter 2).
} 
the significance of the information produced by agencies is evident as it forms the basis of regulatory decision-making within the Community. The provision of information and evidence by agencies clearly influences decision-making and could be considered as a kind of "regulation by information."

Secondly, scholars investigating the formation of policy proposals focus mostly on the role and power of the EU institutions (the European Commission in particular) and interest groups, even though most EU agencies are given and do fulfil the task of providing expert advice to policy-makers. Third, the presence or lack of influence of EU agencies on policy proposals is a topic directly relevant to the ongoing discussions about (input and output) legitimacy of EU policies as well as technocratic governance in the EU. Against this backdrop this research makes its academic contribution, which is explained in the following section.

\subsection{Contribution}

This book makes a distinct contribution to the literature on EU agencies and influence studies in a number of ways. The empirical case studies in this research enrich a scholarly understanding of daily practice, operation, and decision-making within EU agencies. At the same time, they give particular attention to the detailed processes of: 1) how EU agencies ensure the production of high-quality expert advice even in situations of lack of information or experience, high time pressure, or limited resources; and 2) when and how EU agencies interact with the European Commission to provide expert advice as input in the policy formulation stage. This implies that the current research moves away from considering EU agencies only as the European centres of expertise filling in knowledge gaps, to analysing them as policy actors who engage in activities with various experts and policy-makers. By doing so, EU agencies' advisory function is put into the context of policy-making in practice and evaluated to assess the level of influence. Additionally, in order to validate influence of EU agencies, this research suggests text comparison to trace actual signs of influence on policy proposals and provides concrete evidence of influence in the four case studies. While this method enables a systemtic comparison of influence efforts and their effects across a multiple number of cases, there have not been many studies which investigate influence through text comparison. ${ }^{12}$

With regard to the policy-making process, the policy formulation stage remains relatively underexplored even though this stage is "indeed an important part of politics" (Binderkrantz, Christiansen, \& Pedersen, 2014, p. 884). Influence studies mostly focus on the decision-making stage as "it is easier to observe relevant behaviour [of actors]" (Binderkrantz \& Rasmussen, 2015, p. 553). Similarly, a large number of agency studies focus on the implementation stage as "the main activities of EU agencies are more on the implementation side than on the policy

\footnotetext{
${ }^{12}$ One of the notable exceptions is a study by Binderkrantz et al. (2014) on the influence of business interests on Danish bills.
} 
formulation side" (Egeberg \& Trondal, 2011, p. 876). However, this research is one of the first exploratory attempts to measure the actual impact of EU agencies on the development of policy proposals and to analyse conditions facilitating such impact. This also adds to an understanding of "how" the early stage of policy processes unfolds at the European level and "by whom."

Moreover, while most studies on EU agencies have focused on individual case studies of agencies (e.g., Martens, 2010) or comparative studies of regulatory agencies (e.g., Ossege, 2016), this research offers a comparison between information and regulatory agencies which is less common in the research field of EU agencies. Additionally, the two agencies selected for case studies - ECDC itself and ECHA in relation to the biocidal products regulation - have rarely been analysed by scholars.

Lastly, this research contributes to the theoretical debate concerning legitimacy, democracy, and technocracy in the EU. Utilising EU agencies' expert advice is supported for the purpose of evidence-based policy-making and solving policy problems; yet, their influence on policies may be (normatively) contested. This is because "the potential contradiction between democracy and technocracy is one of the core problems in democratic theory" (Lindvall, 2009, p. 704; Dahl, 1989). Is influence of EU agencies on policy-making normatively good or bad for legitimacy and the idea of representative democracy? If EU agencies do exert influence on the formulation of policy proposals in the Commission, does this constitute another element worsening a democratic deficit in the EU? Findings of this research and their implications will provide the basis for these discussions.

\subsection{Outline of the book}

The structure of this book is as follows. Chapter 2 scrutinises the central concept of this research - "influence" - by differentiating it from "power," a term that is often used synonymously. The definition of political influence and political power in the European policymaking context is also offered. Chapter 3 presents the research design and methodology. The research design sets out the three-dimensional approach as well as three conditions - access, activities, and resources - that are expected to affect influence of EU agencies. At the same time, methodological choices, including the case-study approach, data selection, and data analysis, are outlined and justified. Chapters 4 and 5 constitute the empirical analyses of this research. Chapter 4 investigates ECDC's influence in two policy dossiers, which deal with the H1N1 pandemic crisis in 2009 and cross-border health threats. Chapter 5 examines ECHA's influence also in two policy dossiers concerning the regulation of biocidal products. Chapter 6 provides a comparative analysis of the four cases (policy dossiers) in the two selected agencies from a cross-case viewpoint. It looks into the main empirical findings and also offers other explanations about conditions for and indicators of influence. Chapter 7 concludes the book by discussing theoretical, empirical, and methodological implications based on the main findings and suggests some routes for future research. 
Chapter 2

Conceptualisation: Influence and Power in EU PolicyMaking 


\subsection{Introduction}

In the previous chapter it was explained that this research seeks to find out the extent to which, and the conditions under which, EU agencies exert influence in policy-making. The focus is on the policy formulation stage in the policy-making process, and thus the main policy actor on which EU agencies (may or may not) exert influence is the European Commission. If EU agencies do exert influence in this stage, what kind of influence is this? How should we understand the influence of EU agencies in the policy formulation stage in the Commission? By specifying the meanings of influence and power, this chapter will sketch the fundamental ground for an analytical framework (Chapter 3), which will outline the conditions necessary for EU agencies' influence. This is necessary in order to be able to conduct research that is valid and reliable. Depending on how influence is conceptualised and the context in which it is exercised, the choices to be made about how influence is assessed and explained are widespread (Corell \& Betsill, 2008; Luitwieler, 2009). Against this background, this chapter first aims to understand what is meant by influence and power by comparing different views. In addition, it proposes specific definitions of influence and power in the context of policymaking in the EU.

The following section (2.2) begins with the ambiguity of the two terms. In Section 2.3 the concepts of power and influence are explained, and their relations to each other are discussed. Then, Section 2.4 discusses how influence and power of EU agencies as well as the Commission should be understood in the context of EU policy-making in general and in this research specifically. This section provides the definitions of the two terms and also explains the types of expertise that are used by EU agencies. Lastly, this chapter concludes with a short summary of the concepts of influence and power.

\subsection{The lack of clear definitions}

Most scholars in political science would agree that "influence" and "power" are important phenomena in any political analysis. They are elementary aspects of political and social life and therefore among the main themes of current social sciences (Arts \& Verschuren, 1999). Surprisingly, however, there is hardly any consensus on the definition of influence and the relations between influence and the concept of "power." Although there have been some attempts by scholars to define the concepts of influence and power, there still is a lack of clarity of the meaning of influence distinct from that of power - and vice versa - that can be generally accepted and adopted in political science as well as in ordinary language in a broader context (a few notable and commendable exceptions in the academic literature on influence in the political arena include Arts, 1998; Betsill \& Corell, 2008; Luitwieler, 2009). In addition, there is no common understanding of other distinctive features of influence and power, such as whether or not they can be attained rather than given; whether or not they are only exercised intentionally - in other words, in exercising influence and power, whether or not 
influence- and power-holders should be aware (and cannot be unaware) of exercising them; and whether or not influence and power can be transformed into each other. These issues are discussed in this conceptual chapter.

One reason why the terms influence and power are not clearly distinguished and conceptualised is that we all understand what they mean when we hear or use them. These words are commonly used to describe situations of our everyday interaction with other persons or groups in a society, and particularly in a situation that involves political behaviour. Thus, as Dahl and Stinebrickner (2003, p. 12) mention, "most theorists seem to have assumed, as did Aristotle, that they needed no great elaboration [to define these terms], presumably because their meaning would be understood by people of common sense." What can be immediately noticed in the absence of clear meanings of influence and power is that the two terms are closely connected and used interchangeably and synonymously. ${ }^{13}$ One author may use the word "influence" to describe a certain phenomenon that is described as "power" by another author. Moreover, some authors use the two terms as synonyms in a single article or book (e.g., Thomson \& Hosli, 2006; Weinlich, 2014). One advantage of using the terms interchangeably, as Zimmerling (2005, p. 99) points out, is that "theories which say something about power, but nothing specifically about influence - such as most normative theories concerned with the justification of political system - do nevertheless not suffer from an 'influence gap.'”

However, this pattern of usage may deteriorate to ambiguity. It may also create confusion and misunderstandings concerning the concepts that the author is addressing. Therefore, further improvement in the clarification of the concepts of both influence and power - specifically political influence and political power - as well as their relations to each other would appear to be necessary. Additionally, there are other advantages of clearly conceptualising these two terms. Methodologically, "clear understandings of concepts permit the exact definition of variables which can then be used in scientific explanations" (Guzzini, 2005, p. 500). Clear definition of influence reduces the risk of presenting evidence of influence on an ad hoc basis - choosing evidence with a bias that proves influence and disregarding other evidence that shows little or no influence (Betsill \& Corell, 2008). Likewise, clear definitions help researchers look for an appropriate proxy for influence which proves the effects of that influence and increases the validity of claims (Betsill \& Corell, 2008).

In sum, clarifying the meanings of influence and power enables the robustness of research findings (also in multiple cases) and refines researchers' judgment on the accurate measurement of influence and power, which in turn would also contribute to the development of an empirically based analysis in political science.

\footnotetext{
${ }^{13}$ In addition, Wrong (1979/1988) explains that power and influence are used synonymously because of the absence of a verb form for the term power.
} 


\subsection{Concepts of, and relations between, influence and power}

As mentioned earlier, while the term influence is often used interchangeably with the term power, there are clear advantages in clarifying their meanings. In this section, different views on the meanings of these two terms and their relations to each other are explained. It should be noted that the explanations provided here are not an exhaustive account of the meanings of influence and power as it is neither possible nor relevant to discuss all existing literature in all disciplines. Rather, attention is given to the understandings that are essential in the fields of social and political sciences to build and support the definitions of influence and power in the context of EU policy-making, as presented in Section 2.4.

\subsubsection{Power}

The concept of power is understood in many different ways from discipline to discipline. In social sciences alone, there are hundreds, perhaps thousands, of definitions of social power (Wrong, 1979/1988). Out of myriad ways to look at power, how should the concept of power be systematically organised and understood? One approach is to distinguish between "power to" and "power over." For the first of these, the conception of power as "power to" emphasises the "ability" of power-holder(s) to do or achieve something. The core concept, in other words, is the "competence" or "capacity" that the power-holder possesses to bring about outcomes or consequences. Hobbes's (1651/1985, p. 41) definition of power best describes this line of thinking: "The power of a man, [to take it universally], is his present means to obtain some future apparent good." Likewise, the power of political actors can be seen through the "production of intended effects" (Russell, 1938, p. 35). ${ }^{14}$

By contrast, the "power over" view asserts power in a social relationship. Weber, who is one of the most-cited scholars for explaining power, provides this definition:

In general, we understand by "power" the chance of a man or a number of men to realize their own will in a social action even against the resistance of others who are participating in the action. (1922/1978, p. 926)

In a different chapter of the same book, the phrase "[...] to realize their own will [...]" is replaced with the phrase "[...] to impose their own will [...]" (Weber, 1922/1978, p. 631). Considering this, his definition highlights three important elements of power. Power is relational because it exists within social actions. In order to exercise (social) power in a social relation, an actor needs to have the ability to impose its will, intentions, or desires on other actor(s). Weber's definition of power also involves the possibility - but not necessity - of conflict.

\footnotetext{
${ }^{14}$ Lasswell and Kaplan (1950) argue that Russell's definition cannot be automatically translated in the political sense; rather, such effects in his definition should directly involve other persons in order to be considered as political power.
} 
Another well-known definition by Dahl (1957, p. 202) is: "A has power over B to the extent that he can get B to do something that B would not otherwise do." This definition expresses the interest-oriented perspective, and there are two different ways to understand this perspective (see Lukes, 1991, pp. 86-92). The first is that realisation of a power-holder's interests, desire, preference, or will involves actual or potential conflict and resistance. This is in line with the definitions proposed by Weber and Dahl above. Lukes's view is even more radical in that he argues: "A exercises power over $B$ when $A$ affects $B$ in a manner contrary to B's interests" (Lukes, 1974, p. 27). Exercising power in situations of conflict and resistance is explained further in the following subsection "Influence." Second, other scholars regard the realisation of interests not as a zero-sum phenomenon but one where power is a collective capacity for achievement. This view stresses power in terms of a "facilitative" (Clegg, 1989) and communal, rather than competitive, aspect whereby actors with other actors collectively increase a potential to attain their common goals (see, for example, Arendt, 1970; Parsons, 1963).

For the purposes of the current research, it is most appropriate to perceive power as a competence or capability to bring about outcomes or consequences, in accordance with the "power to" rather than the "power over" view. In a political community, actors pursue collective aims, and one actor prevailing over another - power over - is not a typical characteristic of their daily interactions. In the EU, it is indeed the case that the Commission does not exercise power over EU agencies, which are independent and operate at arm's length from traditional controls. Moreover, contrary to the power over view, sometimes power is not one-sided because mutual dependence exists amongst actors to accomplish common goals, and efforts to dominate ( $A$ trying to get $B$ to do what $B$ would not otherwise do) are met by counter-efforts to resist and may result in negotiation and compromise (Stone, 2001).

Before moving to the concept of influence, it is worth noting some general characteristics of power, in order to grasp the concept better. First of all, when an actor has power (over other actors or to achieve what is desired), where is this power derived from? Is power something that is attained or given? In sociology's "group processes" perspective, power results primarily from a position in a social structure; and formal rules, such as those that give authority to supervisors in an organisation, typically grant power to control the behaviour of others (Lucas \& Baxter, 2012). This implies that an actor or an organisation, when assuming a certain position in a social structure, is also given power on the basis of formal rules.

Second, "having" power is not the same as "exercising" power. Having power is best understood as an ability one can have to trigger particular reactions from another agent, and if such an ability, which exists over time in a latent state, is "actualised" on certain occasions, it becomes an exercise of power (Zimmerling, 2005). This implies that in order to exercise power, the power-holder must intentionally choose to do so. Likewise, if the power-holder is not interested in bringing about particular reactions, she may simply not utilise the ability she already possesses, meaning that she does not exercise power although she has the ability to do so. Consequently, third, if an actor exercises power, it always means that she is "aware" of 
her action. Kliemt's definition of power illustrates this point. Power in its social sense means "a kind of ability to exert purposefully a causal influence on social results or on other people. In short, 'power' is the ability to influence social outcomes [...] according to one's wants" (Kliemt, 1981, p. 52, emphasis added). According to him, power is the ability to produce "purposefully" intended outcomes. Thus, in order to exercise power, "awareness on the part of the power-holder is conceptually necessary" (Zimmerling, 2005, p. 90). Zimmerling (2005, pp. 48-49) elucidates this point:

[An actor exercising power] may, of course, be unaware of the fact that it can be called an 'exercise of power', but one surely cannot be unaware of the 'thing itself', since exercising power on that account means successfully completing a "purposeful" exercise. By way of the purpose, awareness is, so to speak, built into the concept.

In short, the basic distinction between "power to" and "power over" can be that while the "power to" view refers to the ability of an actor herself to bring about specific outcomes, the "power over" view sees power in an asymmetric relation between two or more actors. Power, from the "power over" perspective, is exercised when the power-holder imposes its will on other actor(s) and is thought of as either possibly or necessarily conflictual. But, power in both views is in general understood as something given rather than attained, and having power does not mean exercising it. Exercising power takes place only when the power-holder purposefully does so. In this research, it is more appropriate to understand power as "power to" bring about outcomes or consequences. The concept of power is now compared with the concept of influence in the following section to make a clear distinction between them.

\subsubsection{Influence}

Similar to power, the definitions of influence have shown a lack of clarity and consensus in the literature of many disciplines. Moreover, publications about the concept of influence amount to a small portion of the literature on the concept of power since many authors use them as synonyms and do not make a distinction between the two terms (Zimmerling, 2005). But, there are differences between influence and power, and in order to explain them in this section, a broad definition of influence and a specific situation used by Zimmerling as an example are first discussed to elicit some essential characteristics of influence. Then, three different views about the relations between influence and power are elaborated.

Dahl and Stinebrickner (2003, p. 17), by adopting the view on influence from Nagel (1975), suggest an elaborate definition of influence:

[A] relation among human actors such that the wants, desires, preferences, or intentions of one or more actors affect the actions, or predispositions to act, of one or more actors in a direction consistent with - and not contrary to - the wants, preferences, or intentions of the influence-wielder(s). 
Now consider an emerging star in the heavens of pop music. "[H]er way of dressing, walking, talking, etc. may change the tastes of her fans [...] or their ideas about how one should behave [...], or even their outlook on the world [...] if they start to take the lyrics of her songs as truthful assertions about how the world really is" (Zimmerling, 2005, p. 147). ${ }^{15}$ Based on the definition of influence, it can be stated that this pop star may have considerable influence on a great number of people. The first characteristic of influence to understand is whether it is correct to see that this influence is given to the pop star, just like power which is given by formal rules in a social structure. In the case of influence, it is more appropriate to consider that it is attained rather than automatically given because influence is not a competence or capability to produce binding effects. Being a singer, or even an emerging star, does not guarantee any possibility that she can affect actions of other people in a way that is desired by her, because some people may not be affected at all. Unlike power, there is no binding effect on all actors even if this star succeeds in influencing some people. If she affects actions of certain people who previously were not affected by her, it can be argued that she has gained more influence, rather than that more influence has been given to her.

The second characteristic to look at here is intentionality. The discussion on power in Subsection 2.3.1 proposed that "having" and "exercising" power mean different things because an actor who has power needs to intentionally choose (or choose not) to exercise it. Is this also the case for influence? Consider a situation in which a pop star, who has influence, chooses not to influence her fans. This is not a feasible situation because having influence means that the influence is already at work, which also means that choosing to exercise it or not cannot even be considered at this moment. When it is said that $A$ influences $B$, it is understood that A exercises influence on B. Therefore, it is adequate to perceive that "having influence" actually means "exercising influence," and that having and exercising influence cannot happen separately.

This leads to the third point, which is the awareness of an actor who influences. In the case of power, the power-holder's awareness to make use of power is built into the concept of exercising power because, again, the power-holder has to intentionally choose to exercise power. If influence is taking place, does it mean that an actor with influence is "intentionally" exercising it? As with power, it is possible that a pop star purposefully makes attempts (e.g., choosing to dress in a certain way) to bring about certain results in her fans. However, unlike power, it is also possible that her fans have voluntarily changed their tastes or preferences in a direction consistent with the pop star even though she does not make any explicit and intentional attempts (e.g., she happens to dress in a certain way) to elicit such changes. This is in line with Wrong's perception of influence, which may produce unintended effects as opposed to power which produces intended and foreseen effects on others (Wrong, 1979/1988). Therefore, to exercise influence - to have influence - awareness on the part of

\footnotetext{
${ }^{15}$ It should be noted that although Zimmerling's example of a pop star is used here to explain influence and its relation to power, her understanding of influence and power is different from how these concepts are perceived in this research.
} 
the influence-wielder about exercising it is not conceptually necessary. When an actor has influence, it already means that the influence is being exercised regardless of the intentional or unintentional attempt by the actor.

Having examined the semantic differences between influence and power, this section now considers the concept of influence in terms of its relations to power. Scholars who have tried to distinguish influence and power present their position by analysing whether or not one concept is subordinate to the other. According to this approach, three relations of influence and power can be identified (see Figure 2.1 below): (a) influence and power as independent but potentially overlapping concepts; (b) power as the general concept and influence as a special case of power; and (c) influence as the general concept and power as a special case of influence. ${ }^{16}$

Figure 2.1) Three relations between influence and power

(a):

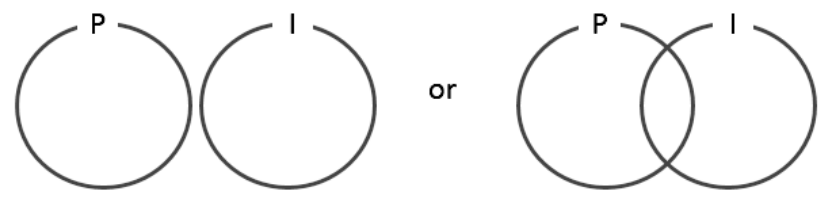

(b):

(c):
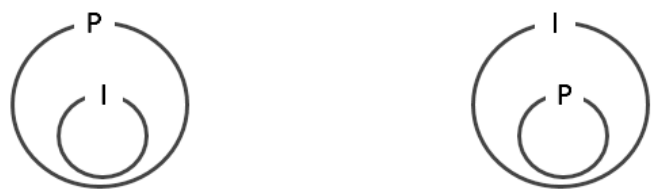

* ' $P$ ' denotes power; and ' $\mathrm{l}$ ' denotes influence.

(Source: Author's own compilation)

The first view (a) claims that power and influence are conceptually independent from each other. Mokken and Stokman (1989) are considered to be the prominent scholars of this view. When explaining the independent relation between power and influence, they use an example that man has power over wild animals by restricting their territory, without influencing animals' freedom of movement within the territory. They regard power as the capacity to determine the elements of the choice menu for other actors and influence as the capacity to

\footnotetext{
${ }^{16}$ Zimmerling (2005) provides a detailed explanation and discussion of these three relations. She considers the relation of influence and power as illustrated in (a) as complementary concepts, and (b) and (c) as conceptual subordination.
} 
determine which option from the menu is chosen. More specific to the political environment, they provide this definition:

Political power in a social system is the capacity to fix or to change (partly) a set of alternative value allocations for the members of that system or for parts of it; and

Political influence is the capacity to determine (partly) within a given set of available alternative value allocations the outcomes of the allocation process. (Mokken and Stokman, 1989, p. 49)

Their proposal seems plausible because they manage to show that power and influence remain independent from each other although they are related. However, influence is defined in an overly narrow way, capturing only a small part of what is usually called influence, and this is especially the case when it comes to influence of the dead (Zimmerling, 2005). For instance, when talking about Mozart's influence on classical music, it should mean, according to Mokken and Stokman, that Mozart has the ability to determine the outcome of the behaviour of others. But, it would not be cogent to say that a dead person has such an ability.

Zimmerling (2005) considers influence and power as two disjoint categories. According to her, power is linked to a subject's action and defined as "the ability to get desired outcomes by making others do what one wants, i.e., by somehow (no matter how) imposing one's own preferences on them" (Zimmerling, 2005, p. 141, italics in original). Influence, by contrast, is defined as:

[T] he ability to affect others' beliefs, that is, their knowledge or opinions either about what is or about what ought to be the case, about what is (empirically) true or false or what is (normatively) right or wrong, good or bad, desirable or undesirable. (Zimmerling 2005 , p. 141, italics in original)

As two disjoint concepts, power and influence should occur separately from each other. But, how can someone possibly change others' action to get desired outcomes (which is defined as power) without affecting their beliefs (which is influence)? If an actor gets desired outcomes by making others do what she wants by imposing her preferences on them, and if she achieves this without presenting positive rewards or negative sanctions, it is surely the case that she has managed to change their beliefs. The actors being affected would not otherwise react in the way that is desired by the actor with power, especially when there is no punishment on those who do not react. Since the understandings suggested by Mokken and Stokman as well as Zimmerling show limitations - overly narrow definition of influence and the lack of clarity in the separation between changing behaviour and affecting beliefs respectively - it does not seem adequate to apply this view.

Nevertheless, it is worth nothing that although the two terms are independent from each other, there might be some cases that can be both power and influence - the overlapping fraction of (a) in Figure 2.1. Mokken and Stokman offer an exceptional argument that power and influence can be transformed into each other. Influence is transformed into power when 
an actor who has the capacity to make a choice also determines the set of alternatives, and power is transformed into influence when an actor provides an alternative and his option is chosen by the decision-makers. When applied to Zimmerling's definitions, this would mean that an actor succeeds in affecting both actions and beliefs of others, and thus exerts both power and influence. The transformation of influence and power into each other is discussed further in Subsection 2.4.1, which provides definitions of influence and power in the policymaking process of the EU.

The second view (b), which sees influence as a sub-category of the general concept of power, considers that "power is presupposed in practices of influence, whereas these practices sustain power" (Arts \& Verschuren, 1999, p. 414). Similarly, Hoogerwerf (1972) sees power as potential influence, and defines power as the possibility to influence the behaviour of others in accordance with the actor's own purposes (cited in Mokken \& Stokman, 1989). To him, influence occurs whenever behaviour leads to change in behaviour. Moreover, Cartwright (1969, p. 125) provides a clear explanation of power and influence: "When an agent, O, performs an act resulting in some change in another agent, $P$, we say that $O$ influences $P$. If $O$ has the capability of influencing $P$, we say that $O$ has power over P." Since influence is subordinate to power, influence cannot exist without power. To put it differently, all actors who are influential must also be powerful although it is possible that some powerful actors do not have influence. The main criticism arises exactly from this point. For example, under this view, an emerging star who has influence on her fans must also have power over them. However, this is not feasible as the pop star's influence does not and cannot bring about binding effect on her fans. In a situation where there is influence without exercise of power, this view is not applicable. Furthermore, Arts and Verschuren (1999) admit that the distinction between power as the general ability to influence and influence as the realisation of a single effect is not always valid. When desired outcomes are achieved despite the ongoing opposition of others, the plausible explanation can be that education, awareness-raising, or the persuasion of others - rather than once-only instances of influence - may be sufficient preconditions for modifying a decision.

Lastly, scholars supporting the third view (c), which recognises power as a sub-category of the general concept of influence, believe that the threat of sanctions is the core element of power that is distinct from influence. Since influence is a superordinate concept to power, not all cases of influence can be cases of power. Only cases of influence accompanied by the threat of sanctions are considered to be power. Thus, in order to exercise power - not influence sanctions and deprivations should be important enough to those being affected to make them do what the power-holder(s) want. Dahl and Stinebrickner (2003) perfectly illustrate this view. According to them, power occurs "when B does what A wants because A will deprive B of something $B$ values unless $B$ complies with $A$ 's wishes [... and] compliance is attained by creating the prospect of severe sanctions for noncompliance" (Dahl \& Stinebrickner, 2003, p. 38). Influence, by contrast, is the ability to get what one wants in the absence of fear of punishment or promise of reward (Lucas \& Baxter, 2012). In the context of political science, 
furthermore, Lasswell and Kaplan (1950, pp. 74-75) see power as "participation in the making of decision: $\mathrm{G}$ has power over $\mathrm{H}$ with respect to the values $\mathrm{K}$ if $\mathrm{G}$ participates in the making of

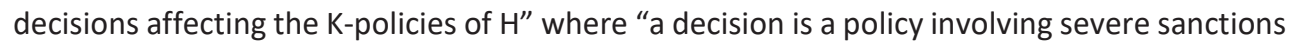
(deprivations)."

The main shortcoming of this third view arises from the question of whether power comprises only those cases where sanctions are applied. This view overlooks a possible situation in which power is used precisely to further some interest of those who are being affected. Moreover, the threat of, or even the actual application of, sanctions is rare in any decision-making processes. This is also the case in the $\mathrm{EU}$, where threats in general are very rarely used during discussions or negotiations (Beach, 2004; Luitwieler, 2009). The use of sanctions in the form of economic or military measures is more common and applicable in international relations when power of states is concerned.

Although this last view (c) does not perfectly fit into the political environment due to the threat of sanctions which is hardly applied, it comes closest to the policy-making context of this research. This is because of the plausible explanation of influence in this view. If powerholders utilise the threat of sanctions as a means to achieve their intended goals, what do influence-wielders utilise? Scholars suggest persuasion. Parsons (1963) explains that political influence, operating in the context of the goal-functioning of collectivities, creates an effect on the attitudes and opinions of others through persuasion. Persuasion is based on convincing arguments given in good faith and the "receiving end" freely and on his own conviction chooses his posterior action (Connolly, 1983, cited in Zimmerling, 2005). When A influences B using persuasion, information is seen as a crucial resource. Influence occurs "when one actor intentionally transmits information to another that alters the latter's actions from what would have occurred without that" (Knoke, 1990, p. 3). By emphasising the importance of rational and truthful communication, Dahl and Stinebrickner (2003, p. 40) also argue that influence occurs when "A conveys to B information, argumentation, or explanation that leads B to do or think something different from what B otherwise would have done or thought."

To summarise, the distinct characteristics of influence are: influence can be attained rather than given; having influence means exercising influence; and awareness on the part of the influence-wielder about exercising influence is not conceptually necessary to influence, thus both intended and unintended influence are possible. Influence can be understood based on its relation to power, and the view that considers influence as the general concept and power as a special case of influence comes closest to the policy-making process in the EU. Having explained the different views and understandings of both power and influence, it is time to reflect on them in the context of policy-making in the EU. The following section explains how influence and power are understood in the policy-formulation stage in the EU and discusses when an actor can be considered to have power or influence. 


\subsection{Positioning EU agencies' influence and power in policy-making}

This section discusses the meanings as well as the characteristics of influence and power in the context of policy-making at the European level. First, the definitions of influence and power used in this context, as well as the understanding of who has influence or power, are provided. Then, the types of expertise that EU agencies utilise as the basis for their potential influence are explained.

\subsubsection{Definitions of, and actors with, influence and power in this research}

A clear image of the meaning of decision-making is that of a person pausing at a fork in the road and choosing one path to reach a desired goal or to avoid an unpleasant outcome (Hastie \& Dawes, 2010). The action of decision-making involves a set of alternatives, and a choice or a decision is made by choosing one option among these alternatives by the decision-makers who have decision-making competence. This means that there are input and output sides in the decision-making process: one policy is chosen - output - out of a set of alternatives - input - which are offered to the formal decision-makers. From the political perspective, this decision has a collective and binding characteristic because it will bind all actors involved in the situation, and it will be imposed despite resistance and regardless of the will of actors being affected. This description corresponds to what is meant by power as it is associated with the restriction of freedom of non-decision-makers. Therefore, power-holders are the decisionmakers in the policy-making process, and political power is the ability to determine the (policy) output within a set of available alternatives. ${ }^{17}$

As explained earlier, power is given by formal rules in a social structure. In a political environment, Parsons (1963) argues that exercising power is directly related to the democratic association, be it governmental or private, which is characterised by a structure of offices that are authorised to take certain decisions binding on the collectivity as a whole. Such authorisation is defined "within constitutional norms, and there are also constitutional procedures by which incumbents of office are chosen" (Parsons, 1963, p. 52). When considering the whole policy-making process which consists of five stages - agenda setting, policy formulation, decision-making, implementation, and evaluation - choosing a policy output takes place in the decision-making stage. Then, political power is in the hand of the actors who choose policy outputs in the decision-making stage, and under the ordinary legislative procedure in the EU, the European Parliament and the Council of the European Union are by law given the political power to decide whether or not to adopt policy proposals. However, it should be noted clearly that, as outlined in Chapter 1, the focus of this research is particularly on the policy formulation stage rather than the whole policy-making process. The European Commission in this stage has the right of initiative, which is the legally defined

\footnotetext{
${ }^{17}$ The definition of political power proposed here is regarded as political influence by Mokken and Stockman (1989).
} 
power to propose new laws (policies). As the body that formally initiates policies or legislation, the Commission in the policy formulation stage has the power to determine and formulate the content of policy proposals. Therefore, in this research, the decision-maker (power-holder) refers to the European Commission - not the European Parliament and the Council of the European Union in the full cycle of the policy-making process.

Regarding the input side of the policy formulation stage, who provides policy options as the set of alternatives from which the Commission can choose? There are a lot of actors who seek access to the Commission to offer high-quality information and policy-relevant knowledge as policy input. None of their input is binding, and the Commission can shop among various sources of information (Van Schendelen, 2006). Without the power to decide the final choice of the content of policy proposals (as it is in the hand of the Commission), they seek to shape the position of the Commission to whom their information is addressed and, in turn, also the content of policy outputs (Panke et al., 2015). Thus, political influence is the ability to shape the content of (policy) output by providing (partly or completely) the set of alternatives to decision-maker(s). In order to offer a set of alternative choices to the formal decision-makers, the actor(s) offering the alternatives should be able to aggregate, organise, and disseminate information, expertise, and intelligence that are required by the formal authorities to make a correct judgment. This is the major function of most of the EU agencies. They gather information in their specific policy area and provide their expertise to the Commission and other EU institutions and the Member States if necessary. It is worth recalling here that information and advice provided by EU agencies are not binding on the Commission, meaning that the Commission is free to choose whose information and which information to take into consideration. Thus, the influence of EU agencies is not guaranteed, and this research seeks to find out the extent to which and under which conditions EU agencies influence the content of policy proposals (see Chapter 1 ).

If EU agencies do exert influence on the Commission, does it mean that persuasion is at work, as explained in Subsection 2.3.2? The fact that the Commission has a great deal of leeway in selecting whose information to consider out of many policy actors and decides to listen to EU agencies over other actors indicates that the Commission finds expert advice from EU agencies persuasive. In fact, some agencies have played a much bigger role than an advisor as the decision-making institutions heavily rely on the opinions from these agencies (see Chapter 1 ). Scholars argue that "as long as the agency adheres to its mandate of producing scientifically convincing [opinions]" its influence remains high (Gehring \& Krapohl, 2007, p. 210, emphasis added). This suggests that EU agencies utilise persuasion as the means to exert influence, and that expertise and the ability to produce scientifically convincing opinions are characteristic sources of influence for them in the policy-making process.

The discussion here leads to the following important question: Can influence of EU agencies be transformed into power if the Commission, for example, continuously relies heavily on policy input from some EU agencies? Formally speaking, the answer is "no" because power, as explained earlier, is given by formal rules in a social structure, and only the Commission is 
given the power of legislative initiative. Since such power was not given to EU agencies when they were established, they cannot have or exercise power. Yet, informally, the answer can be "yes." Consider, for example, that expert advice of an EU agency, which is provided to the Commission as a set of alternatives, ends up being the content of a policy proposal, meaning that the agency's expert advice literally shapes what is written in (most parts of) the proposal. If the agency succeeds in achieving this once, a few times, or sporadically, this should be considered as influence as defined here - "high" influence to be precise (see the research design in Chapter 3). But, if this happens continuously to the extent that the Commission's power to determine the content of policy proposals becomes inactive as expert advice of the agency takes over this function, it should be seen that the agency, while exercising high influence, could also exercise "informal" power. ${ }^{18}$ It is informal because the formal power is not given to the agency.

\subsubsection{Expertise-based influence}

In the previous section, it was proposed that expertise and scientifically convincing opinions are important sources of influence for EU agencies. This means that if EU agencies do succeed in shaping the content of policy proposals in accordance with their expert advice and recommendation, EU agencies exert expertise-based influence. The types of expertise that are used by EU agencies to exert influence are explained below.

Departing from a broad definition of expertise, which is "a high level of familiarity with a body of knowledge and/or experience that is neither widely shared nor simply acquired" (Page, 2010 , p. 258), scholars propose a variety of different types and dimensions of expertise. Table 2.1 below provides a summary of various expertise types. It should be noted that it is challenging to place different expertise into one type since scholars' understandings and categorisations of expertise are slightly different from each other even when they refer to the same type of knowledge.

\footnotetext{
${ }^{18}$ This research is about influence as the central concept rather than power. Thus, going into details of the discussion between formal and informal power would be beyond the scope of the study. "Informal" power in this context should be understood as a phenomenon of exercising power but only by an actor who is not the formal power-holder.
} 
Table 2.1) Different types or dimensions of expertise

\begin{tabular}{|l|l|l|l|}
\hline & Page (2010) & Blom (2016) & Garret et al. (2009) \\
\hline $\begin{array}{l}\text { Knowledge of a } \\
\text { specific subject area }\end{array}$ & $\begin{array}{l}\text { 1) Scientific } \\
\text { expertise }\end{array}$ & $\begin{array}{l}\text { 1) Subject matter } \\
\text { expertise }\end{array}$ & $\begin{array}{l}\text { 1) Subject matter } \\
\text { expertise }\end{array}$ \\
\hline $\begin{array}{l}\text { Knowledge of policies } \\
\text { and instruments }\end{array}$ & 2) Policy expertise & 2) Policy expertise & - \\
\hline $\begin{array}{l}\text { Knowledge of } \\
\text { complex processes }\end{array}$ & $\begin{array}{l}\text { 3) Process } \\
\text { expertise }\end{array}$ & $\begin{array}{l}\text { 3) Procedural } \\
\text { expertise }\end{array}$ & $\begin{array}{l}\text { 2) Interface tool } \\
\text { expertise; } \\
\text { 3) Information flow } \\
\text { path expertise }\end{array}$ \\
\hline $\begin{array}{l}\text { Knowledge of legal, } \\
\text { political, and changing } \\
\text { context }\end{array}$ & $\begin{array}{l}\text { 4) Instrument } \\
\text { expertise }\end{array}$ & 4) Political expertise & $\begin{array}{l}\text { 4) Situational } \\
\text { context expertise }\end{array}$ \\
\hline $\begin{array}{l}\text { Knowledge of experts } \\
\text { Knowledge of } \\
\text { communication }\end{array}$ & - & $\begin{array}{l}\text { 5) Expertise on } \\
\text { experts }\end{array}$ & $\begin{array}{l}\text { 5) Expert } \\
\text { identification }\end{array}$ \\
\hline
\end{tabular}

(Source: Author's own compilation)

Subject matter expertise - scientific expertise - is the most often considered type of expertise and relates to "the content of the issue at hand, more specifically to the scientific, technical and normative aspects of policy problems and their proposed solutions" (Blom, 2016, p. 19). In policy-making, this type of expertise can alter perceptions and understanding, forge common views of policy issues, as well as generate trust (Nasra, 2011).

Policy expertise refers to "the knowledge of the range of policies and instruments, current and past, proposed and enacted, governing a particular policy area as well as knowledge of how they work" (Page, 2010, p. 259).

Process or procedural expertise refers to "extensive knowledge about the legal parameters and requirements of possible policy solutions and about the formal procedures policy-making and implementation are subject to" (Blom, 2016, p. 19). In the broad sense, it can involve expertise on the process of information flow between the human and system (interface tool expertise) and expertise in the information flow path dimension, which is the technical knowledge of what communication paths to follow (Garret, Caldwell, Harris, \& Gonzalez, 2009).

Instrument expertise refers to knowledge of how to put a law together and what is permissible and challenging (Page, 2010). Similarly, political expertise is the ability to assess the political feasibility of possible courses of actions/policies (Blom, 2016). The similar view of Garret et al. (2009) is called situational context expertise which is the ability to understand how the context 
affects the current tasks being done and how the current and changing context affects goaloriented strategic performance.

Knowing who has what level of expertise by creating a network map of other individuals' expertise levels is called expert identification expertise (Garret et al., 2009) or expertise on experts (Blom, 2016). A unique type of expertise proposed by only Garret et al. is communication expertise which is the ability to transmit knowledge and information via media.

Among these different types of expertise, EU agencies are expected to utilise mostly scientific and subject matter expertise in the policy formulation stage. This is because providing this type of expertise is regarded as the main reason for the EU institutions to establish EU agencies in the first place (e.g., Haverland, 2009). According to the well-known proposition by Haas (1992), it is because of content expertise (technical knowledge) that experts (such as EU agencies) gain authority. Moreover, in order to exert influence, EU agencies need to provide expertise that is required by the Commission, which is the receiver of EU agencies' expertise. When developing policy proposals, the Commission "serves a largely apolitical and technocratic function and presumably requires a large amount of technical operational and expert information" (Chalmers, 2013, p. 41). While EU agencies also possess expertise on policy instruments and experts, the Commission is well equipped with procedural and political expertise. In a multi-layered and complicated decision-making system in the EU, and especially within Community policy areas, the Commission is the recognised and acknowledged authority that possesses knowledge of complex processes and the changing political environment on the basis of its particular involvement in the whole policy cycle, from agendasetting to policy evaluation (Chou \& Riddervold, 2015).

To specify the influence of EU agencies, it is essential to explicate that although influence of EU agencies is regarded as expertise-based influence, it is not based exclusively on their expertise alone. To be precise, the influence of EU agencies is based on expertise in combination with some other factors (see Chapter 3). Despite the fact that without highquality expertise no one would be able to make their voice heard by the Commission, it cannot be a sufficient condition for the influence of EU agencies in the policy-making process. This is because there are many other actors who are able to offer expertise to the Commission, but not everyone exerts influence on the Commission. There must be other factors that play a role, and the implication is that the ability to provide high-quality expertise should be combined with such factors in order to exert influence. Page (2010, p. 269), for example, claims based on an empirical study of 52 regulations that even when policy actors who have a high level of scientific or policy expertise, or both, are involved, "the resulting policy does not depend upon their expertise alone, and expertise does not guarantee influence, or even on its own make their greater influence more likely." Accordingly, if EU agencies exert influence in the policy formulation stage, it should be understood that their influence is based on expertise in combination with some other factors, and again, this research seeks to find out which conditions affect EU agencies' influence. 


\subsection{Conclusion}

This chapter has outlined how influence and power are understood from different perspectives and what their relations are to each other. The view of "power to," which concerns ability-based interpretations of power, fits better with the policy-making process than the "power over" view that considers relational aspects of power between two or more actors. Moreover, while power is given based on formal rules, influence is something gained, and while having and exercising power can happen separately by the intentional choice of power-holders, having influence means exercising influence. This also implies that exercising power requires awareness on the part of the power-holder about exercising it.

The following definitions of political power and political influence are applied in this research:

- Political power is the ability to determine the (policy) output within a set of available alternatives; and

- Political influence is the ability to shape the content of (policy) output by providing (partly or completely) the set of alternatives to decision-maker(s).

The core aim of this research is to analyse the extent to which, and the conditions under which, $\mathrm{EU}$ agencies exert influence in the policy formulation stage in the EU. In this process, the European Commission is the decisive institutional actor who has the political power to determine the content of policy proposals, and EU agencies are the actors who may exert influence on the Commission's proposals. This potential influence is further narrowed down albeit not exclusively - as expertise-based influence. It is because scientific, or subject matter, expertise is particularly perceived as the key tool EU agencies have at their disposal in order to exert influence in the policy formulation stage. The following chapter will provide an analytical framework in order to operationalise the influence of EU agencies and possible conditions for such influence. 

Chapter 3

Research Design and Methodology 


\subsection{Introduction}

The previous chapter suggested how to conceptualise influence of EU agencies. It served as the first step to answer the main research question: To what extent and under which conditions do EU agencies use their expertise to influence policy-making in the European Union? As a next step, this chapter outlines the research design as well as methodology that can guide the empirical analyses of this research. Before introducing the research design, it is worth recalling the importance of possessing specialised knowledge and scientific expertise that other actors do not have in order to exert influence in the policy-making process. In European governance, policy decisions are assumed to be based on technical knowledge, empirical evidence, and sound reasoning (Majone, 1994, 1996), and information has long been described as the most important currency (Bouwen, 2002). Especially in regulatory policymaking, which is associated with significant scientific and political uncertainties, knowledge as well as adequate methods and well-functioning systems of collecting, generating, selecting, processing, and distributing knowledge on various issues are required (Biermann et al., 2009).

As mentioned earlier, EU agencies have been created with the mandate to collect and analyse technical and scientific data, and provide expert advice as policy input to the EU institutions, so that policy-makers can make informed decisions. Moreover, in the course of performing their everyday activities, EU agencies continuously accumulate more knowledge and expertise. Therefore, the research design starts from the fact that EU agencies do possess specialised expertise which is a precondition to perform their duties (see Subsection 2.4.2; see also Gehring \& Krapohl, 2007; Majone, 1996, 1997; Ossege, 2016; Vibert, 2007). In other words, the presence or absence of a high level of expertise is not considered as one of the conditions affecting EU agencies' influence; rather, it remains at the centre of the research as the point of departure. In an effort to develop a framework for analysis, therefore, attention is given to identifying other conditions for EU agencies' influence, as well as the causal effects of such conditions.

The first aim of this chapter is to develop a framework for analysis that enables a systematic investigation into the process as well as the effect of influence. This framework will help examine how EU agencies "enhance" their scientific knowledge and expertise (in order to become more competitive with other actors, such as interest groups, who also provide expertise as policy input) and to "transmit" their scientific knowledge and expertise to the policy-makers (in order to constantly appeal to those with political power) (see Section 3.2). Moreover, it will also suggest what to look for as signs of influence. With regard to methodology, the second aim is to select and justify the EU agencies and specific policy issues (dossiers) that will be analysed for this research. This chapter will also explain how and what kind of data are collected and how they are analysed.

The subsequent five sections are devoted to the framework for analysis. In Section 3.2, the general structure of the framework is outlined. As Figure 3.1 shows, there are three dimensions and three conditions for influence of EU agencies. 
Figure 3.1) Three dimensions and three conditions for the analysis

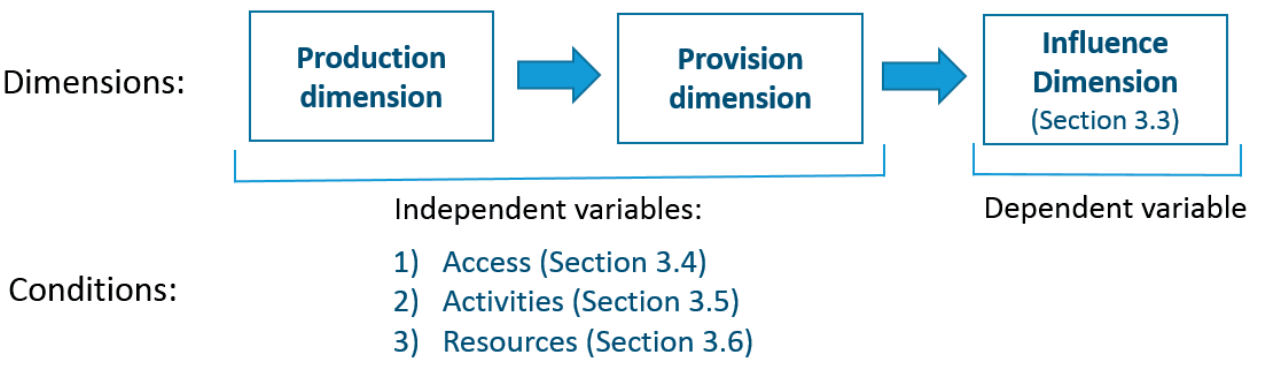

(Source: Author's own compilation)

In Section 3.3, the detailed explanation of the operationalisation of the dependent variable influence of EU agencies - is offered. This constitutes one of the three dimensions. The actual level of influence is measured with two indicators, which are text comparison and reputation. The three conditions, which are analysed as independent variables, are access, activities, and resources. These conditions are addressed in Sections 3.4, 3.5, and 3.6 respectively. The operationalisation of the independent variables is illustrated in two separate dimensions. The first dimension concerns how EU agencies produce expert advice within the agencies, which is called the "production" dimension. The second dimension analyses how EU agencies provide expert advice (which is produced in the production dimension) to the European Commission. This refers to the "provision" dimension. Section 3.7 on methodology explains the case-study approach, data collection, and data analysis. Lastly, this chapter concludes with a short summary of the operationalisation of influence and the three conditions for influence of EU agencies as well as methodology of this research.

\subsection{Three dimensions and three conditions}

Many empirical studies fall short of making their research strategies transparent and intersubjectively comprehensible for identifying and assessing influence of political entities, such as national or international bureaucracies, interest groups, and so on (Weinlich, 2014). Nevertheless, when reviewing the existing literature on influence of policy actors, some common determinants emerge and these help build the foundation of the framework for analysis. Although there is not much empirical research specifically on the influence of EU agencies, it is certainly beneficial to review similar studies on other organisations with similar functions or institutional settings to understand how influence is exerted in the legislative process of the EU (Panke et al., 2015). As explained in Chapter 1, the most studied political entity for influence is interest groups, and EU agencies and interest groups share some similarities. Particularly in the policy formulation stage, the role played by these two boides is 
similar even though their institutional settings are different. They provide specialised knowledge and expertise as policy input to the European Commission. Scholars analysing interest groups' influence have conducted a wide range of studies with different angles and approaches to provide explanations about, for example, influence conditions, attempts, strategies, and their impact on the development of policies. These are very relevant empirical insights that are closely linked to the main question of this research. Naturally, the research design presented in this chapter is developed based on the empirial insights gained from diverse studies on influence of interest groups.

Amongst others, Betsill and Corell (2001) and Chalmers (2011) are noteworthy. In their study on the influence of NGOs in the context of international environmental negotiations, Betsill and Corell (2001) suggest a framework with two dimensions: the first is "intentional transmission" of information by NGOs, and the second is "alterations in behaviour" of decision-makers in response to that information. ${ }^{19}$ The main advantage of this framework is that it clearly links actors' use/non-use of information to the effect/non-effect of that information in international policy negotiations. Many scholars have applied this framework to analyse interest groups' influence in the decision-making process (see, for example, Rasmussen, 2012). Similar to Betsill and Corell, Chalmers (2011) proposes two dimensions of information processing: "information gathering" and "information transmission." The former refers to how policy actors seeking influence anticipate and prepare to meet the informational needs of EU decision-makers, and the latter is related to the type of information sent to decision-makers as well as the tactics used to do so and the targets at which this information is aimed (Chalmers, 2011). Chalmers (2011) argues that these two dimensions focusing on information are essential in order to analyse influence of interest groups and are particularly useful for a systematic comparison of different types of interest groups in the EU.

This research modifies these two frameworks and proposes a three-dimensional approach: (1) the production dimension concerns how EU agencies produce expert advice within the agencies; (2) the provision dimension investigates how EU agencies provide expert advice (which is produced in the production dimension) to the European Commission in order to assist the Commission in drafting policy proposals; and (3) the dimension of influence examines the level of influence of EU agencies on the content of policy proposals. This threedimensional approach allows a more systematic and complete analysis of the very process between production and provision of expert advice by EU agencies as well as the extent to which the conditions in these dimensions affect the output of policy proposals.

The advantage of the three dimensions in this study can be expressed in three ways. Firstly, compared to Betsill and Corell's framework which begins the analysis from the transmission

\footnotetext{
${ }^{19}$ In their edited book published in 2008, these scholars slightly modified the dimensions and indicators applied in their analytical framework in order to apply the concept of influence, which was defined more broadly compared to their definition from 2001. Their first dimension was changed from "intentional transmission" to "intentional communication" as the latter includes not only technical information but also claims of legitimacy or threats (Corell \& Betsill, 2008).
} 
of information, this research examines both the production and the provision aspects of expert advice. While EU agencies are equipped with their specific expertise, the first step of the analysis should begin within the agencies and analyse what they do and have in order to guarantee the highest level of expertise. This production of expert advice within EU agencies, which constitutes the first dimension in this research, is omitted in the framework by Betsill and Corell. Secondly, instead of treating expertise as one type of resource, expertise is kept at the centre of this research and analysed in combination with other conditions in the production and provision dimensions. This allows for more attention to be given to the conditions other than expertise, and how these conditions work in the process of influencing the Commission.

Unlike Chalmers, lastly, this research takes the actual effect of influence attempts into consideration by analysing the dimension of influence. Chalmers (2011) defines influence as the ability to change the mind of decision-makers, and posits that interest groups try to influence like-minded decision-makers rather than those who have opposite views. Thus, he argues that "we cannot expect to see the evidence of influence in changed minds and policy outcomes" as there is no different mind to change (Chalmers, 2011, p. 472). However, he fails to consider the possibility that policy-makers might not yet have formed certain positions. This can happen when policy issues under consideration are exceedingly technical. Therefore, in this research, exerting influence is not necessarily to change but to shape the mind of decisionmakers and, in turn, the content of policy proposals (see Subsection 2.4.1).

As for the conditions for influence, Betsill and Corell (2001, p. 69, emphasis added) explain:

In most studies [on NGOs], scholars rely on evidence regarding NGO activities (such as lobbying, submitting information or draft decisions to negotiators on a particular position), their access to negotiations (such as the number of NGOs attending negotiations and the rules of participation) and/or NGO resources (such as knowledge, financial and other assets, number of supporters and their particular role in negotiations).

They argue that access, activities, and resources can be useful in identifying instances of NGOs' influence in global politics (Betsill \& Corell, 2001). This research adopts these three conditions, but indicators of each condition are modified to the context of policy-making in the EU. This is simply because EU agencies have different status, mandates, and roles than NGOs. What opportunities did EU agencies have to produce and provide expert advice? What did EU agencies do to produce and provide expert advice? What sources of leverage did EU agencies use to produce and provide expert advice? These are precisely the questions that frame the present conditions - access, activities, and resources respectively - for EU agencies' influence. Table 3.1 presents the framework for analysis used in this research, including the three dimensions, the conditions, and indicators for each condition. The dimension of influence (Dimension 3) measures the dependent variable, which is the level of EU agencies' influence. This is explained first (see Section 3.3), and then each condition is described in the following sections. 
Table 3.1) Framework for analysing EU agencies' influence in the policy formulation stage

\begin{tabular}{|c|c|c|}
\hline \multicolumn{2}{|c|}{ Conditions } & Indicators \\
\hline \multicolumn{3}{|c|}{ Dimension 1) Production of expert advice within EU agencies } \\
\hline$\stackrel{1.1)}{>}$ & $\begin{array}{l}\text { Access (input): } \\
\text { Networks established within an } \\
\text { agency and with other } \\
\text { organisations }\end{array}$ & $\begin{array}{l}\text { - Number of internal and external networks } \\
\text { established by an agency }\end{array}$ \\
\hline$\stackrel{1.2)}{>}$ & $\begin{array}{l}\text { Activities: } \\
\text { Contacts with experts }\end{array}$ & $\begin{array}{l}\text { - Frequency of phone calls, emails, and meetings } \\
\text { with internal and external experts } \\
\text { - Organising and/or attending conferences, } \\
\text { workshops, and trainings }\end{array}$ \\
\hline$\stackrel{1.3)}{>}$ & $\begin{array}{l}\text { Resources: } \\
\text { Staff and experts in an agency } \\
\text { Budget of an agency }\end{array}$ & $\begin{array}{l}\text { Number and background of staff and experts in an } \\
\text { agency who deal with the policy proposal } \\
\text { - Amount of annual budget }\end{array}$ \\
\hline
\end{tabular}

Dimension 2) Provision of expert advice by EU agencies to policy-makers

2.1) Access (output):

$>$ By request of the European Commission

By own initiative of an agency

$>$ As part of the policy-making procedure

- Number of requests by the European Commission for expert advice from an agency

- Number of agency's own initiatives to provide expert advice to the European Commission

- Presence of the formal procedure that the European Commission must consult an agency

2.2) Activities:

Contacts with the European Commission

- Frequency of phone calls, emails, and meetings between an agency and the European Commission

2.3) Resources:

Scientific output

- Number of publications by an agency, such as scientific opinions, reports, recommendations, academic articles, etc.

Dimension 3) Influence of EU agencies (dependent variable)

\begin{tabular}{l|l}
\hline 3.1) Goal or preference attainment & $\begin{array}{l}- \\
\text { Text comparison: extent to which the content of } \\
\text { policy proposal includes text in line with expert } \\
\text { advice from an agency }\end{array}$ \\
3.2) Reputation as scientific authority & $\begin{array}{l}\text { EAR instrument (Arts \& Verschuren, 1999; Dür, } \\
2008 a)\end{array}$
\end{tabular}

(Source: Author's own compilation based on the modification of mainly Betsill and Corell (2001) and to some extent Arts and Verschuren (1999) and Dür (2008a)) 


\subsection{Measuring influence of EU agencies}

How exactly can influence of EU agencies be identified and measured? This is an incredibly challenging task. Scholars studying the influence of political institutions, actors, or organisations have acknowledged the problems and difficulties associated with methodological choices in determining the indicators with which actual influence can be assessed. Moreover, measuring influence objectively is quite hard, particularly in complex decision-making (Arts \& Verschuren, 1999). Weinlich (2014) even argues that most studies identified some sort of influence but failed to establish the criteria as to what actually constitutes influence and how to find and measure it. While acknowledging what Weinlich points out, this section outlines what can be considered as the appropriate indicators of influence in order to operationalise influence of EU agencies.

To find out what constitutes influence, the definition of influence should be recalled. In Section 2.4.1, influence of EU agencies is defined as the ability to shape the content of (policy) output by providing (partly or completely) the set of alternatives to decision-maker(s). This definition explicitly points at the content of policy proposals from the Commission; and if partial or full text of expert advice from EU agencies can be traced in the content of policy proposals, it indicates influence of EU agencies. This illustration refers to "goal attainment" or "preference attainment." Many scholars have indeed asserted that evidence on goal or preference attainment is one of the most direct indicators of influence (Betsill \& Corell, 2001; Bunea, 2013; Dür, 2008a; Hönnig \& Panke, 2012; Mahoney, 2007; Panke et al., 2015). The basic idea of goal or preference attainment is that the distance between a policy outcome and the ideal point of an actor reflects the influence of this actor (Dür, 2008a; Dür et al., 2015). Tracing the text of expert advice in policy proposals is done via text comparison between these two sets of documents. The advantages and drawbacks of goal or preference attainment as well as details on text comparison are elucidated in Subsection 3.3.1 below.

Another important indicator of influence is scientific authority based on EU agencies' reputation as the EU's centre of expertise that can generate acceptable solutions to highly scientific and technical issues. Reputation is the "perceived importance of actors when evaluated by their peers and other stakeholders involved in the policy process" (Ingold \& Leifeld, 2014, p. 3). Policy actors would evaluate and acknowledge the importance of EU agencies based on the quality of expert advice that EU agencies provide. In other words, the enhancement and maintenance of reputation depend on EU agencies' performance in providing high-qality expert advice (Carpenter, 2010). This implies that if EU agenices are successful in influencing the content of policy proposals due to their good performance, it is going to be reflected in their reputation (Carpenter, 2010; Groenleer, 2014).

This is called "attributed influence" or "reputation" indicator (Arts \& Verschuren, 1999; Dür, 2008a) and is usually assessed by way of surveys, which ask the actors seeking influence to provide a self-assessment of their influence and/or a peer assessment of the influence of other actors (Dür, 2008a). Arts and Verschuren (1999, p. 416, emphasis added) claim that "the 
perceptions that participants in the decision-making process have of the political influence of the different players may yield additional information and may improve the validity of the measurement." This implies that reputation as a scientific authority should be treated as a supplementary indicator rather than a main indicator of influence. This issue as well as the advantages and drawbacks of the reputation indicator are elaborated further in Subsection 3.3.2.

\subsubsection{Text comparison}

EU agencies cannot force the Commission to follow their advice because their opinions, recommendations, and advice are not binding. Out of many other pieces of information offered by various policy actors, however, if the Commission voluntarily chooses to consider expert advice from EU agencies and consequently formulates policy proposals based on it, this indicates that the Commission is persuaded by expert advice and presumably has a sincere belief that its author is right (see Pryor, 2017). The influence of EU agencies is evident if policy proposals from the Commission incorporate expert advice from those agencies. Of course, it is also possible that policy proposals from the Commission do not reflect the advice and positions of the agencies. In this case, it can be assessed that there is no influence of EU agencies. As mentioned, goal or preference attainment is measured by comparing text between expert advice and policy proposals. The text comparison looks for overlapping text between the two sets of documents. If the same sentences or paragraphs appear in both sets of documents, and/or if direct quotations from or references to agencies' documents are found in the policy proposals, this is considered as evidence of EU agencies' influence.

Depending on how precisely expert advice is incorporated into policy proposals, the influence of EU agencies is categorised into high, moderate, or low influence. In instances of low influence, EU agencies have transmitted their expert advice to the Commission, but the Commission does not incorporate expert advice at all or makes a minor use of it to a very limited extent. In this case, no matching text or references to the agencies' documents can be traced in policy proposals. Thus, low influence involves from zero - meaning no influence - to an insignificant level of influence. Both moderate and high influence of EU agencies mean that policy proposals include part or full text that states the ideas expressed in expert advice. The critical distinction between moderate and high levels of influence is drawn on whether or not exactly matching sentences, paragraphs, or quotations are found between policy proposals and expert advice. If certain text from expert advice is directly copied into policy proposals, without paraphrasing, it means high influence of EU agencies. If some parts of expert advice are incorporated into policy proposals but are written differently by adding or deleting certain information or by paraphrasing, it means moderate influence of EU agencies.

This approach is promising since it provides a highly objective measurement that can detect influence even if influence attempts are not visible. Moreover, it can be applied to a large number of cases (Dür, 2008a). However, the main drawback is that even with the overlapping 
text found in policy proposals, it doesn't guarantee that agencies were the ones who pushed for the text. This might lead to the problem of equifinality. It could be the case that other actors with similar advice and text and/or other explanatory factors could have influenced the Commission (Weinlich, 2014). Then, attaining agencies' goal or preference is due to sheer luck rather than actual influence (Dür et al., 2015; Klüver, 2009, 2013). Nevertheless, Dür et al. (2015) argue that although individual policy actors might occasionally be lucky, luck is not all that matters because there is a statistically significant association between lobbying success and actors' characteristics and influence attempts. Therefore, the appropriate methodological choices are important in order to establish the correct causal link between agencies' advice and the content of policy proposals. On this issue, Panke et al. (2015) suggest that researchers check whether the Commission indeed looked at the advice from the agencies and had meetings and discussions with the agencies during the process of policy drafting. This ensures that the influence is not just a coincidence. In this research, this suggestion is taken by analysing the presence (or absence) of activities between EU agencies and the Commission, particularly in the process of providing expert advice by the agencies to the Commission (see Section 3.5).

Counterfactual argumentation is useful for excluding alternative explanations for observed effects of influence. For example, questions regarding the counterfactual situation are asked to the Commission as well as other actors that interact with the agencies: How would the policy proposal and the behaviour of the Commission have evolved if the agencies in question had not been involved with their expert advice in the policy-making process?

Another important issue to discuss is the difficulty of controlling for the salience of an issue. Dür (2008a, p. 569) explains:

If [an agency] is successful on $20 \%$ of the issues and unsuccessful on $80 \%$, a simple quantitative analysis would suggest that [the agency] has little influence. It may be, however, that [the agency] is successful on all of the issues that are highly salient to it (e.g. because it invests more resources on those issues) and unsuccessful on those that are not salient to it. In that case, even if [the agency] is successful on only $20 \%$ of the issues, it should be considered quite influential.

This research does take the salience of an issue into account but approaches it from a different perspective. Instead of dividing salient and not salient parts in one policy proposal, the salience of an issue is considered per policy proposal. In other words, an agency may perceive certain policy proposals as more salient to it. Some plausible explanations can be that topics discussed in the proposals are exactly in the areas of agency's expertise, or the agency's mandate and primary missions directly match the topics. The agency would find such proposals more relevant and salient. As a consequence, it is expected that the agency would exert high influence on these proposals since it has expertise and may invest more resources in them, as Dür explains. In this research, proposals that are close to the mandate, mission, and expertise of an agency are considered as the most-likely cases (see Subsection 3.7.1). 


\subsubsection{Reputation as scientific authority}

According to Luitwieler (2009, p. 96), "[a]n actor has a reputation for influence when other actors consider it to be influential, important or a force to be reckoned with." Reputation is developed based on purely discretionary belief that is driven by a personal regard or respect. It implies that the best way to determine reputation of EU agencies is to ask them as well as other policy actors involved in policy-making to evaluate the influence of EU agencies on particular policy proposals. On top of the self and peer evaluations, Arts and Verschuren (1999) take a step further and add researcher's analysis to this measurement to check the validity of these actors' perceptions of EU agencies. They name this approach the "EAR instrument." This instrument applies triangulation of (1) political players' own perception of their influence "ego-perception $(E)$ "; other players' perceptions of the influence brought to bear - "alterperception $(A)$ "; and a process analysis by the researcher - "researcher's analysis (R)" (Arts \& Verschuren, 1999).

This research will pay more attention to ego- and alter-perceptions as EU agencies themselves and the policy actors involved in the policy-making process have the most information; yet, the researcher's analysis will be provided whenever necessary. Since this indicator evaluates the influence of EU agencies on certain policy proposals, surveys assessing the work and overall image of EU agencies which were conducted after such policy proposals were introduced are analysed, instead of those taken before those proposals were introduced. The reputation of EU agencies as scientific authorities is categorised into bad, good, and very good. Based on whether or not EU agencies are regarded as scientific authorities, a distinction is drawn between bad and good reputation. In instances of very good reputation, EU agencies are regarded not only as scientific authorities (evidence of good reputation) but also as indispensable actors. If EU agencies are seen as indispensable actors, their peers and other policy actors consider expertise of EU agencies as the most important and useful information in policy-making, and this signals very good reputation.

This reputational approach provides a number of methodological advantages. Hall (1992, p. 207) explains:

It permits the researcher to gather data on influence when the relevant political behavior or substantive political effect of an actor is unrecorded or unobservable. Likewise, this approach allows the researcher to ask the same questions of multiple respondents and thus make systematic checks of the measure's reliability.

At the same time, this approach is criticised for the possible discrepancy between the level of influence based on individuals' perceptions and the actual level of influence. "Self-estimations can be biased both towards an exaggeration of influence and a playing down of influence" (Dür, 2008a, p. 565). Minimising or inflating the role played by EU agencies may also occur in peer assessments by the Commission officials or other policy actors. Moreover, some actors who were asked to evaluate the influence of EU agencies may find it difficult to answer due to a lack of information and analytic capacity (Dür, 2008a). Therefore, Arts and Verschuren 
(1999, p. 422) call for cautiousness when determining the level of influence based on reputation because "the EAR method sticks to the level of an informed guess and may, in some cases, remain more of a guess than an informed conclusion." In order to tackle this shortcoming, Dür (2008a) argues that methodological triangulation is essential, and may be achieved by combining different methods in one study. In fact, this research does not rely on reputation as the only way to measure the level of influence of EU agencies. As outlined earlier, reputation is added as a second indicator to provide additional information on influence and to verify to a certain extent the level of influence measured by the text comparison, which serves as the main indicator of influence.

One might question whether reputation - a good or very good reputation to be more precise - could (or should) be treated as one type of resources that EU agencies can use in order to influence the Commission. In other words, one might argue that reputation should be one indicator of an independent variable rather than a dependent variable. It is a valid point based on the understanding that "perception influences action" as well as on the assumption that "actors who have a reputation for being influential can considerably influence collective decision making" (Ingold \& Leifeld, 2014, p. 3). Similarly, Parsons (1963, p. 50) argues that reputation is a very important category of the justification of influence as "[t]he same statement will carry more "weight" if made by someone with a high reputation for competence, for reliability, for good judgment, etc., than by someone without this reputation or with a reputation for unreliability." Indeed, analysing the reputational aspect as one condition for influence is widely used. For example, when investigating the Nordic influence on the European security and defence policy, Jakobsen (2009) points out that a reputation as a leader or expert is one of the most powerful explanatory factors of influence. Additionally, Beach (2004) claims that the Council Secretariat may be very influential if a combination of expertise, its institutional position, pragmatic and leadership skills, and a good reputation as a trusted assistant is utilised.

However, there are two reasons why reputation is used as an indicator to verify influence of EU agencies (dependent variable) rather than as an indicator that affects their influence (independent variable) in this research. The first reason is related to the age of the two EU agencies selected for the empirical analyses (see Subsection 3.7.1). The European Centre for Disease Prevention and Control and the European Chemicals Agency were carefully selected for this research. Two out of four policy dossiers that will be analysed in the empirical chapters 4 and 5 were introduced in 2009 by the Commission, and these two agencies were relatively young agencies at that point. Considering the fact that a good reputation takes time to develop, the reputation of the young agencies would not have much impact on their influence. Fraussen and Beyers (2015, p. 5) argue that policy-makers "might be tempted to ascribe more legitimacy to older organizations, compared with groups that have only been in existence for a few years." Older agencies, such as the European Medicines Agency, have been in operation for more than 10 years, which could be considered as a reasonably long period to accumulate their reputation within a broad network of policy actors in their field. If these older agencies 
have a high reputation, it can meaningfully carry more weight and affect their influence when providing expert advice to the Commission.

Furthermore, the second reason is related to the general image of EU agencies as a whole. If reputation is used as an independent variable, the "general" reputation that EU agencies had prior to the introduction of certain policy proposals would be analysed instead of their reputation on such proposals after the introduction of these proposals. However, since virtually every EU agency fulfils an information function by pooling expertise to draw up reports, opinions, studies, and so on (Chamon, 2016), they are generally seen as "epistemic networks" (see Trondal \& Jappesen, 2008). Thus, it is difficult to find "unreliable" EU agencies likely to have a bad reputation that will bring about negative consequences to their influence.

In summary, this section introduced the dimension of influence which forms the dependent variable of this research. The level of influence of EU agencies is assessed based on the two indicators, text comparison and reputation. The following three sections will discuss the three conditions for influence: access, activities, and resources.

\subsection{Influence condition 1: Access}

The first condition, access, stems from the notion that groups seeking influence cannot gain influence without access to one or more key points of decision (see Truman, 1951). The analysis of access considers what kind of opportunities EU agencies have to interact with experts in a scientific arena (in order to produce expert advice in the production dimension) and with policy-makers (in order to provide expert advice as input in the provision dimension). Especially in the provision dimension, formal representation or the right of participation is not always granted to EU agencies in the policy formulation stage. This implies that for access to be present, EU agencies need to seek it out and not just aspire to it (Eising, 2007), and relevant gatekeepers (civil servants in the Commission or politicians) need to allow it (Binderkrantz \& Pedersen, 2016).

It is emphasised that access does not necessarily mean and is conceptually different from influence since "access only entails being present and does not specify any requirements of groups being listened to or able to change the attitudes of the decision makers they gain access to" (Binderkrantz \& Pedersen, 2016, p. 307; see also Bouwen, 2002). Access of EU agencies can be found in the formal rules and arrangements under which they carry out their tasks as well as informal practices that have become part of their working culture. The subsequent two subsections discuss access of EU agencies in the production and provision dimensions. 


\subsubsection{Access in the production dimension}

In the production dimension within EU agencies, access refers to the tasks of EU agencies that are directly related to creating or maintaining networks in order to enhance and guarantee the highest level of expert knowledge. When an agency cooperates with other EU agencies, international organisations, civil societies, national competent authorities, or individual experts who possess technical information and expertise, the agency is able to have access to a larger pool of information. This fosters faster information sharing and knowledge and expertise accumulation (Luitwieler, 2009; Maggetti, 2014).

The Founding Regulations of EU agencies can be a good reference point to identify the formal tasks of networking, and experts from EU agencies themselves can be a good source to reveal informal networks that are not formally stated in the Founding Regulations. For example, in the founding regulation establishing a European Centre for Disease Prevention and Control (ECDC), ECDC is mandated to "establish clear procedures for cooperation with the World Health Organization (WHO)" in order to conduct surveillance of communicable diseases. ${ }^{20}$ Thus, ECDC's cooperation with WHO is treated as one access point in the official networks. This kind of networking access point is extended to the sections, units, and committees within one agency because highly qualified experts in their specific field of expertise are appointed or hired by EU agencies. ${ }^{21}$ Experts within an agency can also create their own epistemic community, which will contribute positively to the production of expert advice within the agency. Thus, it is expected that:

(Expectation 1.1) The more access points an EU agency has under the formal rules and informal practices to produce expert advice, the more influence it is likely to exert in the policy-making process.

\subsubsection{Access in the provision dimension}

In terms of access for the provision of expert advice to the Commission, most EU agencies have three formal ways to access the EU institutions in the European policy-making process: first, when the EU institutions consider it appropriate or necessary, they may request agencies to submit their expert advice; second, as part of the policy-making procedure, some agencies are formally required to provide their opinions before the Commission formulates the policy drafts - in other words, the Commission must consult these agencies before it officially issues a policy proposal; and third, EU agencies may submit their own initiative opinions in the situation that they find it necessary to bring attention to a certain topic.

\footnotetext{
${ }^{20}$ See recital 4 in the preamble of the Founding Regulation of ECDC: REGULATION (EC) No 851/2004 of the European Parliament and of the Council of 21 April 2004 establishing a European centre for disease prevention and control, OJ L 142/1, 30 April 2004.

${ }^{21}$ See "Scientific Committees" (Analytical Fiche No. 9) of the "Detailed Analytical Papers" from the European Commission.
} 
In their study of influence of the Economic and Social Committee and the Committee of the Regions in European policy-making, Hönnige and Panke (2012) tested contending hypotheses regarding these three access points: on the one hand, they expect to see high influence when these consultative committees provide advice by request, because the fact that the request is made in the first place means the EU institutions are more interested in listening to the committees' opinions; but on the other hand, they expect that these committees are significantly more influential in case of their own initiatives because they initiate recommendations if their members have high stakes in a specific legislative proposal and thus, their initiatives will be timely and sound. The empirical results, however, reject both hypotheses, finding that the origins of committees' opinions (by request or as the committee's own initiative) are not in fact significant (Hönnige \& Panke, 2012).

Considering the fact that EU agencies and the two consultative committees, EESC and CoR, have similar functions and roles as advisors to the EU institutions, it is reasonable to assume that the type of access to the Commission does not matter. Whether expert advice is provided by request, by the agency's own initiative, or as part of the official procedure would not affect the influence of EU agencies. Instead of how these access points are initiated, how actively these access points are utilised by EU agencies may be a better indicator for influence. The logic here is that if they are very active in providing expert advice to policy-makers, it is more likely that their activities produce effects compared to groups without access (Weinlich, 2004; Binderkrantz \& Pedersen, 2016). In the same vein, Eising (2007, p. 331) explains that if organisations that seek policy influence want to secure a final policy outcome, they should "inform the institutions about their policy preferences and about the merits and drawbacks of alternative courses of action." Access in this dimension thus looks at how many requests for expert advice an EU agency receives from the EU institutions, how many own initiative opinions an agency sends to the EU institutions, and whether agency involvement is required in the policy-drafting procedure. This leads to the expectation that:

(Expectation 1.2) The more access points an EU agency utilises via requests, own initiatives, and as part of the official procedure to provide expert advice, the more influence it is likely to exert in the policy-making process.

\subsection{Influence condition 2: Activities}

The second condition, activities, mainly considers the frequency of contacts with actors in the networks identified above. Networks are one resource for influence for an actor, and according to Luitwieler (2009, p. 96), "being part of a network is defined as an informal position that takes the form of having contact with one (bilaterally) or more (multilaterally) other actors concerning an issue on which these actors have common preferences." An agency's frequent contact with experts in the production dimension and with policy-makers in the provision dimension does not imply that its activities have a direct effect on EU policies 
(Eising, 2007). But, maintaining close contact with internal and external partners is conducive to EU agencies' influence because it makes it possible to build support for agencies' work, to guarantee the most up-to-date expertise in the field that effectively meets industry innovations and trends, to gain information about legislative agenda, and to keep policymakers aware of the scientific capacity and output of EU agencies (Arras \& Braun, 2018; Groenleer, 2009).

How EU agencies interact with internal and external partners can be identified in the Founding Regulation, literature on EU agencies, and also through interviews with actors involved in the policy-making process.

\subsubsection{Activities in the production dimension}

Networking activities with internal and external experts take place by means of emails, phone calls, and organising and attending meetings, workshops, trainings, and so on. These contacts also range from informal bilateral talks and meetings to formally institutionalised meetings on a regular basis among experts within an agency as well as between an agency and the EU institutions. Eising (2007, p. 332) argues that many policy actors "find these contacts necessary in their efforts to have a say in EU policies." For example, through frequent networking activities with the EU institutions, EU agencies are better informed about future agendas and plans on EU policies and specific proposals (Eising, 2007). This will give agencies more time to prepare expert advice in accordance with the need of policy-makers and enable them to submit their advice in a timely manner when the policy-makers seek information. This in turn will better enable EU agencies to exert influence since "there is a premium on early, efficient and reliable information in the EU" (Chalmers, 2011, p. 477; Klüver, 2013; Panke et al., 2015). Therefore, it is expected that:

(Expectation 2.1) The more frequent the networking activities an EU agency engages in to produce expert advice, the more influence it is likely to exert in the policy-making process.

\subsubsection{Activities in the provision dimension}

In the provision aspect of expert advice, the same logic is applied. The frequency of contacts between EU agencies and the Commission provides helpful clues when determining the level of EU agencies' influence because of the "simple idea that 'more is better'" (Chalmers, 2013, p. 47). ${ }^{22}$ If EU agencies interact more frequently with the Commission, the chances that their activities will produce effects, which is their advice being taken by the policy-makers, will increase (Weinlich, 2004). This is because EU agencies can make the policy-makers aware of what is available for them from the agencies. In the same vein, Eising (2007) argues that if

\footnotetext{
${ }^{22}$ See Chalmers (2013) for an overview of other scholars' arguments in this perspective.
} 
organisations that seek policy influence want to secure a final policy outcome, they should interact with institutions and inform them about their policy preferences and the merits and drawbacks of alternative courses of action.

In addition, these activities should be relevant to building a cooperative relationship between EU agencies and the Commission. Since EU agencies may influence the final output of policy proposals only by persuading officials in the Commission who are in charge of drafting the proposals, the "goodwill" of the policy-makers to listen to expert advice from EU agencies is considered to be crucial (Coen, 1997). Managing a good relationship with the Commission is important for EU agencies not only to exert influence on policy proposals but also to get additional contracts so that EU agencies can hire more temporary staff and thus better perform their tasks (Schout \& Pereyra, 2011).

Therefore, it is logical to assume that EU agencies need to ensure that the Commission is aware of what is available by way of policy input from them, and that it is willing to consider expert advice from them. Active networking activities would help build a cooperative relationship between both parties, which will result in more chances for EU agencies to exert influence. In short, networking activities by EU agencies will affect their influence positively in European policy-making, and it is expected that:

(Expectation 2.2) The more frequent the networking activities an EU agency engages in to provide expert advice, the more influence it is likely to exert in the policy-making process.

\subsection{Influence condition 3: Resources}

Many scholars have asserted the importance of resources as a necessary but not a sufficient condition for exerting influence in the policy-making process (e.g., Biermann et al., 2009; Copsey \& Pomorska, 2010; Groenleer, 2009; Klüver, 2012, 2013; Panke et al., 2015). Literature suggests that, depending on the policy areas or the context and procedure of policy-making, different things are considered as resources of an organisation, such as money, personnel, legitimacy, political support, knowledge, expertise, and information (Dür, 2008b). In the production dimension, resources refer to EU agencies' administrative capacity, and in the provision dimension, resources mean EU agencies' scientific output which can serve as input for policy-making. Accordingly, both dimensions are analysed, with different indicators.

Information on the resources of EU agencies in the production and provision dimensions can be collected mainly from their annual reports, evaluation reports on EU agencies, and interview data. 


\subsubsection{Resources in the production dimension}

The administrative capacity of an organisation is perhaps the most important factor in its effort to influence policy-making as it is essential for full and productive engagement with the Brussels technocracy (Copsey \& Pomorska, 2010). The most fundamental indicator is the individuals who carry the knowledge - thus the professional background and training of the workforce, as well as the technical devices to maintain expertise such as data bases, libraries, and research facilities (Biermann et al., 2009). Possessing highly skilled staff is very important for EU agencies since "staff are evidently key in producing high quality products and in building a strong external reputation" and in turn, directly connected to output legitimacy of EU agencies (Schout \& Pereyra, 2011, p. 426). Moreover, the number of staff indicates an agency's potential for specialisation and control for information - the larger the agency, the greater the potential for specialization and control for information (Meier, 1980; Groenleer, 2009).

Besides the number and background of administrative staff and experts, the amount of annual budget and the number of years that EU agencies have functioned in the EU are considered. "Financial resources are a major prerequisite for their activities [and a] larger income allows them to develop an elaborate division of labour" which would allow for more effective performance of their tasks (Eising, 2007, p. 339).

Pulling these strands together, "if several players with similar objectives undertake similar (or collective) attempt to influence a political player and they succeed, then one might discriminate among them on the basis of resources: the player who possesses or invests the most resources is assumed to be most influential" (Arts \& Verschuren, 1999, p. 415). In line with this argument, it is expected that:

(Expectation 3.1) The more administrative resources an agency possesses to produce expert advice, the more influence it is likely to exert in the policy-making process.

\subsubsection{Resources in the provision dimension}

To assess the scientific capacity of EU agencies, the quantity of scientific output is considered. The types of scientific output by EU agencies are diverse: scientific documents, technical reports, risk assessment, studies, opinions, recommendations, guidelines, academic articles, and so on. With the same logic of "more is better," a high volume of scientific output is important. It enables EU agencies to be recognised as an active player in the policy-making process and also to be highly visible to the policy-makers. Moreover, it shows how ready EU agencies are to disseminate their knowledge to other policy actors. Considering the visibility of scientific output by EU agencies as the indicator of resources, it is expected that:

(Expectation 3.2) The more scientific resources an agency possesses to provide expert advice, the more influence it is likely to exert in the policy-making process. 


\subsection{Methodology}

This section discusses the methodological choices made for answering the research question. It proceeds as follows: it starts by spelling out the research design, including discussions on the type of case study analysis conducted, the scope of the population, and criteria for case selection. Then the background information on the selected cases - two EU agencies and four policy dossiers in total - is provided. Further, the data collection process is described, including a discussion of primary and secondary sources as well as a detailed discussion of the interview method. Finally, the process of data analysis is explained.

\subsubsection{Case study approach}

The analysis of this research is carried out based on a case study approach to answer the research question. Before proceeding with the detailed explanation of the case study approach, some scope conditions of this research should be clarified. The territorial boundary is drawn within the EU, thus policy-making and the influence of EU agencies at the national or international level are not considered. While this delimits the main actors of interest at the EU level - EU agencies and the European Commission - relevant actors at the national and international levels are also investigated in order to analyse the first two conditions, which are access and activities in the production dimension of expert advice (see Sections 3.4 and 3.5). Moreover, in terms of the policy field, public health is chosen out of diverse policy areas in which EU agencies play a role, and the reason for this selection is explained below.

In terms of the level of analysis, this research applies both cross-case and within-case analyses, and each analysis involves a different type of case. Accordingly, there are two levels of case selection. The first level concerns the selection of EU agencies, which would lead to a crosscase comparison. The second level concerns the selection of specific policy dossiers per agency which are investigated thoroughly in order to identify the conditions for influence of EU agencies. This indicates a within-case study. For the purpose of effective comparison, purposive sampling is pursued to select two EU agencies in the policy field of public health as well as two policy dossiers per selected agency.

\section{Cross-case level}

In order to avoid selection bias, the following four criteria are applied to choose two EU agencies for empirical analyses. Firstly, EU agencies operating in the early stage of the policymaking process are considered because the interest of this research is on the influence of EU agencies when the Commission formulates policy proposals. Naturally, EU agencies that are involved mainly in the implementation stage after policy proposals are adopted are eliminated. This means that the whole population of EU agencies is narrowed down to those whose work is used by the Commission as input to policy development. This criterion also excludes EU 
agencies that adopt only legally binding decisions on third parties - e.g., the European Union Intellectual Property Office (EUIPO) (which was known as OHIM (Office for Harmonisation in the Internal Market) until March 2016), responsible for managing the EU trade mark - as well as agencies that perform operational activities and thus provide little or no direct input to the Commission's work - e.g., the European Union's Judicial Cooperation Unit.

Based on the list of EU agencies drawn up in the first step, policy areas in which these agencies perform their tasks are considered. The policy areas that involve at least two EU agencies with similar mandates but a different classification - either as a regulatory agency or an information agency - are selected. This distinction would provide insight into whether regulatory agencies access and interact with other actors differently from information agencies (and vice versa) as well as whether the variation in classification affects their influence.

Next, in order to reduce unnecessary variation in the empirical analyses, the list of EU agencies is further narrowed down by selecting the agencies that belong to the same parent Directorate-General (DG) in the Commission and to the same committee in the European Parliament. There is an important reason why this criterion is necessary. While EU agencies tend to relate increasingly to particular "parent DGs" (Groenleer, 2009; Martens, 2010; Egeberg \& Trondal, 2011), there is considerable variation between DGs in their administrative culture, policy views, and working methods, partly due to their sectoral competence (Cram, 1997; Hartlapp, Metz, \& Rauh, 2013; Klüver, Braun, \& Beyers, 2015; Mazey \& Richardson, 1993; Nugent, 2001). Likewise, Clark, Mitchell, and Cash (2006, p.16) argue:

Because actors concerned with an issue differ in their goals, interests, beliefs, strategies, resources, and the local, national, or international scale at which they work, they also tend to differ with respect to what information they will be interested in; what scientific discussions they can actively participate in and understand [...] and how open they will be to new information and persuasion.

Therefore, Coen and Katsaitis (2013) argue that depending on which DG is responsible for drafting a policy proposal, the mobilisation for support, choice of strategy, and prospect of lobbying success are different. This implies that an agency might exert a different level of influence depending on the DGs to which it transmits its expert advice, and thus it is necessary to choose EU agencies that belong to the same DG to increase the reliability of this research. ${ }^{23}$ Lastly, the size of the selected agencies should vary as this would reveal whether or not the agency size affects the level of influence (in relation to the condition "resources"). Based on

\footnotetext{
${ }^{23}$ This is a valid point and has been empirically proven. In the case of EMA, its parent DG changed from DG Enterprise and Industry (ENTR) to DG Health and Consumers (SANCO). This resulted in closer scientific involvement of DG SANCO in the process of formulating opinions in EMA due to the greater organisational duplication between DG SANCO and EMA (Ossege, 2016).
} 
these criteria, the European Centre for Disease Prevention and Control and the European Chemicals Agency are selected. The overview of ECDC and ECHA in relation to the criteria is presented in Table 3.2.

Table 3.2) A cross-case analysis: Selection of EU agencies

\begin{tabular}{|l|l|l|l|l|l|l|}
\hline \multirow{2}{*}{ Policy } & EU agency & Year of & Classifi- & $\begin{array}{l}\text { Parent DG } \\
\text { (Commissi } \\
\text { creation }\end{array}$ & $\begin{array}{l}\text { Responsible } \\
\text { Committee } \\
\text { (European } \\
\text { Parliament) }\end{array}$ & $\begin{array}{l}\text { Budget } \\
\text { in } 2016 \\
\text { (€ M) }\end{array}$ \\
\hline \multirow{2}{*}{$\begin{array}{l}\text { Public } \\
\text { health }\end{array}$} & $\begin{array}{l}\text { European Centre for } \\
\text { Disease Prevention } \\
\text { and Control (ECDC) }\end{array}$ & 2004 & Information & SANTE & ENVI & 114.4 \\
\cline { 2 - 7 } & $\begin{array}{c}\text { European Chemicals } \\
\text { Agency (ECHA) }\end{array}$ & 2006 & Regulatory & SANTE24 & ENVI & 58.2 \\
\hline
\end{tabular}

(Source: Author's own compilation)

It is worth mentioning that the combination of ECDC and ECHA in the public health policy area did not appear as the only option after applying the selection criteria. Other possible combinations of cases include, for example, ECDC and the European Medicines Agency (EMA) or the European Food Safety Authority (EFSA) in public health or the European Environment Agency (EEA) and ECHA in the environmental policy field. However, EMA and EFSA have been by far the most studied EU agencies, and research on EEA is also easily found in the literature on EU agencies as well as environmental policies. By contrast, research on ECDC in general and ECHA with regard to its mandate in the regulation of biocidal products (which is explained below) has been extremely limited. ${ }^{25}$ In order to strengthen originality of this research and to contribute new knowledge to the body of literature on EU agencies, ECDC and ECHA (in relation to the regulation of biocidal products) are selected.

\footnotetext{
${ }^{24}$ It should be noted that ECHA has close links with several DGs. DG Internal Market, Industry, Entrepreneurship and SMEs (GROW), previously DG ENTR, is its "official" parent DG. However, on the specific dossiers selected for empirical analyses in this research - regulation on biocidal products - DG SANTE is the parent DG.

${ }^{25}$ An exception to limited publication on ECDC may be the special issue on communicable diseases in the EU: Journal of Health Politics, Policy, and Law (2012), 37(6). Still, only two out of 16 articles published in this special issue discuss ECDC.
} 
Within-case level

At the within-case level, specific policy dossiers are selected to analyse and measure the influence of ECDC and ECHA. Two policy dossiers are analysed in each agency, and they consist of one most-likely case and one least-likely case for influence. "A most-likely case has a relatively high probability of confirming the proposition under scrutiny, while a least-likely case goes hand in hand with a comparatively low probability" (Rohlfing, 2012, p. 84). It means, on a policy proposal that is a most-likely case, an EU agency is expected to exert high influence or at least moderate influence. On a least-likely case of a policy proposal, an EU agency is expected to exert low influence or at most moderate influence. The most- and least-likely case design is useful for the purpose of testing theoretical arguments or expectations and can provide the strongest evidence concerning hypothesis testing in a single-case study (Levy, 2008).

What can be considered as most- or least-likely cases when researching influence of EU agencies? Policy proposals setting general objectives and directions that certain policy areas would need to follow can be least-likely cases. As Lindvall (2009) argues, the consequences of decisions involving policy goals and objectives are far-reaching and may cause wide and deep social effects and repercussions in other policy areas. For example, economic policy involving long-term goals may affect employment policy, social policy, and many other areas. Since experts have specialised expertise in a narrowly defined area, scientific experts from EU agencies cannot provide adequate advice on these broad consequences. Moreover, such proposals tend to include political considerations and thus, the complexity of the decision process is high (Van Schendelen, 2006). Then, it is less likely that EU agencies would exert influence on these cases.

Policy proposals which concern highly technical, complex, and scientific issues and problems can be most-likely cases for influence of EU agencies. This is because experts and their expertise, scientific assessments, and evaluations, rather than political discussions, are the most desirable and reliable information for the development of such proposals. In addition, policy-makers seek and utilise expert advice in order to tackle uncertainty and complexity, and experts from EU agencies can (or at least are expected to) offer relevant advice in such cases (Lindvall, 2009). In line with the salience of issues discussed in Subsection 3.3.1, EU agencies would also find technical and scientific proposals more closely related to what they were created to do. Thus, it is more likely that EU agencies would exert influence on such cases. 
Table 3.3) A within-case analysis: Selection of policy dossiers

\begin{tabular}{|l|l|l|}
\hline \multicolumn{1}{|c|}{ EU agency } & \multicolumn{1}{|c|}{ Most-likely case } & \multicolumn{1}{c|}{ Least-likely case } \\
\hline $\begin{array}{l}\text { European Centre for } \\
\text { Disease Prevention } \\
\text { and Control (ECDC) }\end{array}$ & $\begin{array}{l}\text { Commission Communication on } \\
\text { Pandemic (H1N1) 2009 }\end{array}$ & $\begin{array}{l}\text { Proposal for a Decision on serious } \\
\text { cross-border threats to health }\end{array}$ \\
\hline $\begin{array}{l}\text { European Chemicals } \\
\text { Agency (ECHA) }\end{array}$ & $\begin{array}{l}\text { Commission Implementing } \\
\text { Regulations (approving individual } \\
\text { active substance of biocidal } \\
\text { products) }\end{array}$ & $\begin{array}{l}\text { Proposal for a Regulation } \\
\text { concerning the placing on the } \\
\text { market and use of biocidal } \\
\text { products }\end{array}$ \\
\hline
\end{tabular}

(Source: Author's own compilation)

Table 3.3 reveals the selection of policy proposals. In the case of ECDC, the event that posed the greatest scientific challenges since its establishment was the H1N1 pandemic crisis in 2009. The level of complexity and uncertainty was exceedingly high especially in the beginning of the pandemic because the pandemic virus was novel and relevant information was extremely limited. Accordingly, ECDC's influence on the Commission Communication on the H1N1 pandemic is a most-likely case. After the pandemic crisis, the European Commission urged the need to establish improved mechanisms at the European level which could better protect EU citizens from cross-border health threats. Against this background, the Commission introduced a proposal in 2011 which contained objectives and plans of a broad range of activities to manage health threats. Therefore, the influence of ECDC on this proposal is a least-likely case. These two cases are analysed in Chapter 4.

With regard to ECHA, evaluating actual and potential risks of chemical substances used for producing biocidal products is an exceptionally technical task. During the risk assessment process, experts in ECHA need to identify which risk factors potentially cause harm, evaluate how severe the risk would be, and determine appropriate ways to eliminate or control the risk. This involves high complexity and undertainty regarding potential harm, and the judgement should be made based purely on science. Accordingly, risk assessment can not be performed by the Commission. On the basis of risk assessment and scientific opinions of ECHA, the Commission develops implementing measures on the approval or non-approval of individual active substances. ECHA's influence on Commission Implementing Regulations thus constitutes a most-likely case, whereas the policy proposal which established objectives and the general framework of approval procedures for managing biocidal products as a whole is a least-likely case. Chapter 5 provides the analyses on these two cases. 
The selection of cases at the within-case level also enhances originality of this research. Although explanations about the background and adoption of the legislative proposal on cross-border threats to health are often found in the literature on public health policies in the EU (e.g., De Ruijter, 2017), the H1N1 pandemic-related EU activities from a political science perspective have rarely been investigated. Likewise, the role and activities of ECHA in the regulation of biocidal products are relatively new and thus very much under-researched. Therefore, the thorough examination of primary sources from the Commission and the EU agencies will be of particular value.

\subsubsection{Introduction of the selected EU agencies}

$E C D C$

The European Centre for Disease Prevention and Control was established in 2005 in Stockholm, Sweden. ${ }^{26}$ Its Founding Regulation states that ECDC "should serve as a Community source of independent scientific advice, assistance and expertise from trained medical, scientific and epidemiological staff from its own resources or from those of recognised competent bodies acting on behalf of Member States' authorities responsible for human health." ${ }^{27}$ ECDC's main aims are to protect and to improve human health by prevention of human disease and to strengthen the EU's defences against infectious diseases and potential threats to health. Article 3 of the Founding Regulation states that its mission is "to identify, assess and communicate current and emerging threats to human health from communicable diseases."

In order to fulfil its mandate, ECDC engages in various activities dealing with different aspects of disease and health threats, including (a) searching for, collecting, collating, evaluating, and disseminating relevant scientific and technical data; (b) providing scientific opinions and scientific and technical assistance including training; (c) providing timely information to the Commission, the Member States, Community agencies, and international organisations active within the field of public health; (d) coordinating the European networking of bodies operating in the fields within the Centre's mission, including networks arising from public health activities supported by the Commission and operating the dedicated surveillance networks; and (e) exchanging information, expertise, and best practices, and facilitating the development and implementation of joint actions. ${ }^{28}$

\footnotetext{
${ }^{26}$ The location of the Agency moved from the campus of the Karolinska Institute in Stockholm to Solna in March 2018.

${ }^{27}$ See recital 5 in the preamble of the Founding Regulation of ECDC.

${ }^{28}$ See Article 3 of the Founding Regulation of ECDC.
} 


\section{ECHA}

EU chemicals policy has emphasised that the EU must "ensure a high level of protection of human health and the environment [...] both for the present generation and future generations while also ensuring the efficient functioning of the internal market and the competitiveness of the chemical industry" (European Commission, 2001, p. 5). In this sense, ECHA, which was set up in 2007 in Helsinki, Finland, is an important actor for managing the policy area in the EU. This is because the main task of ECHA is to:

provide the Member States and the institutions of the Community with the best possible scientific and technical advice on questions relating to chemicals which fall within its remit and which are referred to it in accordance with the provisions of this Regulation. ${ }^{29}$

The website of ECHA states its mission: ${ }^{30}$

ECHA is the driving force among regulatory authorities in implementing the EU's groundbreaking chemicals legislation for the benefit of human health and the environment as well as for innovation and competitiveness. ECHA helps companies to comply with the legislation, advances the safe use of chemicals, provides information on chemicals and addresses chemicals of concern.

As explained in Chapter 1, most EU agencies carry out advisory functions by gathering information and formulating opinions based on specific scientific expertise. On top of its advisory functions, ECHA is also known for its competence to produce scientific opinions with legally binding effects in several REACH ${ }^{31}$ procedures (Busuioc, 2013; Ossege, 2016). This makes ECHA one of only a handful of EU agencies with the ability to take decisions that have binding effects on third parties (see Vaughan, 2015).

\subsubsection{Data collection}

Bardach (2009, p. 69) explains that "in policy research, almost all likely sources of information, data, and ideas fall into two general types: documents and people". This research is not an exception and relies on documents and in-depth qualitative interviews for both data collection and data analysis. These two types of data, along with their advantages and pitfalls, are explained in this section.

\footnotetext{
${ }^{29}$ Article 77 of the REACH regulation: REGULATION (EC) No 1907/2006 OF THE EUROPEAN PARLIAMENT AND OF THE COUNCIL of 18 December 2006 concerning the Registration, Evaluation, Authorisation and Restriction of Chemicals (REACH), establishing a European Chemicals Agency, amending Directive 1999/45/EC and repealing Council Regulation (EEC) No 793/93 and Commission Regulation (EC) No 1488/94 as well as Council Directive 76/769/EEC and Commission Directives 91/155/EEC, 93/67/EEC, 93/105/EC and 2000/21/EC.

${ }^{30}$ See https://echa.europa.eu/about-us/who-we-are/mission.

${ }^{31} \mathrm{REACH}$ stands for Registration, Evaluation, Authorisation and Restriction of Chemicals. It is a regulation of the EU, which entered into force on 1 June 2007.
} 


\section{Primary and secondary sources}

Klüver (2009, p. 536) argues that "textual data are arguably the most widely available source of evidence on political processes." This research accordingly profits from using various primary and secondary documents. The primary sources used for this research are mostly policy (and political) documents from the Commission as well as other EU institutions, along with scientific documents from EU agencies. The advantage of using policy and/or political documents is that they have "a great potential to reveal information about the policy positions of their authors: texts can be analyzed as many times as one wishes and they provide information about policy positions at a specific point in time" (Klüver, 2009, p. 536). Thus, when analysing policy-making processes, texts provide a great deal of information. However, an evaluation and an interpretation of these documents has to be done carefully by considering "who is speaking to whom, for what purpose and under what circumstances" (George \& Bennett, 2005, p. 100, emphasis in original).

The types of policy documents used in this research are, for example, legislative proposals, impact assessments, annual activity reports, work programmes, and evaluation or progress reports from the Commission. Position papers, reports, and opinions from the European Parliament also provide supplementary information on certain policy issues. From the EU agencies, scientific documents, opinions, guidelines, recommendations, technical reports, and risk assessments are analysed. Moreover, minutes of meetings, annual reports, and legal documents pertaining to the selected agencies, such as their founding regulations, also provided an insight into the formal tasks and activities of the agencies. Most of these documents are publicly available on the website of each organisation. However, some expert advice documents sent to the Commission are not available on the website of ECDC and ECHA, and a written request has to be sent to the agencies to obtain access to such documents (see Subsection 7.2.3).

As for the secondary sources, various types of documents are used. Most information comes from the scholarly literature on EU agencies in general and on influence in policy processes. Press releases and media reports are also considered.

\section{Interviews}

Even when relevant archival material is available, there could still be some inherent weaknesses because documents can often be incomplete and present a misleading account (Tansey, 2007). In particular, when it comes to empirical research on policy processes which involve informal interactions and practices by policy actors, Christiansen and Neuhold (2012, p. 8) warn that the ultimate challenge is to get "the access to information about developments that are undocumented and are generally lacking transparency." Therefore, in-depth interviews emerge as a crucial tool to collect data that are missing in the documents. 
No research is free from potential bias. Regarding interview data, researchers should be aware that interviewees may have reasons not to be completely open and honest about certain subjects. They might have conflicting opinions and be inconsistent with their answers. Moreover, due to the stretch of time, the information provided by interviewees may be less reliable as it might be difficult to remember how exactly certain events unfolded. However, this does not necessarily invalidate the interviewees' responses (Dexter, 1970). In order to eliminate bias and increase reliability and credibility of interview data, triangulation of information is essential. In this research, interview data are cross-checked using two different sources: one is the information provided by other interviewees, and the other is the primary and secondary documents.

The main targets of the interviews were ECDC, ECHA, and DG SANTE in the Commission. Within ECDC and ECHA, scientific experts were mainly interviewed because this research focuses on the process of how EU agencies produce and provide expert advice. In the Commission, Commission officials in charge of either drafting legislative proposals or managing overall issues of the four dossiers selected for this research were interviewed. In addition, high ranking officials and Management Board members from the agencies and other policy actors involved in the policy-making process were also interviewed. These interviewees can be characterised as elites since they are policy-makers with decision-making power, scientific experts, or experts with policy-relevant or procedure-relevant expertise. They are the first-hand participants of the policy-making process under investigation and accordingly, it is possible to obtain accounts from direct witnesses to the events in question through elite interviews (Tansey, 2007). These elite interviewees "can help in interpreting the personalities involved in the relevant decisions, [...] explain the outcome of events, [... and also] provide information not recorded elsewhere, or not yet available for public release" (Richards, 1996, p. 200).

In total, 29 interviews were conducted, and Table 3.4 presents the number of interviewees in each organisation. The number of interviews conducted for this research is not extensive, and there are two reasons for this: first, there are only a handful of experts who are involved in each policy dossier selected for the empirical analyses; and second, the number of Commission officials is small because there are also a small number of officials in charge of the specific issues studied in this research and it was very difficult to get interviews with them. Richards (1996, p. 200) mentions that "by definition, elites are less accessible." Nevertheless, the core actors of the four policy dossiers were interviewed, and this ensures the validity of research findings. 
Table 3.4) Number of interviewees

\begin{tabular}{|l|c|}
\hline \multicolumn{1}{|c|}{ Interviewee } & Number of interviews \\
\hline Officials in the Commission (DG SANTE) & 10 \\
\hline $\begin{array}{l}\text { Experts from ECDC (Management Board } \\
\text { and Scientific Committees) }\end{array}$ & 12 \\
\hline $\begin{array}{l}\text { Experts from ECHA (Management Board } \\
\text { and Scientific Committees) }\end{array}$ & 3 \\
\hline $\begin{array}{l}\text { Stakeholders (national competent } \\
\text { authorities, WHO, interest groups, etc.) }\end{array}$ & 29 \\
\hline Total & \\
\hline
\end{tabular}

(Source: Author's own compilation)

All of the interviews were carried out in a semi-structured way. This type of interviews offers a combination of flexibility and structure that "can provide detail, depth, and an insider's perspective, while at the same time allowing hypothesis testing" (Leech, 2002, p. 665). In semi-structured interviews, similar interviewees are subjected to the same interview questions. In this research, questions were formulated in advance based on the five core themes, in order to elicit information on the three dimensions: (1) professional background of the interviewee; (2) expertise and resources of the agency; (3) network and contacts inside the agency; (4) network and contacts outside the agency; and (5) perception of the influence of the agency. Each theme included one or two main questions. During the interviews, the main questions were posed to the interviewees and a number of follow-up questions were also asked in order to give the interviewees the opportunity to elaborate or clarify their answers.

While most interviews were conducted face to face, five interviews were done by telephone and two via email. The face-to-face and phone interviews lasted mostly between 45 minutes and 60 minutes, and in a few exceptional cases lasted between two and three hours. In all cases, a summary of the interview and follow-up questions were sent to each interviewee so that they could verify that the information they provided was understood correctly, and could respond with further information or clarification. All interviews were recorded with the permission of the interviewees and transcribed afterwards in full. "This painstaking work has its benefits as it makes it easier to compare answers to different questions" (Rasmussen, 2012, p. 80). Also, transcribing makes it possible to quote the exact wording from interviewees' responses.

In order to facilitate candid responses, all interviewees were promised that they would not be cited by name or by their position, which might reveal their identity. For reasons of anonymity, therefore, names and exact positions of interviewees are not mentioned in this research. When interviewees are quoted in this book, they are identified by number only. 


\subsubsection{Data analysis}

In the previous section, it is stated that data collected for this research are from primary and secondary sources and interviews. The data contained in the documents and interview transcripts are textual data and thus, this section introduces the process and techniques of textual analysis used for this research.

When dealing with a large number of documents and especially in large- $\mathrm{N}$ case studies, using software is beneficial. There are many software programmes available, and they can efficiently store, organise, manage, and reconfigure a large amount of data (Saldaña, 2013). Among these, ATLAS.ti and NVivo are well known to qualitative researchers. However, if only one or a few cases are studied, hand-coding becomes useful for textual analysis (Klüver, 2009). Although hand-coding is very labour intensive and time consuming, its biggest advantage is the in-depth knowledge of the content and the high validity of the measurement (Mikhaylov, Laver, \& Benoit, 2008, cited in Klüver, 2009). Hand-coding is the primary technique applied to analyse all data collected for this research.

In Subsection 3.3.1 Text Comparison, it is stated that two sets of documents are compared one from EU agencies (expert advice) and the other from the Commission (policy proposal) to find out whether there are any overlapping sentences or paragraphs as well as quotations referring to the documents from EU agencies. In the case of ECHA, the number of documents containing expert advice is 4 in the first case and 10 in the second case. This is a small number, and the size of these documents is not extensive. Thus, text coparison is conducted through hand-coding by reading and comparing the text closely. However, when conducting text comparison to assess ECDC's influence on the Commission's policy proposals, the situation is different. The number of ECDC's scientific documents is high: 19 in the first caes and 10 in the second case. Moreover, the length of some documents is extensive (about 50 pages on average, and one document is exceptionally long with 227 pages). Manually comparing documents to extract the overlaps and quotations would reduce the reliability of the analysis. Therefore, software called WCopyfind - a plagiarism detection tool - is used in a complementary manner. Below, WCopyfind is explained further.

\section{The process of text comparison}

Text comparison is the main indicator to measure the level of influence of EU agencies. When searching for overlapping text and quotations in a large number of documents, a computer programme that is designed to detect plagiarism can best be used. This is by no means to argue that the Commission plagiarises, but the presence of overlapping text and quotations is a clear sign that the Commission takes agencies' expert advice into account and makes use of it. A simple online search provides a long list of available plagiarism detection tools, and some websites provide an analysis of advantages and disadvantages of certain programmes. But, the main problem of these software programmes is that they check plagiarism of certain documents or texts against the entire Internet and other online resources including journals, 
books, and websites. Since the purpose of text comparison in this research is to compare the Commission proposals only to the documents provided by the selected EU agencies, these plagiarism tools are not appropriate to apply.

WCopyfind is a helpful tool because it performs a dedicated plagiarism check of a selected document or text against a set of "chosen" documents. It enables comparison between the Commission proposals and a set of documents from EU agencies which contains expert advice relevant to the proposals. This software is simple and easy to use and allows for flexibility. For each plagiarism check, it is possible to set the minimum string length that the software should consider to be a match and whether or not punctuation, numbers, and capitalisation of letters should be ignored, depending on the purpose of research. Moreover, how it reports the result of plagiarism check is effective for the text comparison. The list and the count of matching phrases between the two sets of documents are presented, and the text including the matching phrases can be viewed side by side on the screen.

The main shortcoming of WCopyfind - and the reason why WCopyfind is used in a complementary manner to hand-coding - is that the results of plagiarism check include phrases that are commonly used but do not contain any value for this research, such as "it is worth noting that" and "it is important to point out." Therefore, after running the plagiarism check between the Commission documents and relevant documents from ECDC, the list of matching phrases was examined by applying hand-coding to eliminate meaninglessly matching phrases. Then, using the side-by-side view of the two sets of documents, the paragraphs containing the matching phrases were read carefully to judge whether the phrases were used in the same context to deliver the same message.

\section{Coding interview transcripts}

In order to analyse the interview transcripts, structural coding is applied. Saldaña (2013) stresses that structural coding is particularly suitable for interview transcripts and also appropriate for those employing multiple participants, standardised or semi-structured datagathering protocols, hypothesis testing, or exploratory investigations to gather topics lists or indexes of major categories or themes. Structural coding is an analysis of data based on the specific research questions or themes that are used to frame the interviews. In the first step of structural coding, a list of codes is developed before analysing the transcripts to harmonise with the analytical framework and to enable an analysis that directly answers the research questions and goals (Saldaña, 2013). The three dimensions of this study were used as the main codes (e.g., "production"). In the production and provision dimensions, furthermore, the three conditions - access, activities, and resources - were used as the sub-codes (e.g., "production - access"). In the second step, the interview transcripts were carefully read, and the data were segmented according to the codes. Lastly, under each code, the segmented data were collected together for more detailed coding (e.g., "production - access - outside agency") and further analysis. As mentioned earlier, the interview transcripts were coded 
manually because it better facilitates consideration of substance and the surrounding contexts (Saldaña, 2013).

\subsection{Conclusion}

This chapter has presented the analytical framework and methodology applied for analysing EU agencies' influence. Assessment of EU agencies' influence and the conditions for influence is performed in three important dimensions: (1) the production of expert advice within EU agencies; (2) the provision of expert advice from EU agencies to the Commission; and (3) the actual impact on the content of policy proposals, which is the influence of EU agencies. The dependent variable is measured mainly through text comparison and, to a lesser degree, through reputation as a scientific authority. The three conditions investigated in this research are access, activities, and resources, and they are analysed in both production and provision dimensions.

The methodology section has set out the case study approach in two steps: first, at a crosscase level, ECDC and ECHA are selected according to carefully planned criteria; and second, at a within-case level, two specific dossiers are selected per agency. The two dossiers per agency consist of one most-likely case and one least-likely case. The primary and secondary sources as well as 29 semi-structured interviews provide data for the empirical analyses, and the textual data are analysed mainly by hand-coding the documents and interview transcripts.

The next two chapters are devoted to presenting the analyses and findings of the influence of ECDC and ECHA. 
Chapter 4

European Centre for Disease Prevention and Control 


\subsection{Introduction}

There have been several disease outbreaks since the beginning of the twenty-first century, such as the severe acute respiratory syndrome (SARS) in 2003, the pandemic influenza (H1N1) in 2009, the Ebola virus in 2014, and the Zika virus in 2016. Some of these outbreaks posed threats to health at a global scale, and the EU was also affected. The primary responsibility for managing health-related threats and organising health services lies at the Member State level, and EU health policy as well as activities taken at the EU level are intended to support and complement national policies in individual Member States. ${ }^{32}$ With the adoption of the Treaty on the Functioning of the European Union, however, the role of the EU in public health has been strengthened. Article 168 of the Treaty provides a legal basis for the EU to adopt health legislation in order to protect and improve the health of EU citizens. Another important improvement was the establishment of the European Centre for Disease Prevention and Control in 2005. The emergence of a new disease in 2003, SARS, together with a perceived pandemic threat, sparked the creation of ECDC (Ammon, 2015; Reiners, 2015). The creation of this EU agency was seen as "a substantial step towards the centralized identification, assessment and communication of current and emerging threats to human health" (Reiners, 2015, p. 149).

When ECDC was set up, it was a very small agency with only 29 staff and a budget of EUR 5 million. But, the agency grew quickly in 2006 with 100 staff and a budget of EUR 16 million (ECDC, 2007). As of 31 December 2016, ECDC had a total of 260 staff members and a budget of EUR 58.2 million (ECDC, 2017). The size of ECDC is relatively small compared to other EU agencies $^{33}$ - one of the large EU agencies, EUIPO, had more than 900 staff and a budget of EUR 400 million in 2016. ECDC's tasks are organised in three key strategic areas: it provides scientific evidence to assist effective and efficient decision-making in the EU, it strengthens public health systems to effectively prevent and control communicable diseases, and it supports the response to public health threats by detecting, assessing, and controlling them. ${ }^{34}$ Under these key strategic areas, the Centre carries out diverse activities including surveillance, epidemic intelligence, risk identification, risk assessment, risk communication, preparedness planning, response to health threats and events, scientific opinions and guidelines, training, and maintaining the scientific journal Eurosurveillance.

The Centre has experienced several structural changes. At the time of writing, the organisational structure of ECDC is based on five Units under the Office of the Director (see Figure 4.1). The Director is responsible for the overall management of the Centre and its external relations and supported by a small number of staff in the Office of the Director. The first Unit, called "Office of the Chief Scientist," oversees the scientific agenda and the quality

\footnotetext{
${ }^{32}$ See the overview of EU health policy: https://ec.europa.eu/health/policies/overview_en.

${ }^{33}$ See ECA $(2017$, p. 12) which presents a comparison of EU agencies' budget and staff numbers using a column chart.

${ }^{34}$ See https://ecdc.europa.eu/en/about-us.
} 
of scientific output and manages seven Disease Programmes ${ }^{35}$ and two sections. Two other Units - "Surveillance and Response Support" and "Public Health Capacity and Communication" - are scientific units. The Surveillance and Response Unit has four sections and they ensure timely detection of communicable disease threats, support health preparedness, and deliver high quality scientific outputs. The Public Health Capacity and Communication Unit has three sections, whose activities include strengthening European capacities and cooperation in communicable disease prevention and control and efficiently communicating scientific and technical knowledge. The two scientific units, together with their sections and the seven Disease Programmes, are characterised as the shared resources of ECDC. This means that experts from these Units, sections, and Programmes vertically and horizontally cooperate together when dealing with scientific matters. It is also described as the matrix structure of ECDC. Experts in the shared resources are the main authors of ECDC's scientific documents. The two remaining Units are in charge of "Information and Communication Technologies" and "Resource Management and Coordination."

Figure 4.1) Simplified organisational chart of ECDC

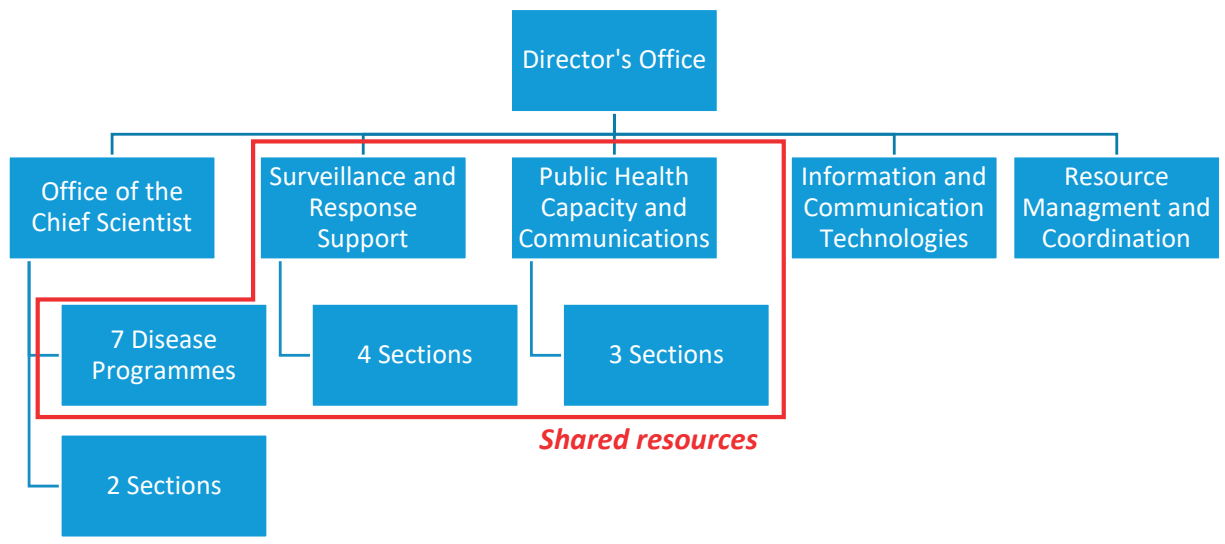

(Source: Author's own compilation)

There are two governing bodies in ECDC, the Management Board and the Advisory Forum. The Management Board approves the budget, monitors implementation of ECDC's work programme, and checks whether ECDC is performing its mission and tasks in accordance with the Founding Regulation. There are in total 33 members in the Management Board - each

\footnotetext{
35 The seven disease programmes are: Antimicrobial Resistance and Healthcare-associated Infections Programme; Emerging and Vector-borne Diseases Programme; Food- and Waterborne Diseases and Zoonoses Programme; HIV, Sexually Transmitted Infections and Viral Hepatitis Programme; Influenza and Other Respiratory Viruses Programme; Tuberculosis Programme; and Vaccine Preventable Diseases Programme.
} 
Member State designates one member, the European Commission appoints three representatives, and two members are designated by the European Parliament. The main function of the Advisory Forum is to advise the Director on the quality of ECDC's scientific work by providing feedback and peer review and to determine priorities for topics on which the Centre will produce scientific advice and guidance. Each Member State appoints one member and one alternate to the Advisory Forum, and these members are usually senior experts from the national competent authorities. The Commission nominates three members without the right to vote who represent interested parties, such as European associations, institutes, or academia in the field of public health. Moreover, EEA/EFTA countries ${ }^{36}$ and candidate countries of the EU may send their representatives as observers. At the time of writing, Iceland and Norway have one member and one alternate each, and Liechtenstein, Montenegro, and Turkey have one member each.

As outlined in the methodology section in the previous chapter (see Section 3.7), two cases will be examined in order to analyse the influence of ECDC. The Centre's influence on the formulation of the Commission Communication on Pandemic (H1N1) $2009^{37}$ is the first case, and its influence on the Commission proposal for a Decision on serious cross-border threats to health ${ }^{38}$ is the second case. While both cases touch upon the core tasks of the Centre - the former is related to the activities of epidemic intelligence and outbreak response and the latter concerns ECDC's support for preparedness - one represents a most-likely case for influence and the other a least-likely case (see Subsection 3.7.1). The H1N1 pandemic crisis was a public health emergency as the novel virus H1N1 spread very rapidly among communities around the globe. Responding to public health disasters requires a high level of knowledge and expertise, thus advice from experts becomes essential to policy-makers. In the same vein, it has been proven that government agencies constituted of epidemiological and medical experts, instead of top-level politicians in power, were the main drivers of vaccination policies at the national level during the H1N1 pandemic (Baekkeskov \& Rubin, 2014). Accordingly, this first case is a most-likely case.

The Commission perceives that "[a] global pandemic is a cross-border health threat which affects not only public health but also society and economies within the EU" (European Commission, 2009a, p. 2). Having experienced a public health emergency of pandemic scale in 2009 and 2010, the Commission felt that a "window of opportunity" had opened for more far-reaching legislation at the EU level (De Ruijter, 2017; Interview \#10). After devoting a period to an elaborate evaluation and learning lessons regarding the EU's response to the pandemic crisis, the Commission, in December 2011, proposed a new legislation on crossborder health threats. The second case explores the influence of ECDC on this proposal: "Commission proposal for a Decision on serious cross-border threats to health." The proposal

\footnotetext{
${ }^{36}$ Iceland, Liechtenstein, and Norway.

${ }^{37}$ Communication from the Commission to the European Parliament, the Council, the European Economic and Social Committee and the Committee of the Regions - Pandemic (H1N1) 2009, COM(2009) 481 final.

${ }^{38}$ Proposal for a Decision of the European Parliament and of the Council on serious cross-border threats to health, $\operatorname{COM}(2011) 866$ final.
} 
consolidated the existing tools and introduced a broader framework for crisis response by expanding the scope from communicable diseases under the previous regime to more diverse types of threats, including biological and chemical threats, threats caused by the effects of climate change, and threats of unknown origin in a crisis situation (European Commission, 2011a). Moreover, a peculiar political logic is inherent in the topic of this proposal. Liverani and Coker (2012, pp. 915-916) argue:

Because of the transnational spread of diseases, prevention and control measures have long challenged existing concepts of territorial sovereignty and required international cooperation. At the same time, the ways governments and health authorities collaborate are inevitably shaped by the context of international relations, institutional dynamics, and the broader landscape of political culture.

Given the broad scope and political deliberation of this proposal, the second case is considered as a least-likely case for ECDC influence.

This chapter proceeds in three steps. The first case on the pandemic H1N1 crisis is analysed in Section 4.2. This section is divided into four parts: background information, analysis of the dependent variable which is the influence of ECDC, and analyses of the production dimension of expert advice in ECDC and of the provision dimension of expert advice to the Commission. Next, Section 4.3 is devoted to the second case of serious cross-border threats to health. The detailed structure of this section is the same as the previous one. Lastly, Section 4.4 concludes that ECDC tackled the limited resources by flexibly adapting the organisational structure and effectively utilising internal and external networks on a regular basis in the production dimension of expert advice. All conditions in the production and provision dimensions were generally conducive to influence in the first case and resulted in a moderate level of influence. In the second case, however, all conditions in both dimensions were not favourable to influence, and ECDC exerted a low level of influence.

\subsection{Case 1: Commission Communication on Pandemic (H1N1) 2009}

\subsubsection{Background}

The H1N1 influenza pandemic virus first emerged in North America. On 4 April 2009, an outbreak of influenza-like illness started in one state of Mexico. It was considered as a novel virus because it had never been identified previously in either animals or people and showed a unique combination of influenza virus genes similar to swine-origin H1N1 influenza viruses. ${ }^{39}$ Therefore, it was initially referred to as a "swine origin influenza A virus." On 15 April 2009, first cases of severe disease were noted in Mexico City, and the United States also identified human infection cases in California on 21 April 2009. Just two days later, Mexico confirmed

\footnotetext{
${ }^{39}$ See the website of the Centers for Disease Control and Prevention in the United States (US CDC): https://www.cdc.gov/h1n1flu/cdcresponse.htm.
} 
120 cases of influenza infection and 20 deaths (HPA, 2010). On the same day, the United States concluded based on the initial human infection cases that the new virus was circulating only among humans, and the infected people had no exposures to pigs. The virus immediately began to spread across the world. Two Member States of the EU - Spain and the UK - reported similar cases on 27 April, and by 29 April 2009, nine countries globally reported 148 cases (HPA, 2010). On 11 June, the World Health Organization (WHO) raised the status from epidemic to pandemic, which officially declared the first influenza pandemic of the new millennium (Del Rio \& Guarner, 2010).

The H1N1 pandemic in 2009 was characterised as a highly complex, uncertain, and challenging event because information on the virus was extremely limited especially at the beginning of the crisis, and circumstances evolved very rapidly. It was one of the most serious health emergencies, resulting in more than 214 countries and territories or communities affected worldwide and causing over 17,919 deaths within a year. ${ }^{40}$ During the crisis, public health authorities at the national, European, and international level made a great effort to reduce uncertainty and risk surrounding the novel virus and to protect the public. As soon as the H1N1 influenza virus was declared to be a pandemic, ECDC and the Member States of the EU developed surveillance plans with input from WHO and countries already affected in and outside the EU (ECDC, 2010a).

The H1N1 pandemic made the year 2009 "a remarkable, and in some ways, historic year for ECDC" (ECDC 2010b, p. vii). It was the first crisis since the establishment of the organisation and led the Centre to activate its Public Health Event (PHE) level 2, which is the highest level of an emergency situation. ECDC had to sustain action on an event of this scale and sensitivity for a prolonged period of 68 weeks. ${ }^{41}$ Only on 10 August 2010 did WHO's Director-General announce at a press conference that the 2009 influenza A (H1N1) pandemic had run its course and was over. ${ }^{42}$

In response to the pandemic, the European Commission, on 15 September 2009, published a "Communication from the Commission to the European Parliament, the Council, the European Economic and Social Committee and the Committee of the Regions on Pandemic (H1N1) 2009." 43 With the protection of public health as its main objective, the Communication aimed at bringing attention to public health coordination issues at the European and international level as well as to the cross-sectoral dimension of the pandemic. The Commission published five "Commission Staff Working Documents" in parallel with the Commission Communication. Under the theme of the H1N1 pandemic in 2009, these technical documents discuss topics of joint procurement of vaccines, vaccination strategies, communication with the public and the

\footnotetext{
${ }^{40}$ See Pandemic (H1N1) 2009-Update 98 published by WHO (retrieved from http://www.who.int/csr/don/2010_04_30a/en/).

${ }^{41}$ The whole pandemic period lasted for 68 weeks, from week 18, 2009, to week 35, 2010 (Amato-Gauci et al., 2011).

${ }^{42}$ See the opening statement of Director-General at http://www.who.int/mediacentre/news/statements/2010/h1n1_vpc_20100810/en/.

${ }^{43} \operatorname{COM}(2009) 481$ final, Brussels.
} 
media, regulatory process for the authorisation of antiviral medicines and vaccines, and support to third countries. The first empirical analysis of ECDC's influence on the formulation of the Commission Communication is outlined below.

\subsubsection{Evidence of ECDC's influence}

In the previous chapter it is explained that EU agencies' influence in the policy formulation stage is measured by two indicators. The first and main indicator is text comparison between expert advice from EU agencies and policy proposals from the European Commission. The second and supplementing indicator is reputation of EU agencies as scientific authority. The results of text comparison and reputation of ECDC in relation to the Commission Communication on pandemic (H1N1) 2009 are presented in this section.

\section{Text Comparison}

In order to measure ECDC's influence, two sets of documents are compared - one is the Commission Communication on pandemic (H1N1) 2009 and the other is the documents from ECDC which contain scientific advice in relation to the H1N1 pandemic. If the Commission Communication reflects expert advice delivered by ECDC, it is considered as a sign of ECDC's influence (see Subsection 3.3.1). The influence of ECDC would be high if there is overlapping text, such as the same sentences or paragraphs, between the two sets of documents and/or if the Commission Communication uses quotations from or makes references to ECDC's documents. If some parts of expert advice are incorporated in the Commission Communication but reformulated by paraphrasing or by adding or deleting certain information, it would imply a moderate level of ECDC influence. If expert advice from ECDC cannot be traced at all in the Commission Communication, it would mean a low influence of ECDC.

In total, 19 documents from ECDC were compared to the Commission Communication. ${ }^{44}$ These documents were published between April and August 2009 - the period between the start of the H1N1 pandemic and the adoption of the Commission Communication. The number of all types of scientific output by ECDC during this period is higher than 19. However, the documents selected for analysis excluded short communication materials which were primarily intended to announce statistical information, such as Daily Updates, rather than to provide scientific knowledge and expert advice. Also not included are Executive Updates which were formulated to inform the Management Board members of ECDC, and numerous

\footnotetext{
${ }^{44}$ ECDC produced more than 200 scientific outputs regarding the novel influenza $A(H 1 N 1)$ virus during the pandemic period of a little over a year (see Subsection 4.2.4). The number of documents selected for text comparison is much smaller because only the ECDC documents published before the Commission Communication was issued are considered in order to analyse whether or not expert advice of ECDC is incorporated in the Commission Communication. See Appendix 1 for the complete list of the 19 documents analysed for text comparison.
} 
scientific articles published by experts of the Centre in academic journals. These documents were excluded as they were not intended to provide expert advice to the Commission.

The analysis based on the text comparison shows that ECDC exerted a moderate level of influence on the formulation of the Commission Communication on the H1N1 pandemic. In the 12-page document from the Commission, ECDC was mentioned in total seven times. Six out of seven times, ECDC was mentioned in the context of the Commission's coordination efforts at the European and international level to manage the pandemic, and one time in relation to its support to third countries. While no direct quotations from or references to ECDC documents could be found, what is noteworthy is Section 4 "EU Coordination on Public Health Response - Joining Forces with Member States" in the Commission Communication. Here, the Commission states that the Member States need to report influenza outbreaks and give prompt notification of cases, and further explains:

The ECDC collects this information. In the case of pandemic influenza, daily situation reports are prepared for the Member States. ECDC is also providing ongoing support to Member States and the Commission in terms of surveillance and response to the crisis. This includes advice to the public on personal protective measures, and to Member States on mitigation activities. (European Commission, 2009a, p. 5, emphasis added)

Some of the documents produced by ECDC contain advice to the public and to the Member States, as illustrated by the Commission. For example, ECDC produced in June 2009 a technical report "Guide to public health measures to reduce the impact of influenza pandemic in Europe: 'The ECDC Menu.'" In this report, ECDC offers advice on various measures, and personal protective measures are included here with detailed advice, such as regular hand-washing, mask-wearing, and so on. Moreover, a guidance document ${ }^{45}$ published by ECDC in June 2009 provides practical considerations for EU/EEA countries to assist them in making policy decisions on mitigation strategies. However, the Commission did not refer to these specific documents. Instead, the Commission provided in footnote the online link to the website of ECDC where all documents relevant to the H1N1 pandemic can be found.

Furthermore, when discussing the value of restricting international travel to and from affected countries and regions, the Commission referred to WHO recommendations which did not consider travel restrictions as an appropriate tool. Then, the Commission stated its decision that "[i]n line with this [WHO] position, no recommendation on travel restriction, including air transport, has been taken at EU level" (European Commission, 2009a, p. 6). ECDC delivered similar advice under the title "Travel measures: Restrictions on international travel" in the technical report mentioned above, but both ECDC and its advice in this document were not acknowledged by the Commission.

\footnotetext{
${ }^{45}$ See "ECDC Interim Guidance: Mitigation and delaying (or 'containment') strategies as the new influenza $\mathrm{A}(\mathrm{H} 1 \mathrm{~N} 1)$ virus comes into Europe" published on 6 June 2009.
} 
Secondly, there are no overlapping sentences or paragraphs between the Commission Communication and the documents from ECDC, which would have indicated high influence of ECDC. As introduced in the previous chapter (see Subsection 3.7.4), WCopyFind, a plagiarism detection software, was used to check matching phrases between the two sets of documents. The result showed some signs of input from ECDC in the Commission Communication. For example, on the topics of the effectiveness of vaccination as well as the need for strategies to maintain essential services and for monitoring situations outside the EU, both the Commission and ECDC present similar - but not the same - phrases with the identical position and context. Table 4.1 presents the examples of similar text between the two sets of documents.

Table 4.1) Examples of similar phrases between the Commission Communication and ECDC documents

\begin{tabular}{|c|c|}
\hline ECDC Text & Commission Text \\
\hline $\begin{array}{l}\text { "In April 2009, a new strain of human } \\
\text { influenza } A(H 1 N 1) \text { causing human disease } \\
\text { was identified and characterised." (ECDC, } \\
\text { 2009d, p. 3) }\end{array}$ & $\begin{array}{l}\text { "In April 2009, a novel strain of human } \\
\text { influenza H1N1 was identified that had } \\
\text { caused illness in Mexico and the United } \\
\text { States first, in March and April 2009." (p. 2) }\end{array}$ \\
\hline $\begin{array}{l}\text { "Vaccination with a strain-specific pandemic } \\
\text { vaccine is considered to be one of the most } \\
\text { effective countermeasures for protecting } \\
\text { individuals in the event of a pandemic." } \\
(E C D C, 2009 d, \text { p. 4) }\end{array}$ & $\begin{array}{l}\text { "As a prophylaxis, vaccination is one of the } \\
\text { most effective public health mitigation } \\
\text { responses in a pandemic while for the } \\
\text { treatment anti-viral medication remains a } \\
\text { key option." (p. 3) }\end{array}$ \\
\hline $\begin{array}{l}\text { "[...] different strategies come into play with } \\
\text { greater emphasis on the need to maintain } \\
\text { essential services by immunization. [...] } \\
\text { Objective [is to] limit the speed of spread of } \\
\text { infection and the burden on the healthcare } \\
\text { system." (ECDC, 2009d, pp. } 1 \text { and 10) }\end{array}$ & $\begin{array}{l}\text { "[...] the need for a carefully planned } \\
\text { vaccination strategy, taking into account the } \\
\text { need to protect vulnerable people, to limit } \\
\text { the spread of infection and to maintain } \\
\text { essential services in the society." (p. 11) }\end{array}$ \\
\hline $\begin{array}{l}\text { "[...] ECDC will continue to closely monitor } \\
\text { the situation in North America and the } \\
\text { temperate countries of the southern } \\
\text { hemisphere. It is from these countries that } \\
\text { further information for the parameters listed } \\
\text { above will come - in addition to the } \\
\text { information from the European Union." } \\
(E C D C, 2009 c, p .12)\end{array}$ & $\begin{array}{l}\text { "The Commission will address the following } \\
\text { specific objectives: to closely monitor the } \\
\text { situation in third countries, through regular } \\
\text { relations with UNSIC, WHO, EU Member } \\
\text { states and with other stakeholders, so as to } \\
\text { be in a position to confirm in time a potential } \\
\text { threat from the pandemic (H1N1) } 2009 \\
{[\ldots] \text { " (p. 10) }}\end{array}$ \\
\hline
\end{tabular}

(Source: Author's own compilation) 
As the references cited in Table 4.1 indicate, only two out of the 19 ECDC documents reveal examples of text similar to the Commission Communication. The remaining 17 documents from ECDC do also show some phrases that can be found in the Commission Communication, but they are placed in a different context. For instance, on the issue of pandemic vaccines, both ECDC and the Commission assert possible cooperation where one Member State is assisted by other countries. But, ECDC discusses this in the context of detecting and testing plausible side effects of vaccines (ECDC, 2009e) whereas the Commission envisages cooperation to address shortages of vaccine. Thus, this kind of similar text in a different context cannot be considered as evidence of ECDC input.

In short, when the Commission Communication is compared with the 19 ECDC documents, there are some - but not numerous - statements with the identical context and position although formulated differently. Based on this evidence of text comparison, it is concluded that ECDC exerted a moderate level of influence on the Commission Communication. In line with the finding here, the second independent external evaluation of ECDC reports that $E C D C$ 's impact on the formulation of risk management measures at the Member State level was also not high.

The evidence of consistent use of ECDC [risk assessment] messages can be found in national documents more or less explicitly making reference to ECDC documents. The examples found are, however, not numerous and in most cases refer to the 2009 pandemic." (Economisti Associati, 2014, p. 75)

While the instances of similar text are not numerous, it is worth noting that the impact of scientific advice by ECDC in general during the H1N1 pandemic should not be downplayed. From the very beginning of the pandemic, ECDC contributed to the risk management measures and activities carried out by the Commission. The Commission Communication provides a list of measures taken at the European level to tackle the pandemic crisis before the Commission Communication was introduced in September 2009 (see Table 4.2). Most of these measures were agreed by a limited number of experts, mainly from the Health Security Committee and the Early Warning and Response System (EWRS) contact points. ECDC was involved in every discussion of the measures as it was a member of the Health Security Committee and managed the operation of EWRS, a secure alert system linking the public health authorities at national and EU levels. 
Table 4.2) Key measures agreed at the European level before September 2009

\begin{tabular}{|l|l|}
\hline Title & Date of agreement \\
\hline The common case definition, adopted in a Commission decision & 1 May 2009 \\
\hline $\begin{array}{l}\text { Agreement on advice to persons planning to travel to or returning } \\
\text { from affected areas }\end{array}$ & 18 May 2009 \\
\hline Extension of the surveillance system to identify new cases in the EU & 18 May 2009 \\
\hline $\begin{array}{l}\text { Guidelines on case management and treatments and advice on } \\
\text { medical countermeasures for health professionals }\end{array}$ & 18 May 2009 \\
\hline Advice for the general public on personal protective measures & 4 May 2009 \\
\hline Statements on school closures and travel advice & 13 August 2009 \\
\hline Statement on “Vaccination Strategies: Target and Priority Groups" & 25 August 2009 \\
\hline
\end{tabular}

(Source: Author's own compilation based on European Commission, 2009a).

A good example of ECDC's influence is the Commission Decision, adopted on 30 April 2009, on case definitions for clinical, laboratory, and epidemiological criteria for influenza A (H1N1)v virus infection. ${ }^{46}$ At the request of the Commission, ECDC provided a technical document which served as the basis for this Decision (ECDC, 2009f). One senior expert from ECDC elaborates:

On technical documents from the Commission, [ECDC] had a lot of influence. There are pieces of the Commission Decisions, such as the Commission Decision on case definitions for diseases, and those words were totally drafted by us. There is a Commission Decision on the list of reportable diseases, which is a technical, supportive document. On this, we had huge influence because we were more or less drafting the text. They are based on our scientific, technical competences. (Interview \#4)

The Commission (2011a, p. 40) confirms that "[u]nder the current EU communicable disease legislation, EU surveillance and a case definition for H1N1 were agreed rapidly on the basis of ECDC and WHO advice."

\section{Reputation}

ECDC's strategic multi-annual plan for 2007-2013 states clearly its vision for becoming a scientific authority:

By the year 2013, ECDC's reputation for scientific excellence and leadership is firmly established among its partners in public health, and ECDC is a major source for scientific

\footnotetext{
${ }^{46}$ Commission Decision No. 2009/363/EC of 30 April 2009 amending Decision No. 2002/253/EC laying down case definitions for reporting communicable diseases to the Community network under Decision No. 2119/98/EC of the European Parliament and of the Council, OJ L 110/58, 1.5.2009.
} 
information and advice on communicable diseases for the Commission, the European Parliament, the Member States and their citizens. (ECDC, 2010b, p. 13)

In line with this vision, ECDC was successful in establishing its scientific authority, and its reputation was very good during and after the H1N1 pandemic. The Commission undertook an EU-wide survey right after it introduced the Commission Communication in September 2009. Twenty-seven Member States of the EU and EFTA countries as well as other actors involved in the crisis management were asked to evaluate the crisis response at the EU level during the first four months (24 April to 31 August 2009) of the H1N1 pandemic. According to the survey result, all countries participating in the survey - in total 22 - were satisfied with the willingness of ECDC to provide scientific support and information on the pandemic (HPA, 2010). Some Member States expressed that risk assessments and situation reports from ECDC were "excellent and reliable" and that ECDC was "the entity that provided the most information and in a timely manner" (HPA, 2010, p. 40). The evaluation by the European Medicines Agency, which worked closely with ECDC during the pandemic, was also positive: "ECDC was very efficient at providing information and sending experts at short notice to provide technical support and advice" (HPA, 2010, p. 40).

Another evaluation of ECDC from 2014 reports that the agency is "generally recognized to have played a useful coordinating and supporting role during the $A(H 1 N 1)$ influenza pandemic [in 2009]" (Economisti Associati, 2014, p. 71). About 70\% of decision-makers and influenza experts from both national and European levels were satisfied with ECDC's response and agreed that ECDC's rapid risk assessments in 2009 "had an impact in framing investigation and strategic decisions" (Economisti Associati, 2014, p. 68). These results are similar to the outcome of an early evaluation on the pandemic response which was conducted in June 2009, where $97 \%$ of the Member States appreciated ECDC's support, 91\% used ECDC's pandemic influenza website, and 97\% utilised ECDC documents and 53\% translated them into their own language (ECDC, 2010b).

Likewise, the Chairman of the ECDC Management Board praised the important role played by ECDC during the H1N1 pandemic: "The daily epidemiological reports published by ECDC, coupled with its excellent scientific guidance documents and hands-on technical support were of immense value to health officials at both national and EU levels" (ECDC, 2010b, p. vii). The Commission also confirms the very good reputation of the Centre. A high-ranking official from DG SANCO acknowledges:

ECDC's technical expertise was paramount to the Commission response during the H1N1 pandemic, starting with surveillance, monitoring EWRS and media, gathering data, analysing the data, providing risk assessments, case definitions, guidelines and technical advice to health professionals on specific issues, and supporting the Commission and the Member States in their communication efforts. (Interview \#9)

Another official from the Commission agrees that "the Commission very much valued the technical work and scientific advice provided by ECDC during the communicable disease 
outbreak. [...] The support provided [by ECDC] was timely and efficient" (Interview \#10). Particularly, ECDC's risk assessment documents were highly appreciated, and the way information was communicated and debriefed to risk managers in the Commission was deemed adequate and effective (Economisti Associati, 2014). "The public and authorities trusted expertise of ECDC [... and therefore] the Commission has always taken [ECDC's] expertise into account when proposing health measures" (Interview \#9).

This section has shown that ECDC exerted a moderate level of influence on the formulation of the Commission Communication on the H1N1 pandemic. Regarding the reputation of the Centre, its scientific expertise was of paramount importance to the Commission as well as other risk managers in the Member States. The following two subsections analyse the conditions for influence in the production and provision dimensions.

\subsubsection{Conditions for influence: Production of expert advice in ECDC}

In the previous chapter "Research Design and Methodology" it is stated that three conditions would affect the influence of EU agencies (see Section 3.2): access, activities, and resources. In this section, these conditions are analysed while focusing on the production dimension of expert advice in ECDC.

\section{ACCESS}

The first condition, access, refers to ECDC's networks and opportunities to pool specific expertise not only among experts within the agency but also from external experts. Given the novel and rapidly spreading characteristics of the H1N1 virus, ECDC mobilised and utilised its various networks during the pandemic. Regarding access within the Centre, ECDC's daily working practices and organisational adjustments should be highlighted. In order to explain daily working practices, the matrix structure of the Centre needs to be reviewed. In 2009, four vertically placed scientific Units - Surveillance Unit, Scientific Advice Unit, Preparedness and Response Unit, and Health Communication Unit - were horizontally connected to and supported by seven Disease-Specific Programmes. All Units and Programmes were heavily involved in the monitoring of the pandemic and the subsequent response to it (ECDC, 2010b). In particular, the Preparedness and Response Unit, composed of 36 staff in 2009, is noteworthy to discuss here as the role played by this Unit was essential for the production of expert advice during the crisis, especially at the beginning of the pandemic.

Epidemic Intelligence and Emergency Operations Centre was a section under this Unit. ${ }^{47}$ About $80 \%$ of the people in this section had a scientific background: they were medical doctors,

\footnotetext{
47 There were two other sections in the Preparedness and Response Unit: "Epidemiological Training" and "Outbreak, Preparedness and Support." On 1 December 2009, the organisational structure of ECDC was modified and the name and the composition of the sections were changed.
} 
public health experts, and experts in certain diseases, communication, or threat detection (Interview \#7). Two major parts of their work involved epidemic intelligence and threat detection. Epidemic intelligence means a structured process for retrieving information from all kinds of web-based sources and different types of unofficial information, such as from online news media or from social media (ECDC, 2013). Threat detection is a process through which experts pick up main issues of possible threats that are discussed together with the Disease Programmes. Their work was organised through "Daily Threat Monitoring Meetings" which were internally known as "roundtable meetings." Every working day at 11:30, the daily meeting was held in the Emergency Operations Centre in ECDC, which was managed by the Unit. ${ }^{48}$ Experts from different Units and Programmes met together in the roundtable meetings to assess threats, official alerts, and epidemic intelligence from the EU and around the world. Another participant in the roundtable meetings was the "24/7 duty officer." Experts in this position work around the clock, Monday to Monday, ensuring the necessary response in case there is a possible threat that needs to be dealt with out of working hours (Interview \#7). During working hours, they cooperate with the threat detection officers or epidemic intelligence officers to monitor and discuss possible threats. ${ }^{49}$

When the United States announced that the first cases of influenza infection had been detected on 21 April, the 24/7 officers noted this publication on the same day. On 22 April, the report was discussed in the roundtable meeting with the officers from the section for Epidemic Intelligence and Emergency Operations Centre mentioned above, as well as other senior experts from ECDC. ECDC's senior experts on influenza decided to activate an internal influenza working group, and this was the very first activity by ECDC to analyse the possible pandemic threat and the implication for Europe of the identification of human cases of influenza viruses. A senior expert involved in this activity explained that "as soon as we got information on the outbreak, we immediately worked on it. [...] We are talking about a decision taken in six hours because it was a very relevant threat" (Interview \#8). The use of the roundtable approach at the operational level was perceived as "the advantage of building on a well-oiled ongoing communication and coordination processes" among experts in ECDC (Greco, Stern, \& Marks, 2011, p. 16).

Then, two days later, ECDC released its first threat assessment on its website, and later that day at 19:00 hours it also published the first rapid risk assessment titled "ECDC rapid risk assessment: Human cases of swine influenza without apparent exposure to pigs, United States and Mexico" (ECDC, 2010c). On the following day, ECDC started publishing a daily update publication called "Situation Report." 50 At that point, ECDC had only a small amount of information coming from Mexico and the United States, and it was largely incomplete (Interview \#8). Yet, experts from various scientific parts of the Centre actively shared

\footnotetext{
${ }^{48}$ Holding a roundtable meeting has long been ECDC's daily practice, and there is a "standard operation procedure about who has to attend, where they have to sit, what their role is, and so on" (Interview \#7).

${ }^{49}$ Apart from the pandemic, ECDC monitored 191 threats in 2009 which led to the production of 25 threat assessments (ECDC, 2010b).

${ }^{50}$ The name of this document changed from "Situation Report" to "Daily Update" on 10 August 2009.
} 
knowledge and expertise through the roundtable meetings. They also carried out an intensive information search through the literature review and web-based search (Interviews \#4, \#8). Based on this input, the Scientific Advice Unit, which was responsible for producing high-level scientific and independent assessments, was "very efficient in rapidly producing high-quality technical documents to be published on the web portal" (Greco et al., 2011, p. 32).

On 24 April - just one day after the United States concluded that the novel influenza A(H1N1) virus had caused the human infection cases - ECDC initiated the PHE level 1, which required 12 hour/6 day activity with rotating teams from a roster of ECDC expert staff (ECDC, 2010c; Greco et al., 2011). PHE is an emergency plan developed by ECDC which can be implemented to cope with the demand for extra and specific emergency work in crisis situations. In accordance with the emergency plan, ECDC made several organisational adjustments to mobilise in-house experts. The Director of ECDC appointed a crisis manager, ${ }^{51}$ and a PHE Strategic Team was created to advise the Director, crisis manager, and senior experts of ECDC on crisis management (ECDC, 2010b). A PHE Management Team, which was led by Influenza Programme, was also created to enact the strategic direction decided by the PHE Strategic Team (Greco et al., 2011). Moreover, the Influenza Programme, which was the most relevant Disease Programme during the H1N1 pandemic, completely reorganised its priorities and activities in order to focus on the pandemic (ECDC, 2010b). In the summer of 2009, ECDC recognised the importance of the development of a specific pandemic vaccine and created a Vaccine team that "contributed to a number of vaccine-related publications on the ECDC website and helped with ECDC's input to the EU Pandemic Vaccine Task Force" composed of ECDC, EMA, and the Commission (Greco et al., 2011, p. 13).

In terms of ECDC's access to external partners, the Founding Regulation specifies: "In public health emergencies the Centre should operate in close collaboration with Commission services and other agencies, Member States and international organisations." 52 ECDC indeed worked closely with, supported, and was supported by the relevant actors at the national, European, and international level. ECDC's networks with the Member States were arranged based on "Focal Points." These are individuals or units in national authorities that help information exchange with ECDC and that are useful mechanisms to counteract resource constraints (such as information deficits) and to avoid duplication of work (Heims, 2016). All Member States, via their Focal Points, reported relevant information to ECDC on a regular basis and ECDC also transmitted guidelines, recommendations, and/or expert advice through these Focal Points. Their interaction was routinised. For instance, "EU/EEA countries report cases of travel-associated Legionnaires' disease to ECDC daily, influenza data weekly, measles and rubella data monthly, food and waterborne disease surveillance data quarterly, and data for most other diseases annually" (Santos-O'Connor et al., 2014, p. 55).

\footnotetext{
${ }^{51}$ The crisis manager had planning (developing appropriate reactions and flexible processes based on possible scenarios) and evaluation (assessing actions and decisions taken during PHE) functions (Greco et al., 2011).

52 See recital 9 in the preamble of the Founding Regulation of ECDC.
} 
This cooperation became stronger when the pandemic hit the EU in 2009. ECDC immediately created an ad hoc database in EWRS and as of 5 May 2009, the EU/EEA countries started to submit detailed case-based reports to ECDC on a daily basis, including information on case numbers of infection or death by the H1N1 virus (Amato-Gauci et al., 2011). Five Member States even voluntarily submitted "extra information including deaths, containment measures, antiviral stockpile information, as well as planning assumptions and scientific committee reports" (HPA, 2010, pp. 40-41). The surveillance data submitted by the EU/EEA countries, supplemented by the ECDC epidemic intelligence and monitoring activities, contributed to quantifying the main pandemic parameters and to producing risk assessment reports (AmatoGauci et al., 2011).

Building and strengthening the cooperation with the Member States was possible partly because ECDC organised training programmes for national experts. All participants remained in contact with their peers in other countries and experts from ECDC, and this network helped the Centre to more rapidly gather data and exchange information with the Member States (Economisti Associati, 2014; Interview \#5). One expert from ECDC elaborated that since participants from the Member States and ECDC experts had created a broad network through the training programmes, if necessary ECDC experts could directly call certain experts in the Member States and ask for specific information during the pandemic (Interview \#5).

ECDC also invited key national institutions to meetings to discuss and improve coordination, and organised several simulation exercises focusing on public health emergency. For instance, in April 2009, ECDC organised a simulation exercise on vaccine-preventable disease and mass vaccination which was attended by ECDC staff, EMA, DG SANCO, WHO, and five Member States (Denmark, Poland, Romania, Slovenia and Sweden). Another meeting targeting the key national institutions in the area of communicable disease prevention, surveillance, and control in Europe was organised by ECDC in October 2009, gathering 270 participants with the aim of improving coordination with the Member States especially in an emergency situation (ECDC, 2010b). Later in November 2009, a similar simulation exercise was organised targeting ECDC staff, WHO, some Member States, as well as countries outside the EU on the topic of mass gathering in a pandemic situation. These training activities helped the Member States understand emergency procedures, which in the end would contribute to effective internal and external communication processes.

Regarding ECDC's networks at the European level, the main partners are the European Commission and other EU agencies. The network with the Commission is explained in detail in the following section on the provision dimension of expert advice. In this section, the network with the London-based EMA is important to look at, as ECDC worked closely with EMA during the pandemic. EMA is responsible for assessing risks of medicines, including influenza vaccines, in the centralised authorisation procedure of the EU. Accordingly, ECDC's cooperation with EMA in 2009 focused on the issues relevant to vaccines against the H1N1 virus. During the early stage of the H1N1 pandemic, both EMA and ECDC joined an EU Task Force to produce an EU plan on vaccines. ECDC, EMA, and EMA's Pharmacovigilance Working 
Party engaged in many discussions regarding the benefit-risk monitoring of vaccines and protocols for safety and effectiveness studies. This cooperation resulted in the co-authored publication titled "European Strategy on Influenza A/H1N1 Vaccines Safety Monitoring" in October 2009 (HPA, 2010).

Furthermore, experts from EMA sometimes joined internal meetings of ECDC to provide their expertise, and ECDC also briefed EMA Committees and provided data and analyses (ECDC, $2010 b)$. In this close cooperation, nevertheless, there was still room for improvement. Given the importance of the availability and accessibility of vaccines in dealing with pandemic viruses, and also the fact that a lot of data sharing and communications were done via EWRS, it was surprising to discover that EMA did not have access to EWRS during the pandemic in 2009 (HPA, 2010).

Lastly, at the international level, the key partner for ECDC was WHO. The Founding Regulation states that ECDC should establish clear procedures for cooperation with the WHO. ${ }^{53}$ A position called "WHO Liaison Officer" existed in ECDC during the first few years of its operation. The officer was in charge of strengthening the coordination and collaboration between ECDC and WHO/EURO (WHO Regional Office for Europe) and supporting the ECDC Director in all WHO matters (Interviews \#1, \#2). In the first rapid risk assessment concerning the pandemic threat, published on 24 April, ECDC already stressed that the Centre "has also established contact with WHO and will continue to collaborate closely with them as the situation evolves" (ECDC, $2009 b$, p. 4). ECDC and WHO jointly developed planning scenarios on pandemic and interpandemic (seasonal) influenza for the following years, and together with WHO/Europe in particular, ECDC organised a workshop involving several south-east European countries to learn from their experience in communication and intensive-care issues during the pandemic (ECDC, 2010b). Several senior experts in ECDC confirmed that they consider WHO/EURO and WHO headquarters as important partners because they share data and information. One expert emphasised that they "try to cooperate as much as possible to avoid duplication of work" (Interview \#8). The H1N1 pandemic in 2009 was the event that proved the value of partnership between ECDC and WHO and also strengthened their network (Interview \#13). Later that year, the founding Director of ECDC, Zsuzsana Jakab, was nominated as WHO's new Regional Director for Europe and took up the post on 1 February 2010. ${ }^{54}$

ECDC also cooperated with similar agencies in third countries in order to exchange knowledge and circulate scientific documents. For example, Situation Reports, which stated daily developments in the past 24 hours in the EU, were circulated to the relevant bodies in and outside the EU. In May 2009, ECDC sent an expert to the Centers for Disease Control and Prevention in the United States to ensure liaison between the European and the US emergency operations centres. Similarly, ECDC also hosted a liaison officer from the Chinese

\footnotetext{
${ }^{53}$ See recital 4 in the preamble of the Founding Regulation of ECDC.

${ }^{54}$ See the WHO website: http://www.euro.who.int/en/about-us/regional-director/biography.
} 
agency who worked at the Emergency Operations Centre for a total of four weeks (ECDC, 2010b).

ECDC experts stress that the Centre's real strength is in crisis situations like the H1N1 pandemic since they can mobilise very specific expertise quickly by pooling resources from internal and external experts (Interviews \#2, \#4, \#7, \#8, \#11). One senior expert from ECDC reiterates:

I think our real strength is really in this kind of [urgent] situations [... because] we could mobilise very specific expertise. For example, there is one expert in the world on virus infections in camels, and we could mobilise and get in contact with this expert, but a single country could not do that. So, it's pooling resources - and no need to duplicate the work - which defines the Centre's capacity. (Interview \#4).

\section{ACTIVITIES}

The second condition, activities, mainly considers the frequency of contacts with internal and external experts. The frequency of networking activities among ECDC experts as well as between ECDC and external partners was very high during the pandemic period. The internal networking activities among experts from different Units and Programmes in ECDC took place on a daily basis with roundtable meetings, as explained earlier. In addition, the two new PHErelated teams also had daily meetings. The PHE Strategic Team discussed strategic issues on a daily basis (later biweekly), and the PHE Management Team met daily to discuss technical, scientific, and practical issues related to management of the crisis (Greco et al., 2011).

In a time of emergency which requires rapid decision-making and responses, cooperation and smooth communication among the experts and staff in ECDC is vital in order to produce expert advice in a timely manner. However, such was not always the case during the H1N1 pandemic. Greco et al. (2011, p. 16) report that

[s]ome informants noted with dismay that at certain key junctures the organisation functioned in a more hierarchical fashion than is generally the case in a relatively collegial expert organisation like ECDC, feeling that the information flow was restricted and opportunities for input on some matters limited. Other, more senior informants concurred but felt that this reflected an adaptive response to the exigencies of the situation, in which key determinations had to be made under heavy time pressure.

As explained earlier, information exchange between ECDC and the Member States was made via EWRS. ECDC also circulated its scientific documents, including the daily Situation Reports and risk assessments, to the Member States and the Commission via EWRS. This resulted in highly frequent interaction between ECDC and the Member States. According to the Annual Report of ECDC: 
[Between April and December 2009,] national health authorities exchanged 509 messages through the Early Warning and Response system (EWRS) which resulted in 820 comments and 721 exchanges among Member States. This represents a fivefold increase compared with $2007.89 \%$ of the messages were related to pandemic influenza. (ECDC, 2010b, p. 16)

But, this does not mean that EWRS was the only means of communication. During the whole pandemic period, ECDC maintained daily contact with the Member States through phone calls, teleconferences, and face-to-face meetings (Interviews \# 4, \#5, \#7, \#8). For example, as early as 29 April 2009 - only five days after the start of the pandemic - ECDC organised a teleconference with six Member States to collate their experiences and information (Greco et al., 2011). Likewise, ECDC maintained close contact with other partners. ECDC and EMA had teleconferences on a weekly basis (also together with WHO and the European Commission) and whenever needed, ECDC also had teleconferences with US CDC to discuss the H1N1 pandemic (ECDC, 2010b).

\section{RESOURCES}

In 2009, ECDC was a young agency with only four years of experience. The H1N1 pandemic was the first that ECDC had to deal with, but "[t]he pandemic didn't find ECDC unprepared" according to ECDC's Annual Report for 2009 (ECDC, 2010b, p. ix). "[I]n its first years of existence ECDC had built the tools, procedures, plans and partnerships to be able to handle such critical situations" (ECDC, 2010b, p. ix). While these capacities still had to be tested during the pandemic, one positive aspect in terms of producing expert advice was that some of the leading experts on influenza and surveillance were serving on the ECDC staff when the pandemic was announced (Greco et al., 2011). An evaluation about the response of ECDC to the 2009 pandemic reports:

[Having prominent experts in ECDC] was extremely relevant, not only because of the available expertise, but also because of personal contacts which facilitated access to the global influenza expert network, which made it possible to candidly share information and data for the benefit of European advice and decision-making processes. (Greco et al., 2011, p. 32)

Regarding the size of ECDC, its budget was EUR 40.2 million in 2008 and EUR 50.7 million in 2009, and the number of staff was 154 in 2008 and 199 in 2009 (ECDC, 2009a, 2010b). This reveals that ECDC was rather a small agency, compared to, for example, EMA whose budget was almost EUR 200 million with 711 staff and European Aviation Safety Agency (EASA) whose budget was about EUR 100 million with 515 staff in 2009 (EMA, 2010; EASA, 2010). Being a small agency entailed both advantages and disadvantages during the pandemic. The biggest advantage was the Centre's flexibility in adjusting the organisational structure and working procedures in accordance with the development of the pandemic. As stated earlier, experts 
from different parts of ECDC were used to working together on a daily basis under the matrix structure and the roundtable meetings, and "internal interoperability" was further strengthened by the Knowledge Management Team in ECDC through writing, editing, and standardising internal procedures (Interviews \#6, \#12; ECDC, 2010b). Additionally, ECDC was able to establish relevant ad hoc groups - e.g., influenza working group - to research the novel virus, and ECDC experts from various backgrounds, also assisted by the Knowledge Management Team, together immediately started producing scientific reports and expert advice. Likewise, when ECDC initiated level 1 or 2 of PHE ${ }^{55}$ which required 12 hour/ 6 day or 24 hour/7 day activities respectively from expert staff in the scientific Units, the Centre was able to adjust its operation promptly.

Moreover, given the small size of ECDC, the scientific areas each expert works on are highly specialised, and the overlap between specialisations is minimal. However, this also means that during a crisis experts in the relevant fields face a sudden increase of workload. In fact, more than $50 \%$ of the ECDC workforce was involved in one way or another in the management of the crisis in 2009, and some staff and experts worked in multiple capacities for prolonged periods of time (ECDC, 2010b). Especially during the level 2 period of PHE, which was described as "ten days of frenzy" with 24 hour/7 day activities, a total staff of 50 worked in three shifts (Greco et al., 2011, p. 23). Although the Centre hired 46 staff members and six trainees in 2009 to cope with the increased workload, a senior expert "reportedly became over-stressed to the point that he was unable to fulfil his duties and was hospitalised" (Greco et al., 2011, p. 24; ECDC, 2010b).

To conclude, experts from different Units and Programmes in ECDC worked with each other and closely cooperated with external experts. Their interactions internally and with external partners were highly frequent. Although ECDC as a small and young agency experienced challenges stemming from the sudden increase of workload during the pandemic, it was able to flexibly adapt to the crisis situation. Also, having prominent experts in relevant fields contributed positively to being able to produce expert advice rapidly. The following section will further analyse the three conditions for influence by focusing on the provision of expert advice by ECDC to the Commission during the formulation stage of the Commission Communication.

\footnotetext{
${ }^{55}$ Level 1 of PHE was activated from 24 to 26 April 2009 and from 9 May 2009 to 18 January 2010. It was raised to the level 2 between 27 April and 8 May 2009. Since 19 January 2010, PHE has remained at level 0.
} 


\subsubsection{Conditions for influence: Provision of expert advice from ECDC to the European} Commission

\section{ACCESS}

As explained in Subsection 3.4.2 which discusses access in the provision dimension, there are three formal ways to access the Commission. EU agencies can provide expert advice when the Commission requests it; when the Commission, based on the formal policy-making procedure, has to receive expert advice from EU agencies before formulating policy proposals; and based on the initiatives of EU agencies themselves when they consider it necessary to bring attention to a certain topic. "Providing scientific advice was the main activity of ECDC during the pandemic year (April 2009 to April 2010)" (Greco et al., 2011, p. 30), and this was done based on requests from the Commission as well as on ECDC's own initiative.

In cases of outbreaks and acute events with potential impact on the EU, there are certain reporting criteria set out by legal provisions. Once an outbreak or an event matching the reporting criteria is notified through the EWRS, the Commission asks ECDC to prepare an assessment report on the situation (Santos-O'Connor et al., 2014). ECDC responds in the form of a scientific opinion that it circulates through the EWRS. During the H1N1 pandemic, the Commission identified a lot of technical and scientific issues that required expert advice in order to make risk management plans. Thus, the requests for scientific advice peaked in 2009 (Economisti Associati, 2014). The Commission sent 22 requests, 12 requests were from the Member States, two were from EU and non-EU international agencies, one from a non-EU country, and six from the general public (ECDC, 2010b). The number of requests that ECDC received in 2009 was exceptionally high when comparing to eight scientific requests in 2008 (Economisti Associati, 2014). When questions were about the evolving nature of the pandemic, the Commission sent the requests directly to the Preparedness and Response Unit which produced rapid risk assessments (Interview \#4). When the Commission had requests for more scientific guidance, sometimes the requests went through the Director or the Chief Scientist who allocated the tasks and assigned specific experts (Interview \#4).

Regarding own initiatives of ECDC, Art. 7 of the Founding Regulation states:

The Centre's mission should be to identify, assess and communicate current and emerging threats to human health from communicable diseases. In the case of outbreaks of illness of unknown origin which may spread within or to the Community, the Centre should be empowered to act on its own initiative until the source of the outbreak is known and then in cooperation with the relevant competent authorities at national or Community level as appropriate. (emphasis added)

In line with this, ECDC made an internal decision to produce a rapid risk assessment the beginning of the pandemic, and updated threat and risk assessments several times as the situation evolved. One good example of own-initiative advice is that on 28 April 2009, ECDC 
delivered recommendations to the Commission and the Member States on policy measures for travellers and their contacts to and from Mexico and the US in order to prevent the virus from spreading in the EU. ECDC also produced other types of scientific documents on a daily and weekly basis (which will be explained further below) on its own initiative, and they were circulated to the Commission as well as to relevant public health authorities both in and outside the EU.

\section{ACTIVITIES}

Just like the contact between ECDC and the Member States, interaction between ECDC and the Commission is organised through the Early Warning and Response System. When the EWRS was established in $1999^{56}$ it was operated by the Commission, but with the establishment of ECDC it was handed over to the Centre. The EWRS is a network ensuring information exchange by bringing ECDC, the Commission, and the competent public health authorities in each Member State into permanent communication. ${ }^{57}$ The access is restricted only to the allowed members including ECDC, the Commission, and the competent authorities of the Member States. Within the Commission, the Directorate General for Health and Consumers (DG SANCO), which is now called the Directorate General for Health and Food Safety (DG SANTE), is responsible for all issues relevant to public health. It is seen as the "parent DG" of ECDC, and its relationship with ECDC was particularly strengthened during the H1N1 pandemic mainly because of their highly frequent and routinised communication via the EWRS (Interview \#3).

In an urgent situation that needs immediate attention, the Commission initiates an EWRS teleconference to support the coordination of risk management at the EU level in close contact with ECDC, WHO, and other stakeholders (Santos-O'Connor et al., 2014). In April 2009, the EWRS teleconference indeed took place, and ECDC and the Commission agreed to establish an ad hoc team to discuss and support the European response (Interview \#8). Moreover, soon after ECDC disseminated its first rapid risk assessment through the EWRS, an urgent teleconference was organised by ECDC together with the Commission and the Member States to discuss the content of this report (Interview \#8), and these members held a daily teleconference via the EWRS during the period of the H1N1 pandemic (Interview \#9). Every day early in the morning, senior experts from ECDC and officials from DG SANCO held regular coordination meetings through a video link, and the frequency of the meetings was only reduced when nearing the end of the pandemic (ECDC, 2010b; Interview \#9). When important issues and emerging threats were detected, ECDC and the Commission had three to five contacts in a day (Interview \#7).

\footnotetext{
${ }^{56}$ The EWRS was established based on Decision No 2119/98/EC of the European Parliament and of the Council of 24 September 1998 setting up a network for the epidemiological surveillance and control of communicable diseases in the Community.

${ }^{57}$ See Art. 2 of the Founding Regulation of ECDC.
} 
Whenever ECDC published threat or risk assessment reports, the agency communicated and debriefed the key information by means of teleconferences jointly organised with the Commission, and the Commission officials considered the overall way of communication with ECDC adequate and effective (Economisti Associati, 2014). In addition, they used several other channels to exchange information, such as emails, audio and video conferences, face-to-face meetings, conferences, specialised workshops, and so on (Interview \#9). When meetings were organised by the Commission, ECDC participated in all meetings and provided technical expertise during the discussion (Interviews \#9, \#10). Moreover, the Commission was always invited to meetings and workshops that ECDC organised in 2009 (Interview \#2). Especially in the areas of preparedness and response to civil disaster, the Commission evaluated the strong network and cooperation between the Commission and ECDC very positively, and a good example was effective and close cooperation between ECDC, DG SANCO, and the Directorate General for European Civil Protection and Humanitarian Aid Operations (DG ECHO) for transport of pharmaceuticals and medical equipment (European Commission, 2011b; Interviews \#4, \#10). When considering broader issues related to the H1N1 pandemic, ECDC also utilised its network with other DGs, such as the Directorate General for Informatics (DG DIGIT) and the Directorate General for Home Affairs (DG HOME) (Interview \#8).

Contact between ECDC and the European Parliament was also made before the Commission issued the Commission Communication. On 4 September 2009, a meeting between the ECDC Director and the Parliament's Committee on the Environment, Public Health and Food Safety took place to exchange views on the pandemic. In addition, the ECDC Director participated in the workshop on the influenza A (H1N1) pandemic which was organised by the European Parliament on 5 October 2010. Participants from ECDC, the European Parliament, the Commission, and WHO shared lessons learned from the pandemic. ${ }^{58}$

\section{RESOURCES}

Resources in the provision dimension refer to the number of scientific documents which contain expert advice of EU agencies. The amount of scientific output by ECDC was high, and this was positive for its influence. From the beginning of the pandemic, ECDC was very active in producing and providing various types of scientific output. According to ECDC's Annual Report for 2009, more than 200 documents were produced during the pandemic period of one year, and between April and December 2009 more than 50 scientific opinions were published, based mainly on requests from the Commission as well as other stakeholders (ECDC, 2010b). The Centre updated the rapid risk assessments, risk assessments, threat assessments, and guidance on a regular basis until the pandemic was over, and these documents were automatically circulated to the Commission and the Member States by ECDC without any requests for them. It was evaluated by the stakeholders including the Commission that "the

\footnotetext{
${ }^{58}$ See http://www.europarl.europa.eu/news/en/headlines/society/20101008ST086172/hearing-on-lessons-ofinfluenza-a-h1n1-pandemic.
} 
series of risk assessments produced by ECDC demonstrated the Centre's significant ability to incorporate new data, provide updates on the evolving picture of the event, and identify key areas of uncertainty" (Greco et al., 2011, p. 26).

Among many types of publications, the highest in quantity was the "Daily Update." Daily Updates included factual information on the number of confirmed cases of H1N1 or deaths within the last 24 hours in the EU as well as outside the EU, assessment of the situation, European response, and other news. Occasionally, they also provided a short list of important documents published by WHO or US CDC as well as the summary of these documents. As the name suggests, they were published daily from 25 April 2009 till 19 January 2010. There was also the "Weekly Executive Update," aiming at informing ECDC's Management Board and key policy-makers on the work of the agency during the crisis. The Centre started producing biweekly (Tuesday and Thursday) webcasts in May 2009 in order to inform about the updated epidemiological situation as well as educational briefings on the novel virus and its implications for public health. In addition, ECDC hosted the online journal Eurosurveillance which closely followed the development of the H1N1 pandemic. The journal published in total 92 articles in 2009, which was more than any other peer-reviewed journal in public health (ECDC, 2010b).

In summary, ECDC accessed the Commission when the Commission requested expert advice - in total 22 times, which represented an exceptionally high number - and also when the Centre produced scientific documents based on its own initiative. The interaction between ECDC and the Commission was remarkably frequent, and the number of scientific outputs by ECDC was very high. All three conditions were favourable to exert influence in the provision dimension.

The next section presents the second case study regarding the influence of ECDC on the Commission proposal on serious cross-border threats to health.

\subsection{Case 2: Commission Proposal for a Decision on Serious Cross-Border Threats to Health}

\subsubsection{Background}

As explained in Section 4.1, the competence of managing and promoting public health mainly belongs to the Member States. But, Art. 168 of the Lisbon Treaty foresees coordination in monitoring, early warning, and combating serious cross-border threats to health. While the EU should not supersede Member States' competence in the field of public health, the Treaty specifies that the EU should complement and support national policies and facilitate cooperation between the Member States. Based on lessons learned from the H1N1 pandemic, the Commission explored a new legislative idea to strengthen the EU's capacities and structures for health security. It held an open stakeholder consultation on health security 
between March and May 2011, and the result showed that most stakeholders were "strongly in favour of having all serious cross-border health threats included in the EU health security policy" (European Commission, 2011a, p. 7). The early versions of the Commission proposal consulted various actors, including the Health Security Committee, and six Member States initiated bilateral meetings with the Commission to address particular issues of concern (European Commission, 2011a).

To better protect the citizens of the EU from a wide range of cross-border health threats and to effectively coordinate responses in the event of a crisis, the Commission introduced the policy proposal ${ }^{59}$ on 8 December 2011 on serious cross-border threats to health. In the proposal, the Commission explains the rationale:

[N]o country can tackle a cross border public health crisis on its own. [...] Recent crossborder events such as the H1N1 pandemic in 2009, the volcanic ash cloud and toxic red sludge in 2010, or the outbreak of E. coli STEC 0104 in 2011, had significant effects on society and demonstrated that none of the impacts of these emergencies can be confined to only one sector. (European Commission, 2011a, p. 2)

The proposal with amendments was adopted after first reading by the European Parliament and the Council and became a Decision - Decision 1082/2013/EU60 - on 22 October 2013. It entered into force on 6 November 2013. This new legislation repealed the previous legal measure ${ }^{61}$ on surveillance and control of communicable diseases because this previous measure addressed threats related to communicable diseases only. The Decision seeks "to support cooperation and coordination between the Member States in order to improve the prevention and control of the spread of severe human diseases across the borders of the Member States, and to combat other serious cross-border threats to health in order to contribute to a high level of public health protection in the Union." 62

Building on lessons learned at the European level from the preceding crises and outbreaks in the public health area, the Decision provides several benefits: ${ }^{63}$

- to extend the existing coordination mechanism for communicable diseases to cover serious cross-border threats to health caused by biological, chemical, and environmental events;

- to strengthen preparedness and response planning capacity for crises;

- to improve risk assessment and management of cross-border health threats;

\footnotetext{
${ }^{59}$ Proposal for a Decision of the European Parliament and of the council on serious cross-border threats to health. $\operatorname{COM}(2011) 866$ final, Brussels, 8.12.2011.

${ }^{60}$ DECISION No 1082/2013/EU of the European Parliament and of the council of 22 October 2013 on serious cross-border threats to health and repealing Decision No 2119/98/EC, OJ L 293/1.

${ }^{61}$ DECISION No. 2119/98/EC of the European Parliament and of the Council of 24 September 1998 setting up a network for the epidemiological surveillance and control of communicable diseases in the Community, OJ L 268 .

${ }^{62}$ Article 1 of Decision No 1082/2013/EU.

${ }^{63}$ See the Commission website:

http://ec.europa.eu/health/preparedness_response/policy/decision/index_en.htm.
} 
- to establish the necessary arrangements for the development and implementation of a joint procurement procedure of medical countermeasures, including vaccines; and

- to enhance the coordination of response at the EU level by formalising the mandate of the Health Security Committee.

This new legislation is seen as "an important step forward in improving health security in the European Union and protecting citizens from a wide range of health threats." ${ }^{64}$ It is a powerful instrument to respond in a coherent way to possible emergency situations in the EU that go beyond communicable disease outbreaks, and to align the EU legal framework on public health emergencies with the International Health Regulation which was developed by WHO in 2005 (Rechel \& McKee, 2014). Likewise, ECDC considered the adoption of the Decision as a crucial development in protecting public health. Even before the proposal was formally adopted by the European Parliament and the Council, ECDC reorganised its structure and established a "new dedicated section (Country Preparedness Support)" in July 2013 "to plan the support to the Commission and Member States for the implementation of the decision on serious cross border threats to health" (ECDC, 2014, p. 6). The Director of ECDC affirmed in the Annual Report for 2013 that "providing the Commission and Member States with technical support in implementing this important new legislation will be a key priority for ECDC in 2014 and beyond" (ECDC, 2014, p. 2).

The following sections present the influence of ECDC on the Commission proposal on serious cross-border threats to health and the analyses of the conditions for ECDC's influence in the production and provision dimensions of expert advice.

\subsubsection{Evidence of ECDC's influence}

As outlined in the research design (see Section 3.3), both text comparison and reputation as scientific authority are analysed in order to assess the influence of ECDC on the Commission proposal on serious cross-border threats to health.

\section{Text Comparison}

In order to conduct text comparison between ECDC expert advice and the Commission proposal, ECDC's scientific documents that contain expert advice were first selected. Since the Commission started the preparation for a broader approach to combat cross-border health threats after the H1N1 pandemic, ECDC's documents from 2010 and 2011 - the period between the end of the H1N1 pandemic and the introduction of the policy proposal - were considered. ECDC's Annual Reports for 2010 and 2011 provide the publication list of scientific

\footnotetext{
${ }^{64}$ See the website of ECDC:

http://ecdc.europa.eu/en/press/news/_layouts/forms/News_DispForm.aspx?List=8db7286c-fe2d-476c-9133$18 f f 4 c b 1 b 568 \& I D=904$.
} 
documents in each year, thus the documents discussing cross-border health threats in general and those relevant to specific topics included in the Commission proposal were selected from these lists. In total, 10 scientific documents ${ }^{65}$ from ECDC were compared to the Commission proposal.

It should be noted that besides scientific documents, ECDC also produced scientific opinions as a response to requests from the Commission. When explaining the steps leading to the introduction of the policy proposal on cross-border threats to health, the Commission stated that ECDC "provided useful input as regards the scientific risk assessment issues" (European Commission, 2011a, p. 8). In fact, this input could come from both scientific documents and scientific opinions of the Centre. Whereas scientific documents can be downloaded from the website of ECDC, scientific opinions are not publicly accessible without explicit reasons. A written request was sent to ECDC to gain access to scientific opinions from 2010 and 2011. Unfortunately, scientific opinions were not provided; instead, ECDC referred to a section on the website of the European Parliament ${ }^{66}$ where thousands of written and oral questions from the members of the European Parliament could be found. When questions concern scientific matters of European policies, they are usually forwarded to appropriate bodies with expertise, such as EU agencies, "through the Commission." 67 Even though questions sent to ECDC were indeed available here, they could not be analysed for this research because they were the questions of the European Parliament sent through the Commission and not those that originated from the Commission in preparation for the policy proposal. Since scientific opinions which were produced based on the Commission's requests were not accessible, ${ }^{68}$ the selected scientific documents of ECDC were used for the text comparison.

In line with the research design (see Subsection 3.7.4) and the first case study of ECDC, WCopyFind was used to detect overlapping phrases, sentences, or paragraphs between 10 scientific documents from ECDC and the policy proposal from the Commission. The result of WCopyFind showed that there was no match between the Commission proposal and any of the documents from ECDC. This also means that the Commission did not make any quotations from and references to the ECDC documents. Therefore, it can be concluded that ECDC exerted a low level of influence on the formulation of the Commission proposal.

The Commission proposal was further examined to investigate whether the Commission referred to any other documents from ECDC, and whether and how ECDC itself was mentioned. In the Commission proposal, which is 64 pages in length, no reference to any other ECDC

\footnotetext{
${ }^{65}$ See Appendix 2 for the complete list of the 10 documents analysed for text comparison.

${ }^{66}$ http://www.europarl.europa.eu/plenary/en/parliamentary-questions.html.

${ }^{67}$ Egeberg et al. (2015, p. 622) argue that EU agencies have a "less intimate relationship" with the European Parliament (compared to their close relationship with the Commission) because the European Parliament "does not have the right to address 'parliament questions' directly to agencies." Written answers from EU agencies are sent to the European Parliament also via the Commission.

${ }^{68}$ It seems that ECDC does not keep an accurate and detailed record of scientific opinions because it does not distinguish between written questions originated from the Commission and those initially originated from the European Parliament (but sent through the Commission). This point is discussed further in relation to limitations of this research in Chapter 7 "Conclusion."
} 
documents was found. When explaining the H1N1 pandemic as an example of cross-border threats to health, the Commission provides a link in a footnote to the ECDC website where all evaluation reports on the H1N1 pandemic can be found. However, the evaluation documents from the link were not produced to advise on the Commission proposal and thus are not related to the proposal. Moreover, ECDC appears in 17 paragraphs in the Commission proposal, but all of them speak of ECDC in the context of the role of ECDC in general. Some examples are: "[...] with scientific support from specialised agencies and organisations such as the ECDC or EMA to provide a basis for comparison and consistency [...]"; "Close cooperation between DG ECHO, DG SANCO, backed up by ECDC, in preparedness and response to civil disasters is ongoing [...]"; and "The budget will be implemented by centralised direct management, though parts of the implementation tasks might be delegated to the ECDC" (European Commission, 2011a, pp. 35-46). These statements do not indicate expert advice from ECDC as policy input.

Although the Commission proposal on serious cross-border threats to health is a least-likely case of ECDC's influence, the weak evidence of ECDC's influence on the formulation of the Commission proposal is somewhat surprising when considering interview responses from ECDC's experts. One senior expert from ECDC explained that ECDC "gave comments on more or less all Articles" when the Commission was formulating the proposal; and particularly with regard to Article 4 on the preparedness and response planning, ECDC was asked by the Commission to provide advice and comments in the early drafting stage (Interviews \#4, \#8). There were "a number of the early drafts on which ECDC had teleconferences, commented, sent back some information and data, and gave the agency's technical view" (Interviews \#4, \#6). Nevertheless, the Commission's proposal does not show any sign of ECDC's input on this topic.

The Commission proposal is accompanied by two technical documents entitled "Commission Staff Working Paper - Impact Assessment" and "Commission Staff Working Paper - Executive Summary of the Impact Assessment." In the impact assessment, which has 134 pages, ECDC appears several times. As in the case above, however, ECDC is referred to in relation to its mandate in public health. There are three references to the scientific documents produced by ECDC in footnotes, with direct links to the ECDC website. Again, these documents are not expert advice aimed at assisting the preparation of the Commission proposal on cross-border threats to health. Rather, they are the documents from 2009 on the H1N1 pandemic.

Nevertheless, it is worth noting that after the proposal was formally introduced by the Commission and adopted by the European Parliament and the Council of the European Union, the Commission had to produce several technical and supporting documents in order to facilitate the implementation of this legislation by the Member States. One such example is the Commission Implementing Decision ${ }^{69}$ about case definitions for reporting communicable

\footnotetext{
${ }^{69}$ Commission Implementing Decision 2012/506/EU of 8 August 2012 amending Decision 2002/253/EC laying down case definitions for reporting communicable diseases to the Community network under Decision No 2119/98/EC of the European Parliament and of the Council, OJ L 262/1; 27.9.2012.
} 
diseases to the Community network. Another is the templates produced by the Commission in order to harmonise the reporting process and elements regarding the status of preparedness in each Member State. On these technical pieces ECDC exerted influence because the Centre was involved in a lot of informal consultations with the Commission as well as the Commission's working groups, and expert advice from ECDC was strongly reflected (Interviews \#4, \#7).

\section{Reputation}

As for the second indicator of influence, ECDC's reputation as scientific authority, ECDC had a good reputation at the time when the Commission proposal was introduced. According to the evaluation report which reviewed ECDC's activities between 2008 and 2012, "ECDC scientific reputation has constantly been increasing over time and has now consolidated at quite high levels in the peer community of public health officers across Europe and among public health experts in general" (Economisti Associati, 2014, p. 44). Moreover, the Centre's scientific products in all areas (even in more controversial areas such as health communication) are of good quality (Economisti Associati, 2014; Interview \#14). Over $80 \%$ of respondents at the Member State level agree that "ECDC has managed to become a centre of scientific excellence and technical leadership and a prime repository for scientific advice on infectious diseases" (Economisti Associati, 2014, p. 44).

ECDC experts' own evaluation of its reputation is also positive. The Centre's Annual Report for 2011 states that "ECDC has been working on becoming a 'one-stop shop' for relevant published scientific studies/reports as well as internally produced scientific advice" (ECDC, 2012, p. 22). Its experts generally believe that the Centre's influence on technical issues is growing ${ }^{70}$ and that ECDC is becoming a more important and visible actor (Interviews \#3, \#7, $\# 8$ ). They hold the view that their expert advice is trusted and is given quite serious consideration by various users, because ECDC provides high quality information and scientific assessments. One expert from ECDC even expresses that "[s]ometimes the Commission trusts our outputs more than we trust them" (Interview \#3). Although ECDC sometimes feels that big Member States, such as Germany, the UK, and France, do not necessarily look carefully at what the Centre delivers as they have their own scientific institutions that provide advice to their government (Interview \#3), one senior expert from ECDC stresses:

More and more, we get the signals from the Commission and the Member States that they trust us. They trust what we say, and they are confident about our advice and our guidance. I cannot say for sure to what extent that is also translated into policies that

\footnotetext{
${ }^{70}$ One expert from ECDC, however, states that on policy proposals which require political consideration, ECDC has "limited influence or its influence is close to zero" as the Centre does not have any legislative power and its expert advice is recommendation without binding effect (Interview \#3).
} 
are developed in the Member States according to our assessment and statement. But, I guess it's going in the right direction. (Interview \#7)

Likewise, the Commission's perception on ECDC's influence and reputation as a scientific authority is positive. The Commission, in general, relies on the capacity of ECDC in providing sound and independent scientific advice, and ECDC's advice is requested repeatedly (Interviews \#9, \#10). By highlighting the increasing number of scientific requests from the EU institutions, mainly from the Commission, some experts from ECDC claim that ECDC's scientific authority is high (Interviews \#2, \#3, \#4). Normally, ECDC receives between two to five requests per week from the Commission, but if certain issues are arising in public health, there can be as many as six requests from the Commission in one week - and usually no requests during the period of summer holidays (Interview \#3).

Overall, evidence of ECDC's influence on the Commission proposal is mixed. The text comparison between the Commission proposal and ECDC's scientific documents reveals a low level of influence. Yet, the self and peer evaluations on ECDC as a scientific authority are good. The Commission and the Member States view that ECDC is a reliable and credible source of information on technical matters. The section below focuses on the production dimension of expert advice in ECDC and analyses the three conditions - access, activities, and resources that affect ECDC's influence.

\subsubsection{Conditions for influence: Production of expert advice in ECDC}

\section{ACCESS}

Suvarierol et al. (2013) argue that EU agencies heavily rely on networks of scientific and technical experts in order to carry out their tasks, and some agencies have networks extending to several thousands. In fact, the number of networks that ECDC has established internally and with external partners is high, and one ECDC expert describes ECDC as "really a networking agency" (Interview \#4). Within ECDC, it is a routinised working practice that experts from different parts of the organisation work together on a daily basis to manage scientific projects and produce scientific documents (Interviews \#6, \#8). This informal network under the matrix structure is seen as a "hidden structure" of the Centre for producing expert advice (Interview \#3). In 2010, the procedure for developing scientific advice involved expert panels with different expertise. Experts in these panels discussed systematic literature reviews and synthesised results before drawing conclusions. External experts were invited to the panels if desired, but for rapid risk assessments in-house experts carried out all tasks in ECDC (ECDC, 2011). "This approach has proved valuable and has increased the transparency and robustness of scientific advice given by ECDC" (ECDC, 2011, p. 23). In addition, an internal procedure for priority setting and responding to requests for expert advice was updated in 2010. A computer system was implemented to log requests for and keep track of scientific advice (ECDC, 2011). 
The Founding Regulation of ECDC recognises the importance of networking with the Member States in order to ensure the highest level of expertise in the Centre. It is stated: "The Centre should seek to maintain scientific excellence at all times through its own expertise and the expertise in the Member States [...]." 71 Furthermore, Article 5 of the Founding Regulation states that "[t]he Centre, through the operation of the dedicated surveillance networks and the provision of technical and scientific expertise to the Commission and Member States, shall support the networking activities of the competent bodies recognized by the Member States." As explained in the first case presented in this chapter, a big part of the networks with the Member States - and one of the very important ways to improve ECDC's ability to collect data and strengthen expertise - has been the training programmes that ECDC organises. On the topic of cross-border health threats, what is relevant is the European Programme for Intervention Epidemiology Training (EPIET). This programme is offered to health scientists and experts - mostly at the junior level - from the Member States. The main objective is to provide expertise in response to activities and to strengthen the surveillance and control of infectious diseases and other cross-border health threats or issues of public health concern inside and beyond the EU. ${ }^{72}$ Similar to the previous analysis on the H1N1 pandemic, the added value of the training programmes, in terms of their contribution to ECDC's scientific output, is the creation of a broad network between trainees, trainers, and ECDC experts. Previous trainees, after many years, become senior experts with a high level of expertise in their specific field and are registered in ECDC's database as external experts who can be contacted for scientific work and input. Some of them come back to the Centre as EPIET trainers.

One senior expert from ECDC described how EPIET created a network among experts and how ECDC has benefitted from it:

Let's say for our one-week training activities we invite seven or ten senior experts from different countries as teachers. They are not full-time teachers. They are experts in their specialised area of expertise, and teaching is what they do because they have reached this high level of expertise. When ten high level experts are put together for a week, they start to share their experiences, problems they struggle with, or questions they have. And they give each other answers, so you create this added value by putting them together as teachers for the one-week training course. It is highly appreciated [by them], and it allows for a lot of personal and informal contacts. If someone has a problem, he calls other experts in the network, and they try to help because it is the spirit that they want to keep in the network. [...] ECDC also ask the experts in the network to contribute to risk assessments or the development of training materials [...] and they work on it with their own budget and resources. [...] The idea is that the entire network benefits from each other, and that's the true network experience. (Interview \#5)

\footnotetext{
${ }^{71}$ See recital 10 in the preamble of the Founding Regulation of ECDC.

72 See the website of ECDC: https://ecdc.europa.eu/en/epiet-euphem/about/intro.
} 
Since 2011, moreover, ECDC has developed a database of external experts with specialised expertise. It is called a "Candidate Expert Directory" and experts submit an application to be on the roster of potential experts who could be asked to participate in the work of ECDC on the basis of their specific competence. These experts are usually selected for ECDC's scientific panels and assist the Centre in production of expert advice to support policy-makers and risk managers in the EU. ${ }^{73}$ In addition, in 2011 ECDC was one of the founding members of the network for EU agencies - which is officially called the EU Agencies Network (EUAN) (Interview \#1). ECDC also signed an "Agreement on Strategic Cooperation" with the European Police Office (EUROPOL) in October 2011 to improve preparedness against biological attacks, which were designated as one type of the cross-border threats to health in the Commission proposal. However, there is no clear evidence that ECDC cooperated with the Member States, EUROPOL, or any other EU agencies with the specific purpose of producing expert advice on the topics discussed in the Commission proposal.

The same is observed with regard to the network between ECDC and WHO. Both parties signed an administrative agreement in March 2011 to support their collaboration at a technical level on the areas of HIV, tuberculosis, influenza, antimicrobial resistance, preparedness, and outbreak, which fall in the category of serious cross-border threats to health (ECDC, 2012). Furthermore, they jointly organised a series of regional workshops on pandemic preparedness between one and three months before the Commission introduced the policy proposal. Nevertheless, there is no evidence that ECDC produced expert advice on the basis of joint effort between ECDC and WHO.

\section{ACTIVITIES}

All interviewees from ECDC pointed out that ECDC staff and experts have maintained close and frequent contact with each other. Daily roundtable meetings (which were mentioned in the first case study in this chapter) as well as expert panels and the matrix structure of the Centre facilitate their frequent interaction. This approach also contributes to "getting work done smoother and faster because people know who is responsible for what and whom to address" (Interview \#1).

With regard to contact between ECDC and partners outside the Centre, ECDC's experts are well acquainted with the front-line of research in all areas of communicable disease control, and they actively participate in all key scientific conferences and meetings. Through these activities, they are able to network with experts and scientists who work in diverse fields and levels, thereby accessing what is described as an "inventory of resources" (Interview \#4). Additionally, ECDC developed its networks with the Member States and WHO many years before the Commission introduced the policy proposal, and has remained in close and regular

\footnotetext{
${ }^{73}$ See the website of ECDC: https://ecdc.europa.eu/en/about-us/work-us/external-experts.
} 
contact. Nevertheless, there is no evidence of explicit activities of ECDC with external partners in relation to the production of expert advice on the Commission proposal.

\section{RESOURCES}

In 2010 and 2011, ECDC had five to six years of experience. ECDC's budget in 2010 was EUR 57.8 million and EUR 56.6 million in 2011, and the number of staff including temporary and contract agents and seconded national experts was 254 in 2010 and 270 in 2011 (ECDC, 2012). These two years were a transitional period for ECDC. It was nearing its maximum size in terms of staffing and budget, and by the end of 2010 the era of expansion was over (ECDC, 2011). Then, 2011 was "a period of consolidation" and "a new era of limited resources" according to the Director of ECDC (ECDC, 2011, p. 3). The limited resources of ECDC become apparent when compared to the resources of some of its counterparts at the Member State level. For example, the coordinating competent authority of Belgium - Sciensano - has about 700 staff $^{74}$ while ECDC has less than 300. Despite its limited budget and number of experts, a major strength of ECDC was that its experts were widely recognised for their high expertise, as shown by its good reputation. EU agencies generally seek to hire individuals who possess specialist knowledge and scientific expertise in a particular field, rather than those who are well versed in the institutions and policies of the EU and committed to the European project (Suvarierol et al., 2013). Indeed, experts in ECDC and those applying for a post from all over Europe have a profile showcasing "high expertise" and are "very ambitious" (Interviews \#4, \#7). Thus, "[t]he scientific quality of ECDC work in [the field of early warning, preparedness, and response to health threats] is well recognised and the best expertise available are employed" (Economisti Associati, 2014, p. 75).

However, the production of expert advice in 2010 and 2011 on the Commission proposal did not completely benefit from prominent experts and the high level of expertise in ECDC. There were two reasons. First, ECDC was continuously experiencing difficulty in retaining staff and experts in the Centre. Under a newly elected Director in 2010, the organisation of ECDC was restructured to reallocate staff to a new Unit called the Office of the Chief Scientist and also to overcome the challenge of "some notable turnover among staff, which appears on the high range when compared to similar European agencies, although possibly on a slightly declining trend" (Economisti Associati, 2014, p. 118). One senior expert from ECDC elaborates:

Stockholm is a nice place to live but at the same time, it seems that people moved to Stockholm often find it difficult to mingle in the society. [...] And the location [of Stockholm] and weather here are maybe not so favourable [to the issue of staff turnover]. (Interview \#4)

Second, ECDC was occupied with other priorities. In 2010, ECDC was undergoing a major reorganisation and as part of its effort, the new Director established 15 working groups to

\footnotetext{
${ }^{74}$ See the website of Sciensano: https://www.sciensano.be/en/about-sciensano/sciensano-figures.
} 
investigate critical areas for improvement (ECDC, 2011). Moreover, ECDC devoted a huge amount of its resources to several outbreaks in 2011 - the Shiga-toxin-producing E. coli outbreak in Germany from May till July, outbreaks of malaria and West Nile virus in Greece, and the cholera outbreak in Haiti (ECDC, 2012). The Director of ECDC noted that "having to respond to an emergency while still bedding down a reorganisation put considerable pressure on the experts, managers and administrators involved" (ECDC, 2012, p. 3).

In summary, the analysis on the production dimension of expert advice reveals that ECDC, in 2010 and 2011, had a strong internal network and the new internal procedure of developing expert advice could add value to the production dimension. While its networks with the Member States, EU agencies, and WHO were established and maintained with regular contact, there was no evidence that ECDC utilised these networks to produce expert advice on the Commission proposal. Although ECDC had a high level of expertise, its limited resources, the challenge of staff turnover, and other priorities did not contribute positively to the production of expert advice on the Commission proposal. The section below will analyse the three conditions for influence in the provision dimension of expert advice to the Commission.

\subsubsection{Conditions for influence: Provision of expert advice from ECDC to the European}

\section{Commission}

\section{ACCESS}

Out of the three ways to access the Commission in the provision dimension of expert advice by request from the Commission, agency's own initiatives, and procedural requirement that the Commission has to receive agency input before drafting proposals - only one was utilised. ECDC provided expert advice on technical matters of the proposal upon request from the Commission. Indeed, given the fact that the scope of the proposal goes beyond the areas of ECDC's mandate, such as chemical and environmental threats and biotoxins, the Commission also reached out to EMA and the Consumers, Health, Agriculture and Food Executive Agency (CHAFEA) as well as numerous stakeholders, such as the pharmaceutical industry, nongovernmental organisations, and national authorities (Interview \#9).

While the interviewees from both ECDC and the Commission, as well as the Commission proposal itself, confirm that the Commission did ask for expert advice from ECDC when formulating the policy proposal, the exact number of the requests could not be verified by ECDC's Annual Reports for 2010 and 2011 or by the Commission officials who were interviewed. Instead, the interviewees from both organisations stress that beside the Commission's formal requests and subsequent responses on the part of ECDC with expert advice, there were a lot of "informal" consultations between ECDC and the Commission without any written documents (Interviews \#1, \#2, \#4, \#9). Nevertheless, what is interesting to point out is that the Annual Reports for 2010 and 2011 make no mention of the Commission's preparation for the proposal on serious cross-border threats to health and 
ECDC's provision of exert advice in a written or informal manner. The only statement that comes closest to indicating ECDC's input to the Commission proposal is: "Three joint pandemic preparedness workshops held with the WHO Regional Office for Europe leading towards the development of new indicators on preparedness, which would contribute to the Commission's initiative on health security" (ECDC, 2012, p. 15).

The fact that the Annual Reports of ECDC do not specify the details of its expert advice on the Commission proposal might have been because ECDC received quite a small number of requests from the Commission, or because the Commission proposal itself was not one of the priority topics for ECDC. Be that as it may, the case not being mentioned in the Annual Reports is very different from what was observed in the first case on the H1N1 pandemic, in which ECDC clearly stated in its Annual Report for 2009 that it provided expert advice to the Commission and even specified how many requests it received from the Commission.

\section{ACTIVITIES}

In general, ECDC is in contact with the Commission on a regular basis. The Director of ECDC and the Deputy Director General of DG SANCO engage in a "structured monthly exchange" via video conferences to discuss general coordination and international issues (Interview \#3; ECDC, 2012). Between seven and eight senior experts - usually from the Disease Programmes in ECDC - as well as the heads of the Health Threats Unit and the Health Law and International Unit from DG SANCO participate in the meetings (Interview \#10). These monthly coordination meetings "ensure close cooperation and enable ECDC to respond effectively to requests for assistance" (ECA, 2016, p. 64). Likewise, several technical sections in ECDC also have regular links with their counterparts at DG SANCO (ECDC, 2012). For example, experts from the Scientific Assessment Section in ECDC remain in communication with the Commission on a daily basis via telephone and email (Interview \#8). Experts from the Disease Programmes also talk to officials in DG SANCO to gather information on the Commission's view and understanding of expert advice from ECDC and on the agenda and priority of the Commission for upcoming months (Interview \#3). Moreover, ECDC experts meet in person with the Commission officials every three months in the Advisory Forum meetings. In addition, once a year ECDC invites some Commission officials to at least one of the workshops organised by the Centre on topics intended to bring public health scientists and policy-makers closer together (Interview \#5).

However, when it comes to the preparation of the Commission proposal on serious crossborder health threats, this kind of regular contact did not occur between ECDC and DG SANCO. Contact between them was made "as required" (Interviews \#9, \#10). They communicated mainly by telephone and exchanged documents via email (Interview \#9). Their contact became more frequent only after the proposal was adopted in October 2013. The Country Preparedness and Support Section, which was created in ECDC to support the implementation 
of this legislation, worked closely with the Health Threat Unit within DG SANCO as the main contact point and maintained close cooperation and daily contact (Interview \#4).

\section{RESOURCES}

The amount of scientific output is considered as an indicator for the resources in the provision dimension. The Centre issued 35 scientific publications in 2010 and 122 in 2011 (ECDC, 2011, 2012). In terms of scientific opinions, 20 in 2010 and 27 in 2011 were produced by ECDC based on stakeholders' requests (ECDC, 2011, 2012). Compared to more than 50 scientific opinions produced based on requests in 2009, ECDC produced less scientific opinions in 2010 and 2011. These documents, as well as daily and weekly newsletters and risk assessment output, were circulated to the Commission and the Member States without request, and this is considered as a "service function" of ECDC (Interview, \#3).

Although there was a high volume of scientific output in general, only 10 documents were directly related to the topics covered by the Commission proposal (and therefore, as explained in the beginning of this section, these 10 documents were analysed to assess the level of ECDC's influence on the Commission proposal on serious cross-border threats to health). Considering that the 10 documents were produced in two years, the resources were limited in the provision dimension.

To sum up, this section showed that the three conditions were not favourable to the influence of ECDC in the policy formulation stage. ECDC provided expert advice to the Commission only when it was requested, although there were a lot of informal consultations between them. While ECDC and the Commission maintained regular contact in general, their interaction aiming at discussing the Commission proposal was not frequent. Moreover, ECDC published a limited amount of scientific output related to the Commission proposal.

\subsection{Conclusion}

This chapter analysed the influence of ECDC on the Commission Communication on the H1N1 pandemic (Case 1 ) and on the Commission proposal for a decision on serious cross-border threats to health (Case 2). Table 4.3 below presents the summary of each case analysis. 
Table 4.3) A comparative look at ECDC influence and influence conditions in two cases

\begin{tabular}{|l|l|l|l|l|l|}
\hline \multicolumn{2}{|l|}{} & \multicolumn{2}{|l|}{ CASE 1 } & \multicolumn{2}{|l|}{ CASE 2 } \\
\hline \multirow{2}{*}{ Influence } & Text comparison & \multicolumn{2}{|c|}{ Moderate } & \multicolumn{2}{|c|}{ Low } \\
\cline { 2 - 6 } & Reputation & \multicolumn{2}{|c|}{ Very good } & \multicolumn{2}{|c|}{ Good } \\
\hline Conditions: & $\begin{array}{l}\text { Production } \\
\text { dimension }\end{array}$ & $\begin{array}{l}\text { Provision } \\
\text { dimension }\end{array}$ & $\begin{array}{l}\text { Production } \\
\text { dimension }\end{array}$ & $\begin{array}{l}\text { Provision } \\
\text { dimension }\end{array}$ \\
\hline Access & $\begin{array}{l}\text { Internal and } \\
\text { external } \\
\text { networks }\end{array}$ & $\begin{array}{l}\text { Both by } \\
\text { request and } \\
\text { by own } \\
\text { initiative }\end{array}$ & $\begin{array}{l}\text { Internal } \\
\text { network }\end{array}$ & $\begin{array}{l}\text { Only by } \\
\text { request }\end{array}$ \\
\hline Activities & $\begin{array}{l}\text { Frequent } \\
\text { and regular }\end{array}$ & $\begin{array}{l}\text { Frequent } \\
\text { and regular }\end{array}$ & $\begin{array}{l}\text { Frequent } \\
\text { and regular } \\
\text { (only } \\
\text { internally) }\end{array}$ & $\begin{array}{l}\text { Not } \\
\text { frequent } \\
\text { and not } \\
\text { regular }\end{array}$ \\
\hline Resources & Limited & Sufficient & Limited & Limited \\
\hline
\end{tabular}

(Source: Author's own compilation)

ECDC exerted a moderate level of influence on the Commission Communication on the H1N1 pandemic, but its influence was low on the Commission proposal for cross-border threats to health. ECDC's reputation as scientific authority was good in general; and particularly during the pandemic in 2009, its reputation was very good and ECDC was considered as an essential body for risk assessments and scientific expertise.

In the first case, the budget and the number of experts in ECDC were limited compared to the scale of the pandemic and the high number of requests for scientific advice coming from the Commission. Although the limited number of experts and the intensity and urgency of the crisis posed some challenges to the young agency, ECDC produced an extraordinary amount of scientific output mainly based on the effective utilisation of various networks with in-house as well as external experts. ECDC provided expert advice both at the request of the Commission and on its own initiative. The frequency of activities in both dimensions was very high - mostly on a daily basis through various channels of communication.

The picture is somewhat different in the second case. Although the size of ECDC's budget and the number of staff were increased, the resources were still limited and not fully employed for the production of expert advice on the Commission proposal. In order to produce expert advice, ECDC utilised its networks, but the difference to the first case is that collaboration remained on a daily basis among in-house experts rather than between ECDC and external experts. When the Commission was preparing the proposal, ECDC provided expert advice based on requests from the Commission and was involved in informal consultations. But the volume of scientific output by ECDC on the topics of the Commission proposal was limited. 
Contacts between ECDC and the Commission were made whenever necessary but were not as frequent and intense as in the first case.

What is particularly noticeable when comparing the two cases is a variation in the provision dimension. All three conditions in this dimension contributed positively to the influence of ECDC in the first case while all of them were not favourable to ECDC's influence in the second case. At this point, though, the interpretation should be carefully made. While it is the finding of this chapter that what happens in the provision dimension is more important than in the production dimension in order to exert influence, which of the three conditions - or all together - is actually at work cannot be determined.

The next chapter will analyse influence of the European Chemicals Agency with two cases, and the findings from the analyses of ECDC and ECHA will be compared in Chapter 6. 
Chapter 5

European Chemicals Agency 


\subsection{Introduction}

Chemicals are everywhere in our daily lives. We come into contact with them without realising it. They bring us quality of life, but at the same time pose safety concerns. While modern society is entirely dependent on the benefits of chemicals, certain chemicals have caused serious damage to human health and the environment. Asbestos is known to cause lung cancer and mesothelioma, and benzene leads to leukaemia. Consequently, some chemicals have been totally banned or subjected to other controls (European Commission, 2001). In the EU, several legal measures have been implemented to regulate chemicals. Among others, an extensive regulatory system called REACH (Registration, Evaluation, Authorisation and Restriction of Chemicals), which entered into force on 1 June 2007, is now the most well-known one. It is designed to control and manage old and new chemical substances. On the basis of the REACH regulation, ${ }^{75}$ the European Chemicals Agency was set up in Helsinki, Finland.

Article 77 of the REACH regulation defines the main task of the Agency:

[It] shall provide the Member States and the institutions of the Community with the best possible scientific and technical advice on questions relating to chemicals which fall within its remit and which are referred to it in accordance with the provisions of this Regulation.

In 2007, the Agency began its operation with 37 seconded European Commission officials and by the end of the first year, the number of staff had increased to 102 (ECHA, 2012b). They focused mainly on the first step of the REACH framework, which was the pre-registration process. The remit of ECHA has expanded two times: first in 2008 with the adoption of Regulation (EC) No 1272/2008 on the Classification, Labelling and Packaging of substances and mixtures (hereafter "CLP Regulation"), ${ }^{76}$ and second in 2012 with the adoption of the Biocides Regulation ${ }^{77}$ as well as the Prior Informed Consent (PIC) Regulation. ${ }^{78}$ These four regulations - REACH, CLP, Biocides, and PIC - have been the legal mandates for ECHA under the "common aim of protecting human health and the environment from the most hazardous chemicals" (ECHA, 2016a, p. 8). At the moment, ECHA is fully self-financed for its activities under the REACH and CLP Regulations because of fee income, but its activities under the other two regulations are financed by both EU subsidy and fee income.

\footnotetext{
75 REGULATION (EC) No 1907/2006 OF THE EUROPEAN PARLIAMENT AND OF THE COUNCIL of 18 December 2006 concerning the Registration, Evaluation, Authorisation and Restriction of Chemicals (REACH), establishing a European Chemicals Agency, amending Directive 1999/45/EC and repealing Council Regulation (EEC) No 793/93 and Commission Regulation (EC) No 1488/94 as well as Council Directive 76/769/EEC and Commission Directives 91/155/EEC, 93/67/EEC, 93/105/EC and 2000/21/EC, OJ L 396, 30.12.2006.

${ }^{76}$ REGULATION (EC) No 1272/2008 OF THE EUROPEAN PARLIAMENT AND OF THE COUNCIL of 16 December 2008 on classification, labelling and packaging of substances and mixtures, amending and repealing Directives 67/548/EEC and 1999/45/EC, and amending Regulation (EC) No 1907/2006, OJ L 353/1, 31.12.2008.

${ }^{77}$ REGULATION (EU) No 528/2012 of the European Parliament and of the Council of 22 May 2012 concerning the making available on the market and use of biocidal products, OJ L 167, 27.6.2012.

${ }^{78}$ REGULATION (EU) No 649/2012 OF THE EUROPEAN PARLIAMENT AND OF THE COUNCIL of 4 July 2012 concerning the export and import of hazardous chemicals, OJ L 201/60, 27.7.2012.
} 
In terms of the organisational structure, there are four Committees in ECHA that prepare scientific opinions. They are the Member State Committee, the Risk Assessment Committee, the Committee for Socio-economic Analysis, and the Biocidal Products Committee. There is a network called "Forum" for authorities responsible for the enforcement of the REACH, CLP, and PIC regulations. In order to decide on appeals against certain decisions taken by ECHA under the REACH and Biocides regulations, the Board of Appeal exists as part of the Agency but takes decisions independently. ${ }^{79}$ The Management Board is the governing body of ECHA. The Board is composed of 28 members from the EU Member States, six representatives of the Commission, two representatives appointed by the European Parliament, and one observer each from Iceland, Liechtenstein, and Norway ${ }^{80}$. Due to the subject matters handled by ECHA, three out of the six representatives from the Commission are sent from three different Directorates-General, namely DG Health and Food Safety (DG SANTE), DG Internal Market, Industry, Entrepreneurship and SMEs (DG GROW) and DG Environment. The representatives are from either the Deputy Director-General or the Director level and have voting rights. Three other individuals appointed by the Commission are high-ranking members from Europeanlevel associations for the chemicals industry and trade unions as well as from a consultancy for environmental and energy policies. They represent interested parties and have no voting rights in the Management Board.

The Executive Director is the legal representative of the Agency. Under the Executive Director, there are seven Directorates, which are Cooperation, Regulatory Affairs, Registration, Risk Management, Evaluation, Information Systems, and Resources. Each Directorate has two or three Units. With 564 staff at the end of 2016, ECHA has become one of the biggest EU agencies (ECHA, 2017a).

Out of the four legal mandates of ECHA explained above, this research is concerned solely with ECHA's role, activities, and influence in relation to REGULATION (EU) No 528/2012 concerning the making available on the market and the use of biocidal products (hereafter "BPR"). In line with the research design (see Chapter 3), the influence of ECHA is analysed through two case studies. The first case explores ECHA's influence on the Commission proposal for BPR, ${ }^{81}$ which was introduced in June 2009 . This is a least-likely case for ECHA, as it touches upon broad issues, including specific technical matters and policy directions, in one proposal (see Subsection 3.7.1). This proposal was adopted in May 2012, and under BPR, ECHA was given a new task of assessing applications for the approval of active substances and for the Union authorisation of biocidal products. The second case focuses on the influence of ECHA with respect to this task. Based on the opinions of ECHA, the Commission takes its decisions on active substances and biocidal products. The second case is more technical in nature and is a most-likely case for ECHA.

\footnotetext{
${ }^{79}$ See https://echa.europa.eu/about-us/who-we-are/board-of-appeal/the-board-of-appeal.

${ }^{80}$ See https://echa.europa.eu/about-us/who-we-are/management-board.

${ }^{81}$ Proposal for a REGULATION OF THE EUROPEAN PARLIAMENT AND OF THE COUNCIL concerning the placing on the market and use of biocidal products, $\operatorname{COM(2009)} 267$ final, Brussels, 12.6.2009.
} 
To facilitate comparison, the structure of this chapter follows the structure of the previous chapter on ECDC. Section 5.2 investigates ECHA's influence on the first case, which is the Commission proposal for BPR in 2009, and Section 5.3 assesses the influence of ECHA on the second case, the Commission's implementing acts on the approval of individual active substances under BPR. Each of these two sections is divided into four parts. The first part offers background information on the case, and the second part assesses influence of ECHA. After that, analysis of the three conditions (access, activities, and resources) follows in two dimensions - first in the production dimension of expert advice and then the provision dimension. By comparing the two cases, Section 5.4 concludes that ECHA effectively utilised its internal and external networks to overcome its challenge of limited resources, and that it was able to exert moderate and high influence in the first and second case respectively. Frequent and regular interactions with the network partners contribute to the influence of ECHA and, in particular, the secured involvement of ECHA in the authorisation process in the second case is essential for the high influence of the Agency.

\subsection{Case 1: Commission Proposal for a Regulation of Biocidal Products}

\subsubsection{Background}

Biocidal products are intended to destroy or control harmful or unwanted organisms (such as viruses, bacteria, fungi, insects, or vertebrate animals) that have detrimental effects on the environment, on animals, on humans, on humans' activities, or on the products they use or produce (European Commission, 2016). Under the current EU regulation on biocidal products, such products are classified into four large groups: disinfectants, preservatives, pest control, and other biocidal products. These four groups are more specifically divided into 22 different product types (PTs). ${ }^{82}$ For instance, human hygiene (PT 1) and drinking water (PT 5) belong to disinfectants; wood preservatives (PT 8) and working or cutting fluid preservatives (PT 13) are under preservatives; and rodenticides (PT 14) and antifouling products (PT 21) are examples of pest control and other biocidal products respectively.

Biocidal products are essential to protect public health and hygiene because disinfectants and insecticides, for instance, help control various diseases such as malaria, dengue fever, Zika, salmonellosis, and so on (European Commission, 2016). At the same time, they also come with risks inherent to chemicals themselves as well as risks related to how they are used. Especially when biocidal products are used not only by industry and professionals but also by the general public, their safety, usage, and movement in the EU internal market need to be effectively

\footnotetext{
${ }^{82}$ For a comprehensive description of biocidal product types, see ECHA website: https://echa.europa.eu/regulations/biocidal-products-regulation/product-types.
} 
regulated. To fulfil this purpose, the EU adopted the Directive $98 / 8 / \mathrm{EC}^{83}$ on biocidal products (hereafter "BPD") in 1998.

The aim of this Directive was to reduce differences in the regulatory situation in the Member States and to improve the trade of biocidal products across Member States. A so-called twostep system was applied under BPD. First, the active substances used in biocidal products had to be approved; and second, biocidal products had to receive a national authorisation in order to be allowed on the national market. The size of the market could be expanded to other countries in the EU through mutual recognition. Article 18(5) of BPD required the Commission to draw up a report on the implementation and functioning of the Directive seven years after its entry into force. In October 2008, the Commission submitted this report and this led, less than a year later, to a proposal for a regulation of biocidal products. BPR would repeal BPD. The Commission stated that the proposal for a revision of BPD "aims to tackle the identified weaknesses of the regulatory framework during the first eight years of its implementation, to improve and update certain elements of the system and to avoid problems anticipated in the future" (European Commission, 2009b, p. 2).

As the name of the proposal suggests, the most notable change is that the Directive is turned into a Regulation. "As a result, there will be no need for a transposition period or for national transposition measures, which is also expected to ensure more harmonised implementation of the regulatory framework in the Member States" (European Commission, 2009b, p. 8). Another new and important element introduced in the proposal is a centralised authorisation system at the Union level. In addition to the national authorisation of biocidal products, the Union-level authorisation enables applicants to place their products in all EU Member States with a single application. In addition, other improvements in the proposal include the extension of the scope of what is considered as a biocidal product, labelling requirements, and ECHA's new role in managing the administrative, technical, and scientific aspects of the centralised system. Furthermore, the proposal intended to "simplify the data protection rules, to avoid duplicating vertebrate animal studies through mandatory data-sharing, increase harmonisation of fee systems in Member States, and establish rules for parallel trade of biocidal products" (European Commission, 2009b, p. 2).

There are many new elements in the proposal, but the centralised system and the new mandate of ECHA are of interest in this chapter since these topics are directly related to the analysis of ECHA's influence. The proposal for BPR states:

The technical and scientific tasks relevant to this centralised system will be carried out by the European Chemicals Agency (ECHA). To this end, the proposal incorporates the necessary provisions governing the procedural and organisational details. In addition, ECHA will undertake the coordination of organisational and technical tasks for the evaluation of all applications for inclusion of active substances in Annex I (the

\footnotetext{
${ }^{83}$ Directive 98/8/EC of the European Parliament and of the Council of 16 February 1998 concerning the placing of biocidal products on the market.
} 
Community positive list for active substances) which were until now attributed to the Commission Joint Research Centre. (European Commission, 2009b, pp. 8-9)

It is also important to mention that the centralised system, which is termed "Union authorisation" in BPR, comes with a strict timeline for the assessment of applications. Such a time frame did not exist under BPD, and a prolonged period for assessment was highlighted as one of its weaknesses. When the proposal for BPR was discussed in the Council of the European Union, one of the debated issues was whether or not the proposed regulation should provide authorisation of biocidal products at the EU level. The Member States were generally in favour of the possibility of Union authorisation of biocidal products, and the UK, in its written response to the Presidency question on this issue, emphasised:

There are significant problems with the existing European controls on biocides, resulting in slow progress. For instance, ten years after adopting the Directive there are only around 35 active substances on the EU positive list and very few biocidal products have been authorised under the EU scheme. [...] The UK believes central authorisation is a key opportunity to improve the current system and remedy the extremely slow progress under Directive 98/8. (Council of the European Union, 2009, p. 4)

The whole legislative process took longer than initially anticipated by the Commission (European Commission, 2011c). It took almost three years for the EU to adopt the Biocidal Products Regulation in May 2012, after discussions within the Council and the European Parliament on first reading in 2010 and on second reading in 2012. The following sections first examine ECHA's influence on the formulation of the Commission proposal for BPR and then discuss the conditions for ECHA's influence in two dimensions (as outlined in Chapter 3 ) - the production of expert advice in ECHA and the provision of expert advice from ECHA to the European Commission.

\subsubsection{Evidence of ECHA's influence}

Chapter 3 outlining the research design explains that two indicators are applied to measure the influence of EU agencies: text comparison and reputation as a scientific authority. This section will examine these indicators accordingly.

\section{Text comparison}

In order to check whether ECHA was able to shape the content of the Commission proposal, text comparison was conducted to compare ECHA's scientific advice and the Commission proposal for BPR. Before presenting the results of the text comparison, it is important to explain the way in which ECHA's documents containing expert advice on the proposal were selected for analysis. Document selection was not easy in this particular case: the documents created by ECHA for the purpose of providing input to the Commission in 2008 and 2009 are 
not publicly available. Apart from a couple of short statements that ECHA advised the Commission on the revision of BPD, which were found in the General Reports of the Agency, no further information could be found. Who or which units of ECHA were responsible for developing expert advice for the Commission? How many documents were produced by ECHA to advise the Commission? When and how did ECHA provide expert advice to the Commission? What was the content of the advice? None of these questions could be answered as there was no access to the relevant documents from ECHA.

For this case study, a request for access to documents was sent to ECHA, and four documents were disclosed by the Agency. Two of them were formulated in 2008 and the other two in 2009. However, one document from 2009 was written for the Commission's Joint Research Centre (JRC) and had more to do with the CLP regulation than with the proposal for BPR. In addition, while the other document from 2009 directly touched upon Article 17 of the proposal about the criteria for low-risk active substances, it was submitted to the Commission almost five months after the proposal was introduced. Thus, these two documents were excluded from the text comparison since they could not be considered as the Agency's input to the Commission proposal during the policy formulation stage. Nevertheless, on the key issues of the Commission proposal, such as the role of the agency and the operational scenarios of the Union authorisation procedure, the position and advice of ECHA could clearly be traced in the two documents from 2008. The validity of the results of text comparison can be established, yet the influence of ECHA based on the text comparison should be carefully handled given the small number of documents available for the analysis (see Subsection 7.2.3). ${ }^{84}$

As mentioned above, during the policy formulation process in 2008 and 2009, ECHA was involved and gave advice to the Commission. The General Report for 2008 states:

Upon the request of the Commission, ECHA examined the option of taking over scientific, technical and administrative tasks regarding the authorisation of biocidal products, and contributed to the drafting of the legislative proposal for a new EC Biocides Regulation. (ECHA, 2009, p. 16)

Similarly, the General Report for 2009 reveals that providing expert advice on the revision of the Biocides Directive was one of ECHA's priorities in connection to its activities of "other scientific and technical advice on questions relating to chemicals" (ECHA, 2010):

ECHA continued to provide scientific advice to the Commission in the preparation of the proposal for the new Biocides Regulation. This work also covers the planning of ECHA's

\footnotetext{
${ }^{84}$ It could be possible that ECHA submitted its advice to the Commission only two times in 2008 in a written form, meaning that the two documents used for this analysis covers the whole population of ECHA's advice to the Commission. This is plausible given that EU agencies are asked by the Commission only a few times a year to provide scientific and technical expertise on specific questions. Regarding the two documents from 2008, questions were sent to ECHA about how many documents were submitted to the Commission before the proposal was introduced and how the documents disclosed for this research were selected. Unfortunately, ECHA's response was not sufficiently clear to answer these questions. Therefore, the actual total number of documents which ECHA produced to advise the Commission on the proposal for BPR is unknown.
} 
future biocide tasks, including preparatory activities to ensure appropriate staffing, ITtools, and processes to be in place early enough. (ECHA, 2010, pp. 4-5)

Since involvement in the policy formulation stage does not directly mean influence (see Dür \& de Bièvre, 2007; Hönnige \& Panke, 2012), ECHA's advice written in the two documents from 2008 is compared with the Commission proposal to check whether and to what extent the Commission incorporated expert advice from ECHA into the legislative proposal. The result demonstrates that ECHA exerted a moderate level of influence on the proposal for BPR. Only a few (minor) suggestions from ECHA were not reflected at all in the proposal (which would have hinted at low influence) and the text of ECHA's advice was not literally copied into the proposal (which would otherwise have hinted at high influence). Most of the expert advice from ECHA was adopted and developed further by the Commission in other wording, thus leading to the categorisation of moderate influence. The remainder of this section describes $E C H A$ 's advice and moderate influence in more detail.

As mentioned earlier, two documents of ECHA from 2008 are analysed for this case. One of them is two pages in length, and the other is three pages. Both are written in the format of a letter from the Executive Director of ECHA. Largely, ECHA focused on three topics in the two documents: first, the potential synergies between REACH and the biocides-related work in the Agency; second, the resources that would be necessary for ECHA to carry out the new tasks under BPR; and third, the new procedure of centralised authorisations for biocidal products. Regarding potential synergies, ECHA argued that "the suggested new role in relation to the Biocides Directive is consistent with ECHA's role under REACH and future CLP Regulation and I can see possibilities for synergies between REACH, CLP and biocide tasks" (ECHA, 2008a). In this context, ECHA emphasised that "the full participation of ECHA in the further development of the draft legislative proposal" would be essential to ensure synergies (ECHA, 2008a). In the proposal for BPR, the Commission acknowledged possible synergies that ECHA would bring with reference to $\mathrm{REACH}$, but not to the CLP regulation:

[...] ECHA is expected to create significant synergies, on the basis of the following considerations: [...]

- In addition, the proposal includes rules concerning data sharing for biocidal products, which have now been aligned on those of REACH. [...] Only REACH and ECHA have already set up the mechanisms and the databases to make such sharing possible.

- Last but not least, producers, downstream users of biocidal products and even the Commission already have a number of obligations under REACH. Notably the data held by the Commission JRC relating to active substances under evaluation in the review programme shall be made available to ECHA, in accordance with the position of Article 16 of the REACH Regulation. (European Commission, 2009b, pp. 178-179)

About resources, ECHA highlighted the need for appropriate and additional resources for potential new tasks. It advocated that the budgetary resources could be arranged "through 
fees and/or through increased contribution from the Community budget" and that ECHA should be "closely involved in the development of the legislative proposals, in particular in finalising the financial statement on the revision of the Directive" (ECHA, 2008a). In addition, for the preparatory phase between 2010 and 2012, ECHA proposed that recruiting ECHA staff should begin "1-2 years before the activity starts" (ECHA, 2008b) and enumerated:

For 2010, resources are needed for the development of the detailed guidance and process descriptions, the refinements of staff and other resource calculations, the provision of legal advice and the coordination of the IT development and other preparatory activities. It is estimated that for these tasks two seconded national experts (50,000 € each) and three contract agents $(80,000 €$ each), totaling $340,000 €$ are required. (ECHA, 2008b)

In the proposal, the Commission generally agreed that the budgetary resources of the Agency would be supplied by both fees and a subsidy from the EU. Yet, the Commission stressed its vision of a self-financed ECHA:

The Agency will receive specific fees from applicants for certain of these activities as well as an annual fee on products centrally authorised by the Community. The revenue from the fees will have to be supplemented by a subsidy from the Community. It is, however, expected that this support from the Community will be limited in time as the activities of the Agency should be self-funding through fee revenues after a number of years." (European Commission, 2009b, p. 11)

ECHA's desire to be closely involved in the discussions about finance was met. Although ECHA's involvement was not spelled out in the proposal, the Commission remained in close discussion with ECHA about the future finance structure of the Agency through the relevant budget units of both organisations (ECHA, 2008b). Similarly, ECHA's recruitment plan was taken up by the Commission, and it is stated in the proposal that "financial resources are needed to ensure that ECHA has the appropriate level of staff" (European Commission, 2009b, p.179) and that "[f]or 2012, it is proposed that ECHA should be able to recruit staff to prepare the grounds before the date when ECHA tasks relating to biocidal products come into operation" (European Commission, 2009b, p. 188). However, the specific plan of ECHA for the year 2010 was not accepted by the Commission. The proposal does not lay out any preparatory activities on the part of ECHA for 2010, let alone any financing for that year. This is indeed confirmed in the General Report for 2010:

ECHA's main interest was to ensure that appropriate staffing, IT-tools, and processes can be in place early enough in order to start the effective implementation of the new activities. As no specific funding was yet available for ECHA, these preparatory activities were so far relatively limited. (ECHA, 2011, p. 26)

Regarding the procedure for centralised authorisations of biocidal products, ECHA advised on the following three elements: 
The opinion delivery times proposed in the current draft legislative text for the future ECHA Biocidal Products Committee are in our view clearly too short. The deadline [...] to deliver its opinion [...] should be preferably 9 months to cover also difficult cases and minimum 6 months for the most simple cases.

[...] we strongly prefer for all deadlines for the Agency and the Committee to be expressed as working days instead of as calendar days [...]

[For the renewal of active substance approvals and Community authorisations, a] more efficient form of the renewal applications would be to require an updated dossier, instead of the "commented reference list of new available information" as currently proposed, because all the necessary information is then provided by the registrant or applicant. (ECHA, 2008b, emphasis added)

The first point of advice listed above was adopted by the Commission. In the proposal, a sixmonth deadline is set for simple cases, such as reviewing or renewing active substances and biocidal products that have already been approved or authorised under BPD. For more difficult cases, such as evaluating new active substances and biocidal products as well as judging on Annex 1 inclusion which defines low-risk active substances, the suggested nine-month deadline is applied in the proposal. Moreover, the advice of ECHA to impose the responsibility of providing all necessary information on the registrant or applicant is also adopted by the Commission. In the proposal, it is stated that the applicant for renewal needs to:

Submit a list of all data [...] that have been generated [...] and a justification as to whether the conclusions of the initial assessment [...] are still valid. The evaluating competent authority may require the applicant to submit the data referred to in this list at any time. (European Commission, 2009b, p. 35)

The suggestion about expressing all deadlines as working days, however, was not incorporated into the proposal. At the end of the legislative process when the proposal was adopted by the European Parliament and the Council of the European Union, the text of BPR nonetheless expresses all deadlines for ECHA as working days. ${ }^{85}$

In summary, none of ECHA's advice was quoted in or literally copied into the Commission proposal, and the Commission did not make references to ECHA's documents. However, certain advice of ECHA was accepted and followed by the Commission. When the Commission adopted the suggestions proposed by ECHA, it elaborated further on the ideas. Notwithstanding these positive signs of influence, on the topics of the financial need for 2010 and expressing deadlines as working days, advice of ECHA was not followed by the Commission.

\footnotetext{
${ }^{85}$ In fact, when the Commission proposal for BPR was being discussed for adoption, ECHA was asked by the European Parliament to provide scientific and technical advice during the first and second readings. This hints at the possibility that ECHA succeeded in convincing the European Parliament on this matter and as a consequence, the adopted text of BPR expresses the deadlines in working days. However, this presumption has not been verified as it is beyond the focus of this research.
} 


\section{Reputation}

The second indicator of ECHA's influence is its reputation as a scientific authority. At the time when the Commission proposal was drafted, ECHA was gaining authority rapidly. In 2009, an evaluation undertaken by the European Commission on the work of EU agencies concluded that ECHA, although it was a new agency, was already being considered as a benchmark at the international level, for example by the US, Japan, and China (Ramboll et al., 2009c; ECHA, 2016c). The evaluation underlines that "in dealing with technical dossiers, taking individual decisions, and providing opinions, the agency performs a role that the Commission would have difficulties to take on. The agency also ensures independence of scientific assessment from policy development" (Ramboll et al., 2009c, p. 75). Furthermore, scientific output of ECHA was "timely, useful and of high quality benefiting both the European Commission and other European Institutions, and unsurprisingly of particular value for the implementation of European policy" (Ramboll et al., 2009c, p. 77).

Although not directly referring to the case of the Commission proposal for BPR, another positive confirmation of ECHA's influence can be found in academic research. For example, when describing the empirical finding that scientific advice of some EU agencies becomes an official decision of the European Commission without any changes, Scholten (2014, p. 75; see also Dehousse, 2008) quoted a statement made by a senior official from ECHA in 2011:

We publish our technical assessments. If the Commission does not follow the advice [in the comitology decision], it is seen. [...] In theory - it can happen, perhaps, the comitology groups have national experts who have a different opinion; in practice - I do not see it happening.

This section has shown that ECHA exerted a moderate level of influence on the Commission proposal for BPR during the policy formulation stage and that ECHA was already viewed as a valuable asset to the EU institutions only a couple of years after its establishment. The next two sections explain how ECHA became influential by focusing on the production and provision of expert advice.

\subsubsection{Conditions for influence: Production of expert advice in ECHA}

As outlined in the research design (see Section 3.2), there are three conditions which are expected to affect influence of EU agencies: access, activities, and resources. This subsection focuses on the production dimension of expert advice in ECHA and analyses the three conditions. Before presenting the analysis, relevant background information is provided in order to facilitate understanding of the processes of developing the Commission proposal as well as selecting ECHA for expert advice.

Under BPD, the Commission Joint Research Centre (JRC) provided significant input to the Commission, but the Commission JRC downsized its activities in the field of chemical substances and transferred many of these activities to ECHA after ECHA was established in 
June 2007 (European Commission, 2009b, 2011c). The year 2007 was also when the Commission raised and discussed numerous issues regarding the implementation of BPD and started exploring ideas about either the revision of BPD or a new legislative proposal for biocidal products (Interview \#1; Chemicalwatch, 2007, 2008). Three things soon became clear to the Commission. First, without scientific input from the Commission JRC, the Commission did not have enough in-house expertise and resources to address issues of scientific and technical nature related to biocides and thus needed to seek expert advice from an external body, such as an agency at the European level (European Commission, 2009b). Relying on an external body was also "in line with the approach adopted in other sectors such as medicinal products, plant protection products, food, where there is a clear separation between risk assessment (carried out by scientific bodies) and risk management (carried out by the Commission)" (European Commission, 2009b, p. 178).

Second, "at that time, there was a tendency - which there still is - to go for a regulation rather than a directive" (Interview \#1). As a regulation is directly applicable in all EU Member States without transposition, it is easier for the Member States to implement. Easier implementation was "in any case important criteria to switch to a regulation rather than revising a directive" (Interview \#1). Last, the Commission wanted to achieve "more harmonisation of the internal market" through a harmonised regulatory framework for granting authorisations, including harmonised rules and procedures on fees, conditions of payment, data sharing and protection, and so on (Interview \#2). The Commission's desire to achieve more harmonisation (preferably through an EU agency) was understandable since, under BPD, there were diverse standards, fees, terms and conditions for the authorisation of biocidal products at the national level. Such diversity was not good for bringing about true community views and actions (see Dehousse, 1997).

In January, April, and May 2008, the Commission organised consultations with the Member State governments, competent authorities, and stakeholders such as industry, NGOs, and consultants. The possibility of having a single Community authorisation for biocidal products - and the role of an EU agency in it - was discussed, and the conclusion was that "providing for harmonised authorisation procedures is seen as a plus by the industry, and even better if a centralised procedure were adopted" (European Commission, 2009b, p. 5). Here, certain EU agencies could be a model and a source of inspiration for other agencies (Chiti, 2013). The Commission, in fact, considered the legislation of medicines as a good example for the new proposal for biocidal products and analysed how well the medicines legislation was implemented and what the clear benefit of the centralised authorisation system was (Interviews \#1, \#2; Martens, 2012).

When the proposal for BPR was being prepared in the Commission, three EU agencies were initially considered as possible candidates to carry out a set of new tasks: 1 ) establishing the Union authorisation procedure for biocidal products; 2) creating a Biocidal Products Committee; and 3) developing IT tools to support the application and evaluation processes for the Union authorisation. One of the EU agencies was obviously the European Medicines Agency "because the proposal to authorise certain biocidal products at the Community level 
is modelled upon the lines and principles of what already exist since 1995 for medicinal products for veterinary and human use" (European Commission, 2009b, p. 178). The European Food Safety Authority was another candidate as it was in charge of producing scientific opinions for the Commission on the placing on the market of plant protection products which were closely related to biocidal products (European Commission, 2009b). But, ECHA was chosen to carry out the new tasks under BPR.

First and foremost, the evaluation of active substances used in biocidal products follows many of the methodologies and principles that also apply to chemical substances. Data requirements [and data sharing] are similar [to those of $\mathrm{REACH}$,] and the risk assessment of these substances [...] is even of the direct competence of ECHA. [...] [A]nother important element of choice is that many of the ECHA scientific staff is already familiar with biocidal products, through previous work at the Commission JRC, in Member States Competent Authorities as well as in industry. (European Commission, 2009b, pp. 178179)

At an early stage of the drafting process of the proposal the selection of the EU agency was made, and accordingly ECHA was asked by the Commission to provide expert advice as input to the proposal. The topics on which the Commission requested input from ECHA were directly related to the new tasks of ECHA summarised above (Interviews \#3, \#8).

\section{ACCESS}

The first condition refers to the internal and external networks that ECHA can utilise in order to produce expert advice. ECHA mostly utilised the internal network within the Agency and its network with the Member States and EMA. As explained above, ECHA already had many staff with expertise in biocides since they had dealt with biocides-related issues for other authorities or industry before moving to ECHA. Additionally, a team of ECHA experts was created by the Director General of the Agency "to have a closer look at the proposed new tasks and their resource implications" (ECHA, 2008a). For creating the Biocidal Products Committee as a scientific body that would carry out risk assessment, ECHA relied on its knowledge in and experience from the REACH implementation. One senior official from ECHA explains that "we started to learn, first of all, from our colleagues in charge of REACH about how they set up their committees" (Interview \#3). ECHA looked at the feasibility of setting up BPC within the Agency given the anticipated time period and later discussed internally other details related to the operation of this committee. More specifically, internal discussions took place regarding how to make rules of procedure for BPC, the whole invitation process by which members of BPC could be appointed, and the time period that would be allowed for BPC to produce an opinion (Interviews \#3, \#5).

The proposal states that "[f]ormats and software for submission of information to the Agency [shall be made] available on [ECHA's] website. [...] The competent authorities and applicants 
shall use these formats and packages in their submissions to the Agency pursuant to this Regulation" (European Commission, 2009b, p. 80). REACH-IT was the main IT system of ECHA at that time, and it was already under development starting in early 2007 (ECHA, 2008a). To develop IT tools for the evaluation procedure for biocidal products, ECHA once again relied on its experience from the REACH implementation (Interview \#3).

On the topic of establishing the authorisation procedure at the Community level, ECHA gained more knowledge by networking with other EU agencies and the Member States. These bodies have many years of experience, but "everything was new for ECHA as a new actor in the field of biocides" (Interview \#15). ECHA was in line with the Commission's objective of achieving more harmonisation in the regulatory framework and visited EMA in London to learn about the centralised system for medicines (Interviews \#1, \#2, \#3, \#8). The role of EMA was thoroughly analysed by both ECHA and the Commission because "the whole idea about the Union authorisation of biocidal products was taken partly from the authorisation procedure within EMA, especially on medicines for veterinary uses" (Interview \#3; see also Martens, 2012). The Agency, likewise, visited some national competent authorities dealing with biocides to be better informed about the national authorisation procedure of biocidal products and mutual recognition (Interviews \#4, \#7).

\section{ACTIVITIES}

The second condition, activities, considers the frequency of interactions with internal and external experts. The contact between in-house experts of ECDC was high but only when ECHA was asked by the Commission to provide advice (Interview \#5). This was not surprising because ECHA started providing expert advice on the proposal only one year after the Agency was established, and the main priority of ECHA at that time was to get ready for the entry into operation of REACH on 1 June 2008 (ECHA, 2009). Moreover, because ECHA had no role in the regulation of biocidal products under BPD, ECHA's interaction with the national competent authorities was also limited to the occasions when ECHA was seeking to gather relevant information on authorisations of biocidal products (Interview \#5). Their interaction became much more frequent on a regular basis only after the proposal was adopted by the European Parliament and the Council of the European Union, via the Biocidal Products Committee meetings in ECHA, Biocides Competent Authority meetings in Brussels, and international meetings (ECHA, 2011, 2012a).

\section{RESOURCES}

The resources of ECHA, which is the third condition, were not supportive of ECHA's effort in advising the Commission on the proposal. Since the REACH implementation was the only and main responsibility of ECHA at that time, there was no separate budget within ECHA for biocides-related work. Therefore, although the Agency more than doubled in size, growing 
from 102 statutory staff members to 219 in the year 2008, there was no dedicated unit or staff working in the area of biocides (ECHA, 2009). ECHA provided expert advice to the Commission on the proposal for BPR, but this was basically seen as a service of the Agency to the Commission.

To conclude, despite some challenges in resources and rather sporadic networking activities, ECHA was able to produce expert advice for the Commission mainly based on its networks among internal experts as well as with external partners. The following section focuses on the provision dimension of expert advice and analyses the three indicators as conditions for influence.

\subsubsection{Conditions for influence: Provision of expert advice from ECHA to the European}

\section{Commission}

In this section, the three conditions are analysed with the focus on the provision dimension of expert advice from ECHA to the Commission.

\section{ACCESS}

In Chapter 3, it is explained that EU agencies access the Commission with their expert advice in three different ways. Providing expert advice occurs when the Commission requests advice from EU agencies, when agencies find certain issues very important and voluntarily submit expert advice, or when agencies' expert advice should be submitted to the Commission as a prerequisite for the Commission's decision in a legally defined legislative process. In the case of ECHA in 2008 and 2009, the Agency provided expert advice on the Commission proposal only when it was requested by the Commission (ECHA, 2009, 2010). The fact that the Commission started discussing the ideas of improving and revising BPD as early as 2007 means that ECHA, soon after it became operational, worked on producing expert advice on this topic. As explained earlier, ECHA's focus was only on the implementation of REACH. Without legal mandate, designated units, experts, and a fixed budget in relation to the work of biocides, it was not unusual that ECHA did not provide expert advice on its own initiative.

\section{ACTIVITIES}

Regarding the second condition, activities, the two documents (and there might be more, as explained in Subsection 5.2.2) that ECHA provided to the Commission in 2008 imply that the frequency of interaction between ECHA and the Commission was rather low. Nevertheless, this does not mean that written communication was the only means of interaction between ECHA and the Commission. According to one senior official from ECHA, expert advice was also given through teleconferences, face-to-face meetings, and informal discussions with the 
Commission during this time period (Interview \#5). Indeed, the two ECHA documents analysed for this case study indicate this type of informal interaction. Evidence from the text includes: "I have been informed about the progress made in the informal discussions on [...]"; "[...] discussions [...] have already been initiated [...]"; and "I have raised this point recently with Mr. Delbeke on my visit [to the Commission] of 27 November [...]" (ECHA, 2008b).

At this point, it is worth specifying that although DG Environment was the lead DG of the proposal for BPR, all ECHA documents were addressed to both DG Environment and DG Enterprise. Either the Director General or the Deputy Director General of the two DGs were named as the specific recipients, and ECHA's expert advice was sent by the Executive Director of the Agency. Since 2014, though, this has changed. Now, all ECHA's expert advice on biocides is submitted to DG SANTE, and DG SANTE is the parent DG of ECHA in relation to the biocidal products regulation. This change occurred due to the structural reorganisation in the European Commission under the new leadership of Juncker in 2014, and the biocides-related responsibility of DG Environment - Unit A3 on biocides to be precise - was entirely transferred to DG SANTE (European Commission, 2014). All the files on biocides as well as the Commission officials responsible for the proposal for BPR and other issues related to the implementation of BPR moved from DG Environment to DG SANTE (Interview \#1).

While formal and informal interactions did occur between ECHA and the Commission to discuss the proposal for BPR, they were not routinised or highly frequent. At the same time, the Commission also sought input from other partners such as the Commission JRC, industry organisations, civil society, and Member States and their competent authorities (European Commission, 2009b). The contact between ECHA and the Commission became more active only after the proposal was adopted in order to prepare for the entry into force of BPR. The tasks indicated in BPR were identified as 42 individual tasks in a list that specified which tasks were led by ECHA alone and which by ECHA in conjunction with either the Commission or the Commission JRC (European Commission, 2013b). According to the list, ECHA was in close contact with the Commission on the topics related to data requirements, assessment of technical equivalence, product authorisation, and other common principles for the evaluation of dossiers for biocidal products (European Commission, 2013b). ECHA performed these tasks in a team called PREP-BPR (Preparation for the entry into force of the Biocidal Products Regulation) and cooperated closely with DG Environment, national competent authorities, and a few accredited stakeholders (European Commission, 2013b).

\section{RESOURCES}

The number of scientific outputs by ECHA is the last indicator in the provision dimension. As explained earlier, ECHA provided scientific and technical advice to the Commission both before and after the introduction of the proposal for BPR. The total number of documents that ECHA produced as input for the Commission proposal is unknown as these documents are not publicly available, and ECHA does not provide details on the number of documents 
submitted to the Commission. However, it is plausible to believe that the number is not likely to be very much higher than two (which is the number of documents released by ECHA and analysed for this case study), considering the fact that most informal interactions are not documented (Christiansen \& Neuhold, 2012).

Overall, the small number of scientific outputs by ECHA in relation to the proposal for BPR highlights that ECHA's resources were not favourable to exert influence in the provision dimension. Moreover, ECHA accessed the Commission with expert advice only when the Agency was requested to do so, and the interaction between them was neither routinised nor highly frequent. The next section introduces the second case: the influence of ECHA on the Union authorisation procedure of biocidal products under BPR.

\subsection{Case 2: Union Authorisation of Biocidal Products}

\subsubsection{Background}

The Commission proposal for BPR was adopted on 22 May 2012, and the Biocidal Products Regulation entered into operation on 1 September 2013. The two-step system, whereby the active substances responsible for the biocidal effect have to be approved first and then the biocidal products have to be authorised to be placed on the market, remains the same under BPR. The new element is that next to the national authorisation and mutual recognition, companies producing biocidal products can also apply directly for the Union authorisation with a single application. The benefit is that once the Union authorisation is granted, the biocidal products are allowed to be placed on the market throughout the entire Union and have the same rights and obligations in all the Member States as those provided by national authorisations. ${ }^{86}$

The procedures for active substance approval and Union authorisation are very similar. As Figure 5.1 shows, these procedures can be explained with four stages. The first preparation stage is not mandatory, but it is "strongly recommended" by ECHA that applicants who plan to apply for a Union authorisation for biocidal products make use of it (Interview \#4). During the preparatory discussions, applicants may discuss with an evaluating competent authority (eCA) technical or methodological questions, such as the scope, approach, and requirements that are necessary to fulfil the application dossier. Then, the applicants are also "strongly advised to make a pre-submission to ECHA" (Interview \#4). The applicants inform one of $E C H A$ 's national helpdesks, which function as the first point of contact for questions related to $\mathrm{BPR}, \mathrm{CLP}$, and $\mathrm{REACH}$ regulations. ${ }^{87}$ After that, they submit a draft summary of the product characteristics to ECHA, and ECHA circulates the documents to all national competent authorities in the EU and the European Commission who may provide comments.

\footnotetext{
${ }^{86}$ See https://echa.europa.eu/regulations/biocidal-products-regulation/authorisation-of-biocidalproducts/union-authorisation.

87 See https://echa.europa.eu/support/helpdesks.
} 
Figure 5.1) Flowchart of the process for active substance approval and Union authorisation

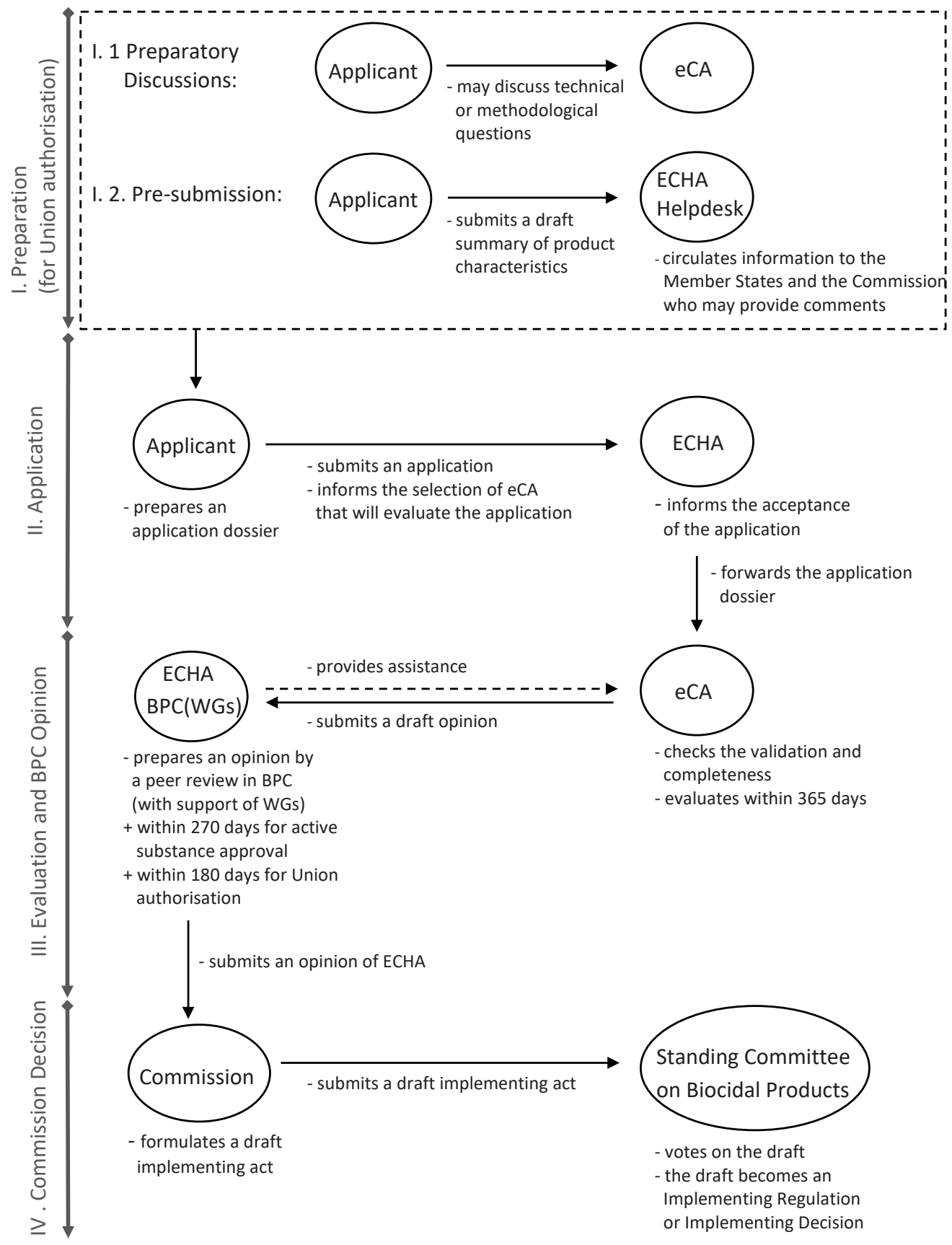

(Source: Author's own compilation) 
The application is submitted to ECHA although the Agency does not evaluate the application - risk assessment of the application is performed by one of the national competent authorities. When an application is submitted to ECHA, the Agency informs of its acceptance after receiving the fees payable from the applicant and forwards the application dossier to the eCA of the applicant's choice. ${ }^{88}$ (Of course, the eCA will have previously agreed to evaluate the application.) The evaluation stage begins when the application passes the validation and completeness check by the eCA. The eCA assesses the application and produces a draft opinion including an assessment report and conclusions of its evaluation within 365 days. During the evaluation, ECHA is in close and regular contact with the eCA and "proactively asks whether there are any issues or questions" in order to provide assistance (Interview \#4). Once the eCA finalises the assessment, the draft opinion is submitted to ECHA. The Biocidal Products Committee, with the support of its Working Groups, performs a peer review and prepares an opinion within 270 days for active substance approval and within 180 days for the Union authorisation of biocidal products.

The opinion of ECHA is submitted to the Directorate-General for Health and Food Safety in the European Commission. The Unit E4 Pesticides and Biocides in DG SANTE is responsible for formulating a draft implementing act. The vote on the adoption of the draft implementing act is taken by the Standing Committee on Biocidal Products in which all EU Member States are represented. If this Standing Committee agrees with approving active substances or granting authorisations, the draft implementing act becomes a Commission Implementing Regulation. If the active substances or biocidal products in question are subject to non-approval or rejection of authorisation, the draft implementing act becomes a Commission Implementing Decision. Overall, the whole procedure from preparation until decision takes approximately two and a half years as a minimum (ECHA, 2016b).

The following sections demonstrate whether ECHA's influence is evident in the Commission implementing acts under the procedure described above, and explain this influence by analysing how expert advice is produced in ECHA and provided by ECHA to the Commission.

\footnotetext{
${ }^{88}$ Applicants choose which one of the eCAs would evaluate their application. According to the survey conducted by A.I.S.E. \& Cefic EBPF (2015), companies as applicants consider a combination of several criteria for selecting the eCA. "Fees level is by far the main criteria reported by companies, regardless of their size" and other criteria include communication and past interactions with the eCA, the experience and competence of the eCA, and adherence to timelines and eCA's internal resources (A.I.S.E. \& Cefic EBPF, 2015, p. 24).
} 


\subsubsection{Evidence of ECHA's influence}

As in the first case above, the two indicators - text comparison and reputation - are analysed to measure influence of ECHA.

\section{Text comparison}

The text comparison between 10 BPC opinions and subsequent Commission implementing regulations on the approval of active substances was conducted (the selection of BPC opinions is explained below). The result shows that there is high influence of ECHA. What is interesting is that the high influence of ECHA was not present in the beginning of the BPC operation but gained over time. In April 2014, BPC produced its first opinions and met three other times in 2014 to discuss the approval of active substances. In the first year of BPC's operation, "the Commission was not completely satisfied with the way the opinions were written down" (Interview \#7). As a result, there were differences in the text from the two parties (Interviews \#3, \#7, \#9).

Then, discussions took place between the Member States, ECHA, and the Commission to modify the format and the presentation of the BPC opinion so that it would become "really workable for the Commission to prepare for its decision" (Interview \#9). The Commission presented a guideline on how BPC opinions should be formulated to make them more "fit for purpose," followed by several updates and new proposals to simplify the drafting of opinions (Interviews \#3, \#7, \#9). After the guideline and suggestions from the Commission were implemented in BPC opinions, it has been the trend that the Commission uses the text of BPC opinions "almost as it is" (Interview \#3). One of the BPC members claims that "usually the opinions of [BPC on] the active substances are used [by the Commission] without changes for the implementing regulations" (Interview \#13). Likewise, one official from ECHA confirms that "the Commission has always taken into account what was agreed at the BPC meetings and adopted the legislative acts accordingly. On the approval or non-approval of active substances, the deviation [between BPC and the Commission] has never happened" (Interview \#4).

All BPC opinions follow the same standard format. The first two pages introduce the active substance that is evaluated and explain the steps taken for the adoption of BPC opinions, the rapporteur, and whether or not the opinion was adopted by consensus. Then the following 10 pages, on average, under the title "Detailed BPC opinion and background," give details on the conclusion of the evaluation, summary of risk analysis, elements to be taken into account when authorising products, and requirement for further information. The detailed grounds for the conclusion and explanations on the risk analysis are provided in the assessment report, and the Commission receives both assessment report and BPC opinion for each active substance.

To the Commission, the overall conclusion of BPC about whether the active substance in question may be approved or not is essential. What is more, one specific section of the BPC 
opinion is directly relevant to the Commission when drafting Commission implementing acts. This is section "2.3 BPC opinion on the application for approval of the active substance $x x x$ in product type $x x . "$ This section elucidates specific conditions that come with the approval. While all Commission implementing regulations have almost the same text in the preamble and the body, the accompanying Annex is different for each active substance. The Annex consists of brief information on the active substance itself and specific conditions under which it is approved. This part on specific conditions in the Annex is written based on section 2.3 of BPC opinions.

A senior official from ECHA explains that "up to now, all [BPC] opinions have been taken over by the Commission in terms of approving or not approving certain active substances" (Interview \#3). However, there have been cases where the terms and conditions in section 2.3 of BPC opinions were amended by the Commission, especially in the beginning of the BPC operation. These amendments mostly dealt with the structure and wording of the sentences, not the scientific aspect. ${ }^{89}$ After the Commission's guideline was implemented, meaning that the BPC opinions became more in line with the Commission officials' expectation, the text in section 2.3 of BPC opinions is "directly copied into the Commission's draft implementing acts" (Interview \#3; also Interviews \#4, \#7). Nowadays, if the Commission would like to change something from the BPC opinion when incorporating the BPC text in its drafts, it even adds a note next to the changed part to explain why the Commission made changes (Interview \#7).

In order to verify the high influence of ECHA, the actual documents of 10 active substances on which BPC adopted opinions ${ }^{90}$ and on which the Commission adopted implementing regulations are compared and analysed. As shown in Table 5.1 below, five active substances which were discussed by BPC in 2014 and five other active substances from 2016 were randomly selected. This selection in two different time periods makes it possible to validate the claim by both ECHA officials and BPC members that the agency's opinions are now more directly copied into Commission implementing acts, compared to 2014. In other words, if this is proven by the text comparison, it demonstrates not only the high influence of ECHA but also the fact that the influence of ECHA has increased to a high level in less than three years of its operation.

\footnotetext{
${ }^{89}$ A senior official from ECHA highlighted that members of BPC were used to write reports for scientific audience rather than policy-makers (Interview \#4). The comprehensive evaluation report on EU agencies from 2009 also points out this issue and recommends that EU agencies should write opinions in a manner that is understandable to the Commission officials (Ramboll et al., 2009b).

${ }^{90}$ By the end of the $21^{\text {st }}$ meeting of BPC, which was held during 27-29 June 2017, BPC had adopted 159 opinions on the approval or non-approval of active substances. For the complete list of active substances on which BPC has issued its opinions, see ECHA's website: https://echa.europa.eu/regulations/biocidal-productsregulation/approval-of-active-substances/bpc-opinions-on-active-substance-approval.
} 
Table 5.1) List of the active substances selected for text comparison

\begin{tabular}{|c|c|c|c|}
\hline Active Substance & Product Type & $\begin{array}{c}\text { Date of BPC } \\
\text { Opinion }\end{array}$ & $\begin{array}{c}\text { Date of Commission } \\
\text { Decision }\end{array}$ \\
\hline \multicolumn{4}{|l|}{ From 2014} \\
\hline Permethrin & 18 & 8 April 2014 & 16 October 2014 \\
\hline Tralopyril & 21 & 9 April 2014 & 16 October 2014 \\
\hline Alpha-cypermethrin & 18 & 17 June 2014 & 11 March 2015 \\
\hline Folpet & 6 & 17 June 2014 & 28 September 2015 \\
\hline Glutaraldehyde & 2 & 1 October 2014 & 28 September 2015 \\
\hline \multicolumn{4}{|l|}{ From 2016} \\
\hline Peracetic acid & 12 & 14 June 2016 & 16 December 2016 \\
\hline Brodifacoum & 14 & 16 June 2016 & 25 July 2017 \\
\hline Flocoumafen & 14 & 16 June 2016 & 25 July 2017 \\
\hline Silicon dioxide Kieselguhr & 18 & 11 October 2016 & 10 May 2017 \\
\hline OIT & 8 & 15 December 2016 & 14 July 2017 \\
\hline
\end{tabular}

(Source: Author's own compilation)

The result of the text comparison strikingly illustrates that among five active substances from 2014, only one - Tralopyril - shows that section 2.3 of the BPC opinion is entirely copied into the Annex of the Commission implementing regulation. For all four other active substances, the Commission amended one or more conditions written in section 2.3 of their respective BPC opinion. What is worth noting is that the extent to which the Commission amended the text of BPC opinions differs. For Alpha-cypermethrin, for instance, three out of four conditions written in the BPC opinion appear unchanged in the Annex of the Commission's implementing regulation. One condition was amended by the Commission, but it was only paraphrased. This condition is stated in the BPC opinion:

To prevent risks for the aquatic environment products shall not be used for the treatment of surfaces that are prone to frequent wet cleaning, other than crack and crevice treatment, unless data are submitted demonstrating that the product will meet the requirements of Article 19 and Annex VI of Regulation (EU) No 528/2012, if necessary by the application of appropriate risk mitigation measures. (ECHA, 2014b, p. 11)

In the Annex of the Commission implementing regulation, the above sentence appears amended:

To prevent risks for the aquatic compartment, for the treatment of surfaces prone to frequent wet cleaning, products shall only be used to treat crack and crevices, unless it can be demonstrated in the application for product authorisation that risks for the 
aquatic compartment can be reduced to an acceptable level. (European Commission, 2015a, p. 11)

More substantial changes by the Commission, which go beyond simple paraphrasing, are recognised in the cases of Folpet and Glutaraldehyde. Some examples of the texts are shown in Table 5.2 below. For Folpet, three out of seven conditions written in the BPC opinion appear in the Commission implementing regulation with only minor changes (e.g.,"The biocidal product assessment" is changed to "The product assessment"). However, the Commission merged two conditions into one by deleting repeated phrases and specific information about products and their applications. The text "biocidal products authorised for the preservation of paints, films or coatings used for outdoor application by brush" written by BPC is simplified to just one word "products." Other texts such as "outdoor application by brush" and "outdoor use preserved with folpet" are also replaced with the expression "the outdoor application for the preserved mixtures" (ECHA, 2014c, pp. 9-10; European Commission, 2015b, p. 14).

A similar pattern of amendment is noticed for the remaining two conditions. What is surprising, though, is the last condition about a treated article, which is treated with or intentionally incorporating folpet. The BPC opinion states that in the case of treated articles and "where necessary due to the possibility of skin contact as well as the release of folpet under normal conditions of use of the article" the label of the article should provide information on the risk of skin sensitisation and relevant information defined in BPR (ECHA, 2014c, p. 10, italics added to emphasise). Yet, the Commission deleted the parts about skin contact and the risk of skin sensitisation, and imposed the labelling requirement in a much less detailed manner by referring only to the "second subparagraph of Article 58(3) of Regulation (EU) No 528/2012" (ECHA, 2014c, p. 10). The same condition by BPC on a treated article and the same exact amendment by the Commission are also seen in the case of Glutaraldehyde. 
Table 5.2) Examples of conditions amended by the Commission: Active substances discussed by BPC in 2014

\begin{tabular}{|c|c|c|}
\hline $\begin{array}{c}\text { Active } \\
\text { Substance }\end{array}$ & Condition written in BPC opinion & $\begin{array}{l}\text { Condition amended in } \\
\text { Commission Implementing } \\
\text { Regulation }\end{array}$ \\
\hline \multirow[t]{4}{*}{ Folpet } & $\begin{array}{l}\text { "4. Labels and, where provided, safety } \\
\text { data sheets of biocidal products } \\
\text { authorised for the preservation of } \\
\text { paints, films or coatings used for } \\
\text { outdoor application by brush shall } \\
\text { indicate that measures shall be taken to } \\
\text { protect the soil to prevent losses and } \\
\text { minimise emissions to the environment, } \\
\text { unless it can be demonstrated in the } \\
\text { application for product authorisation } \\
\text { that risks can be reduced to an } \\
\text { acceptable level by other means." }\end{array}$ & \multirow{2}{*}{$\begin{array}{l}\text { "(2) In view of the risks to } \\
\text { the soil compartment, labels } \\
\text { and, where provided, safety } \\
\text { data sheets of products shall } \\
\text { indicate that measures shall } \\
\text { be taken to protect the soil } \\
\text { during the outdoor } \\
\text { application of the preserved } \\
\text { mixtures to prevent losses } \\
\text { and minimise emissions to } \\
\text { the environment, unless it } \\
\text { can be demonstrated that } \\
\text { risks can be reduced to an } \\
\text { acceptable level by other } \\
\text { means." }\end{array}$} \\
\hline & $\begin{array}{l}\text { "6. Due to the risks identified for the soil } \\
\text { compartment the label and where } \\
\text { provided the Safety Data Sheets of } \\
\text { paints, films and coating for outdoor use } \\
\text { preserved with folpet shall indicate that } \\
\text { they shall not be applied outdoors by } \\
\text { spraying, and that measures shall be } \\
\text { taken to protect the soil when they are } \\
\text { applied by brush, unless it can be } \\
\text { demonstrated that risks can be } \\
\text { mitigated by other means." }\end{array}$ & \\
\hline & $\begin{array}{l}\text { "5. Biocidal products shall not be } \\
\text { authorised for the preservation of } \\
\text { paints, films or coatings used for } \\
\text { outdoor application by spraying, unless it } \\
\text { can be demonstrated in the application } \\
\text { for product authorisation that risks for } \\
\text { the soil compartment can be reduced to } \\
\text { an acceptable level." }\end{array}$ & $\begin{array}{l}\text { "(3) In view of the risks to } \\
\text { the soil compartment, } \\
\text { products shall not be } \\
\text { authorised for preservation } \\
\text { of mixtures to be applied } \\
\text { outdoor by spraying, unless } \\
\text { it can be demonstrated that } \\
\text { risks can be reduced to an } \\
\text { acceptable level." }\end{array}$ \\
\hline & $\begin{array}{l}\text { "7. Where a treated article has been } \\
\text { treated with or intentionally } \\
\text { incorporates one or more biocidal }\end{array}$ & $\begin{array}{l}\text { "The placing on the market } \\
\text { of treated articles is subject } \\
\text { to the following condition. }\end{array}$ \\
\hline
\end{tabular}




\begin{tabular}{|c|c|c|}
\hline & $\begin{array}{l}\text { products containing folpet, and where } \\
\text { necessary due to the possibility of skin } \\
\text { contact as well as the release of folpet } \\
\text { under normal conditions of use of the } \\
\text { article, the person responsible for } \\
\text { placing the article on the market shall } \\
\text { ensure that the label provides } \\
\text { information on the risk of skin } \\
\text { sensitisation, as well as the information } \\
\text { referred to in the second subparagraph } \\
\text { of Article 58(3) of Regulation (EU) No } \\
528 / 2012 . "\end{array}$ & $\begin{array}{l}\text { The person responsible for } \\
\text { the placing on the market of } \\
\text { a treated article treated } \\
\text { with or incorporating folpet } \\
\text { shall ensure that the label of } \\
\text { that treated article provides } \\
\text { the information listed in the } \\
\text { second subparagraph of } \\
\text { Article } 58(3) \text { of Regulation } \\
\text { (EU) No 528/2012." }\end{array}$ \\
\hline \multirow[t]{2}{*}{ Glutaraldehyde } & $\begin{array}{l}\text { "5. Products can not be applied by } \\
\text { wiping unless it can be demonstrated at } \\
\text { product authorisation that there is no } \\
\text { unacceptable risk." }\end{array}$ & $\begin{array}{l}\text { "(2) In view of the risks to } \\
\text { professional users, products } \\
\text { cannot be applied by wiping } \\
\text { unless it can be } \\
\text { demonstrated that risks can } \\
\text { be reduced to an acceptable } \\
\text { level." }\end{array}$ \\
\hline & $\begin{array}{l}\text { "6. Where a treated article has been } \\
\text { treated with or intentionally } \\
\text { incorporates one or more biocidal } \\
\text { products containing glutaraldehyde and } \\
\text { where necessary due to the possibility of } \\
\text { skin contact as well as the release of } \\
\text { glutaraldehyde under normal conditions } \\
\text { of use of the article, the person } \\
\text { responsible for placing the article on the } \\
\text { market shall ensure that the label } \\
\text { provides information on the risk of skin } \\
\text { sensitization, as well as the information } \\
\text { referred to in the second paragraph of } \\
\text { Article 58(3) of Regulation (EU) No } \\
528 / 2012 . "\end{array}$ & $\begin{array}{l}\text { "The placing on the market } \\
\text { of treated articles is subject } \\
\text { to the following condition. } \\
\text { The person responsible for } \\
\text { the placing on the market of } \\
\text { a treated article treated } \\
\text { with or incorporating } \\
\text { glutaraldehyde shall ensure } \\
\text { that the label of that treated } \\
\text { article provides the } \\
\text { information listed in the } \\
\text { second sub-paragraph of } \\
\text { Article 58(3) of Regulation } \\
\text { (EU) No 528/2012." }\end{array}$ \\
\hline
\end{tabular}

(Source: Author's own compilation based on ECHA, 2014c, 2014d; European Commission, 2015b, 2015c)

Regarding the five substances discussed by BPC in 2016 (see Table 5.1), the result of the text comparison between BPC opinions and Commission implementing regulations is completely different from what is analysed above. On two active substances, namely Peracetic acid and 
OIT, section 2.3 of the BPC opinion is entirely copied into the Commission implementing regulations without any change. Moreover, the BPC opinions of three other active substances also show high influence of ECHA because the Commission made only minor changes to the BPC text. In the case of Brodifacoum, the BPC opinion provides an exceptionally long list of conditions which takes up three pages, and the Commission copied the whole section almost as is. There are only a few minor changes in wording, such as the word "sewage" being changed to "sewers." Other examples are shown in Table 5.3 below.

For the active substances Flocoumafen and Silicon dioxide Kieselguhr, evidence of influence is very similar: the Commission copied section 2.3 of BPC opinion almost entirely while making only minor changes in wording. On these five substances, the Commission relied heavily on the BPC opinions, and this evidence is opposite from what was observed in the earlier five active substances on which the Commission even changed the content of BPC opinions (e.g., by omitting the parts about skin contact and the risk of skin sensitisation).

Table 5.3) Examples of conditions amended by the Commission: Active substances discussed by BPC in 2016

\begin{tabular}{|c|c|c|}
\hline $\begin{array}{c}\text { Active } \\
\text { Substance }\end{array}$ & Condition written in BPC opinion & $\begin{array}{c}\text { Condition amended in } \\
\text { Commission Implementing } \\
\text { Regulation }\end{array}$ \\
\hline \multirow[t]{3}{*}{ Brodifacoum } & $\begin{array}{l}\text { "3 b) [...] conditions set in Article } \\
5(2) \text { of Regulation (EU) No } \\
528 / 2012 \text { is met." }\end{array}$ & $\begin{array}{l}\text { "(2) [...] conditions set out in } \\
\text { Article } 5(2) \text { of Regulation (EU) No } \\
528 / 2012 \text { is satisfied;" }\end{array}$ \\
\hline & $\begin{array}{l}\text { "3 i) [...] described specifically in } \\
\text { the national SPC }[. . .] \text { " }\end{array}$ & $\begin{array}{l}\text { "(9) }[. . .] \text { described specifically in } \\
\text { the summary of the product } \\
\text { characteristics of the national } \\
\text { authorization [...]" }\end{array}$ \\
\hline & $\begin{array}{l}\text { "B.1. c. [...] authorised for use as a } \\
\text { permanent bait or in pulse baiting } \\
\text { treatments." }\end{array}$ & $\begin{array}{l}\text { "(5) [...] authorised for in } \\
\text { permanent or pulse baiting } \\
\text { treatments;" }\end{array}$ \\
\hline Flocoumafen & $\begin{array}{l}\text { "B.3.d. [...] authorised for use as a } \\
\text { permanent bait." }\end{array}$ & $\begin{array}{l}\text { "(5) [...] authorised for use in } \\
\text { permanent baiting treatments;" }\end{array}$ \\
\hline $\begin{array}{l}\text { Silicon dioxide } \\
\text { Kieselguhr }\end{array}$ & $\begin{array}{l}\text { "3.c. }[. . .] \text { in accordance with } \\
\text { Regulation (EC) No 470/2009 or } \\
\text { Regulation (EC) No 396/2005 [...]" }\end{array}$ & $\begin{array}{l}\text { "(3) [...] in accordance with } \\
\text { Regulation (EC) No } 470 / 2009 \text { of } \\
\text { the European Parliament and of } \\
\text { the Council or Regulation (EC) No } \\
396 / 2005 \text { of the European } \\
\text { Parliament and of the Council [...]" }\end{array}$ \\
\hline
\end{tabular}

(Source: Author's own compilation based on ECHA, 2016d, 2016e, 2016f; European Commission, 2017a, 2017b, 2017c) 
The interviews with the Commission officials also support the findings from the text comparison. One official emphasises: "So far, we haven't had any disagreement [on the approval or non-approval of active substances]. I wouldn't expect that [the Commission and ECHA] would have diverging views" (Interview \#1). Another official explains that while it is possible that the Commission and ECHA could have different views due to the nature of scientific opinions or risk management reasons, such disagreement has not happened. Moreover, the Commission, in general, has the view that "we always try to follow the scientific opinions and risk assessment provided by the Agency" (Interview \#2).

Although the text comparison between the BPC opinions and the drafts of Commission implementing acts shows the high influence of the Agency, it does not mean that the Commission is blindly following BPC opinions. Between 2015 and 2016, there were three active substances on which $\mathrm{BPC}$ recommended the inclusion in Annex 1 and the Commission did not follow the recommendations (Interview \#7). If certain active substances are characterised with low risk and concern, they could be placed on the list of Annex 1 . However, it is worth noting that many interview respondents from ECHA, the European Commission, and the national competent authorities consider that inclusion in Annex 1 is a political issue

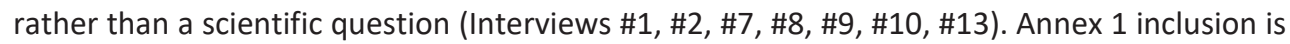
a topic for "legal and policy discussion" (Interview\#1). At the time of writing, the issues related to the management of specific requirements and provision of Annex 1 inclusion are still on the agenda for further policy discussion with national competent authorities on biocides. One Commission official argues that "it was not that there was disagreement [between ECHA and the Commission] or there was an error made [by ECHA], but we just needed further reflections on the management of this specific provision" (Interview \#1).

\section{Reputation}

Evidence on reputation gathered from the Member States, the European Commission, and various stakeholders is very positive. Considering that BPC has been operational only for three years so far, it is a remarkable achievement for ECHA and BPC that they have managed to make the whole approval procedure work smoothly, speed up the approval process in the Review Programme, and produce opinions that are taken up by the Commission almost word for word (Interviews \#4, \#5).

According to the 2013, 2014, and 2015 General Reports of ECHA, the level of satisfaction with the quality of scientific, technical, and administrative support provided to the members of BPC, Coordination Group, the Commission, Member State competent authorities, and industry is high (ECHA, 2014a, 2015, 2016a). Similarly, the Commission's evaluation report on ECHA in 2017 reveals that "[s]takeholders consulted via our survey consider that the Agency is effective in processing applications under BPR" (Deloitte \& VVA, 2017, p. 54). A majority of national competent authorities are also "satisfied with the quality of the support provided by 
the Agency regarding national authorisation and mutual recognition" (Deloitte \& VVA, 2017, p. 48).

Moreover, what is remarkable about ECHA is the added value it provides, and its contribution to the harmonisation of the EU's internal market, as recognised by national authorities, concerned third parties, and internationally. According to a study which assesses cost of nonagencies - that is, the cost of having the EU agencies as opposed to a hypothetical situation where the tasks carried out by these agencies are undertaken at the national level instead most of ECHA's national, European, and international stakeholders claim that the role of ECHA in the authorisation process and updating and maintaining the chemicals database cannot be easily transferred to any other bodies (Malan et al., 2016). A quotation from one of the study interviewees describes ECHA as an indispensable actor:

To skip the ECHA would generate a very serious situation. A harmonisation of chemical legislation needs a central steering agency. The collaboration between companies in different Member States would become very difficult [...,] without ECHA we would have the need to register in each country." (Malan et al., 2016, p. 44)

To conclude, the text comparison shows that ECHA's influence on Commission implementing regulations concerning active substances is high, and ECHA has established a good reputation as a scientific authority among its partners. The comparison between the BPC opinions from 2014 and 2016 reveals that the influence of ECHA recently increased to this high level, and this was possible mainly due to the strong support from the Commission by introducing guidelines and recommendations. The next two sections will analyse conditions for this high influence of ECHA, by applying three conditions, namely access, activities, and resources.

\subsubsection{Conditions for influence: Production of expert advice in ECHA}

This section analyses the three conditions in the production dimension of expert advice in ECHA. To strengthen the logic of the presentation, the third indicator - resources - is explained first.

\section{RESOURCES}

When analysing the production dimension of expert advice in ECHA, the limited financial and human resources are repeatedly pointed out as a challenge for ECHA to perform its tasks defined under BPR. This challenge has been noticed since the beginning of ECHA's involvement in the implementation of BPR. In 2012 when the Agency was undertaking the preparatory activities before BPR entered into operation, the Executive Director of ECHA stated that the new tasks came "with some extreme time and resource constraints" and carrying out the preparatory activities under this circumstance was described as "mission impossible" (ECHA, 2013a, p. 6). The initial preparatory work included the recruitment and 
training of ECHA staff and biocides experts, setting up of the Biocidal Products Committee, and the development of IT tools for submission of applications, working procedures, and necessary guidance documents (ECHA, 2013a). To perform these tasks, ECHA allocated 20 staff in 2012, including 11 newly recruited personnel. The staff number increased to 42 in 2013 with a large number of interim workers hired on an exceptional basis (Deloitte \& VVA, 2017; ECHA, 2013a, 2014a). Since then, the number of staff responsible for biocides has remained around 50 (Deloitte \& VVA, 2017; ECHA, 2017a). However, given the resource-intensive work in the area of biocides, ECHA staff believe that "biocides related operations are not adequately resourced" and the limited resources are still a challenge for the Agency (Deloitte \& VVA, 2017, p. 129).

The limited human resources partly resulted from the difficulty in recruiting and retaining highly scientific and technical experts in ECHA due to the specificity of the work itself. There is only a limited pool of experts from which ECHA can choose highly specialised profiles (Deloitte \& VVA, 2017). Some staff moved from national competent authorities to ECHA, and in some countries there are only a couple of experts specialised in biocides (Interview \#10). In addition, one could argue that a more profound factor is the remote geographic location of the agency. The first evaluation report of the agency from 2012 states:

[A] member of the Commission's recruiting team for the initial ECHA staff of 2007 told us it was frustrating to see candidates withdraw after three successful interviews, due to an unwillingness to relocate to Helsinki, where the Agency is located. ECHA offered higher than average grades and compensation to their potential employees, however the location was viewed as a disadvantage by potential employees. (PWC, 2012, p. 23)

Likewise, the Commission comments:

The location of ECHA in Helsinki is reported to pose a particular challenge for staffing. In spite of considerable, and highly appreciated, efforts of Finland and the City of Helsinki to create a welcoming environment for staff members and their families, promising candidates have been reported to turn down offers of employment for reasons linked to the climatic conditions, the remoteness of the location compared to the rest of the EU, and difficulties for spouses and partners to find attractive employment. (European Commission, 2013a, p. 82)

In terms of financial resources, ECHA received specific funding from the Commission in 2011 and 2012 for planning and initial preparation of its anticipated tasks for BPR (ECHA, 2012a, 2013a). However, one Management Board member argues that the amount of resources allocated in relation to BPR was "somewhat underestimated compared to the demand from the ECHA's point of view" (Interview \#6). As Table 5.4 shows, the budget under BPR was increased to $€ 7.48$ million in 2013 and to $€ 7.73$ million in 2014, and it was mostly covered by the EU contribution (ECHA, 2014a, 2015). In 2014, fee income was much lower than anticipated, resulting in heavy financial constraints on ECHA (ECHA, 2015). Although the fee 
revenue increased in the following years, uncertainty of fee income and the constraints in financial and human resources do not create a positive environment for influence of ECHA.

Table 5.4) ECHA's budget for BPR-related tasks

\begin{tabular}{|l|l|l|l|l|l|l|}
\hline \multicolumn{1}{|c|}{ Year } & \multicolumn{1}{c|}{$\mathbf{2 0 1 1}$} & \multicolumn{1}{c|}{$\mathbf{2 0 1 2}$} & \multicolumn{1}{c|}{$\mathbf{2 0 1 3}$} & \multicolumn{1}{c|}{$\mathbf{2 0 1 4}$} & \multicolumn{1}{c|}{$\mathbf{2 0 1 5}$} & \multicolumn{1}{c|}{$\mathbf{2 0 1 6}$} \\
\hline $\begin{array}{l}\text { EU } \\
\text { contribution }\end{array}$ & Unknown & 3.2 & 6.07 & 5.064 & 5.8 & Unknown \\
\hline $\begin{array}{l}\text { Biocidal } \\
\text { fee revenue }\end{array}$ & N/A & N/A & 0.31 & 1.265 & 5.4 & 7.6 \\
\hline $\begin{array}{l}\text { Other } \\
\text { contributions }\end{array}$ & N/A & N/A & 1.1 & 1.394 & 0.3 & Unknown \\
\hline $\begin{array}{l}\text { Total amount } \\
\text { (million } € \text { ) }\end{array}$ & Unknown & 3.2 & 7.48 & 7.73 & 11.5 & 8.6 \\
\hline
\end{tabular}

(Source: Author's own compilation based on the General Reports of ECHA between 2012 and 2017)

\section{ACCESS}

The challenge posed by limited resources has been effectively tackled by ECHA's access to internal and external networks. When new tasks were added to ECHA due to the adoption of $B P R$, the Executive Director emphasised the importance of increased efficiency and synergies between REACH, CLP, and BPR (ECHA, 2012b, 2012c). In particular, as the organisational structure of ECHA was set up with a function-based approach from the beginning, using "internal mobility" to share or transfer resources across different areas of the Agency was encouraged (ECHA, 2012c). When the Biocides Unit was created in February 2012 to manage BPC and carry out tasks defined under BPR, it was initially added to the Directorate B "Regulatory Affairs." But, it was moved to the Directorate D "Risk Management" in 2014 with the new name "Biocides Assessment Unit." As of May 2017, this Unit has 27 scientific staff and 7 administrative staff, who are divided into different teams dealing with either regulatory aspects or more scientific components of assessment (Interview \#4).

Collaboration among ECHA staff is evaluated to be good and it seems that it does not matter where the Biocides Assessment Unit is located because several tasks are managed in a horizontal manner, involving other Directorates where specific expertise is present (Deloitte \& VVA, 2017). For example, the Unit "Dossier Submission \& PIC" located in the Directorate C Registration "provides advice and support to stakeholders on dossier submission under REACH, CLP, biocides and PIC, in the form of technical manuals, helpdesk support and other communications activities." 91 In addition, a cross-Directorate team was created to support the rollout of the ECHA IT tools, such as IUCLID and R4BP 3, developed for the Member States'

\footnotetext{
${ }^{91}$ See https://echa.europa.eu/about-us/who-we-are/directorates-and-units/directorate-c.
} 
competent authorities and industry to access and communicate about biocides dossiers (ECHA, 2014a). ECHA's Helpdesks, which were created in each Member State to provide advice on the REACH and CLP regulations and IT tools, started also providing support on issues related to BPR in April 2013 (ECHA, 2014a). Furthermore, the assessment of harmonised classification and labelling of active substances, which is one element of the assessment report from eCA and BPC opinion, is not done by BPC but by the Committee for Risk Assessment in ECHA whose responsibilities cover both REACH and CLP (Interview \#13). Similarly, BPC cooperates with the PBT (Persistent, Bioaccumulative, and Toxic) Expert Group and the ED (Endocrine Disruptor) Expert Group of ECHA when the PBT or ED properties of an active substance are assessed (Deloitte \& VVA, 2017). The Biocides Assessment Unit also collaborates and cross-checks with the Legal Unit whenever there are issues that need to be clarified at the legal level or if there are new things in the application that might have practical implications (Interview \#4).

Outside the Agency, ECHA utilises its networks with the Member States, and this is particularly essential when producing BPC opinions on active substances and biocidal products. The main reason is that ECHA's role in the Union authorisation of biocidal products is relatively new, so "the Member States are more experienced in assessing biocidal products than ECHA" and "at this point in time, ECHA still needs to grow in this role" (Interview \#7). How ECHA utilises resources from the Member States to produce expert advice can be best illustrated by following the steps in the evaluation procedure of active substances and biocidal products.

When a Member State acts as a rapporteur to evaluate an application, the main source of information is the application dossier submitted by the applicant (Interviews \#7, \#13). There are many guidance documents produced by ECHA which explain what kind of studies should be included, how the studies should be done, how they should be written down, and so on (Interview \#7). The applicant has to conduct an assessment and include the result in the dossier. Based on the studies and assessment in the dossier, the evaluating competent authority formulates a draft opinion which consists of an assessment report and conclusions of its evaluation. The persons who actually conduct the assessment and make the assessment report are experts in the risks to humans, animals, and the environment and the efficacy of active substances or biocidal products. These experts are usually the evaluating competent authority's own staff, but some Member States with the limited human resources work with external experts (Interview \#12).

When a draft opinion is submitted to ECHA, the peer review process begins. The BPC members provide comments on the assessment report, which are written down in a so-called "commenting table" by ECHA, and the rapporteur can react on it. In this process, the BPC members also consult experts in their own competent authority to hear their comments and opinions on whether the draft opinion can be adopted or not (Interview \#8). All technical questions that are still open are discussed in the Working Groups of BPC. There are four Working Groups in the four fields - Efficacy; Analytical Methods and Physico-chemical Properties; Human Health; and Environment - and these Working Groups hold meetings prior to the BPC meetings to discuss and resolve these issues. The experts from the Member States' 
competent authorities - the "real experts who can do the assessment and discuss the results" - participate in the Working Group meetings as a core or flexible member (Interview \#7). Every Member State can appoint one member to each Working Group, and there are usually six core members per Working Group who comment on each and every dossier (Interview \#3). Other Member States participate as flexible members when there is an interest in a certain dossier or when their Member State acts as a rapporteur (Interview \#3).

Since Working Group meetings take place before BPC meetings, scientific issues are discussed at the Working Group level. Discussions in the BPC meetings are mostly on the terms and conditions that are necessary for the approval of active substances; or in case of non-approval, the main reasons for this conclusion are discussed (Interviews \#7, \#10). When rapporteurs attend the BPC meetings, they usually bring one staff member from their competent authority as an advisor, who answers all detailed questions that may arise and defends the assessment (Interviews \#3, \#7).

\section{ACTIVITIES}

Most contacts and exchanges between ECHA and the competent authorities as well as among BPC members take place during the peer review process. From the rapporteur's side, the nearer to finalisation of the evaluation process, the more frequent the communication with ECHA to discuss issues such as the need to involve any Expert Groups of ECHA or the need for an early Working Group discussion, or to ask advice on procedural issues such as delays in the evaluation process (Interviews \#8, \#13). From ECHA's side, the Agency engages in "regular checks" with the evaluating competent authority to "proactively ask whether they have issues they encounter or if they have any questions" (Interview \#4). The actual person who makes contact is called project leader or coordinator of the dossier from the competent authorities and in ECHA this is a dossier manager. Assigned to certain dossiers, they manage the life of the dossiers from submission to the BPC meeting and are the main contact point for these dossiers. Many interview respondents claim that ECHA and the Member States' competent authorities are in good and close cooperation, and there is direct and very good contact between the project leader and the dossier manager (Interviews \#4, \#6, \#7, \#9, \#10, \#11, \#13). The means of communication is usually emails, phone calls, or teleconferences (Interviews \#4, \#8, \#9, \#13).

With regard to contact among BPC members, they do not engage in regular contact with each other. This contrasts to the frequent contact between ECHA and the competent authorities, especially those acting as rapporteurs. Only during the peer review process or close to the BPC meetings do they contact each other. "As soon as severe issues with respect to the active substances evaluated by the rapporteurs are identified in advance of the BPC meetings, we are in contact" (Interview \#8). One BPC member elaborates further: 
Only when needed, I have contact with other BPC members. But, because we [the BPC members] are five times a year, a few days each, in Helsinki, we get good contact and network. When needed, it is not difficult to pick up the phone and discuss [issues in the draft opinions] with the colleagues in BPC, also with the Chair or the secretariat of BPC. (Interview \#7)

Another BPC member also explains:

If there is a need, contacting other members or other competent authorities is not a problem. [...] Communication is quite easy because I know the BPC members from other counties and the members of the Working Groups. So, depending on the question, I can address it to the right person or at least know how to find an answer in a very quick way. [...] I think the network and cooperation is quite good. (Interview \#10)

When the BPC members are in Helsinki for the committee meetings, they also use their lunch time and coffee breaks to network and discuss issues, and opinions are shared in this type of informal meeting (Interview \#7). As the BPC members interact with each other over time, they come to know each other personally, and a feeling of mutual responsibility for the outcome of the work emerges (see Egeberg, 1999). One interviewee describes:

The field of biocides is very small compared to other chemical-related areas, such as pharmaceuticals, pesticides, or cosmetics. The number of experts specialised in biocides is small, and the longer you are involved [in this field], the better you know each other. [...] It is like a family, but the family that doesn't necessarily agree on every issue." (Interview \#15)

All these formal and informal contacts among the BPC members help the committee to share knowledge and strengthen their expertise, and this makes the group a "very efficient committee" (Interview \#8). Evidence of efficiency is that "discussions are normally finalised on the first attempt and postponing issues to later meetings is an exception" (Interview \#8). "From a BPC perspective, there is a good mix of members with background in various scientific disciplines, and many of them have had experience or are currently at a more technical level" (Interview \#11).

Nevertheless, it should be noted that while all Member States are represented in BPC, "it might be only about 10 countries who are actively involved" (Interview \#7). One member calls the non-participating Member States a "silent majority," and explains that "unfortunately, a high number of Member States do not have enough resources to actively participate in the BPC discussions" (Interview \#8). In fact, some BPC members are overloaded with work in their competent authority and in some cases, the competent authorities do not have enough experts who can attend different meetings and one and the same person is sent to the BPC meetings, Standing Committee meetings, and competent authority meetings. The members facing these situations do not have time and resources to prepare for the meetings and usually focus only on the items that are of interest to their country. One member explains that 
last week, before the BPC meeting, we tried to follow some documents that were most interesting to us and discussed internally. Definitely, we were not prepared for the discussion for all documents, even the ones that we chose. (Interview \#10)

Although there is a general consensus that BPC has expertise that is sufficient and at a high level and produces high quality opinions, not all members participate in the discussions and "this is an unsatisfying situation for the Chair of BPC and the members contributing actively" (Interview \#8).

The next section analyses the provision dimension of expert advice from ECHA to the European Commission and discusses how it contributes to the high influence of the Agency.

\subsubsection{Conditions for influence: Provision of expert advice from ECHA to the European}

\section{Commission}

\section{ACCESS}

In terms of the three possible ways for $\mathrm{EU}$ agencies to access the Commission - by request from the Commission, by own initiative of EU agencies, or by being involved in the legislative process as a prerequisite step - ECHA's access to the Commission is certainly "secured" as one crucial part of the decision-making process for active substance approvals and Union authorisations of biocidal products. During the authorisation procedure, which is illustrated in Figure 5.1, ECHA "shall prepare and submit to the Commission an opinion on the approval of the active substance" ${ }^{\prime 2}$ within 270 days of receipt of the conclusions of the evaluation from the evaluating competent authority. For Union authorisation of biocidal products, the time frame is reduced to 180 days..$^{93}$ On the basis of opinions from ECHA, the Commission drafts Commission implementing regulations or decisions, meaning that ECHA's opinions are prerequisite for the Commission to begin its work in the authorisation procedure.

In addition to the involvement of ECHA as a procedural step, the Agency has also provided its expert advice to the Commission based on the requests of the Commission. Article 75(1)(g) of BPR states:

The Biocidal Products Committee shall be responsible for preparing the opinion of the Agency [...] at the request of the Commission or of Member States' competent authorities, any other questions that arise from the operation of this Regulation relating to technical guidance or risks to human health, animal health or the environment.

When ECHA receives a question from the Commission, it informs BPC and in the following BPC meeting, a rapporteur is appointed. Either this could be one of the BPC members, or one of ECHA's scientific staff who does not belong to BPC acts as a rapporteur. When the rapporteur

\footnotetext{
${ }^{92}$ Article 8(4) of BPR.

${ }^{93}$ Article 44(3) of BPR.
} 
prepares a draft opinion, it is discussed in the BPC meeting, and the opinion is amended if necessary before being submitted to the Commission. On the webpage of BPC ${ }^{94}$ there is a section titled "Opinions on other questions." This is where all BPC opinions developed under Article 75(1)(g) of BPR can be found. By the end of 2017, there were seven opinions in total which provide answers to various questions from the Commission. Two of them were produced in 2014, one in 2015, and four in 2017.

\section{ACTIVITIES}

ECHA and the Commission have had a "very cooperative and collaborative atmosphere" since the very beginning:

We were communicating and exchanging a lot with the Commission via phone calls, emails, and physical meetings because it was a matter of understanding all the provisions in BPR and also to have a common ground to understand what the requirements were and what the Commission expected from us [ECHA]. (Interview \#4)

ECHA and the Commission have regular exchanges with each other, and if ECHA faces issues concerning biocidal products applications, it cross-checks with the Commission (Interview \#4). "It is usually very fruitful because we try to reach a common understanding so that we are aligned on the issues" (Interview \#4).

What is also important to mention is that the Commission has always been a part of the Biocidal Products Committee. From the first meeting of BPC in March 2013 up until now, one or two representatives from the European Commission have always participated in the BPC meetings as observers. To be more specific, these Commission representatives are from Unit E4 "Pesticides and biocides" under the Directorate E "Food and feed safety, innovation" in DG SANTE. Since there are only a small number of people in charge of biocides-related issues in Unit E4, usually the same persons attend the BPC meetings. They cannot vote on BPC opinions because they are not formal members of BPC. However, they participate in the discussion and speak out whenever necessary. For example, when the BPC members are not clear about how to interpret and apply some provisions of BPR or when the planning of the assessment of applications is being delayed, the Commission representatives always take the floor (Interview $\# 7)$.

The Commission's presence in the opinion-forming stage in BPC meetings is a crucial factor for ECHA's influence. It enables the Commission to exchange views with the scientific experts responsible for risk assessment at an early stage (Interviews \#1, \#2). It also gives an opportunity for the Commission to understand the core issues of discussion regarding the active substances on which the Commission has to take decisions in the later legislative stage (Interview \#9). One BPC member elaborates further that in the BPC meetings there is an

\footnotetext{
${ }^{94}$ See https://echa.europa.eu/about-us/who-we-are/biocidal-products-committee.
} 
"expected input" from the Commission, which is to point out what remains unclear in the draft BPC opinions even after the discussion by the members is done (Interview \#7).

When the Commission does not understand what is there [in the BPC opinion], of course it should be clarified. So, that is the good thing that the Commission is there [in the BPC meetings] because if they receive the opinion after the BPC meeting is over and say "I do not understand it," then it is a little bit late. (Interview \#7)

Another BPC member also states that since the Commission attends the BPC meetings, "this makes situations where the Commission has reservations with regard to the BPC opinions very rare" (Interview \#8). The direct effect of the Commission's participation in the BPC meetings is that the Commission is able to "ensure that the opinions from the Committee can be directly processed in the Commission without a need to re-discuss with the Member States" (ECHA, 2013 b, p. 6). It does imply that the Commission intends to keep all potential issues resolved at the BPC level before the BPC opinion is finalised and submitted to the Commission, and thus the Commission can use the BPC opinion to formulate implementing acts without reevaluating the opinion.

Additionally, the BPC members have a good relationship and collaborate closely with the members from the same country in the Standing Committee on Biocidal Products. This is the official body that takes a vote on the Commission proposals for implementing regulations or implementing decisions. Almost all BPC members give the Standing Committee member from their country an oral update or a short report about the issues discussed in the BPC meetings and recommend how he/she should vote in the Standing Committee (Interviews \#7, \#8, \#9, \#10, \#12, \#13). Occasionally, some BPC members accompany their Standing Committee members as an advisor, and some countries even send one and the same person to both BPC and Standing Committee meetings (Interviews \#7, \#9, \#12). "Most of the time, I would say in 99 percent of the cases, what happens in the Standing Committee on Biocidal Products is really only voting because the discussions have already been done in the BPC meetings" (Interview \#7). Having said that, it becomes clear that ECHA, via BPC and its members, maintains a cooperative relationship and network with the Commission and to a certain extent with the Standing Committee on Biocidal Products.

\section{RESOURCES}

The last condition to be analysed is the number of scientific outputs of BPC as resources to influence the Commission decisions. BPC has increased its scientific output since 2014. It produced 34 opinion in 2014, 49 in 2015, and 53 in 2016 (ECHA, 2015, 2016a, 2017a). Out of these numbers, 31 in 2014, 46 in 2015, and 41 in 2016 are the opinions produced for the existing active substances that are included in the Review Programme (ECHA, 2015, 2016a, 2017a). The active substances that were already on the market on 14 May 2000 as an active substance for a biocidal product are in the Review Programme, and every active substance in 
this Programme is subject to an assessment based on updated evidence of risk. Between 2001 and 2013 - thus under BPD - only 90 opinions were issued. As on January 2017, there are 453 active substances still in the Review Programme, and ECHA has the annual target of delivering 50 such opinions per year so that the Review Programme on existing active substances will be finalised in 2024 as planned (ECHA, 2017a; Interview \#3). Compared to the speed under BPD, " $[t]$ he peer review process has, as foreseen, become significantly more efficient than in the past ( 3.5 times more), amongst others due to the efficient management of the process and meetings and the scientific support provided by ECHA" (ECHA, 2015, p. 48).

As explained in the previous case, the format of the BPC opinion has been revised several times to make it more appropriate for its intended use by the Commission. The BPC opinions used to include detailed information, recommendations, risk mitigation measures, and so on, which were also explained in the assessment report from eCA. These duplicated parts were streamlined and standardised (Interview \#9). As a consequence, section 2.3 of BPC opinions, which is most relevant for the Annex of Commission implementing acts, became simplified, coherent, and more focused on the key issues and could be more directly included in the Commission's drafts (Interview \#9).

In addition, ECHA has produced a number of Guidance documents to assist the work of the BPC members and applicants, and many of these documents have been updated several times. In 2013 alone, ECHA presented five new Guidance documents, namely "Guidance on information requirements," "Guidance on applications for technical equivalence," "Regulatory guidance on the Biocidal Products applications," "Guidance on active substance suppliers," and "Vol. III Human Health, Part B Risk Assessment" (ECHA, 2014a). Likewise, ECHA has contributed to the drafting of the Commission's documents, such as User Guides on Data Sharing, Letters of Access, Consortia, and SME-specific considerations in preparation for the Article 95 deadline (ECHA, 2014a, 2015, 2016a).

It should be noted that the number of scientific outputs of BPC will increase in the near future. As explained earlier, BPC has produced opinions concerning active substances, which is the first step of the two-step system of the regulatory framework for biocides. Only during the latter half of 2015, the first 11 applications for the Union authorisation of biocidal products came in (ECHA, 2016a). After the discussion at the Working Groups, "if everything goes smoothly, ECHA expects to produce the first opinions on the Union authorisation of biocidal products at the BPC meeting in December 2017" (Interview \#4). This means that on top of the annual target of 50 BPC opinions on active substances in the Review Programme, BPC will also produce its opinions on the authorisation of biocidal products.

This section showed that resources, access, and activities are all working favourably for the high influence of ECHA in the Commission. Unlike the other case in this chapter and the two cases in the previous chapter on ECDC, ECHA's access to the Commission is secured as a prerequisite to formulating and adopting a decision on Commission implementing acts. Although recruiting and maintaining experts and ensuring stable financial revenue create a 
challenge, ECHA is able to produce a high volume of expert advice by encouraging internal collaboration and by exploiting external partners and their resources. All these activities take place frequently and regularly. The following section will summarise the main findings of the two cases analysed in this Chapter and discuss what they imply with respect to the influence of ECHA.

\subsection{Conclusion}

This chapter analysed the influence of ECHA on the Commission proposal for BPR (Case 1) and on the Commission implementing acts on the approval of active substances for biocidal products (Case 2). The summary of each case analysis is presented in Table 5.5 below.

Table 5.5) A comparative look at ECHA influence and influence conditions in two cases

\begin{tabular}{|c|c|c|c|c|c|}
\hline & \multicolumn{2}{|c|}{ CASE 1} & \multicolumn{2}{|c|}{ CASE 2} \\
\hline Influence & Text comparison & \multicolumn{2}{|c|}{ Moderate } & \multicolumn{2}{|c|}{ High } \\
\hline dimension & Reputation & \multicolumn{2}{|c|}{ Good } & \multicolumn{2}{|c|}{ Very good } \\
\hline Conditions & & $\begin{array}{l}\text { Production } \\
\text { dimension }\end{array}$ & $\begin{array}{l}\text { Provision } \\
\text { dimension }\end{array}$ & $\begin{array}{l}\text { Production } \\
\text { dimension }\end{array}$ & $\begin{array}{l}\text { Provision } \\
\text { dimension }\end{array}$ \\
\hline Access & & $\begin{array}{l}\text { Internal and } \\
\text { external } \\
\text { networks }\end{array}$ & $\begin{array}{l}\text { Only by } \\
\text { request }\end{array}$ & $\begin{array}{l}\text { Internal and } \\
\text { external } \\
\text { networks }\end{array}$ & $\begin{array}{l}\text { Both by } \\
\text { request and } \\
\text { as a } \\
\text { procedural } \\
\text { step }\end{array}$ \\
\hline Activities & & $\begin{array}{l}\text { Not } \\
\text { frequent } \\
\text { and not } \\
\text { regular }\end{array}$ & $\begin{array}{l}\text { Not } \\
\text { frequent } \\
\text { and not } \\
\text { regular }\end{array}$ & $\begin{array}{l}\text { Frequent } \\
\text { and regular }\end{array}$ & $\begin{array}{l}\text { Frequent } \\
\text { and regular }\end{array}$ \\
\hline Resources & & Very scarce & Limited & Limited & Sufficient \\
\hline
\end{tabular}

(Source: Author's own compilation)

ECHA's level of influence in the two cases is different. In the first case, based on the text comparison, it is shown that ECHA exerted a moderate level of influence and was establishing a good reputation in the early years of its operation. ECHA did not have any financial and human resources dedicated to biocides-related tasks, but it was still able to produce expert advice on the proposal for BPR by learning from its own staff who had experience with the REACH implementation and also learning from EMA and national competent authorities who had expertise on the authorisation procedure either at the European or the national level. ECHA provided expert advice only when it was asked to by the Commission, and while the exact number of documents containing expert advice from the Agency is unknown, it is 
expected that it would not greatly exceed the two used for this research. In both dimensions, ECHA's activities with its network partners were sporadic instead of on a regular basis.

In the second case, it is verified through the text comparison that ECHA maintains a high level of influence on the Commission decisions for the approval of active substances. The influence has increased over time as the text comparison demonstrated, and ECHA is enjoying a very good reputation as a scientific authority. In terms of the production of expert advice, the situation is better than in the first case as ECHA has the dedicated budget and staff for biocides. Yet, the resources are still considered to be insufficient to match the resource-intensive work. This challenge has been effectively tackled by utilising both its own staff located in different Units via cross-directorate cooperation, as well as the BPC members and their resources at the national competent authorities. ECHA delivers expert opinions not only by request from the Commission but also as a procedural step in the decision-making process for active substances and biocidal products. ECHA maintains a close network with the Commission and even with the Standing Committee on Biocidal Products to a certain extent, and the Commission also contributes to the formation of BPC opinions by participating in every BPC meeting. The number of scientific outputs produced by BPC has increased and will increase further as applications for the Union authorisation of biocidal products are being discussed on top of applications for the approval of active substances. In contrast with the first case, ECHA's networking activities with the internal and external partners have been very frequent and on a regular basis.

The human and financial resources were not sufficient in both cases, but this challenge was effectively tackled by the internal and external networks that the agency actively utilised. It is particularly evident in the production dimension that ECHA gained more expertise by learning from experts in its networks. With regard to the provision dimension, the secured access to the Commission as a procedural step in the authorisation process is definitely crucial. Due to this, improving the format and quality of BPC opinions was of interest to the Commission so that the Commission could apply the opinions more directly to the implementing acts. The participation of the Commission in the BPC meetings in this context also contributes positively to the influence of ECHA.

The following chapter will compare the empirical findings from ECDC and ECHA and further discuss implications of these findings on the influence of EU agencies from a comparative perspective. 

Chapter 6

A Comparative Analysis between ECDC and ECHA 


\subsection{Introduction}

This research has applied both cross-case and within-case analyses. At the within-case level, one general legislative proposal (least-likely case) and one technical proposal (most-likely case) were selected and analysed for each agency. The findings were presented in Chapter 4 on ECDC and in Chapter 5 on ECHA. While the previous two chapters provide the detailed analyses of the influence of ECDC and ECHA on specific policy dossiers, a comparison at the cross-case level is necessary to deduce a general understanding about under which conditions and to what extent EU agencies exert influence in the policy formulation stage. Thus, this chapter provides a comparative analysis of the two EU agencies - ECDC and ECHA. The aim of this chapter is twofold: 1 ) to perform a comparative analysis of the influence and conditions for influence from the two empirical studies on ECDC and ECHA; and 2) based on this comparative analysis, to evaluate the expectations stated in Chapter 3 "Research Design and Methodology" in order to highlight the main findings.

This chapter is organised as follows: the next section compares the four case studies at the cross-case level. This is done through a comparison between the two least-likely cases and a comparison between the two most-likely cases (Section 6.2). Based on the observations made in this section, the expectations stated in Chapter 3 are validated (Section 6.3) which further helps illustrate the meanings and implications of the influence of ECDC and ECHA (Section 6.4). Before stating concluding remarks, Section 6.5 will explain other observations which do not constitute the main findings but provide insights into the conditions and measurement concerning the influence of EU agencies.

\subsection{Comparison at the cross-case level}

\subsubsection{Comparison between the two general legislative proposals}

General legislative proposals cover broad and often political items which set the general aims, guidelines, and regulatory directions in the policy field. They are considered as least-likely cases for EU agencies' influence (see Subsection 3.7.1). In this category, ECDC's influence on the Commission proposal on serious cross-border threats to health and ECHA's influence on the Commission proposal for a regulation concerning biocidal products were analysed. For an effective comparison of the influence of ECDC and ECHA on these general legislative proposals, Table 6.1 presents the summary of the two case studies. 
Table 6.1) Comparison between the two agencies' influence and conditions regarding general legislative proposals (least-likely cases)

\begin{tabular}{|c|c|c|c|c|c|}
\hline & & \multirow{2}{*}{\multicolumn{2}{|c|}{$\begin{array}{l}\text { ECDC: } \\
\text { Proposal for cross-border } \\
\text { threats to health } \\
\text { Low }\end{array}$}} & \multirow{2}{*}{\multicolumn{2}{|c|}{$\begin{array}{l}\text { ECHA: } \\
\text { Proposal for biocidal } \\
\text { products regulation } \\
\text { Moderate }\end{array}$}} \\
\hline \multirow{2}{*}{$\begin{array}{l}\text { Influence } \\
\text { dimension }\end{array}$} & Text comparison & & & & \\
\hline & Reputation & \multicolumn{2}{|c|}{ Good } & \multicolumn{2}{|c|}{ Good } \\
\hline \multicolumn{2}{|l|}{ Conditions: } & $\begin{array}{l}\text { Production } \\
\text { dimension }\end{array}$ & $\begin{array}{l}\text { Provision } \\
\text { dimension }\end{array}$ & $\begin{array}{l}\text { Production } \\
\text { dimension }\end{array}$ & $\begin{array}{l}\text { Provision } \\
\text { dimension }\end{array}$ \\
\hline \multicolumn{2}{|c|}{$\begin{array}{l}\text { Access } \\
\text { (opportunities to access } \\
\text { experts) }\end{array}$} & $\begin{array}{l}\text { Internal } \\
\text { network }\end{array}$ & $\begin{array}{l}\text { Only by } \\
\text { request }\end{array}$ & $\begin{array}{l}\text { Internal and } \\
\text { external } \\
\text { networks }\end{array}$ & $\begin{array}{l}\text { Only by } \\
\text { request }\end{array}$ \\
\hline \multicolumn{2}{|c|}{$\begin{array}{l}\text { Activities } \\
\text { (frequency of interaction) }\end{array}$} & $\begin{array}{l}\text { Frequent } \\
\text { and regular } \\
\text { (only } \\
\text { internally) } \\
\end{array}$ & $\begin{array}{l}\text { Not } \\
\text { frequent } \\
\text { and not } \\
\text { regular }\end{array}$ & $\begin{array}{l}\text { Not } \\
\text { frequent } \\
\text { and not } \\
\text { regular }\end{array}$ & $\begin{array}{l}\text { Not } \\
\text { frequent } \\
\text { and not } \\
\text { regular }\end{array}$ \\
\hline \multicolumn{2}{|c|}{$\begin{array}{l}\text { Resources } \\
\text { (organisational resources \& } \\
\text { scientific output) }\end{array}$} & Limited & Limited & Very scarce & Limited \\
\hline
\end{tabular}

(Source: Author's own compilation)

The summary of the two cases demonstrates that the three conditions - access, activities, and resources - in the production and provision dimensions were not conducive to the influence of ECDC and ECHA. The only exception was ECHA's access in the production dimension since ECHA utilised internal as well as external experts. Due to the fact that there were no designated experts responsible for biocides-related issues (which explains very scarce resources of ECHA in the production dimension), ECHA actively sought expertise from inhouse experts in charge of the REACH regulation as well as from EMA and national competent authorities to become acquainted with the formal and practical aspects of the authorisation procedures. But still, ECHA's interaction with the internal and external partners was neither frequent nor on a regular basis.

In the case of ECDC, the frequent and regular interaction between its in-house experts could have been a contributing factor to the influence of ECDC, but its impact was very limited as proven by a low level of influence. In the provision dimension of expert advice, furthermore, there is no variation between ECDC and ECHA. All three conditions were not conducive to their influence on the general legislative proposals. They provided expert advice to the Commission in a reactive manner because they responded with expert advice only when they were requested to do so, and advising the Commission did not occur based on their own initiative. 
Therefore, it was not surprising that their interaction with the Commission was not frequent and that the number of scientific outputs from ECDC and ECHA was also limited.

What is interesting is a variation in their level of influence. While ECDC's influence was low, ECHA exerted a moderate level of influence. This means that there was no overlapping text between the Commission proposals and the documents from ECDC and ECHA which contain expert advice. Moreover, the Commission did not refer to any documents from these agencies. However, to a certain extent, the Commission indeed took ECHA's expert advice into consideration when formulating the Commission proposal for the biocidal products regulation. The Commission accepted some - not all - suggestions proposed by ECHA, and they were reflected in the Commission proposal. What explains the different levels of influence between ECDC and ECHA when all conditions were generally not favourable to their influence?

Three factors observed in the empirical research provide plausible explanations. First, ECHA was given a privileged position by the Commission to provide expert advice on the Commission proposal for BPR. As explained in Chapter 5, the Commission initially considered EMA, EFSA, and ECHA as possible candidates to perform the risk assessment role in the field of biocides. Out of the three agencies, ECHA was chosen by the Commission as this was expected to create significant synergies between its existing mandate and the new regulation. From that moment, the Commission sent its requests for expert advice concerning the role of a centralised evaluating body or the authorisation procedure to ECHA, not to EMA or EFSA. During the policy formulation stage, the Commission sought policy input also from other external sources such as the Commission JRC, relevant competent authorities in the Member States, and stakeholders. But, since ECHA was going to be the main body in charge of the risk assessment of active substances and biocidal products, it became the dominant advisor on the topics directly related to the authorisation procedure of biocidal products, and it was logical for the Commission to pay close attention to expert advice from ECHA.

One may point to the fact that the Commission also chose ECDC to have informal consultations in the early drafting stage and asked for expert advice particularly on the preparedness and response planning. However, ECDC did not hold a privileged position such as ECHA enjoyed because ECDC was just one of many bodies that provided policy input to the Commission. In fact, the Commission requested policy input on serious cross-border health threats from various actors, including other EU agencies (EMA and CHAFEA), the Health Security Committee, and the EWRS network. Moreover, the Commission carried out an open stakeholder consultation and held bilateral consultation meetings with six Member States. The Commission did not initiate these types of consultations when formulating the proposal for BPR.

The second factor that affected the different levels of influence is connected to this point. In the case of the Commission proposal on cross-border threats to health, the Commission engaged in consultations with diverse actors because the topics covered by the proposal were very broad, from communicable diseases to threats caused by environmental effects and of 
biological, chemical, or unknown origin. Although the Commission proposal for BPR discussed the general direction and mechanisms for chemicals regulation in the $\mathrm{EU}$, the issues included in the proposal were focused on biocidal products. This implies that ECDC had a less explicit stake in the proposal on cross-border health threats compared to its stake in the Commission Communication on the H1N1 pandemic and to ECHA's stake in the two case studies.

Third, the types of expert advice required by the Commission and provided by the EU agencies mattered. Metz (2015) claims that the Commission, when designing European legislation, needs not only technical expertise for knowledge-based problem-solving but also policy expertise for operational aspects of the policy and political concerns. This supports what Duncan and Harrop (2006, pp. 168-169) argue:

[In the policy formulation stage] information that draws together lessons from abroad or considers the potential impact and views of different groups of people is of value, alongside conceptual thinking about the implications of the basic principles of the policy. Pilots may be set up to test whether the new policy will work in practice.

ECHA's expert advice on the Commission proposal for BPR resembled the type of information quoted above. ECHA produced expert advice by learning from its staff and experts responsible for the REACH regulation as well as from the European Medicines Agency, which were involved in the authorisation of safe chemicals and medicines respectively. Moreover, ECHA carefully analysed operational aspects of the Union-level authorisation procedure and proposed, for example, a longer time frame for the evaluation of applications than initially proposed by the Commission. In addition, ECHA suggested that applicants should supply data and information necessary for the evaluation instead of this being done by evaluating competent authorities who had been responsible for gathering such information under the previous regulatory framework of BPD. This reveals that ECHA offered both subject-matter expertise and policy expertise regarding policy instruments and knowledge of how the policy would work.

While ECDC provided both technical and policy-relevant expertise on the H1N1 pandemic (examples include possible travel restrictions and vaccination strategies), its expert advice on the Commission proposal on cross-border threats to health focused mostly on scientific and technical issues of specific diseases. This can be easily seen in the list of ECDC's documents analysed in relation to the Commission proposal on cross-border health threats (see Appendix 2). ECDC played a purely scientific role when advising the Commission, perhaps because analysing potential impact and implications of the proposed legislation was beyond its capacity due to the wide range of issues discussed in the proposal. Or perhaps it felt that providing policy expertise was beyond its mandate as the EU has complementary competence in public health issues and ECDC has a "scientific" advisory role. In a situation in which there is no access to ECDC's scientific opinions produced on the basis of the Commission's requests (see Chapter 4), it remains a matter of speculation why ECDC concentrated mainly on subjectmatter expertise. 


\subsubsection{Comparison between the two technical proposals}

Policy proposals that are technical in nature are considered as most-likely cases for the influence of EU agencies. In this research, the two technical proposals analysed are the Commission Communication on the H1N1 pandemic (for ECDC's influence) and the Commission's implementing measures on the approval of active substances under BPR (for ECHA's influence). Table 6.2 presents the summary of these analyses.

Table 6.2) Comparison between the two agencies' influence and conditions regarding technical proposals (most-likely cases)

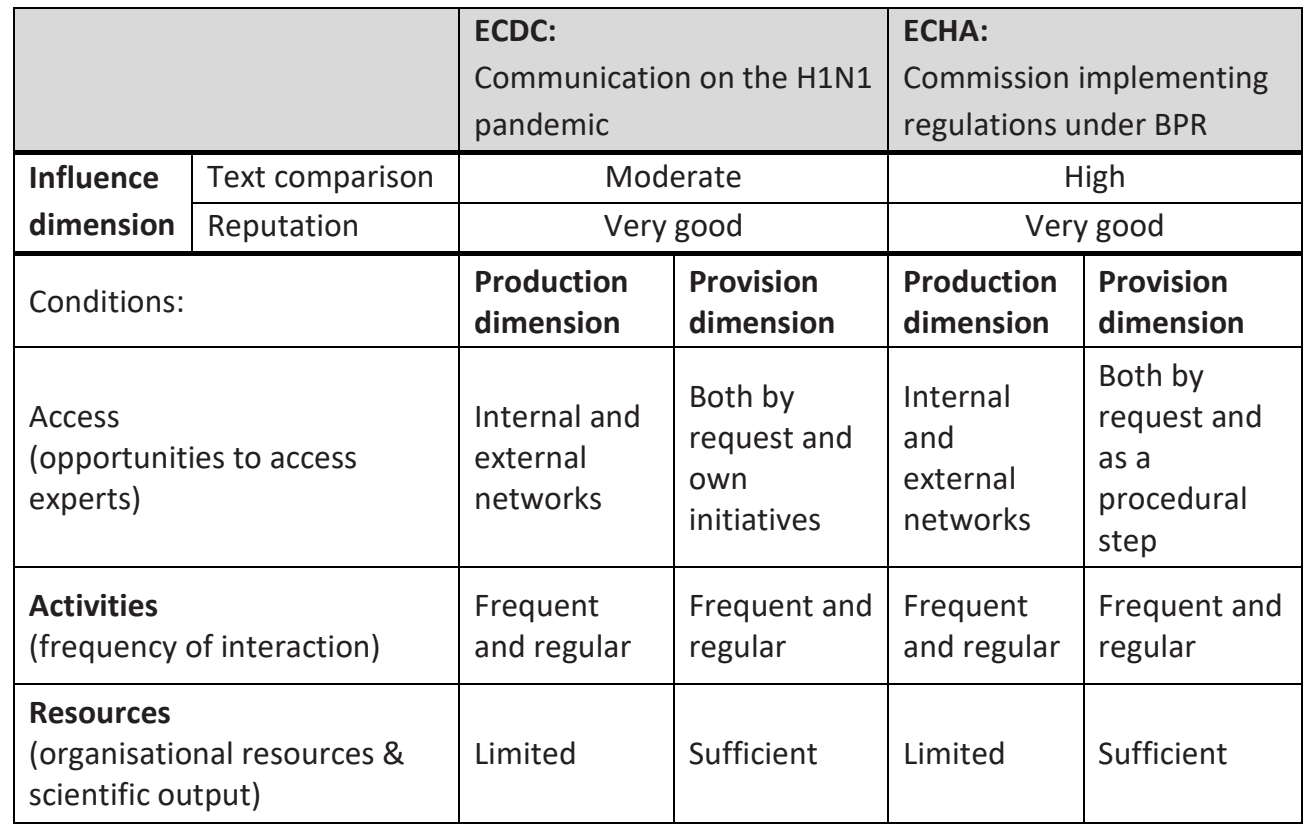

(Source: Author's own compilation)

This table shows two distinct differences compared to the analysis for the general legislative proposals presented in the previous section. First, except for the limited resources in the production dimension in ECDC and ECHA, all conditions in both production and provision dimensions were conducive to their influence. Both agencies were active in pooling expertise from internal and external experts and interacted with them frequently. Their interaction with the Commission was also frequent and regular. ECDC provided expert advice based on the requests from the Commission and the Centre's own initiatives. ECHA's expert advice was submitted to the Commission as part of the authorisation procedure under the biocidal products regulation, and it also provided expert advice when the Commission requested it. The number of scientific outputs was sufficient in ECDC and ECHA. In particular, ECHA has an 
annual target of 50 opinions on the active substances in the review program, on top of the evaluation of new active substances and biocidal products (see Chapter 5).

Second, both agencies did exert influence on the formulation of the Commission proposals. ECDC had a moderate level of influence on the Commission Communication on the H1N1 pandemic, and the influence of ECHA has been high on each and every implementing measure drafted by the Commission on the approval or non-approval of active substances under BPR. ${ }^{95}$ On regulatory decisions about active substances that are intended for use in biocidal products, the text of ECHA's expert advice has been literally copied into the Commission Implementing Regulations (in the case of approval) and Implementing Decisions (in the case of non-approval). Regarding ECDC, the topics of the H1N1 pandemic crisis were highly complex and technical and as explained in Chapter 4, the Centre exerted high influence on other relevant technical measures that dealt with specific issues derived from the pandemic crisis. However, ECDC's influence was not as high as ECHA's. When all conditions in both dimensions in ECDC and ECHA were conducive to their influence, why was ECHA able to exert high influence while ECDC exerted moderate influence?

As Table 6.2 indicates, the only variation in the conditions between ECDC and ECHA is access in the provision dimension. Unlike ECDC, ECHA's participation in the development of the Commission's implementing acts is "secured" as a necessary prerequisite. The fact that the legally defined procedure under BPR requires the Commission to receive scientific opinions from ECHA contributes positively to its high influence for the following reasons. First, the logic behind this procedure is that ECHA's expert advice provides the grounds for the Commission's evidence-based decision-making. Since the Commission formulates implementing measures based on ECHA's input, the Commission has a strong incentive to guide ECHA to draft expert advice in a way that is easily and directly usable by Commission officials. In the early period of the operation of the Biocidal Products Committee in ECHA, the Commission was not satisfied with the style of ECHA's scientific opinions and indeed provided guidelines regarding how scientific opinions should be formatted and phrased.

Second, this structure further motivates the Commission to participate in the opinion-forming process within the Agency. In fact, the Commission has not missed a BPC meeting, and one or two Commission officials have always been present. ECHA and the Commission have a core interest here. For the Commission, participating in the BPC meetings gives it a crucial opportunity to understand the fundamental issues under discussion (thus, concerning the topic) and to point out unclear parts of the scientific opinions that need to be rephrased (concerning the style). For ECHA, this approach allows for its scientific opinions to receive

\footnotetext{
${ }^{95}$ As explained in Chapter 5, after BPR came into operation in September 2013, the approval and non-approval of active substances that could be used in biocidal products were carried out first in a two-step approach. The first opinions of ECHA on the Union authorisation of biocidal products were discussed only in December 2017 when BPC convened its $23^{\text {rd }}$ meeting (ECHA, 2017b).
} 
feedback from the main user - the Commission - prior to official adoption by the Agency and submission to the Commission.

Third, because the Commission has already reviewed and given its feedback on the scientific opinions of ECHA - and if needed, BPC revises its scientific opinions according to the feedback from the Commission - there is no need for the Commission to scrutinise these opinions again when they are transmitted to the Commission. At this point, ECHA's scientific opinions are readily useable by Commission officials, and this increases the possibility for ECHA to exert high influence. The implications of this immediate usability on the influence of EU agencies are further discussed in Section 6.4.

\subsection{Validating expectations}

This section reflects upon how the three conditions for influence corroborate the numbered expectations presented in Chapter 3 on the research design and methodology. To review and effectively present the expectations, they are listed in Table 6.3 below. The last column of this table indicates whether the expectations are confirmed or rejected.

Table 6.3) Expectations about the conditions for influence

\begin{tabular}{|c|c|c|}
\hline Number & Expectation & Validation \\
\hline 1.1 & $\begin{array}{l}\text { The more access points an EU agency has under the formal rules } \\
\text { and informal practices to produce expert advice, the more } \\
\text { influence it is likely to exert in the policy-making process. }\end{array}$ & Rejected \\
\hline 1.2 & $\begin{array}{l}\text { The more access points an EU agency utilises via requests, its } \\
\text { own initiative, and as part of the official procedure to provide } \\
\text { expert advice, the more influence it is likely to exert in the } \\
\text { policy-making process. }\end{array}$ & $\begin{array}{l}\text { Confirmed } \\
\text { if modified }\end{array}$ \\
\hline 2.1 & $\begin{array}{l}\text { The more frequent the networking activities an EU agency } \\
\text { engages in to produce expert advice, the more influence it is } \\
\text { likely to exert in the policy-making process. }\end{array}$ & Rejected \\
\hline 2.2 & $\begin{array}{l}\text { The more frequent the networking activities an EU agency } \\
\text { engages in to provide expert advice, the more influence it is } \\
\text { likely to exert in the policy-making process. }\end{array}$ & Rejected \\
\hline 3.1 & $\begin{array}{l}\text { The more administrative resources an agency possesses to } \\
\text { produce expert advice, the more influence it is likely to exert in } \\
\text { the policy-making process. }\end{array}$ & Rejected \\
\hline 3.2 & $\begin{array}{l}\text { The more scientific resources an agency possesses to provide } \\
\text { expert advice, the more influence it is likely to exert in the } \\
\text { policy-making process. }\end{array}$ & Rejected \\
\hline
\end{tabular}

(Source: Author's own compilation) 
The cross-case comparisons demonstrate that the "resources" in both the production and provision dimensions did not affect the influence of ECDC and ECHA. Under the limited budget and staff, both agencies were still able to produce expert advice mainly by mobilising staff internally and utilising their networks with external experts. In the case of the Commission proposal for the biocidal products regulation, ECHA's resources were even less than limited very scarce - but the Agency still exerted a moderate level of influence. Thus, the expectation 3.1 is rejected. In the provision dimension of expert advice to the Commission, the number of agency scientific outputs is considered as the resources. On the general legislative proposals, both agencies provided a limited amount of expert advice, but ECHA was able to exert a moderate level of influence whereas ECDC's influence was low. Moreover, even with the sufficient number of scientific outputs in the case studies of technical measures, ECDC's influence on the Commission Communication on the H1N1 pandemic was moderate (instead of high as in the case of ECHA). Accordingly, expectation 3.2 is also rejected.

"Activities" did not affect the influence of ECDC and ECHA, and this is evident when comparing the two cases of the general legislative proposals. In the production dimension, the contact between in-house experts in ECDC was frequent, but the Centre's influence was low. ECHA's interactions with its internal and external experts were not frequent, but it exerted a moderate level of influence. Thus, expectation 2.1 is rejected. Likewise, while both agencies engaged in frequent interactions with internal and external experts as well as with the Commission when discussing the technical measures, ECDC's influence was moderate and ECHA's influence was high. This also does not meet expectation 2.2. However, it should be noted that the rejection of expectations 2.1 and 2.2 does not mean this condition is completely irrelevant to EU agencies' influence. Continuous interaction with internal and external experts provides great opportunities for the agencies to share valuable assets such as knowledge, information, practices, and experiences, and in turn enables the agencies to tackle the challenge of limited resources and to produce high quality expert advice (Calcara, 2017; Vestlund, 2017).

Regarding "access" in the production dimension, the Commission proposal on serious crossborder threats to health was the only case in which only the internal network of ECDC was utilised, and in this case ECDC's influence was low. This could have implied confirmation of expectation 1.1. However, the remaining three cases showed access to both internal and external experts and the varying levels of influence from moderate to high. Especially during the H1N1 pandemic, ECDC pooled expertise from diverse external sources, but its influence was not high. Thus, expectation 1.1 cannot be confirmed. "Access" in the provision dimension offers a considerably mixed picture. When looking at the results of the two cases on the general legislative proposals, expectation 1.2 should be rejected because both agencies provided expert advice based only on requests from the Commission, and ECHA was still able to exert a moderate level of influence while ECDC's influence was low. However, as explained in the comparative analysis of the two cases on the technical measures (see Subsection 6.2.2), access in the provision dimension matters for influence. ECHA's secured access to the 
Commission in the policy-making process was conducive to its high influence. Therefore, expectation 1.2 needs modification. It is not about how many access points an EU agency utilises to provide expert advice to the Commission. Instead, what is crucial for the influence of EU agencies is secured access to the Commission as a procedural step in the policy formulation stage. This implies that institutional arrangements through which expert advice is communicated to the Commission affect EU agencies' influence. This point is discussed further in the following section which sets out the meaning of such influence.

At this moment, it is worth specifying that an official procedure for involving EU agencies does not in itself guarantee high influence of the agencies. In other words, this may be necessary but is certainly not sufficient for high influence of EU agencies. According to Chamon (2016), scientific opinions from the EU agencies involved in the procedure of the Union-level market authorisations possess an authoritative quality because the Commission has to properly justify cases in which it does not follow agencies' opinions. When this "comply-or-explain" mechanism is in place, the chances that the Commission will deviate from agencies' opinions are drastically reduced (Ossege, 2016). However, "authoritative opinions are 'merely' authoritative and may often not deal with every aspect of the final decisions [...] since the agencies are only responsible for risk assessment and not risk management" (Chamon, 2016, p. 31). Such was the case for ECHA on the issues of Annex 1 inclusion of low-risk active substances. As explained in Chapter 5, the Commission deviated from ECHA's advice on the inclusion of certain active substances in Annex 1 as the Commission viewed Annex 1 inclusion to be appropriate for policy-relevant, political, and risk management issues.

This research has revealed that five out of six expectations are rejected and only one (access in the provision dimension) is confirmed with a modification. Why are most of the expectations rejected? As stated in Chapter 3, the expectations about the three conditions were developed based largely on the literature on interest groups' influence on policy-making. Does this suggest that what could be conducive to interest groups' influence is not applicable to studies on EU agencies' influence? Are EU agencies too dissimilar to interest groups after all?

EU agencies and interest groups play a similar role in the policy-making process. They support policy-making by providing expertise and policy-relevant information demanded by policymakers. However, the specific institutional context in which EU agencies and interest groups communicate their expertise and information to policy-makers is different, and this explains why most of the expectations were rejected.

Two points should be highlighted in this regard. First, EU agencies and interest groups have uneven participation opportunities. As shown in all four case studies in this research, the Commission requests expert advice from one or a few agencies that have expertise in relevant policy issues, and the agencies, in response to the request, advise the Commission. The initiation of consultation comes from the Commission, and in this way the agencies are involved in the policy formulation stage. In the case of interest groups, there is hardly any policy debate on which only a single interest group mobilises, and there is always a plurality 
of interest groups simultaneously lobbying policy-makers (Klüver, 2013). Moreover, out of multiple interest groups, only those that provide useful "access goods" attain access to policymakers in exchange, and others are ignored (Bouwen, 2002; Michalowitz, 2004). In other words, interest groups have to compete with each other to gain access. This is not surprising given the high number of interest groups ${ }^{96}$ and even higher number of lobbyists acting on their behalf. Therefore, concerning the conditions such as access opportunities and activities, the logic of "the more, the better" works for interest groups but not for EU agencies. In the same vein, given the fact that secured access to the Commission as a procedural rule is not granted at all to any particular interest group (which is desirable from the perspective of democratic legitimacy), the presence of secured access to the Commission has not been considered as a condition in studies of interest groups' influence.

Second, another institutional context that differs is the number of policy-makers that EU agencies and interest groups try to influence during the policy-making process. EU agencies interact mainly with the Commission and, to a lesser extent, with the European Parliament (Egeberg et al., 2015). However, interest groups have various venues, including the EU institutions and national governments. They (are encouraged to) strategically choose policymakers at the national and/or European level depending on their organisational types, information types, or information tactics (Bouwen, 2002; Chalmers, 2013). They may target multiple policy-makers in different policy stages. Therefore, possessing sufficient financial and human resources, for example, is more important for interest groups than for EU agencies in order to influence various policy-makers in different policy-making stages and to increase their chance of influence.

Assessment on the validation of each expectation has highlighted the importance of the procedural involvement of EU agencies in the policy formulation stage as a crucial condition for their influence. How should this be interpreted in light of the observations on the influence of ECDC and ECHA? Section 6.4 is dedicated to answering this question.

\subsection{Real but guided influence of EU agencies}

In order to enhance the understanding of EU agencies' influence, this section will reflect on the findings about the influence of ECDC and ECHA as well as the conceptualisation of influence and power (see Chapter 2). The first observation to report is that ECDC and ECHA did exert influence on the formulation of policy proposals. Text comparison, the first indicator of influence, revealed that in three out of four case studies the Commission proposals reflected expert advice from ECDC and ECHA but to a different degree. Second, in line with the

\footnotetext{
${ }^{96}$ According to the EU's Transparency Register, which is an online database of information about lobbying activities carried out with the intention of influencing policy-making, there were over 11,000 registrations by January 2017 (see the Transparency Register website:

http://ec.europa.eu/transparencyregister/public/homePage.do?redir=false\&locale=en).
} 
expectation about the most-likely and least-likely cases for influence (see Chapter 3), ECDC and ECHA exerted higher influence on technical measures than on general legislative proposals. On the policy issues that go beyond the mandate of EU agencies or require substantial political considerations (such as the Commission proposal on serious cross-border threats to health and the issues of Annex 1 inclusion of active substances), the influence of ECDC and ECHA was low. Lastly, the fact that ECHA's expert advice is a prerequisite for developing implementing acts in the Commission contributed positively to the high influence of ECHA.

These findings imply that EU agencies can make a real impact on policy proposals developed by the Commission, and this is more likely when the proposals are technical in nature. However, their influence does not depend only on their ability, capability, or willingness. What also matters is an institutional arrangement specifying the official involvement of EU agencies in the policy-making process. Such an arrangement brings about two consequences. First, when the institutional arrangement acts as the "comply-or-explain" mechanism, it drastically reduces the chances that the Commission will deviate from expert advice of EU agencies (Ossege, 2016). But, it cannot completely prevent deviation on the part of the Commission. Thus, second, the more important consequence is that it positively affects the willingness of the Commission to steer and enable EU agencies to exert influence in the policy-making process.

The case on the Commission's implementing measures under BPR provides valuable insights here. The official involvement of ECHA in the process of drafting implementing acts gives the Commission a strong incentive to guide ECHA through how scientific opinions, once adopted by experts, should be formatted and phrased and also to provide feedback on the scientific opinions in every BPC meeting. The feedback here is on the stylistic elements of the scientific opinions, such as unclear expressions or complex sentences, and not on the content or conclusion of scientific opinions. Based on the Commission's feedback, ECHA, if necessary, rewrites unclear or complex parts to make their opinions more comprehensible and readable by officials in the Commission. This process, consequently, contributes to the high influence of ECHA. From this perspective, it can be concluded that the influence of EU agencies is guided influence: EU agencies are able to exert high influence under the steering of the Commission.

Reflecting upon the real but guided influence of EU agencies, the Commission, needless to say, is the power-holder that has the ability to determine the (policy) output within a set of available alternatives (as defined in Chapter 2) and fully exercises this power. This dynamic is evident in the cases on which ECDC and ECHA had a moderate level of influence. These cases showed evidence of the agencies' input in the policy proposals while there was no overlapping text between the documents from the agencies and the Commission proposals (see, for example, Table 4.1 which presents the examples of similar text between ECDC's documents and the Commission Communication on the H1N1 pandemic). Even though the Commission incorporated expert advice from the agencies into the policy proposals, it did not make reference to the agencies' documents and usually reformulated the text from the agencies. It seems as if the Commission would like to be in the driver's seat when developing policy proposals. 
Political influence is defined in Chapter 2 as the ability to shape the content of (policy) output by providing (partly or completely) the set of alternatives to decision-maker(s). Accordingly, in order to exert influence on the formulation of policy proposals, EU agencies need to be able to shape the position of the Commission in line with their preference and views and, in turn, also the content of proposals. Shaping the position of the Commission is not a simple task for EU agencies, as proven particularly in the case of the Commission proposal on cross-border threats to health. If EU agencies seek to exert high influence, the picture becomes even more complicated. EU agencies need to be able to not only shape the position of the Commission but also formulate expert advice in a way that can be understood and accepted by the Commission. Furthermore, if no secured access to the Commission as a procedural step is granted, EU agencies need to be able to convince the Commission to provide guidance and feedback on their expert advice in order to understand and meet the Commission's need.

In Chapter 2, it is specified that when expert advice of an EU agency literally turns into the text of (most parts of) a proposal, and this happens once, a few times, or sporadically, it is considered to indicate high influence of the agency. But, if this happens continuously to the extent that the Commission's power to formulate policy proposals becomes inactive as expert advice of the agency takes over this function, it should be seen that the agency's high influence is transformed into informal power. Is it then correct to claim that the high influence of ECHA has been transformed into informal power? Although this was not the case in the early period of implementation of BPR in 2013 and 2014, at least since 2016 one section of ECHA's scientific opinions has been literally copied into the Commission's implementing measures. ECHA has continuously exerted high influence on the approval of active substances and accordingly, ECHA has informal power. The role, influence, and informal power of ECHA in the area of biocidal products start to closely mirror those of EMA in the centralised authorisation of pharmaceuticals. EMA has continuously exerted high influence for over 10 years, and thus its high influence and informal power are seen as a fixed pattern in the pharmaceutical authorisation procedure (see Blom, van Suijlekom, Versluis, \& Wirtz, 2014; Gehring \& Krapohl, 2007).

Even in the case of informal power, ECHA's high influence is still guided influence because without the Commission's guidelines and feedback, ECHA would not have achieved its high influence in the first place. On the one hand, the Commission organises informal power for ECHA by providing guidelines and feedback, and this informal power puts the Commission under pressure as it leaves little room for the Commission to deviate from ECHA's opinions. On the other hand, the Commission allows ECHA to exert informal power since this reduces complexity in terms of topics, tasks, and procedures during the policy-making process. Therefore the Commission, as a formal power-holder, is in the driver's seat to decide whether or not to organise and steer influence (and informal power) for EU agencies. 


\subsection{Other explanations}

Having reviewed the validation of the three conditions and the meaning of EU agencies' influence, this section discusses three other potential conditions for influence and also evaluates the reputation indicator for assessing influence.

\subsubsection{Other potential conditions for influence}

Composition of scientific bodies in EU agencies

One potential factor that could affect the influence of EU agencies is the composition of scientific bodies in the agencies. These bodies are composed of either independent experts (as in the case of ECDC) or experts appointed by each Member State (as in the case of ECHA). This factor was not considered as one of the conditions for influence because, as mentioned earlier, the conditions analysed in this research were drawn from the literature on interest groups' influence in policy-making. Interest groups are composed of members who advocate their specific interests rather than representatives of the Member States. However, the empirical analyses of this research have shown that the composition of scientific bodies creates different dynamics in how expert advice is produced in the agencies and perceived by the Member States. For instance, some large and resource-rich Member States are sometimes reluctant to follow ECDC's expert advice because their national competent authorities are capable of producing their own scientific opinions. The newer and poorly resourced Member States, such as Bulgaria, Romania, and Malta, are often not able to carry out evidence-based research and tend to rely more on ECDC's expert advice.

By contrast, the BPC members from the large as well as several smaller and well-resourced Member States, such as Germany, France, and the Netherlands, are much more active in producing the expert advice of ECHA. A handful of these Member States are actually the ones who are repeatedly selected by applicants for the evaluation of their application, contribute to scientific discussions in the BPC meetings, and produce opinions for ECHA. Other BPC members who are typically from the Member States with poor resources and/or limited experience usually remain silent in the BPC meetings and thus are called "a silent majority" (see Chapter 5). According to the BPC members who were interviewed, these silent members are in most cases not prepared for the meetings due to the lack of resources in their organisations. Considering that being silent is taken as an agreement when BPC adopts its opinions, BPC opinions adopted by unanimity - which is usually the case - are in reality the unanimous opinions among the handful of experts from the large as well as several smaller and well-resourced Member States. This implies that it is inevitable for ECHA to maintain close networks with national competent authorities, especially those that are well-resourced and have high expertise, in order to produce expert advice for ECHA.

Which type of composition (independent experts or experts appointed by the Member States) is more conducive to EU agencies' influence, and why? Since political influence in the policy 
formulation stage requires the shaping of the Commission's position (see Chapter 2), what the Commission looks for in this stage should be considered to answer this question. To increase legitimacy, the Commission seeks to ensure a mandate of pluralism by obtaining "diverse viewpoints" from a broad range of actors (Chalmers, 2014; European Commission, 2002b). Moreover, to increase policy success, the Commission is geared towards promoting "common European interests" so that the European Parliament and the Council of the European Union accept policies proposed by the Commission and the Member States do not resist the implementation of these policies (Bouwen, 2002).

EU agencies that include scientific committee members recruited from national competent authorities and appointed by their government possess higher potential to satisfy the Commission's needs than the ones whose members are independent experts. Scientific bodies composed of experts appointed by the Member States represent broader national experiences and backgrounds. Additionally, although these experts primarily identify themselves as professional experts (just like independent experts) rather than as delegates (Egeberg, 1999; Ossege, 2016; Quaglia, de Francesco, \& Radaelli, 2008), they are simultaneously experts and officials as they carry the authority of science and of the state and may use state resources (Baekkeskov \& Öberg, 2017). Also, they have a strong affiliation with their national competent authority (Egeberg, 1999). From this perspective, as Ossege (2016) argues, their discussion in the scientific bodies of EU agencies is seen as intergovernmental bargaining, and it reduces the willingness (or ability) of the Member States to deviate from the agencies' opinions in the decision-making stage. Especially when it comes to policy-making through the standing committee procedures, the effect is bigger:

A member state that disagrees with the agency opinion in the standing committee for scientific reasons seriously risks its credibility for undermining a scientific opinion at EU level that has been supported by its own national regulator. (Ossege, 2016, p. 52)

Furthermore, based on the claim by Dunlop (2010) on the logic of delegation to epistemic communities, it is expected that expert advice from the agencies whose scientific bodies are composed of experts appointed by the Member States contributes to the satisfaction of the Commission's policy preferences and, in doing so, increases policy efficiency defined as a higher degree of preference alignment. Therefore, it is expected that the composition with experts appointed by the Member States is conducive to the influence of EU agencies in the policy formulation stage.

\section{Types of EU agency}

Another potential factor that could affect the influence of EU agencies is the type of EU agency. When broadly classifying EU agencies based on their primary functions, they can be grouped into information agencies or regulatory agencies (see Chapter 1). Regulatory agencies are expected to exert higher influence than information agencies based on two observations. First, 
the four case studies in this research have demonstrated that the three conditions in ECDC and ECHA were generally not conducive to their influence on the general legislative proposals or conducive to their influence on the technical measures. Regardless of this variation, however, ECHA was able to exert higher influence than ECDC on both types of policy proposals. ECDC is considered as an information agency that collects, produces, and disseminates highquality information, and ECHA is a regulatory agency and has decision-making power in some areas. This suggests the possibility that regulatory agencies in general tend to exert higher influence than information agencies.

Second, Section 6.3 above claimed that the secured involvement of EU agencies as a procedural prerequisite for developing policy proposals is a crucial condition for EU agencies' influence. Regulatory agencies, rather than information agencies, tend to meet this condition. In fact, while EU agencies do not usually have the power of rule-making, enforcement, and adjudication (Majone, 1997), some empirical studies have argued that certain EU agencies act as de facto decision-makers (see, for example, Gehring \& Kraphol, 2007) or risk managers (see, for example, Van Asselt \& Vos, 2008). The agencies in these studies - namely EMA and EFSA - are regulatory agencies (not information agencies) and indeed those whose participation is secured in the decision-making process for the Union-level market authorisation.

Since there are other EU agencies increasingly lined up to take up responsibilities similar to those undertaken by EMA, EFSA, and ECHA (Kim et al., 2013), the application of the crucial condition (procedural involvement) is not limited only to these well-known and most analysed agencies involved in market authorisation. More recent examples are the European Supervisory Authorities (ESAs) ${ }^{97}$ which were established as a response to the financial crisis in the EU. ESAs may develop draft regulatory and implementing technical standards and submit these drafts to the Commission, which either takes a final decision under a comitology procedure (in the case of implementing technical standards) or endorses, rejects, or amends (in the case of regulatory technical standards). As ESAs meet the crucial condition for influence, they are expected to exert high influence and again, they are regulatory agencies rather than information agencies.

Then, are information agencies extraneous to this condition as they normally do not possess secured access to the Commission as a necessary procedural step in the policy-making process? This is not always the case. Chiti (2013) argues that the EU Agency for Fundamental Rights is an information agency but may participate in procedures leading to the adoption of binding implementing rules - just like ECHA in the authorisation procedure for biocidal products - by formulating conclusions and opinions on specific thematic topics based on its knowledge and expertise. This suggests that whereas regulatory agencies are generally expected to exert a higher level of influence than information agencies, information agencies in combination with

\footnotetext{
${ }^{97}$ ESAs refer to the European Banking Authority (EBA), the European Securities and Markets Authority (ESMA), and the European Insurance and Occupational Pensions Authority (EIOPA).
} 
the (formal or informal) presence of procedural involvement might create a different effect on influence.

\section{Type of expert advice}

Last but not least, as stated in Subsection 6.2.1 above, the type of expert advice that is requested by the Commission and provided by EU agencies could also affect the influence of $\mathrm{EU}$ agencies. This may not be a decisive factor for EU agencies' influence since EU agencies do possess technical (subject matter) expertise (see Section 3.1), and providing expert advice to the EU institutions is either a primary or secondary function of most EU agencies. However, what matters is their ability to provide not only technical expertise but also policy expertise if requested by the Commission. Why does the Commission request expert advice on subject matter as well as on issues related to risk management? On the one hand, risk assessment performed by EU agencies is, in theory, separated from risk management, but in practice it is difficult to separate the two (Jasanoff, 2005). Accordingly, it is possible that questions from the Commission may touch upon aspects of both risk assessment and risk management including regulatory and control elements. From the "demand" side of the Commission, on the other hand, the Commission needs not only subject matter expertise but also expertise relevant to risk management issues in order to improve the quality of EU legislation by embedding different types of expert advice at all levels of the European policy-making process (European Commission, 2015d). The Commission views that high-quality expert advice contributes directly to better regulation, thereby enhancing legitimacy of EU policies (see Boswell, 2008).

\subsubsection{Observations on reputation as an indicator of influence}

This research applied text comparison as the first and main indicator for assessing influence of EU agencies, and their reputation as scientific authority as the second and supplementary indicator. Unlike text comparison, reputation of ECDC and ECHA did not show much variation between the most-likely and the least-likely cases. Their reputation was good in general and became even better in relation to the technical measures. The officials from the Commission who were interviewed for this research emphasised the importance of scientific input from ECDC and ECHA when developing policy proposals. Likewise, experts from ECDC and ECHA agreed that their scientific opinions were trusted by the Commission and the Member States and that they received more and more requests from them for scientific advice - which many of them considered to be a sign of their increasing influence.

What is striking, though, is a discrepancy between the commonly good (or very good) reputation of these two agencies and weaker evidence of their influence that can be traced in the Commission documents. Except the case of the Commission's implementing measures under BPR (on which ECHA exerted a high level of influence), the remaining three case studies 
showed that there was no overlapping text between the Commission documents and the agencies' expert advice and also that there was no references to the agencies' scientific documents in the policy proposals. What are the explanations for this discrepancy?

One might raise a question about whether the Commission symbolically praised the role played by ECDC and ECHA, and therefore the reputation was good while the evidence of influence was weaker in the policy proposals. This is a plausible expectation on the following grounds. First, the Commission is the one who proposed the establishment of the EU agencies in the first place and has constructed a close relationship with them. As Egeberg et al. (2015) demonstrate, the Commission has systematically allocated the EU agencies among its DGs according to issue area, and the DGs supervise, have regular meetings with, and consider themselves to be parent DGs - in other words, the main political principal. ${ }^{98}$ Some DGs even advocate for the agencies which belong to them vis-à-vis other DGs in annual budgetary processes for example (Egeberg et al., 2015). Furthermore, the objectivity and independence associated with EU agencies and their knowledge production process ensure that "in practice, decision-makers must at least pay lip service to the epistemic agents' 'truths'" (Dunlop, 2010, p. 208). Considering these factors, it is awkward to imagine that officials from the Commission criticise the agencies that they proposed themselves and that they established a "parent" relationship with.

Another explanation can be made based on the complex procedure for formulating policy proposals at the European level. Although ECDC and ECHA were consulted in the early drafting stage of policy proposals and provided expert advice as policy input to the responsible DG DG SANCO - on all four case studies, what came after this stage was the internal consultations with other DGs in the Commission (Interviews \#4, \#9). The text could be revised or rephrased numerous times again at this point with input given by other DGs, and their input could derive from non-scientific considerations (Interview \#9; see Hartlapp, Metz, \& Rauh, 2014; Wonka, 2008). In this process, expert advice from ECDC and ECHA might be de-emphasised.

The discrepancy can also be explained by the different roles of the Commission and the EU agencies. One of the main tasks of ECDC and ECHA is to provide evidence-based scientific information and risk assessments, and the Commission has the formal power to formulate and issue policy proposals based on information and advice from the agencies as well as other policy actors. Although it is true that the Commission generally takes EU agencies' information and expert advice into account when proposing recommendations and legal measures, the agencies do not have the mandate to assist the formulation of policy proposals or to interfere in risk management decisions (Interview \#9). Thus, ECDC, for example, participated in discussions regarding the Commission Communication on the H1N1 pandemic and provided technical advice, but the Health Threat Unit in DG SANCO drafted the Commission Communication based on its experience and role as a risk manager in coordinating the response to the pandemic. In the same manner, officials in the Health Threat Unit might desire

\footnotetext{
${ }^{98}$ See also Analytical Fiche No. 31, "Commission Role."
} 
to remain fully in charge of the formulation of legislative proposals. In this case, even if the Commission decides to accept and follow what is advised by EU agencies, it would prefer to draft and rephrase (instead of literally copy, use quotations from, or make references to) the text of expert advice from the agencies.

Lastly, the Commission might have found the expert advice from ECDC on the two proposals - one on the H1N1pandemic and the other on serious cross-border threats to health - too technical to be incorporated. Expert advice has to have a dual reference: "It must be scientifically sound, and it must be politically useful and acceptable" (Lentsch \& Weingart, 2011, pp. 7-8, italics in original). An evaluation report on ECDC indeed states that "ECDC activities have generally resulted in good quality outputs appreciated by different professional communities. Their immediate usefulness for policy-makers could, however, be further improved" (Economisti Associati, 2014, p. 5). Likewise, another evaluation report on ECDC points out that "[expert advice of ECDC] would not always be conveyed in a format and language adequate for policymakers, in particular executive summaries sometimes would appear as missing" (Economisti Associati, 2014, p. 50).

Considering the discrepancy between the levels of influence assessed through text comparison and reputation and also considering the generally good reputation of EU agencies, it is more appropriate to disregard reputation as an indicator of influence.

\subsection{Conclusion}

This chapter has presented the comparative analysis between ECDC and ECHA by focusing on cross-level comparisons. In all cases, the Commission did consult the two agencies in the early stages of policy-making. Compared to the cases on the general legislative proposals, ECDC and ECHA produced and provided expert advice on the technical proposals in a more proactive manner and generally exerted higher influence. While it cannot be denied that the three conditions, namely access, activities, and resources, are important elements for EU agencies' daily operation and functioning, this research reveals that access in the provision dimension matters for the influence of ECDC and ECHA. More specifically, the involvement of ECHA is secured by the procedural rule under $B P R$, and this is the crucial condition for its high influence. While everything else was the same in both production and provision dimensions, ECDC was not able to exert high influence partly due to the absence of procedural involvement. Being procedurally involved as a prerequisite for the development of policy proposals affects the influence of EU agencies in two ways: it reduces the chance that the Commission will deviate from the opinions of EU agencies, and it motivates the Commission to steer and enable the agencies to exert influence.

Moreover, political influence of EU agencies, which is defined as the ability to shape the position of the Commission and the content of policy proposals, implies more than just convincing the Commission by providing expert advice. Ability to convince the Commission - 
Chapter 6

the power-holder - to guide EU agencies is also required because it is necessary that the Commission is receptive to EU agencies' influence (so that it allows the agencies to exert influence).

These findings lead to the conclusion that EU agencies do influence the formulation of policy proposals in the Commission when the Commission enables the agencies to exert influence. In other words, EU agencies' influence is guided influence. Broader implications of the influence of EU agencies on policy-making and technocratic governance in the EU as well as theoretical and empirical contributions are discussed in the following chapter. 
Chapter 7

Conclusion 


\subsection{Overview of the study and new insights}

This research was derived from two observations and subsequent puzzles that are closely connected to each other in the context of European policy-making. As introduced in Chapter 1 , there has been a general acknowledgement (or assumption) that $\mathrm{EU}$ agencies contribute to policy-making by providing expertise that is required by policy-makers. However, even though it is true that expert advice from EU agencies is generally not resisted, that does not mean that such advice is automatically followed by policy-makers. Expert advice from EU agencies has no binding effect, and thus the Commission is not obliged to incorporate it when developing policy proposals. What makes the Commission follow EU agencies' advice has not been systematically and empirically tested or validated, and indeed neither has the more generalised assumption about EU agencies' contribution. Therefore, this book investigated EU agencies' actual influence on the formation of policy proposals in the Commission and conditions for such influence, under the research question: To what extent and under which conditions do EU agencies use their expert advice to influence policy-making in the European Union?

As a first step to tackle the research question, it was necessary to conceptualise the term "influence" and distinguish it from "power," which is synonymously and interchangeably used by many scholars and laypersons alike. Based on a relational approach and unique characteristics of influence and power (see Chapter 2), the following definitions were proposed for this research:

Political power is the ability to determine the (policy) output within a set of available alternatives; and political influence is the ability to shape the content of (policy) output by providing (partly or completely) the set of alternatives to decision-maker(s).

As a second step, this research developed a three-dimensional approach: 1) the production dimension for analysing how EU agencies produce expert advice; 2 ) the provision dimension for examining how EU agencies provide expert advice to assist the Commission in formulating policy proposals; and 3) the dimension of influence for measuring EU agencies' level of influence on the formulation of policy proposals. 
Figure 7.1) Three dimensions and three conditions for the analysis

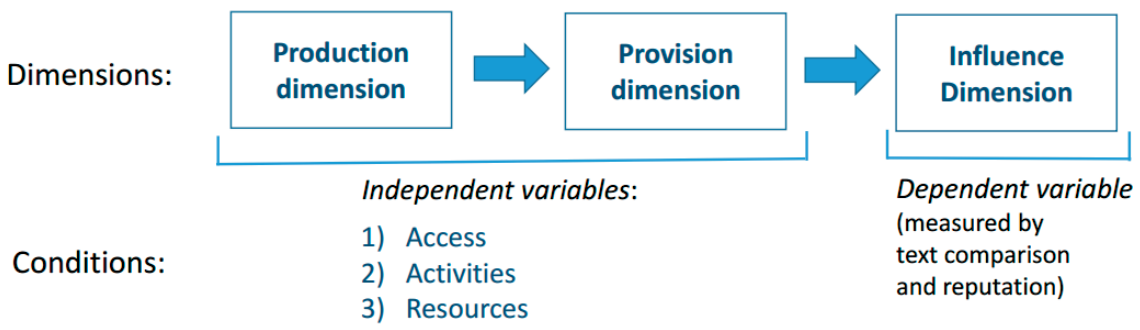

(Source: Author's own compilation)

Three conditions for influence - access, activities, and resources - were selected to analyse the production and provision dimensions, and two indicators - text comparison and reputation as scientific authority - were outlined for assessing the level of influence (Chapter 3). Under the case study approach, moreover, the European Centre for Disease Prevention and Control and the European Chemicals Agency were selected for cross-case level analysis, and two specific policy proposals (dossiers) - one most-likely case and one least-likely case for influence - were selected for each agency for within-case level analysis.

The research design explained above was applied to examine influence of ECDC and ECHA. The empirical analysis of ECDC (see Chapter 4) demonstrated that on the Commission Communication on the H1N1 pandemic (most-likely case), all conditions in the production and provision dimensions were mostly conducive to ECDC's influence, and the Centre exerted a moderate level of influence. However, on the Commission proposal for cross-border threats to health (least-likely case), its influence was low, and the three conditions particularly in the provision dimension were not conducive to its influence. In the analysis of ECHA (see Chapter 5 ), where all conditions in the two dimensions were mostly not conducive to influence, ECHA still exerted moderate influence on the Commission proposal for the regulation of biocidal products (least-likely case). On the Commission's implementing acts on the approval of active substances (most-likely case), all conditions in the two dimensions were mostly conducive to influence, and ECHA's influence was high.

The analyses of all four cases were compared at the agency (cross-case) level (see Chapter 6). This revealed that ECHA exerted higher influence than ECDC in general, and access in the provision dimension was a crucial condition for influence. More specifically, secured access of ECHA as a procedural step in the development of the Commission's implementing acts provided a strong incentive to the Commission to participate and give feedback (on the style and language of advice) in the opinion-forming process in ECHA. As a consequence, expert advice of ECHA became directly useable by officials of the Commission in the policy formulation stage. In addition, EU agencies' influence was not totally dependent on their ability, capability, or willingness to convince the Commission by providing high-quality expert 
advice. The Commission steers and enables EU agencies to exert influence in the policymaking process.

In summary, which new insights can be generated from this research? Four points should be highlighted here. First, EU agencies are involved in the early stage of policy-making. In all four cases, the Commission did request expert advice from EU agencies when it was preparing for the development of policy proposals. Second, EU agencies do exert (moderate and high) influence on the formulation of policy proposals, but their influence is guided and organised by the Commission. This leads to the third point: Formally and also in practice, the Commission is the "commander" in the policy formulation stage. The Commission fully exercises its power to decide and draft the content of policy proposals. This also means that the Commission does not blindly follow agencies' expert advice. High-quality expert advice, needless to say, is necessary for EU agencies to exert influence or even to be considered by the Commission in the first place, but what also matters is the Commission's willingness to incorporate expert advice into the content of policy proposals. In other words, EU agencies exert influence when the Commission allows and steers their influence as shown in the case studies. Lastly, regarding access to the Commission as a crucial condition for influence, not just the right to participate but the "obligation to participate" as a procedural step gives EU agencies a direct ticket to influence in the policy formulation stage. This is because in this institutional setting the Commission is strongly motivated to guide the agencies to produce expert advice in a way that is immediately useable by the Commission officials.

\subsection{Implications}

What are the implications of the main findings about the influence of EU agencies? Three implications in terms of theory, practical operation, and methodology are discussed in this section.

\subsubsection{Theoretical implication}

The EU, and particularly the European Commission, has long been a notorious example of technocracy (Harcourt \& Radaelli, 1999). While the use of expertise is an inherent part of policy-making, there has been increasing public scepticism towards the domination of unelected technocratic elites (instead of democratically elected politicians) and the growing dependence on knowledge and expertise (instead of public and political discussions) in the policy-making process. In this context, the agencification process in the EU has intensified an inevitable tension between democracy and technocracy, particularly from the perspective that the use of technical expertise entails a cost in democratic legitimacy for which the legitimacy of expertise does not compensate (see Shapiro, 1997). Especially with the emergence of EU agencies with greater competences and stronger autonomy and authority (see Busuioc, 2013; Chiti, 2009; Groenleer, 2009), it has been generally assumed without 
concrete empirical evidence that "[t]he establishment of agencies can be seen as a move towards an increasingly technocratic society where the influence of unelected technocrats expands on behalf of the influence of elected politicians" (Ekelund, 2010, p. 6). Concerns about the rise of technocracy in the EU may be exacerbated under a situation in which EU agencies "alter the relationship between scientific advice and public decision-making: rather than contributing to public decision-making, the scientific 'advice' of [EU agencies] might actually replace it" (Ossege, 2016, p. 12, italics in original).

In light of the research findings, however, one may wonder whether EU agencies and their influence on policy-making indeed fuel these technocratic concerns. Do unelected experts actually decide policies in the EU? Does scientific advice replace public and political discussions when making policies? The answer is "no," at least in the cases studied in this book. This research has demonstrated that EU agencies do contribute to the formulation of policy proposals, as expert advice from EU agencies is either directly copied into or incorporated in the content of policy proposals. Notwithstanding these clear signs of the use of agencies' input, their influence does not "replace" the right of initiative that is legally held by the Commission. The European Commission does not blindly accept expert advice from EU agencies, and it does consult various actors when developing policies, including not only EU agencies but also, for example, civil society organisations.

The rise of technocracy in the EU has been somewhat misunderstood as an excessive intensity of technocracy. As stated earlier, EU agencies' influence is guided influence (even in the case of high influence), and the Commission is, formally and in practice, in the driver's seat in the policy formulation stage. Given the findings here, such criticism about EU agencies having too much power or aggravating technocratic governance in the EU is not justified. As Egeberg et al. (2015, p. 612) argue, EU agencies are integral components of and closely tied to the Commission, but their relationship "may indicate a hierarchy with the Commission at the helm" (see also Egeberg \& Trondal, 2011). The guided influence of EU agencies and the power of the Commission in the policy formulation stage are in line with democratic rules and legitimacy of the EU rather than deficit of those.

\subsubsection{Practical implication}

From the findings of this research, what kind of lessons can be extracted for officials in the Commission who are involved in formulating legislative proposals as well as experts in EU agencies who produce expert advice for policy-makers? Also, what could be suggested to improve the current operation of EU agencies and their role in the policy-making process? What this study has demonstrated is that EU agencies need to provide not only technical expertise for problem-solving but also policy-related advice, and that their expert advice should be formulated in a manner that is highly useful for policy-makers. In this regard, two remarks should be clearly made: First, this research does not make a proposition that exerting influence on the content of policy proposals is (or should be) an ultimate goal of EU agencies, 
or that EU agencies should exert influence on policy-making at the European level. The focus on the influence of EU agencies towards the European Commission in the policy drafting stage does not imply that EU agencies always act with the intention to increase their influence in the Commission. Rather, interviewees from the two agencies emphasise the role EU agencies take in risk assessment and the importance of providing the best possible expertise and policy options for the Commission so that the Commission and other decision-makers can make an informed decision.

Second, expert advice of EU agencies should be useful. As Duncan and Harrop (2006, p. 169) insightfully contend:

Research that has little or no value in influencing policy or practice might be valuable for other reasons, but we would argue that to identify its 'ability to satisfy implicit or stated needs' (i.e. 'external validity'), whatever they are, is an inherent element of quality.

Although EU agencies are relatively close to the Commission and more firmly embedded in the policy formulation stage compared to, for instance, interest groups who also provide specialised expertise to the Commission (see Section 6.3), they are placed in a competitive environment. There are more than one thousand "in-sourced" expert committees in the Commission and thousands of lobbyists knocking on the door of the Commission with expertise (e.g., Gornitzka \& Sverdrup, 2011; Van Schendelen, 2006). In this environment, increasing the usefulness of agencies' expert advice entails meeting the Commission's needs. This can be achieved by offering high-quality advice that meets the Commission's informational needs and by presenting such advice in a format and style easily understandable by policy-makers. One critical example, and a learning point for all EU agencies, can be drawn from an evaluation report on ECDC's response during the H1N1 pandemic. The report points out: "The phrase 'reasonable worst case scenario' caused confusion [on the part of policymakers] because 'reasonable' was interpreted as 'likely' when in fact [experts in ECDC] meant 'still very unlikely'” (Greco et al., 2011, p. 31).

The Commission can play an important role in this context. In order to help EU agencies increase the usefulness of their expert advice in the policy-making process, the Commission may consider providing general guidelines that could be applicable to all EU agencies, such as those offered to the Biocidal Products Committee in ECHA. Of course, the Commission is not, and should not be, in the position to steer how experts discuss science in the agencies, but it can guide how the result of scientific discussions is presented from a policy-making viewpoint. Once these guidelines are applied by the agencies, "parent" DGs in the Commission could consider giving feedback to the agencies belonging to them regarding what was particularly useful or what could be improved further. This does not necessarily have to follow the practice between DG SANTE and BPC in ECHA where one or two Commission officials attend BPC meetings and point out, for example, unclear parts in BPC opinions. It could be periodic feedback reports from DGs to their agencies. In fact, this type of feedback is not totally new to the Commission. According to a study from 1997 on the Committee of the Regions, "the 
Secretariat of the Commission has, since 1995, provided the CoR with regular feedback reports on the impact of CoR opinions on legislative outcomes" (McCarthy, 1997, p. 443).

\subsubsection{Methodological implication}

Studying influence of political actors is indeed a challenging task, and many scholars have admitted methodological difficulties in finding appropriate measurements, searching for evidence, and measuring actual influence (e.g., Arts \& Verschuren, 1999; Dür, 2008a; Klüver, 2013; see Chapter 3). This research was no exception. The difficulties encountered in this research will be elaborated on in this section. Since this is one of the first studies investigating influence of EU agencies, these difficulties should be regarded as issues that need additional attention and further improvement, rather than as limitations.

The current study has made a contribution by proposing text comparison as an effective way to trace direct evidence of EU agencies' influence and assess the level of influence. It has also demonstrated that applying a plagiarism detection tool, such as WCopyfind, is beneficial when searching for evidence of influence in a large number of and/or lengthy documents. However, researchers should be aware that text comparison does not capture non-textual evidence of influence especially during informal consultations between EU agencies and the Commission which usually do not leave written records. When there is a lack of documents revealing what was discussed and who proposed what, interviewing actors involved in the process is an option to gather information and evaluate EU agencies' influence. But, it requires considerable financial and human resources and time as well as careful handling of shortcomings inherent in the interviewing method itself.

Next to text comparison, EU agencies' reputation as scientific authorities was used as a complementary indicator to measure influence. However, it was explained in Chapter 6 that there was a discrepancy between limited evidence of influence identified through text comparison and generally good reputation of EU agencies. Moreover, there were reasons to question whether the Commission symbolically praised the role and value of EU agencies and their expert advice in the policy-making process. Therefore, analysing reputation of EU agencies is neither suggested as an indicator of influence (for measuring a dependent variable) nor as a condition for influence (as an independent variable) (see Subsection 6.5.2).

In addition, data collection has a methodological implication. The EU has gradually improved public access to documents. The Treaty of Amsterdam (1997) institutionalised the right of public access to documents, and the Lisbon Treaty broadened the scope of access to documents from the EU institutions to all EU bodies, offices, and agencies. Yet, as Leppävirta and Darbishire (2017, p. 401) argue, there are still "serious black holes." On the one hand,

legislative transparency [via the mechanism of public access to documents] is generally understood to start only after the Commission has made a proposal and the official co- 
legislators start working on it. As a result, the key early phases of the legislative process remain difficult to access. (Leppävirta \& Darbishire, 2017, p. 412)

On the other hand, EU agencies, which provide expert advice as policy input in this key early phase, make only part of their scientific output publicly accessible. As stated in Chapter 4, scientific opinions of ECDC that were produced in response to the Commission's requests are not open to the public without explicit reasons. ${ }^{99} \mathrm{ECHA}$ was no different in this regard. Upon receipt of its form in which the purpose of a request for documents must be explained in detail, the Agency responded with the statement: "ECHA has concluded that [the requested documents] may be partially disclosed." 100 Moreover, before releasing these "partially disclosed" documents, some personal data and sentences were intentionally deleted by ECHA. It was exceedingly ambiguous how and why ECHA selected certain scientific opinions to release and decided to maintain others as confidential. Additional information regarding the background and criteria for its decision was unfortunately not provided. This implies that while EU agencies are generally approachable and make a large portion of their documents publicly accessible, data collection for research on EU agencies' influence is to a certain extent dependent on the openness and willingness of the agencies to grant access to documents, especially to those documents which cover a more direct - but informal - discussion between the agencies and the Commission.

Nevertheless, it should be noted that this guarded practice in EU agencies is slowly but surely changing. For example, in 2017 ECHA created a section in its website where biocides-related questions from the Commission and answers from the Biocidal Products Committee are archived. It is not yet clear whether ECHA makes all questions and answers open to the public or is still selective about what goes on the website. However, this is a step in the right direction for greater transparency of documents and will eventually facilitate data collection for academic research.

\subsection{Limitations of this study}

The difficulty in gaining access to a complete set of documents calls for a careful interpretation of the influence of ECDC and ECHA. As stated above, scientific opinions of EU agencies are not readily available on their website, and since ECDC and ECHA did not release all scientific opinions relevant to the case studies in this research, there was no clear picture of the total number of scientific outputs and which documents were omitted from analysis. For the case studies which showed moderate or high influence, this issue did not pose a great concern because even a partial set of documents could clearly show signs of influence. However, the story is different when it comes to the case study on the Commission proposal on cross-border

\footnotetext{
${ }^{99}$ Requests for expert advice originated from the European Parliament and sent "via the Commission" are archived in the website of the European Parliament, and they are publicly accessible (see Chapter 4).

${ }^{100} \mathrm{ECHA}^{\prime} \mathrm{s}$ written response via email.
} 
threats to health, which showed low influence of ECDC. The result indicating low influence was based on analysis of ECDC's scientific documents only, as there was no access to its scientific opinions.

Would the result be different if scientific opinions of ECDC were also analysed? Higher influence of ECDC might be possible considering that scientific opinions usually deal with the Commission's specific policy issues targeted to a small number of EU agencies and their expertise; yet, it could also remain at low influence considering that this was a least-likely case of influence, which discussed broad aims and policy framework for cross-border threats to health. Therefore, the low influence of ECDC in this particular case should be understood to the extent that the data used here were not complete. Does this mean that this particular case is peripheral to this research? It should be recalled that influence studies are notorious for posing methodological difficulties and, therefore, there is a lack of empirical studies that measure influence of certain policy actors especially in the policy formulation stage where a lot of discussions and meetings are not documented (and not made public). Although a complete data set was not achievable, this research provided new insight about the level of ECDC's influence on the basis of the available data.

Another issue to discuss is the extent to which the findings of this study can explain influence of other EU agencies. A recurrent trade-off of the case-study method is indeed

the related tension between achieving high internal validity and good historical explanations of particular cases versus making generalizations that apply to broad populations. The inherent limitations include a relative inability to render judgments on the frequency or representativeness of particular cases. (George \& Bennett, 2005, p. 22)

Although a chosen case is usually expected to "perform a heroic role: to stand for (represent) a population of cases that is often much larger than the case itself" (Seawright \& Gerring, 2008, p. 294), this study did not aim at reaching conclusions that could possibly be generalised to all EU agencies. Instead, as a theoretically-informed exploratory study (and as one of the first empirical studies) investigating influence of EU agencies, this research employed case studies to enable an in-depth analysis and understanding of the processes of both production and provision of expert advice by ECDC and ECHA as well as their influence on the specific policy proposals. As Woll (2007) argues, studies on influence of certain political actors need to be carried out in a context-specific way in order to enhance an understanding about a particular policy development.

The findings here can nevertheless contribute to knowledge accumulation in the field of EU agencies and to a broader understanding of influence of the general population of agencies as well as influence of other policy actors in the policy formulation stage. After enough knowledge is accumulated across different agencies, actors, and policy areas, it will be possible to draw meaningful generalisations. 


\subsection{Future research agenda}

This study has made a first step with regard to developing and testing a framework for the analysis of EU agencies' influence, most notably the three-dimensional approach and text comparison as an indicator to measure the level of influence. These elements could be a vital basis for knowledge accumulation, and additional research is necessary. In order to stimulate further knowledge accumulation, the following research agenda is suggested. First, as two out of three conditions analysed in this research are found not to affect the level of influence, searching for other potential conditions deserves more attention. The three conditions access, activities, and resources - were drawn from the literature on interest groups, and this means that the institutional environment in which EU agencies perform their tasks and their unique position and relationship under the "parent" DGs in the Commission are not fully reflected. Thus, a revised set of conditions could be developed to address the question of which (combinations of) conditions are necessary and/or sufficient for EU agencies' influence. Besides the potential conditions for influence discussed in Subsection 6.5.1 - namely, the composition of scientific bodies in EU agencies, the type of EU agency, and the type of expert advice - other factors that could be explored are legitimacy or autonomy of EU agencies (e.g., Busuioc et al., 2012; Groenleer, 2009, 2014).

Second, the three-dimensional approach (with the revised set of conditions) could be applied to analyse influence of other EU agencies in different policy areas. For instance, more empirical research on influence of EU agencies in the policy areas of finance and migration would be interesting since such policies have received a lot of attention lately, and the most recent agencification process has taken place in these areas. Likewise, the three-dimensional approach could also be applied to other policy actors who provide expert advice on policy proposals, such as interest groups and various types of expert committees and groups. Moreover, the application can be extended to study influence of similar bodies at the national level.

Third, making methodological advances is of importance in studying influence of EU agencies. Which indicators are able to capture non-textual evidence of EU agencies' influence in the informal consultation process, and thus can be used together with text comparison in a complementary manner? How should researchers collect relevant data from the early phases of the policy formulation stage which largely remains non-transparent? How exactly should researchers tackle issues of (limited) access to documents? Scholarly attention and innovative ideas are necessary to overcome methodological challenges, and these efforts, in the end, will contribute to a systematic understanding of EU agencies and their influence in the policy formulation stage. 


\section{References}


A.I.S.E. \& Cefic EBPF (2015). A.I.S.E. \& EBPF Survey: BPR Impact on Biocidal Products and Innovation. Retrieved from https://www.aise.eu/documents/document/ 20160212173604- aise_ebpf_survey_bpr_2015_-_report.pdf.

Amato-Gauci, A., Zucs, P., Snacken, R., Ciancio, B., Lopez, V., Broberg, E., et al. (2011). Surveillance trends of the 2009 influenza $A(H 1 N 1)$ pandemic in Europe. Eurosurveillance, 16(26), 1-11.

Ammon, A. (2015). From SARS to Ebola - 10 years of disease prevention and control at ECDC. Eurosurveillance, 20(37), 2-4.

Arendt, H. (1970). On Violence. New York: Harcourt Publishing Company.

Arras, A., \& Braun, C. (2018). Stakeholders wanted! Why and how European Union agencies involve non-state stakeholders, Journal of European Public Policy, 25(9), 1257-1275.

Arter, D. (2000). Small State Influence within the EU: The Case of Finland's 'Northern Dimension Initiative.' Journal of Common Market Studies, 38(5), 677-697.

Arts, B. (1998). The Political Influence of Global NGOs: Case Studies on the Climate and Biodiversity Conventions. Utrecht: International Books.

Arts, B., \& Verschuren, P. (1999). Assessing Political Influence in complex Decision-making: An Instrument Based on Triangulation. International Political Science Review, 20(4), 411424.

Baekkeskov, E., \& Öberg, P. (2017). Freezing deliberation through public expert advice. Journal of European Public Policy, 24(7), 1006-1026.

Baekkeskov, E., \& Rubin, O. (2014). Why pandemic response is unique: powerful experts and hands-off political leaders. Disaster Prevention and Management, 23(1), 81-93.

Barbieri, D., \& Ongaro, E. (2008). EU agencies: what is common and what is distinctive compared with national-level public agencies. International Review of Administrative Sciences, 74(3), 395-420.

Bardach, E. (Ed.). (2009). A Practical Guide for Policy Analysis: The Eightfold Path to More Effective Problem Solving. Washington: SAGE Publications.

Beach, D. (2004). The unseen hand in treaty reform negotiations: the role and influence of the Council Secretariat. Journal of European Public Policy, 11(3), 408-439.

Betsill, M. M., \& Corell, E. (2001). NGO Influence in International Environmental Negotiations: A Framework for Analysis. Global Environmental Politics, 1(4), 65-85.

Betsill, M. M., \& Corell, E. (Eds.) (2008). NGO Diplomacy: The Influence of Nongovernmental Organizations in International Environmental Negotiations. Cambridge, MA: The MIT Press.

Biermann, F., Siebenhüner, B., Bauer, S., Busch, P., Campe, S., Dingwerth, K., et al. (2009). Studying the Influence of International Bureaucracies: A Conceptual Framework. In F. Biermann \& B. Siebenhüner (Eds.), Managers of Global Change. The Influence of International Environmental Bureaucracies (pp. 37-74). Cambridge, MA: The MIT Press.

Binderkrantz, A., \& Pedersen, H. (2016). What is access? A discussion of the definition and measurement of interest group access. European Political Science, 16, 306-321.

Binderkrantz, A., \& Rasmussen, A. (2015). Comparing the domestic and the EU lobbying context: perceived agenda-setting influence in the multi-level system of the European Union. Journal of European Public Policy, 22(4), 552- 569.

Binderkrantz, A., Christiansen, P., \& Pedersen, H. (2014). A Privileged Position? The Influence of Business Interests in Government Consultations. Journal of Public Administration Research and Theory, 24(4), 879-896. 
Blom, T. (2016). A Note on the Functioning and Role of Experts and Expertise in Policy-Making Processes. Presented at the Annual PCE Conference, Maastricht, 7 December 2016.

Blom, T., \& Vanhoonacker, S. (2014). The Politics of Information: A New Research Agenda. In T. Blom \& S. Vanhoonacker (Eds.), The Politics of Information. The Case of the European Union (pp. 1-14). Houndmills: Palgrave Macmillan.

Blom, T., van Suijlekom, L., Versluis, E., \& Wirtz, M. (2014). The Politics of Information in the EU: The Case of European Agencies. In T. Blom \& S. Vanhoonacker (Eds.), The Politics of Information. The Case of the European Union (pp. 93-108). Houndmills: Palgrave Macmillan.

Boswell, C. (2008). The political functions of expert knowledge: knowledge and legitimation in European Union immigration policy. Journal of European Public Policy, 15(4), 471-488.

Boswell, C. (2009). The Political Uses of Expert Knowledge: Immigration Policy and Social Research. Cambridge: Cambridge University Press.

Bouwen, P. (2002). Corporate lobbying in the European Union: the logic of access. Journal of European Public Policy, 9(3), 365-390.

Brandsma, G. J. (2013). Controlling comitology: accountability in a multi-level system. Houndmills: Palgrave Macmillan.

Buess, M. (2014). European Union Agencies' Vertical Relationships with the Member States: Domestic Sources of Accountability?. Journal of European Integration, 36(5), 509-524.

Buess, M. (2015a). European Union agencies and their management boards: an assessment of accountability and demoi-cratic legitimacy. Journal of European Public Policy, 22(1), 94- 111.

Buess, M. (2015b). Accountable and Under Control? Explaining Governments' Selection of Management Board Representatives. Journal of Common Market Studies, 53(3), 493508.

Bunea, A. (2013). Issues, preferences and ties: determinants of interest groups' preference attainment in the EU environmental policy. Journal of European Public Policy, 20(4), $552-570$.

Burns, C. (2005). Who Pays? Who Gains? How do Costs and Benefits Shape the Policy Influence of the European Parliament? Journal of Common Market Studies, 43(3), 485-505.

Busuioc, M. (2009). Accountability, Control and Independence: The Case of European Agencies. European Law Journal, 15(5), 599-615.

Busuioc, M. (2012). European agencies and their boards: promises and pitfalls of accountability beyond design. Journal of European Public Policy, 19(5), 719-736.

Busuioc, M. (2013). European agencies: Law and practices of accountability. Oxford: Oxford University Press.

Busuioc, M., Curtin, D., \& Groenleer, M. (2011). Agency growth between autonomy and accountability: The European Police Office as a 'living institution'. Journal of European Public Policy, 18(6), 848-867.

Busuioc, M., Groenleer, M., \& Trondal, J. (Eds.) (2012).The Agency Phenomenon in the European Union: Emergence, Institutionalisation and Everyday Decision-Making. Manchester: Manchester University Press.

Calcara, A. (2017). The Role of Experts in the European Defence Agency: An Emerging Transgovernmental Network. European Foreign Affairs Review, 22(3), 377-392.

Carpenter, D. (2010). Reputation and power: Organizational image and pharmaceutical regulation at the FDA. Princeton, NJ: Princeton University Press. 
Cartwright, D. (1969). Influence, Leadership, Control. In R. Bell, D.V. Edwards, \& R.H. Wagner (Eds.), Political Power: A Reader in Theory and Research (pp. 123-165). New York, NY: Free Press.

Chalmers, A. W. (2011). Interests, Influence and Information: Comparing the Influence of Interest Groups in the European Union. European Integration, 33(4), 471-486.

Chalmers, A. W. (2013). Trading information for access: informational lobbying strategies and interest group access to the European Union. Journal of European Public Policy, 20(1), 39-58.

Chalmers, A. W. (2014). Getting a Seat at the Table: Capital, Capture and Expert Groups in the European Union. West European Politics, 37(5), 976-992.

Chamon, M. (2016). EU Agencies. Legal and Political Limits to the Transformation of the EU Administration. Oxford: Oxford University Press.

Chemicalwatch (2007). First thoughts emerge on review of EU biocides regime. Retrieved from https://chemicalwatch.com/173/first-thoughts-emerge-on-review-of-eu-biocidesregime.

Chemicalwatch (2008). EU biocides law revision imminent. Retrieved from https://chemicalwatch.com/1206/eu-biocides-law-revision-imminent.

Chiti, E. (2009). An Important Part of the EU's Institutional Machinery: Features, Problems and Perspectives of European Agencies. Common Market Law Review, 46, 1395-1442.

Chiti, E. (2013). European Agencies' Rulemaking: Powers, Procedures and Assessment. European Law Journal, 19(1), 93-110.

Chou, M., \& Riddervold, M. (2015). The Unexpected Negotiator at the Table: How the European Commission's Expertise Informs Intergovernmental EU Policies. Politics and Governance, 3(1), 61-72.

Christensen, J. G., \& Nielsen, V. L. (2010). Administrative capacity, structural choice and the creation of EU agencies. Journal of European Public Policy, 17(2), 176-204.

Christiansen, T., \& Neuhold, C. (Eds.). (2012). International Handbook on Informal Governance. Cheltenham: Edward Elgar Publishing Limited.

Clark, W., Mitchell, R., \& Cash, D. (2006). Evaluating the Influence of Global Environmental Assessments. In R. Mitchell, W. Clark, D. Cash, \& N. Dickson (Eds.), Global Environmental Assessment. Information and Influence (pp. 1-28). Cambridge, MA: The MIT Press.

Clegg, S. (1989). Frameworks of Power. London: Sage.

Coen, D. (1997). The Evolution of Large Firm Political Action in the European Union. Journal of European Public Policy, 4(1), 91-108.

Coen, D., \& Katsaitis, A. (2013). Chameleon pluralism in the EU: an empirical study of the European Commission interest group density and diversity across policy domains. Journal of European Public Policy, 20(8), 1104- 1119.

Coman-Kund, F. (2018). European Union Agencies as Global Actors: A Legal Study of the European Aviation Safety Agency, Frontex and Europol. Oxon: Routledge.

Connolly, W. E. (1983). The Terms of Political Discourse (2 ${ }^{\text {nd }}$ ed.). Princeton, NJ: Princeton University Press.

Copsey, N., \& Pomorska, K. (2010). Poland's power and influence in the European Union. The case of its eastern policy. Comparative European Politics, 8(3), 304-326.

Corell, E., \& Betsill, M. M. (2008). Analytical Framework: Assessing the Influence of NGO Diplomats. In M. M. Betsill \& E. Corell (Eds.), NGO Diplomacy: The Influence of 
Nongovernmental Organizations in International Environmental Negotiations (pp. 1942). Cambridge, MA: The MIT Press.

Council of the European Union (2009). Interinstitutional File: 2009/0076 (COD). 17630/09 18 December 2009. Brussels: Council of the European Union.

Cram, L. (1997). Policy-making in the European Union: Conceptual Lenses and the Integration Process, London: Routledge.

Dahl, R. (1957). The Concept of Power. Behavioral Science, 2, 201-215.

Dahl, R. (1989). Democracy and Its Critics. New Haven, MA: Yale University Press.

Dahl, R., \& Stinebrickner, B. (2003). Modern Political Analysis (6th ed.). Upper Saddle River, NJ: Prentice Hall.

De Bruycker, I. (2016). Pressure and Expertise: Explaining the Information Supply of Interest Groups in EU Legislative Lobbying. Journal of Common Market Studies, 54(3), 599-616.

De Ruijter, A. (2017). Mixing EU Security and Public Health Expertise in the Health Threats Decision. In M. Weimer \& A. De Ruijter (Eds.), Regulating Risks in the European Union. The Co-Production of Expert and Executive Power (pp. 101-120). Portland, Oregon: Hart Publishing.

Dehousse, R. (1997). Regulation by Networks in the European Community: The Role of European Agencies. Journal of European Public Policy, 4(2), 246-61.

Dehousse, R. (2008). Delegation of powers in the European Union: The need for a multiprincipals model. West European Politics, 31(4), 789-805.

Del Rio, C., \& Guarner, J. (2010). The 2009 Influenza A (H1N1) Pandemic: What Have We Learned in the Past 6 Months. Transactions of the American Clinical and Climatological Association, 121, 128-140.

Deloitte \& VVA (2017). Review of the European Chemicals Agency (ECHA) established under Regulation N 1907/2006: Final Report. Brussels: European Commission.

Dexter, L. A. (1970). Elite and Specialised Interviewing. Evanston: Northwestern University Press.

Duncan, S., \& Harrop, A. (2006). A User Perspective on Research Quality. International Journal of Social Research Methodology, 9(2), 159-174.

Dunlop, C. (2010). Epistemic communities and two goals of delegation: hormone growth promoters in the European Union. Science and Public Policy, 37(3), 205-217.

Dür, A. (2008a). Measuring Interest Group Influence in the EU: A Note on Methodology. European Union Politics, 9(4), 559-576.

Dür, A. (2008b). Interest Groups in the EU: How Powerful Are They? West European Politics, 31(6), 1212-30.

Dür, A., \& De Bièvre, D. (2007). Inclusion without influence? NGOs in European trade policy. Journal of Public Policy, 27(1), 79-101.

Dür, A., Bernhagen, P., \& Marshall, D. (2015). Interest Group Success in the European Union: When (and Why) Does Business Lose? Comparative Political Studies, 48(8), 951-983.

Eberlein, B., \& Grande, E. (2005). Beyond delegation: transnational regulatory regimes and the EU regulatory state. Journal of European Public Policy, 12(1), 89-112.

ECDC. (2007). Annual Report of the Director 2006. Stockholm, Sweden: Corporate Publication.

ECDC. (2009a). Annual Report of the Director 2008. Stockholm, Sweden: Corporate Publication.

ECDC. (2009b). ECDC Threat Assessment - UPDATE. Human cases of swine influenza without apparent exposure to pigs, United States and Mexico, 24 April 2009 - 19:00 hours. Stockholm, Sweden: Corporate Publication. 
ECDC. (2009c). ECDC Interim Risk Assessment. Pandemic (H1N1) 2009 influenza, 21 August 2009. Stockholm, Sweden: Corporate Publication.

ECDC. (2009d). Interim Guidance: Use of specific pandemic influenza vaccines during the H1N1 2009 pandemic, August 2009. Stockholm, Sweden: Corporate Publication.

ECDC. (2009e). Technical Report: Surveillance and studies in a pandemic in Europe, June 2009. Stockholm, Sweden: Corporate Publication.

ECDC. (2009f). Executive Science Update, No. 7, April-June 2009. Stockholm, Sweden: Corporate Publication.

ECDC. (2010a). ECDC Special Report: The 2009 A(H1N1) pandemic in Europe - a review of the experience. Stockholm, Sweden: Corporate Publication.

ECDC. (2010b). Annual Report of the Director 2009. Stockholm, Sweden: Corporate Publication.

ECDC. (2010c). ECDC Timeline: European 2009 Influenza Pandemic Timeline. Stockholm, Sweden: Corporate Publication.

ECDC. (2011). Annual Report of the Director 2010. Stockholm, Sweden: Corporate Publication.

ECDC. (2012). Annual Report of the Director 2011. Stockholm, Sweden: Corporate Publication.

ECDC. (2013). ECDC Director's Presentation: ECDC's approach to outbreaks with international background and cross-border dimension. Presented at the LÜKEX visitors program, Bonn, Germany, 27-28 November 2013.

ECDC. (2014). Annual Report of the Director 2013. Stockholm, Sweden: Corporate Publication.

ECDC. (2017). Annual Report of the Director 2016. Stockholm, Sweden: Corporate Publication.

ECHA. (2008a). Subject: Work under the Biocides Directive (Ref.: ENV.B3/PS/pw D/7164) [Letter to the European Commission]. 30 September 2008. Helsinki, Finland: European Chemicals Agency.

ECHA. (2008b). Subject: Role of ECHA under the proposed new Biocides Regulation (Ref.: D(2008) Anés 40298) [Letter to the European Commission]. 15 December 2008. Helsinki, Finland: European Chemicals Agency.

ECHA. (2009). General Report 2008: The year of pre-registration. Helsinki, Finland: Corporate Publication.

ECHA (2010). General Report 2009: The year of preparations. Helsinki, Finland: Corporate Publication.

ECHA. (2011). General Report 2010: The year of registration. Helsinki, Finland: Corporate Publication.

ECHA. (2012a). General Report 2011: The year of dissemination. Helsinki, Finland: Corporate Publication.

ECHA. (2012b). Minutes of the 27th Meeting of the Management Board, 27-28 September 2012, MB/M/03/2012 final. Helsinki, Finland: Corporate Publication.

ECHA. (2012c). Minutes of the 28th Meeting of the Management Board, 13-14 December 2012, MB/M/04/2012 final. Helsinki, Finland: Corporate Publication.

ECHA. (2013a). General report 2012: The year of evaluation. Helsinki, Finland: Corporate Publication.

ECHA. (2013b). Newsletter, No: 4, August 2013. Helsinki, Finland: Corporate Publication.

ECHA. (2014a). General Report 2013. Helsinki, Finland: Corporate Publication.

ECHA. (2014b). Biocidal Products Committee (BPC) - Opinion on the application for approval of the active substance: Alpha-cypermethrin, Product type: 18, ECHA/BPC/009/2014. Helsinki, Finland: Corporate Publication. 
ECHA. (2014c). Biocidal Products Committee (BPC) - Opinion on the application for approval of the active substance: Folpet, Product type: 06, ECHA/BPC/010/2014. Helsinki, Finland: Corporate Publication.

ECHA. (2014d). Biocidal Products Committee (BPC) - Opinion on the application for approval of the active substance: Glutaraldehyde, Product type: 02. ECHA/BPC/019/2014. Helsinki, Finland: Corporate Publication.

ECHA. (2015). General Report 2014. Helsinki, Finland: Corporate Publication.

ECHA. (2016a). General Report 2015. Helsinki, Finland: Corporate Publication.

ECHA. (2016b). Practical guide on Biocidal Products Regulation. Helsinki, Finland: Corporate Publication.

ECHA. (2016c). ECHA Programming Document 2017-2019. Helsinki, Finland: Corporate Publication.

ECHA. (2016d). Biocidal Products Committee (BPC) - Opinion on the application for renewal of the approval of the active substance: Brodifacoum, Product type: 14, ECHA/BPC/113/2016. Helsinki, Finland: Corporate Publication.

ECHA. (2016e). Biocidal Products Committee (BPC) - Opinion on the application for renewal of the approval of the active substance: Flocoumafen, Product type: 14, ECHA/BPC/115/2016. Helsinki, Finland: Corporate Publication.

ECHA. (2016f). Biocidal Products Committee (BPC) - Opinion on the application for approval of the active substance: Silicon dioxide Kieselguhr, Product type: 18, ECHA/BPC/121/2016. Helsinki, Finland: Corporate Publication.

ECHA. (2017a). General Report 2016. Helsinki, Finland: Corporate Publication.

ECHA. (2017b). Minutes of the $19^{\text {th }}$ meeting of the Biocidal Products Committee (BPC), 1-3 March 2017. Helsinki, Finland: Corporate Publication.

Economisti Associati. (2014). Specific Contract: The second independent evaluation of the ECDC in accordance with its Founding Regulation (European Parliament and Council Regulation (EC) no 851/2004. FINAL REPORT: Volume 1 - Main Text. Retrieved from https://ecdc.europa.eu/sites/portal/files/media/en/aboutus/Key\%20Documents/ECD C-external-evaluation-2014.pdf

Egeberg, M. (1999). Transcending intergovernmentalism? Identity and role perceptions of national officials in EU decision-making. Journal of European Public Policy, 6(3), 456474.

Egeberg, M., \& Trondal, J. (2011). EU-level agencies: new executive centre formation or vehicles for national control? Journal of European Public Policy, 18(6), 868-887.

Egeberg, M., \& Trondal, J. (2017). Researching European Union Agencies: What Have We Learnt (and Where Do We Go from Here)? Journal of Common Market Studies, 55(4), 675-690.

Egeberg, M., Gornitzka, A., \& Trondal, J. (2017). Merit-based recruitment boosts good governance: How do European Union agencies recruit their personnel?. International Review of Administrative Sciences, O(0), 1-17.

Egeberg, M., Trondal, J., \& Vestlund, N. M. (2015). The Quest for Order: Unravelling the Relationship between the European Commission and European Union Agencies. Journal of European Public Policy, 22(5), 609-629.

Eising, R. (2007). Institutional Context, Organizational Resources and Strategic Choices. European Union Politics, 8(3), 329-362. 
Ekelund, H. M. (2010). The Agencification of Europe: Explaining the Establishment of European Community Agencies (Unpublished doctoral dissertation). University of Nottingham, Nottingham, United Kingdom.

European Aviation and Safety Agency (EASA). (2010). Annual Report 2009. Cologne: Corporate Publication.

European Commission. (2001). White Paper: Strategy for a future Chemicals Policy. $\operatorname{COM}(2001) 88$ final. Brussels: European Commission.

European Commission. (2002a). Communication from the Commission: The operating framework for the European Regulatory Agencies. (COM (2002) 718 final). Brussels: European Commission.

European Commission. (2002b). Communication from the Commission: Consultation Document: Towards a reinforced culture of consultation and dialogue - Proposal for general principle and minimum standards for consultation of interested parties by the Commission. (COM (2002) 277 final). Brussels: European Commission.

European Commission. (2008). Communication from the Commission to the European Parliament and the Council. European agencies - The way forward. (COM(2008) 135 final). Brussels: European Commission.

European Commission. (2009a). Communication from the Commission to the European Parliament, the Council, the European Economic and Social Committee and the Committee of the Regions - Pandemic (H1N1)2009. (COM(2009) 481 final). Brussels: European Commission.

European Commission. (2009b). Proposal for a Regulation of the European Parliament and of the Council concerning the placing on the market and use of biocidal products. (COM (2009) 267 final). Brussels: European Commission.

European Commission. (2011a). Proposal for a Decision of the European Parliament and of the Council on serious cross-border threats to health. (COM(2011) 866 final). Brussels: European Commission.

European Commission. (2011b). Commission Staff Working Paper Impact Assessment. Accompanying the document Decision of the European Parliament and of the Council on serious cross-border threats to health. (SEC(2011) 1519 final). Brussels: European Commission.

European Commission. (2011c). Communication from the Commission to the European Parliament pursuant to Article 294(6) of the Treaty on the Functioning of the European Union concerning the position of the Council on the adoption of a Regulation of the European Parliament and of the Council concerning the placing on the market and use of biocidal products. (COM(2011) 498 final). Brussels: European Commission.

European Commission. (2013a). Commission Staff Working Document. General Report on REACH, Accompanying the document, Report from the Commission to the European Parliament, the Council, the European Economic and Social Committee and the Committee of the Regions in accordance with Article 117(4) of REACH and Article 46(2) of CLP, and a review of certain elements of REACH in line with Articles 75(2), 138(3) and 138(6) of REACH SWD(2013) 25 final. (COM (2013) 49 final). Brussels: European Commission.

European Commission. (2013b). Task leaders and participants in PREP-BPR (Preparation for the Entry into Force of the Biocidal Products Regulation). Retrieved from https://circabc.europa.eu/webdav/CircaBC/SANTE/BPR\%20-\%20Public/Library/CA\% 
20meetings/50th\%20CA\%20meeting\%20February\%202013/CA-Feb13-Doc.5.1.a\%20\%20Task\%20leaders\%20and\%20participants.pdf

European Commission. (2014). Press Release - The Juncker Commission: A strong and experienced team standing for change. 10 September 2014. Brussels: European Commission.

European Commission. (2015a). COMMISSION IMPLEMENTING REGULATION (EU) 2015/405 of 11 March 2015 approving alpha-cypermethrin as an active substance for use in biocidal products for product-type 18. Official Journal of the European Union L 67. 12 March 2015. Brussels: European Commission.

European Commission. (2015b). COMMISSION IMPLEMENTING REGULATION (EU) 2015/1757 of 28 September 2015 approving folpet as an active substance for use in biocidal products for product-type 6. Official Journal of the European Union L 257. 2 October 2015. Brussels: European Commission.

European Commission. (2015c). COMMISSION IMPLEMENTING REGULATION (EU) 2015/1757 of 28 September 2015 approving glutaraldehyde as an active substance for use in biocidal products for product-types 2, 3, 4, 6, 11 and 12. Official Journal of the European Union L 257. 2 October 2015. Brussels: European Commission.

European Commission. (2015d). Strengthening Evidence Based Policy Making Through Scientific Advice: Reviewing existing practice and setting up a European Science Advice Mechanism. Retrieved from https://ec.europa.eu/research/sam/pdf/strengthening_ evidence_based_policy_making.pdf

European Commission. (2016). Report from the Commission to the European Parliament and the Council on the sustainable use of biocides pursuant to Article 18 of Regulation (EU) No 528/2012 of the European Parliament and of the Council concerning the making available on the market and use of biocidal products. (COM(2016) 151). Brussels: European Commission.

European Commission. (2017a). COMMISSION IMPLEMENTING REGULATION (EU) 2017/1381 of 25 July 2017 renewing the approval of brodifacoum as an active substance for use in biocidal products of product-type 14. Official Journal of the European Union L 194. 26 July 2017. Brussels: European Commission.

European Commission. (2017b). COMMISSION IMPLEMENTING REGULATION (EU) 2017/1383 of 25 July 2017 renewing the approval of flocoumafen as an active substance for use in biocidal products of product-type 14. Official Journal of the European Union L 194. 26 July 2017. Brussels: European Commission.

European Commission. (2017c). COMMISSION IMPLEMENTING REGULATION (EU) 2017/794 of 10 May 2017 approving silicon dioxide Kieselguhr as an existing active substance for use in biocidal products of product-type 18. Official Journal of the European Union $\mathrm{L}$ 120. 11 May 2017. Brussels: European Commission.

European Court of Auditors (ECA). (2016). Special Report. Dealing with serious cross-border threats to health in the EU: important steps taken but more needs to be done. Luxembourg: Corporate Publication.

European Court of Auditors (ECA). (2017). 2016 Audit of EU agencies in brief. Summary of the results of the ECA's annual audits of the European Agencies and other bodies for the financial year 2016. Luxembourg: Corporate Publication.

European Medicines Agency (EMA). (2010). Annual report 2009 - Adopted by the Management Board in March 2010. London: Corporate Publication. 
Everson, M. (1995). Independent Agencies: Hierarchy Beaters? European Law Journal, 1(2), 180-204.

Everson, M., Monda, C., \& Vos, E. (Eds.) (2014). European Agencies in Between Institutions and Member States. Alphen aan den Rijn: Kluwer Law International.

Fantini, M., \& Staal, K. (2018). Influence in the EU: Measuring Mutual Support. Journal of Common Market Studies, 56(2), 212-229.

Font, N. (2015). Policy properties and political influence in post-delegation: the case of EU agencies. International Review of Administrative Sciences, 81(4), 773-792.

Font, N., \& Pérez-Durán, I. (2016). The European Parliament oversight of EU agencies through written questions, Journal of European Public Policy, 23(9), 1349-1366.

Fraussen, B., \& Beyers, J. (2015). Who's in and who's out?: Explaining access to policymakers in Belgium. Acta Politica, 1-23. doi:10.1057/ap.2015.9.

Garret, S., Caldwell, B., Harris, E., \& Gonzalez, M. (2009). Six dimensions of expertise: a more comprehensive definition of cognitive expertise for team coordination. Theoretical Issues in Ergonomics Science, 10(2), 93-105.

Gehring, T., \& Krapohl, S. (2007). Supranational regulatory agencies between independence and control: The EMEA and the authorization of pharmaceuticals in the European single market. Journal of European Public Policy, 14(2), 208-226.

George, A. L., \& Bennett, A. (2005). Case studies and theory development. Cambridge, MA: MIT Press.

Geradin, D., \& Petit, N. (2004). The Development of Agencies at EU and National Levels: Conceptual Analysis and Proposals for Reform. Jean Monnet Working Paper 01/04. New York: Jean Monnet Center, School of Law, New York University.

Gornitzka, A., \& Sverdrup, U. (2011). Access of Experts: Information and EU Decision-making. West European Politics, 34(1), 48-70.

Greco, D., Stern, E. K., \& Marks, G. (2011) Review of ECDC's response to the influenza pandemic 2009-2010. Stockholm: European Centre for Disease Prevention and Control.

Groenleer, M. (2009). The Autonomy of European Agencies: A Comparative Study of Institutional Development. Delft: Eburon.

Groenleer, M. (2014). Agency Autonomy Actually: Managerial Strategies, Legitimacy, and the Early Development of the European Union's Agencies for Drug and Food Safety Regulation. International Public Management Journal, 17(2), 255-292.

Groenleer, M., Kaeding, M., \& Versluis, E. (2010). Regulatory governance through agencies of the European Union? The role of the European agencies for maritime and aviation safety in the implementation of European transport legislation. Journal of European Public Policy, 17(8), 1212-1230.

Guzzini, S. (2005). The concept of power: a constructivist analysis. Millennium: Journal of International Studies, 33(3), 495-521.

Haas, P. M. (1992). Introduction: Epistemic communities and international policy coordination. International Organization, 46(1), 1-35.

Hall, R. (1992). Measuring Legislative Influence. Legislative Studies Quarterly, 17(2), 205231.

Harcourt, A., \& Radaelli, C. (1999). Limits to EU technocratic regulation? European Journal of Political Research, 35, 107-122.

Hartlapp, M., Metz, J., \& Rauh, C. (2013). Linking agenda setting to coordination structures: bureaucratic politics inside the European Commission. Journal of European Integration, 35(4), 425-441. 
Hartlapp, M., Metz, J., \& Rauh, C. (2014). Which Policy for Europe? Power and Conflict inside the European Commission. Oxford: Oxford University Press.

Hastie, R., \& Dawes, R. M. (2010). Rational choice in an uncertain world (2nd ed.). Thousand Oaks, CA: Sage.

Haverland, M. (2009). How leader states influence EU policy-making: Analysing the expert strategy, European Integration online Papers, 13(25), 1-19.

Health Protection Agency (HPA). (2010). Assessment Report on the EU-wide Response to Pandemic (H1N1) 2009. Covering the period 24 April 2009-31 August 2009 (excluding vaccine policy issues). Salisbury: Health Protection Agency.

Heims, E (2016). Explaining coordination between national regulators in EU agencies: the role of formal and informal social organization. Public Administration, 94(4), 881-896.

Hobbes, T. (1651/1985). Leviathan. Harmondsworth: Penguin.

Hönnig, C., \& Panke, D. (2012). The Committee of the Regions and the European Economic and Social Committee: How Influential are Consultative Committees in the European Union? Journal of Common Market Studies, 51(3), 452-471.

Hoogerwerf, A. (1972). Politicologie, Begrippen en Problemen. Aalphen aan den Rijn: Sansom Aalphen aan den Rijn.

Ingold, K., \& Leifeld, P. (2014). Structural and Institutional Determinants of Influence Reputation: A Comparison of Collaborative and Adversarial Policy Networks in Decision Making and Implementation. Journal of Public Administration Research and Theory, 129, doi:10.1093/jopart/muu043.

Jakobsen, P. V. (2009). Small States, Big Influence: The Overlooked Nordic Influence on the Civilian ESDP. Journal of Common Market Studies, 47(1), 81-102.

Jasanoff, S. (2005). Designs on Nature: Science and Democracy in Europe and the United States. Princeton, NJ: Princeton University Press.

Johansson, K. M. (2016). Europarty Influence and Its Limits: The Case of the European People's Party and the Amsterdam Treaty. Journal of European Integration, 38(1), 79-94.

Kelemen, D. R. (2002). The politics of 'eurocratic' structure and the new European agencies. West European Politics, 25(4), 93-118.

Kelemen, D. R. (2005). The Politics of Eurocracy: Building a New European State. in N. Jabko \& C. Parsons (Eds.), With US or Against US? European Trends in American Perspective (pp. 173-189). Oxford: Oxford University Press.

Kim, J., Klika, C., \& Versluis, E. (2013). Agencies as risk managers? Exploring the role of EU agencies in authorization procedures. In M. van Asselt, E. Versluis, \& E. Vos (Eds.), Balancing between Trade and Risk: Integrating Legal and Social Science Perspectives (pp. 173-194). Oxon: Routledge.

Kliemt, H. (1981). A Philosophical View of Power. In M. Holler (Ed.), Power, Voting, and Voting Power (pp. 52-64). Würzburg: Physica-Verlag.

Klika, C. (2015). The Implementation of the REACH Authorisation Procedure on Chemical Substances of Concern: What Kind of Legitimacy? Politics and Governance, 3(1), 128138.

Klüver, H. (2009). Measuring Interest Group Influence. Using Quantitative Text Analysis. European Union Politics, 10(4), 535-549.

Klüver, H. (2012). Informational Lobbying in the European Union: The Effect of Organisational Characteristics. West European Politics, 35(3), 491-510.

Klüver, H. (2013). Lobbying in the European Union: Interest groups, lobbying coalitions and policy change, Oxford: Oxford University Press. 
Klüver, H., Braun, C., \& Beyers, J. (2015). Legislative lobbying in context: towards a conceptual framework of interest group lobbying in the European Union. Journal of European Public Policy, 22(4), 447-461.

Knoke, D. (1990). Political Networks. The Structural Perspective. Cambridge: Cambridge University Press.

Krapohl, S. (2004). Credible Commitment in Non-Independent Regulatory Agencies: a Comparative Analysis of the European Agencies for Pharmaceuticals and Foodstuffs. European Law Journal, 10(5), 495-648.

Lasswell, H., \& Kaplan, A. (1950). Power and Society. A Framework for Political Inquiry. New Haven, Conn.: Yale University Press.

Leech, B. (2002). Asking Questions: Techniques for Semistructured Interviews. Political Science \& Politics, 35(4), 665-668.

Lentsch, J., \& Weingart, P. (2011). The politics of scientific advice: Institutional design for quality assurance. Cambridge: Cambridge University Press.

Leppävirta, L., \& Darbishire, H. (2017). The Right to Ask...The Right to Know - The Successes and Failures in Access to Documents Rules and Practices from an NGO Perspective. In C. Harlow, P. Leino, \& G. della Cananea (Eds.), Research Handbook on EU Administrative Law (pp. 399-422). Cheltenham: Edward Elgar.

Levy, J. S. (2008). Case Studies: Types, Designs, and Logics of Inference. Conflict Management and Peace Science, 25, 1-18.

Lindvall, J. (2009). The Real but Limited Infuence of Expert Ideas. World Politics, 61(4), 703730.

Liverani, M., \& Coker, R. (2012). Protecting Europe from Diseases: From the International Sanitary Conferences to the ECDC. Journal of Health Politics, Policy and Law, 37(6), 915-934.

Lord, C. (2011). The European Parliament and the legitimation of agencification. Journal of European Public Policy, 18(6), 909-925.

Lucas, J., \& Baxter, A. (2012). Power, Influence, and Diversity in Organizations. The ANNALS of the American Academy of Political and Social Sciences, 639, 49-70.

Luitwieler, S. (2009). The Black Box of the Nice Treaty Negotiations. The influence of the Dutch cabinet. (Unpublished doctoral dissertation). Erasmus University Rotterdam, Rotterdam, Netherlands.

Lukes, S. (1974). Power, A Radical View. London: Macmillan.

Lukes, S. (1991). Moral Conflict and Politics. Oxford: Clarendon Press.

Maggetti, M. (2014). The rewards of cooperation: The effects of membership in European regulatory networks. European Journal of Political Research, 53(3), 480-499.

Mahoney, C. (2007). Lobbying success in the United States and the European Union. Journal of Public Policy, 27(1), 35-56.

Majone, G. (1994). The rise of the regulatory state in Europe. West European Politics, 17(3), 77-101.

Majone, G. (1996). Regulating Europe. London: Routledge.

Majone, G. (1997). The new European agencies: regulation by information. Journal of European Public Policy, 4(2), 262-275.

Malan, J., Blomeyer, R., Smit, J., Krarup, A., Carlberg, M., Moeller, C., et al. (2016). The Cost of Non-Agencies with Relevance to Internal Market. A study prepared for Policy Department D, Budgetary Affairs, Directorate-General for Internal Policies, European Parliament. Brussels: European Parliament. 
Martens, M. (2010). Voice or loyalty? The evolution of the European Environment Agency (EEA). Journal of Common Market Studies, 48(4), 881-901.

Martens, M. (2012). Executive Power in the Making: The Establishment of the European Chemicals Agency. In M. Busuioc, M. Groenleer \& J. Trondal (Eds). The Agency Phenomenon in the European Union (pp. 42-62). Manchester: Manchester University Press.

Mazey, S., \& Richardson, J. (Eds.) (1993). Lobbying in the European Community. Oxford: Oxford University Press.

McCarthy, R. (1997). The Committee of the Regions: an advisory body's tortuous path to influence. Journal of European Public Policy, 4(3), 439-454.

Meier, K. J. (1980). Measuring Organizational Power: Resources and Autonomy of Government Agencies. Administration \& Society, 12(3), 357-375.

Metz, J. (2015). The European Commission, Expert Groups, and the Policy Process. Demystifying Technocratic Governance. Uitgeverij: Palgrave Macmillan.

Michalowitz, I. (2004). EU Lobbying - Principals, Agents and Targets. Strategic Interest Intermediation in EU Policy-making. Münster: LIT.

Michalowitz, I. (2007). What determines influence? Assessing conditions for decision-making influence of interest groups in the EU. Journal of European Public Policy, 14(1), 132151.

Mikhaylov, S., Laver, M. \& Benoit, K. (2008). Coder Reliability and Misclassification in Comparative Manifesto Project Codings. Paper presented at the annual meeting of the Midwest Political Science Association, 3-6 April, Chicago.

Mokken, R., \& Stokman, F. (1989). Power and Influence as Political Phenomena. In B. Barry (Ed.), Democracy, Power and Justice: Essays in Political Theory (pp. 33-54). Oxford: Clarendon Press.

Musa, A. (2014). Reforming the European Union Agency Governance: More Control, Greater Accountability. Croatian and Comparative Public Administration, 14(2), 317-353.

Nagel, J. (1975). The Descriptive Analysis of Power. New Haven, Conn.: Yale University Press.

Nasra, S. (2011). Governance in EU foreign policy: exploring small state influence. Journal of European Public Policy, 18(2), 164-180.

Nugent, N. (2001). The European Commission. Basingstoke: Palgrave.

Ossege, C. (2016). European Regulatory Agencies in EU Decision-Making: Between Expertise and Influence. Hampshire: Palgrave MacMillan.

Page, E. (2010). Bureaucrats and expertise: Elucidating a problematic relationship in three tableaux and six jurisdictions. Sociologie Du Travail, 52(2), 255-273.

Panke, D., Hönnige, C., \& Gollup, J. (2015). Consultative Committees in the European Union. No Vote - No Influence? Colchester: ECPR Press.

Parsons, T. (1963). On the Concept of Influence. The Public Opinion Quarterly, 27(1), 37-62.

Peterson, J. (1995). Decision-making in the European Union: Towards a framework for analysis. Journal of European Public Policy, 2(1), 69-93.

Pryor, T. (2017). Using Citations to Measure Influence on the Supreme Court. American Politics Research, 45(3), 366-402.

PWC. (2012). Final Report on the Review of the European Chemicals Agency: Main report. Brussels: European Commission.

Quaglia, L., de Francesco, F., \& Radaelli, C. M. (2008). Committee governance and socialization in the European Union. Journal of European Public Policy, 15(1), 155-166. 
Ramboll, Euréval, \& Matrix (2009a). Evaluation of the EU decentralised agencies in 2009. Final Report Volume I-Synthesis and prospects. Retrieved from https://europa.eu/ european-union/sites/europaeu/files/docs/body/synthesis_and_prospects_en.pdf

Ramboll, Euréval, \& Matrix (2009b). Evaluation of the EU decentralised agencies in 2009. Final Report Volume II - Conclusions at System Level. Retrieved from https://europa.eu/european-union/sites/europaeu/files/docs/body/conclusions_at _system_level_en.pdf

Ramboll, Euréval, \& Matrix (2009c). Evaluation of the EU decentralised agencies in 2009. Final Report Volume III - Agency level findings. Retrieved from https://europa.eu/european-union/sites/europaeu/files/docs/body/agency_level_ findings_en.pdf

Rasmussen, M. K. (2012). The Influence of Interest Groups in the European Parliament: Does Policy Shape Politics? (Unpublished doctoral dissertation). London School of Economics and Political Science, London, United Kingdom.

Rasmussen, M. K. (2015). The Battle for Influence: The Politics of Business Lobbying in the European Parliament. Journal of Common Market Studies, 53(2), 365-382.

Rechel, B., \& McKee, M. (Eds.) (2014). Facets of Public Health in Europe. Berkshire: Open University Press.

Reillon, V. (2015). Scientific advice for policy-makers in the European Union [Briefing]. Retrieved from http://www.europarl.europa.eu/EPRS/EPRS-Briefing-559512Scientific-advice-for-policy-makers-in-the-EU-FINAL.pdf

Reiners, W. (2015). The Institutionalisation of Infectious Disease Control in the European Union - The Effect of the Securitisation of BSE/TSES and SARS. (Unpublished PhD dissertation). University of Köln, Köln, Germany.

Richards, D. (1996). Elite Interviewing: Approaches and Pitfalls. Politics, 16(3), 199-204.

Rimkutè, D. (2015). Explaining Differences in Scientific Expertise Use: The Politics of Pesticides. Politics and Governance, 3(1), 114-127.

Rohlfing, I. (2012). Case Studies and Causal Inference. Basingstoke: Palgrave Macmillan.

Russell, B. (1938). Power. A New Social Analysis. London: George Allen and Unwin.

Sabatier, P. (1978). The Acquisition and Utilization of Technical Information by Administrative Agencies. Administrative Science Quarterly, 23(3), 396-417.

Saldaña, J. (2013). The Coding Manual for Qualitative Researchers ( $2^{\text {nd }}$ ed.). Los Angeles: SAGE Publications.

Santos-O'Connor, F., Pukkila, J., Varela Santos, C., Salvi, C., Faix, D., Van Cangh, T., et al. (2014). The Health Security Framework in Europe. In B. Rechel \& M. McKee (Eds.), Facets of Public Health in Europe (pp. 43-70). Berkshire: Open University Press.

Scholten, M. (2014). The Political Accountability of EU Agencies: Learning from the US experience. (Unpublished PhD dissertation). Maastricht University, Maastricht, Netherlands.

Schout, A., \& Pereyra, F. (2011). The Institutionalization of EU Agencies: Agencies as "Mini Commissions." Public Administration, 89(2), 418-432.

Schrefler, L. (2013). Economic Knowledge in Regulation: The Use of Expertise by Independent Agencies. Colchester: ECPR Press.

Seawright, J., \& Gerring, J. (2008). Case Selection Techniques in Case Study Research. A Menu of Qualitative and Quantitative Options. Political Research Quarterly, 61(2), 294-308.

Shapiro, M. (1997). The problems of independent agencies in the United States and the European Union. Journal of European Public Policy, 4(2), 276-291. 
Stone, C. (2001). Powerful Actors Versus Compelling Actions. Educational Policy, 15(1), 153167.

Suvarierol, S., Busuioc, M., \& Groenleer, M. (2013). Working for Europe? Socialization in the European Commission and Agencies of the European Union. Public Administration, 91(4), 908-927.

Tansey, (2007). Process Tracing and Elite Interviewing: A Case for Non-probability Sampling. PS: Political Science and Politics, 40(4), 765-772.

Thatcher, M. (2011). The creation of European regulatory agencies and its limits: A comparative analysis of European delegation. Journal of European Public Policy, 18(6), 790-809.

Thomson, R., \& Hosli, M. (2006). Who Has Power in the EU? The Commission, Council and Parliament in Legislative Decision-making. Journal of Common Market Studies, 44(2), 391-417.

Trondal, J., \& Jappesen, L. (2008). Images of agency governance in the European Union. West European Politics, 31(3), 417-441.

Trondal, J., \& Peters, B.G. (2013). The rise of European administrative space: lessons learned. Journal of European Public Policy, 20(2), 295-307.

Truman, D.B. (1951). The Government Process. Political Interests and Public Opinion. New York, NY: Alfred A. Knopf.

Van Asselt. M., \& Vos, E. (2008). Wrestling with uncertain risks: EU regulation of GMOs and the uncertainty paradox. Journal of Risk Research, 11(1-2), 281-300.

Van Schendelen, R. (2006). The In-Sourced Experts. Journal of Legislative Studies, 8(4), 27-39.

Vaughan, S. (2015). EU Chemicals Regulation: New Governance, Hybridity and REACH. Cheltenham: Edward Elgar Publishing.

Versluis, E. (2007). Even Rules, Uneven Practices: Opening the "Black Box" of EU Law in Action'. West European Politics, 30(1), 50-67.

Versluis, E., \& Tarr, E. (2013). Improving Compliance with European Union Law via Agencies: The case of the European Railway Agency. Journal of Common Market Studies, 51(2), 316-333.

Versluis, E., van Keulen, M., \& Stephenson, P. (Eds.). (2011). Analyzing the European Union Policy Process. London: Palgrave Macmillan.

Vestlund, N. M. (2017). Pooling administrative resources through EU regulatory networks. Journal of European Public Policy, 24(1), 61-80.

Vibert, F. (2007). The rise of the unelected: Democracy and the new separation of powers. Cambridge: Cambridge University Press.

Vos, E. (2000). Reforming the European Commission: What Role to Play for EU Agencies? Common Market Law Review, 37, 1113-1134.

Vos, E. (2003). Agencies and the European Union. In L. Verhey \& T. Zwart (Eds.), Agencies in European and Comparative Perspective (pp. 113-148). Antwerp: Intersentia.

Weber, M. (1922/1978). Economy and Society (4th ed.). (G. Roth, \& C. wittich, Vert.). Berkeley, CA: University of California Press.

Weinlich, S. (2014). The UN Secretariat's Influence on the Evolution of Peacekeeping. London: Palgrave Macmillan.

Woll, C. (2007). Leading the Dance? Power and Political Resources of Business Lobbyists. Journal of Public Policy, 27(1), 57-78.

Wonka, A. (2008). Decision-making dynamics in the European Commission: partisan, national or sectoral? Journal of European Public Policy, 15(8), 1145-1163. 
Wonka, A., \& Rittberger, B. (2010). Credibility, complexity and uncertainty determinants of institutional independence of 29 EU agencies. West European Politics, 33(4), 730-752.

Wonka, A., \& Rittberger, B. (2011). Perspectives on EU governance: An empirical assessment of the political attitudes of EU agency professionals. Journal of European Public Policy, 18(6), 888-908.

Wood, M. (2018). Mapping EU agencies as political entrepreneurs. European Journal of Political Research, 57, 404-426.

Wrong, D. (1979/1988). Power. Its Forms, Bases, and Uses (2nd ed.). Oxford: Basil Blackwell.

Zimmerling, R. (2005). Influence and Power. Variations on a Messy Theme. Dordrecht: Springer. 
Appendices 
Appendix 1: List of ECDC documents analysed for text comparison of case 1

\begin{tabular}{|c|c|c|}
\hline No. & Title & Publication Date \\
\hline \multicolumn{3}{|c|}{ Risk Assessment } \\
\hline 1 & $\begin{array}{l}\text { Public health issue: Implication for Europe of the } \\
\text { identification in North America of human cases of influenza } \\
\text { A/H1N1, with a unique gene segment combination }\end{array}$ & 30 April 2009 \\
\hline 2 & Implication for Europe of the novel influenza A (H1N1) virus & 8 May 2009 \\
\hline 3 & Human cases of influenza $\mathrm{A}(\mathrm{H} 1 \mathrm{~N} 1)$ & 20 May 2009 \\
\hline 4 & Human cases of influenza $\mathrm{A}(\mathrm{H} 1 \mathrm{~N} 1) \mathrm{v}$ & 12 June 2009 \\
\hline 5 & Pandemic H1N1 2009 & 20 July 209 \\
\hline 6 & Pandemic H1N1 2009 & 21 August 2009 \\
\hline \multicolumn{3}{|c|}{ Threat Assessment and Rapid Risk Assessment } \\
\hline 7 & $\begin{array}{l}\text { Human cases of swine influenza without apparent exposure } \\
\text { to pigs, United States and Mexico }\end{array}$ & 24 April 2009 \\
\hline 8 & $\begin{array}{l}\text { First isolation of a secondary oseltamivir-resistant } \mathrm{A}(\mathrm{H} 1 \mathrm{~N} 1) \mathrm{v} \\
\text { strain in Denmark }\end{array}$ & 1 July 2009 \\
\hline 9 & $\begin{array}{l}\text { Reassortment seasonal influenza virus and swine influenza } \\
\text { virus in Saskatchewan, Canada }\end{array}$ & 9 July 2009 \\
\hline \multicolumn{3}{|c|}{ Guidance } \\
\hline 10 & $\begin{array}{l}\text { Interim ECDC public health guidance on case and contact } \\
\text { management for the new influenza } \mathrm{A}(\mathrm{H} 1 \mathrm{~N} 1) \text { virus infection }\end{array}$ & 19 May 2009 \\
\hline 11 & $\begin{array}{l}\text { Public health use of influenza antivirals during influenza } \\
\text { pandemic }\end{array}$ & June 2009 \\
\hline 12 & $\begin{array}{l}\text { Mitigation and delaying (or 'containment') strategies as the } \\
\text { new influenza } A(H 1 N 1) \text { virus comes into Europe }\end{array}$ & 6 June 2009 \\
\hline 13 & $\begin{array}{l}\text { Managing schools during the current pandemic (H1N1) } 2009 \\
\text { - Reactive and proactive school closures in Europe }\end{array}$ & 20 June 2009 \\
\hline 14 & $\begin{array}{l}\text { Use of specific pandemic influenza vaccines during the H1N1 } \\
2009 \text { pandemic }\end{array}$ & 13 August 2009 \\
\hline 15 & $\begin{array}{l}\text { Public health use of influenza antivirals during influenza } \\
\text { pandemic - Update }\end{array}$ & 18August 2009 \\
\hline \multicolumn{3}{|c|}{ Technical Reports } \\
\hline 16 & Surveillance and studies in a pandemic in Europe & June 2009 \\
\hline 17 & $\begin{array}{l}\text { Guide to public health measures to reduce the impact of } \\
\text { influenza pandemics in Europe: 'The ECDC Menu' }\end{array}$ & June 2009 \\
\hline \multicolumn{3}{|c|}{ Surveillance Reports } \\
\hline 18 & $\begin{array}{l}\text { Analysis of influenza } \mathrm{A}(\mathrm{H} 1 \mathrm{~N} 1) \mathrm{v} \text { individual data in EU and } \\
\text { EEA/EFTA countries }\end{array}$ & June 2009 \\
\hline 19 & $\begin{array}{l}\text { Preliminary report on case-based analysis of influenza } \\
A(H 1 N 1) \text { in EU and EEA/EFTA countries }\end{array}$ & June 2009 \\
\hline
\end{tabular}


Appendix 2: List of ECDC documents analysed for text comparison of case 2

\begin{tabular}{|c|c|c|}
\hline No. & Title & Publication Date \\
\hline \multicolumn{3}{|c|}{ Technical Reports } \\
\hline 1 & $\begin{array}{l}\text { Core functions of microbiology reference laboratories for } \\
\text { communicable diseases }\end{array}$ & June 2010 \\
\hline 2 & $\begin{array}{l}\text { Fostering collaboration in public health microbiology in the } \\
\text { European Union }\end{array}$ & December 2010 \\
\hline 3 & $\begin{array}{l}\text { Current and future burden of communicable diseases in the } \\
\text { European Union and EEA/EFTA countries - Methodology } \\
\text { protocol }\end{array}$ & June 2011 \\
\hline 4 & Evidence-based methodologies for public health & September 2011 \\
\hline 5 & $\begin{array}{l}\text { A literature review of trust and reputation management in } \\
\text { communicable disease public health }\end{array}$ & September 2011 \\
\hline 6 & $\begin{array}{l}\text { Risk assessment on the spread of carbapenemase-producing } \\
\text { Enterobacteriaceae (CPE) through patient transfer between } \\
\text { healthcare facilities, with special emphasis on cross-border } \\
\text { transfer }\end{array}$ & September 2011 \\
\hline \multicolumn{3}{|c|}{ Rapid Risk Assessment } \\
\hline 7 & Outbreak of Shiga toxin-producing E. coli (STEC) in Germany & June 2010 \\
\hline \multicolumn{3}{|c|}{ Surveillance Reports } \\
\hline 8 & $\begin{array}{l}\text { Annual epidemiological report on communicable diseases in } \\
\text { Europe } 2010\end{array}$ & November 2010 \\
\hline 9 & $\begin{array}{l}\text { Annual epidemiological report Reporting on } 2009 \\
\text { surveillance data and } 2010 \text { epidemic intelligence data - } 2011\end{array}$ & November 2011 \\
\hline \multicolumn{3}{|c|}{ Technical Document } \\
\hline 10 & $\begin{array}{l}\text { Climate change and communicable diseases in the EU } \\
\text { Member States: Handbook for national vulnerability, impact } \\
\text { and adaptation assessments }\end{array}$ & March 2010 \\
\hline
\end{tabular}


Appendix 3: List of ECHA documents analysed for text comparison of case 1

\begin{tabular}{|l|l|l|}
\hline No. & Title & Publication Date \\
\hline 1 & $\begin{array}{l}\text { Subject: Work under the Biocides Directive } \\
\text { (Ref.: ENV.B3/PS/pw D/7164) }\end{array}$ & 30 September 208 \\
\hline 2 & $\begin{array}{l}\text { Subject: Role of ECHA under the proposed new Biocides } \\
\text { Regulation } \\
\text { (Ref.: D(2008) Anés 40298) }\end{array}$ & 15 December 2008 \\
\hline
\end{tabular}




\section{Appendix 4: List of ECHA documents analysed for text comparison of case 2}

\begin{tabular}{|c|c|c|}
\hline No. & Title & Publication Date \\
\hline 1 & $\begin{array}{l}\text { BPC Opinion on the application for approval of the active } \\
\text { substance: Permethrin (Product type: } 18 \text { ) } \\
\text { ECHA/BPC/004/2014 }\end{array}$ & 8 April 2014 \\
\hline 2 & $\begin{array}{l}\text { BPC Opinion on the application for approval of the active } \\
\text { substance: Tralopyril (Product type: } 21 \text { ) } \\
\text { ECHA/BPC/002/2014 }\end{array}$ & 9 April 2014 \\
\hline 3 & $\begin{array}{l}\text { BPC Opinion on the application for approval of the active } \\
\text { substance: Alpha-cypermethrin (Product type: } 18 \text { ) } \\
\text { ECHA/BPC/009/2014 }\end{array}$ & 17 June 2014 \\
\hline 4 & $\begin{array}{l}\text { BPC Opinion on the application for approval of the active } \\
\text { substance: Folpet (Product type: 06) } \\
\text { ECHA/BPC/010/2014 }\end{array}$ & 17 June 2014 \\
\hline 5 & $\begin{array}{l}\text { BPC Opinion on the application for approval of the active } \\
\text { substance: Glutaraldehyde (Product type: } 2 \text { ) } \\
\text { ECHA/BPC/019/2014 }\end{array}$ & 1 October 2014 \\
\hline 6 & $\begin{array}{l}\text { BPC Opinion on the application for approval of the active } \\
\text { substance: Peracetic acid (Product type: } 12 \text { ) } \\
\text { ECHA/BPC/107/2016 }\end{array}$ & 14 June 2016 \\
\hline 7 & $\begin{array}{l}\text { BPC Opinion on the application for renewal of the } \\
\text { approval of the active substance: Bromadiolone (Product } \\
\text { type: } 14 \text { ) } \\
\text { ECHA/BPC/111/2016 }\end{array}$ & 16 June 2016 \\
\hline 8 & $\begin{array}{l}\text { BPC Opinion on the application for renewal of the } \\
\text { approval of the active substance: Flocoumafen (Product } \\
\text { type: } 14 \text { ) } \\
\text { ECHA/BPC/115/2016 }\end{array}$ & 16 June 2016 \\
\hline 9 & $\begin{array}{l}\text { BPC Opinion on the application for approval of the active } \\
\text { substance: Silicon dioxide Kieselguhr (Product type: 18) } \\
\text { ECHA/BPC/121/2016 }\end{array}$ & 11 October 2016 \\
\hline 10 & $\begin{array}{l}\text { BPC Opinion on the application for approval of the active } \\
\text { substance: OIT (Product type: } 8 \text { ) } \\
\text { ECHA/BPC/139/2016 }\end{array}$ & 15 December 2016 \\
\hline
\end{tabular}




\section{Appendix 5: List of Interviews}

\section{CHAPTER 4:}

1. Official, European Centre for Disease Prevention and Control

2. Official, European Centre for Disease Prevention and Control

3. Official, European Centre for Disease Prevention and Control

4. Official, European Centre for Disease Prevention and Control

5. Official, European Centre for Disease Prevention and Control

6. Official, European Centre for Disease Prevention and Control

7. Official, European Centre for Disease Prevention and Control

8. Official, European Centre for Disease Prevention and Control

9. Official, DG SANTE, European Commission

10. Official, DG SANTE, European Commission

11. Member, Management Board, European Centre for Disease Prevention and Control

12. Member, Management Board, European Centre for Disease Prevention and Control

13. Official, World Health Organisation/ Regional Office for Europe (WHO/Europe)

14. Member, Stakeholder organisation

\section{CHAPTER 5:}

1. Official, DG SANTE, European Commission

2. Official, DG SANTE, European Commission

3. Official, European Chemicals Agency

4. Official, European Chemicals Agency

5. Official, European Chemicals Agency

6. Member, Management Board, European Chemicals Agency

7. Member, Management Board, European Chemicals Agency

8. Member, Biocidal Products Committee, European Chemicals Agency

9. Member, Biocidal Products Committee, European Chemicals Agency

10. Member, Biocidal Products Committee, European Chemicals Agency

11. Member, Biocidal Products Committee, European Chemicals Agency

12. Member, Biocidal Products Committee, European Chemicals Agency

13. Member, Biocidal Products Committee, European Chemicals Agency

14. Member, Biocidal Products Committee, European Chemicals Agency

15. Member, Stakeholder organisation 
Summary 


\section{Research question}

It is generally acknowledged that EU agencies have facilitated the development of EU policies by providing expert advice. They are composed of experts with specialised expertise, and the fast-growing number of EU agencies since the 1990s has been described as "agency fever" and "agencification" in the EU. When developing policy proposals, the European Commission, which has the right of initiative to decide the content of policy proposals and introduce them, may consult EU agencies in order to make informed decisions. However, the Commission is not obliged to follow expert advice from EU agencies, and there are other policy actors who can also provide scientific and technical information to the Commission.

Reflecting both the role of EU agencies and the Commission's right of initiative as well as discretion to choose expert advice from various policy actors, this research investigates: To what extent and under which conditions do EU agencies use their expert advice to influence policy-making in the European Union? In the literature on EU agencies no systematic empirical evidence has been gathered so far on de facto influence of EU agencies in the policy formulation stage. Thus, this research is one of the first (theoretically informed) exploratory studies that provides empirical insights on the actual level of EU agencies' influence and conditions for influence. Influence is understood as the "ability to shape the content of policy output by providing (partly or completely) the set of alternatives to decision-maker(s)." This definition distinguishes the concept of influence from a similar concept "power" which is understood as the "ability to determine the policy output within a set of available alternatives."

\section{Research design}

In order to facilitate systematic empirical analysis, a three-dimensional approach is employed: (1) the production dimension investigates how expert advice is produced by EU agencies; (2) the provision dimension examines how expert advice is transmitted from EU agencies to the Commission; and (3) the influence dimension assesses the level of EU agencies' influence by tracing evidence of expert advice in policy proposals. Moreover, three conditions for influence access, activities, and resources - are analysed in the production and provision dimensions. The level of EU agencies' influence in the last dimension is measured by text comparison between expert advice and policy proposals as well as reputation of EU agencies as scientific authority.

The above framework is applied in two levels of case studies. At the cross-case level, the European Centre for Disease Prevention and Control and the European Chemicals Agency are selected and their influence is compared to each other. At the within-case level, two policy proposals are analysed in each of the two agencies. One of the two policy proposals is highly scientific and technical in nature (thus a most-likely case for influence), and the other aims to set broad policy objectives through scientific as well as political considerations (thus a leastlikely case for influence). Relevant data are collected from the primary and secondary sources as well as 29 semi-structured interviews. Textual data are analysed by means of hand-coding primarily, complemented by use of the plagiarism detection software WCopyfind. 


\section{Empirical findings}

In the analysis of the European Centre for Disease Prevention and Control, the two case studies demonstrate different levels of influence. On a technical proposal, namely the Commission Communication on the H1N1 pandemic, all conditions in the production and provision dimensions - except limited resources in the production dimension - are conducive to influence, and the Centre's influence is at a moderate level. On a general proposal, namely the Commission proposal on serious cross-border threats to health, all conditions in the production and provision dimensions - except activities in the production dimension - are not favourable to influence, and the level of influence is low.

The levels of influence are higher in the case of the European Chemicals Agency. On the Commission proposal for the biocidal products regulation, a general proposal, all conditions in the production and provision dimensions - except access in the production dimension - are not favourable to influence, but the Agency is still able to exert a moderate level of influence. On technical measures, that is the Commission implementing acts on the approval of active substances, the Agency's influence is high, and all conditions in the production and provision dimensions - except limited resources in the production dimension - are conducive to influence. At the within-case level, it is revealed that the two agencies' influence is higher on the technical proposals than on the general legislative proposals.

Based on a comparative analysis at the cross-case level, it becomes clear that secured access to the Commission in the provision dimension contributes to a high influence. The procedural requirement that the Commission has to consult an agency when developing policy proposals brings about two consequences. First, it drastically reduces the chances that the Commission will deviate from expert advice of the agency, as this institutional arrangement acts as the "comply-or-explain" mechanism. Second, more importantly, it positively affects the willingness of the Commission to steer and enable the agency to exert influence in the policymaking process.

At the agency level, such an institutional arrangement gives the Commission a strong incentive to: 1) guide the agency through how expert advice should be formatted and phrased in order to increase readability and usability for Commission officials; and 2) participate in the opinionforming process in the agency to inform itself of crucial issues under discussion and to point out unclear parts of expert advice. As a consequence, when the expert advice is submitted to the Commission, it is not necessary for the Commission to scrutinise it again.

To conclude, EU agencies do influence the development of policy proposals, but their influence is possible under the Commission's willingness to steer and enable their influence. Only when expert advice meets the "needs" of the Commission - both the high-quality expert advice and, also importantly, the style elements (e.g., the format, clarity, and the style of writing) - are EU agencies able to exert influence. 

Valorisation addendum 


\section{Introduction}

Research in every discipline should fulfil two broad objectives: One is to contribute to knowledge development in academia, and the other is to translate this knowledge into specific activities, services, processes, or products that can be beneficial to society at large. Focusing on the latter, knowledge valorisation is the "act of making research results appropriate and useful in order to enhance opportunities for others to use them." 101 Based on this understanding, the aim of this addendum is to describe the societal relevance and innovation of my research and suggest how the findings of this research can be used in practice, not only by the academic community but, more importantly, by citizens and various actors involved in policy-making at the national and the European level.

Before proceeding, it is necessary to briefly recall the topic of this dissertation. In this PhD research, I investigated EU agencies' influence on the content of policy proposals which are developed by the European Commission. EU agencies are one of many sources of information that the Commission can rely on when drafting policy proposals, and the Commission is not obliged to follow advice from agencies. How, then, and to what extent do EU agencies exert influence? The main findings are that EU agencies do influence the content of policy proposals, albeit to varying degrees, and the level of influence is higher on technical policy proposals than on general legislative proposals that include political considerations. Moreover, if there is a formal procedure that requires the Commission to consult EU agencies, the influence of EU agencies increases. Even in this situation, however, EU agencies' influence is not guaranteed because the Commission does not blindly follow expert advice from EU agencies. Only under the steering and guidance provided by the Commission - if it is willing to do so - do EU agencies increase their influence.

\section{Relevance and innovation}

How close do you feel the EU is to you? It is not surprising to hear that citizens feel distant from the EU. This is pointed out as one of the main reasons why the turnout for European Parliament elections has been steadily decreasing. The most recent elections in 2014 showed the lowest turnout, just over $40 \%$ on average. For those who feel that they have nothing to do with the EU and that what the EU does is not of interest to them, it might come as a surprise that their everyday life is directly affected by policies that are made at the European level. In fact, a lot of consumer products as well as invisible quality standards that EU citizens come into contact with on a daily basis are now regulated by the EU. The policy areas of EU regulations are vast and still expanding, such as toys, cosmetics, medicines, education, air quality, safety of airplanes, and food (even the shape of bananas!). In short, policies decided

\footnotetext{
${ }^{101}$ See "70 Alfa en Gamma stralen Valorisatiebeleid voor de Alfa- en Gammawetenschappen" at https://www.awti.nl/documenten/adviezen/2007/3/15/alfa-en-gamma-stralen.
} 
at the European level affect us, with or without us recognising it. Therefore, it is of importance to EU citizens to know how these policies are made and by whom.

As mentioned earlier, the European Commission is the official body with the right to draft policy proposals. However, it is a relatively small institution compared to national central administrations and does not have sufficient resources and expertise to understand and solve highly scientific issues (for example, which vaccines are effective to cure certain diseases? Which chemical substances are safe enough to be used in consumer products?). This implies that it is inevitable for the Commission to seek advice from external sources. In this early stage of the policy-making process, EU agencies support the European Commission by providing non-binding expert advice on technical and scientific matters that are relevant to policy proposals. Nevertheless, some EU agencies are seen to be highly influential, and this raises a question about whether they predetermine the European Commission's policy decisions. This further intensifies the criticism about the EU's democratic deficit and technocratic governance. Since the number of EU agencies is growing and more and more taxpayers' money is allocated to EU agencies, it is crucial to enhance our understanding on the day-to-day role and functions of EU agencies and how their expert advice influences policy-making in the EU.

Under the growing concern that policy-making in the EU is highly technocratic, the findings of this research offer an essential and innovative message to society that the rise of technocracy in the EU has been somewhat misunderstood as an excessive intensity of technocracy. Do unelected experts, instead of democratically elected politicians, decide policies in the EU? Does scientific advice replace public and political discussions when making policies? As proven in this research, the answer is "no." The European Commission does consult various actors when developing policies, and civil society organisations voice their opinions in this process. Furthermore, in accordance with the formal rules and procedures governing policy-making in the EU, the Commission does exercise its official power to initiate policy proposals and does not blindly accept expert advice from EU agencies. This is in line with democratic rules and legitimacy rather than deficit of those.

\section{Policy recommendations}

Based on the experience gained during the research process and the findings of this research, a number of policy recommendations can be made for both EU agencies and the European Commission. With regard to the Commission, the process of formulating policy proposals should be more transparent. What is striking is that nobody knows what the Commission does with all the expert advice that is submitted by various policy actors, such as EU agencies, interest groups, and non-governmental organisations. Do officials in the Commission actually read them all? Do officials give more weight to expert advice from certain actors? If so, why? How do officials determine which advice is worth considering and reflecting in policy proposals? These unanswered questions exacerbate criticism about the lack of transparency in the Commission. Since what is written in policy proposals usually becomes the content of 
European policies that all Member States are obligated to implement, increasing transparency in this stage of the policy-making process will increase legitimacy of policies.

In relation to the topic of this research, moreover, the Commission may consider providing EU agencies with general guidelines on the style elements of expert advice, such as the format and writing style. As demonstrated in this dissertation, the European Chemicals Agency streamlined the structure of its reports that are submitted to the Commission in order to assist the Commission officials in easily finding relevant sections and information. The Agency also changed its "scientific" style of writing to more of a "policy" style of writing in order to improve readability and make its advice easily understood by policy-makers.

As for EU agencies, this research claims that an important condition for high influence is their procedural involvement in the policy formulation stage, because this motivates the Commission to guide EU agencies through how to draw up expert advice that is readily useable by policy-makers. However, the reality is that the Commission's mandatory consultation with EU agencies is not common. This suggests that EU agencies may actively seek to receive feedback on their expert advice from the Commission. Section 7.2.2 of this dissertation provided a notorious example in this regard. The phrase "reasonable worst case scenario" written by the European Centre for Disease Prevention and Control caused confusion in the Commission because policy-makers understood "reasonable" as "likely" while ECDC meant "still very unlikely." This type of misleading expression should be communicated back to the agencies. In this context what is recommended is that the Commission provide a periodic (ideally annual) feedback report to EU agencies in order to point out what has been particularly useful from their expert advice and what could be still improved.

In addition, EU agencies should actively explore ways to facilitate learning from each other and to share resources. The European Chemicals Agency could serve as a good example. When preparing expert advice on the regulation of biocidal products, the Agency reached out to other EU agencies and national agencies that perform similar tasks in order to learn from their experience and expertise. By doing so, the Agency was also able to overcome challenges posed by its limited human resources - in fact, the European Chemicals Agency at that time did not even have any personnel responsible for biocide issues. From this perspective, the formation of the EU Agencies' Network is a step in the right direction. The Network promotes sharing best practices, resources, information, and expertise between various EU agencies, and the Network's activities could contribute to more effective and efficient performance of EU agencies.

\section{Dissemination of the findings}

I have disseminated the results of this research mainly by publications and presentations. Parts of this research have been published as a book chapter and an academic journal article, and I plan to produce more journal articles based especially on the empirical insights of this 
dissertation. For example, the case study on the H1N1 pandemic in the chapter on the European Centre for Disease Prevention and Control has been developed into an article which investigates complex policy problems in the multilevel regulatory system in the EU. This article, co-authored with two other scholars, is currently under review by an international journal. Similarly, I plan to develop journal articles discussing the case studies on the European Chemicals Agency as well as analysing both agencies on the basis of the cross-case comparison.

In terms of presentations, I have participated in a number of academic events to discuss the findings and their implications with academic audiences. These occasions also provided a good opportunity to receive feedback on my research. Some examples of the events are:

- The 14th Annual UACES Student Forum Research Conference (Loughborough, 2013)

- The 5th ECPR Graduate Student Conference (Innsbruck, 2014)

- Workshop on "European Agencies: Challenges Ahead" (Brussels, 2014)

- NIG Annual Work Conference (Nijmegen, 2015)

- TARN (The Academic Research Network on Agencification of EU Executive Governance) Launching Event (Brussels, 2015)

- The 8th Pan-European Conference on the European Union (Trento, 2016)

- The 6th Biennial Conference of ECPR Standing Group on Regulatory Governance (Tilburg, 2016)

For the conference in Innsbruck in 2014, I organised a panel on "The role of expertise in EU regulatory governance" in order to compare how different entities in the EU, including EU agencies and the European Commission, use expertise to manage regulatory issues. Some events comprised participation by both academic scholars and policy-makers to exchange information and views on EU agencies. There are two more events in which I plan to participate in the near future. One is the 77th Annual MPSA Conference which is going to take place in Chicago in April 2019. The main target audience here is academic scholars. The other is the 12th EU Agencies' Network on Scientific Advice Meeting in Brussels in November 2018. This is an event organised by both the EU Agencies' Network and the European Commission to promote cooperation between senior experts from EU agencies and policy-makers from the EU institutions and the Member States. I aim to present the main findings and discuss policy recommendations with them, and at the time of writing the possibility of my participation is under discussion.

Lastly, another form of knowledge dissemination is achieved by teaching courses in the Bachelor and Master European Studies programmes at the Faculty of Arts and Social Sciences, Maastricht University. One good example can be drawn from the Bachelor's course "Policy Domains: Analysing the European Policy Process." My role as a policy expert and tutor in this course is to introduce the EU chemicals policy - one of the case studies in this research - to the students and guide their analysis on relevant policy measures in the policy-making process. Disseminating knowledge to students is as important as disseminating to academic audiences and practitioners, and my current position as a Postdoctoral Lecturer ensures this activity will take place. 



\section{About the author}

Jinhee Kim obtained a Bachelor degree in Business Administration at Korea University in South Korea and a Master degree in International Relations at American University in Washington D.C. After working for four years as a Legislative Researcher in the Embassy of Korea in Washington D.C., she moved to the Netherlands and obtained a Master of Science degree (cum laude) in Research Master European Studies at Maastricht University. During this study she won an award for being a top 3\% student, and her master thesis was awarded the 2012 Best Master Thesis Award in the Netherlands.

In September 2012 Jinhee started working as a PhD Candidate in the Department of Political Science, Faculty of Arts and Social Sciences at Maastricht University. Her research focused on regulatory policy-making in the EU and particularly the role and influence of EU agencies therein. During her PhD trajectory, she co-authored a book chapter and a peer-reviewed article, and one article is currently accepted for publication in an international peer-reviewed journal. She has taught various courses in Bachelor and Master European studies and supervised numerous Bachelor theses. Currently, she is working as a Post-doctoral Lecturer in the Faculty of Arts and Social Sciences, Maastricht University. 